\title{
CD36: a target to restore cardiac function in type 2 diabetes
}

Citation for published version (APA):

Steinbusch, L. K. M. (2011). CD36: a target to restore cardiac function in type 2 diabetes. [Doctoral Thesis, Maastricht University]. Maastricht University. https://doi.org/10.26481/dis.20111013ls

Document status and date:

Published: 01/01/2011

DOI:

10.26481/dis.20111013ls

Document Version:

Publisher's PDF, also known as Version of record

\section{Please check the document version of this publication:}

- A submitted manuscript is the version of the article upon submission and before peer-review. There can be important differences between the submitted version and the official published version of record.

People interested in the research are advised to contact the author for the final version of the publication, or visit the DOI to the publisher's website.

- The final author version and the galley proof are versions of the publication after peer review.

- The final published version features the final layout of the paper including the volume, issue and page numbers.

Link to publication

\footnotetext{
General rights rights.

- You may freely distribute the URL identifying the publication in the public portal. please follow below link for the End User Agreement:

www.umlib.nl/taverne-license

Take down policy

If you believe that this document breaches copyright please contact us at:

repository@maastrichtuniversity.nl

providing details and we will investigate your claim.
}

Copyright and moral rights for the publications made accessible in the public portal are retained by the authors and/or other copyright owners and it is a condition of accessing publications that users recognise and abide by the legal requirements associated with these

- Users may download and print one copy of any publication from the public portal for the purpose of private study or research.

- You may not further distribute the material or use it for any profit-making activity or commercial gain

If the publication is distributed under the terms of Article $25 \mathrm{fa}$ of the Dutch Copyright Act, indicated by the "Taverne" license above, 
CD36; a target to restore cardiac function in type 2 diabetes 
The study presented in this thesis was performed at the department of Molecular Genetics, within CARIM, school for cardiovascular diseases, Maastricht University, the Netherlands, which is acknowledged by the Royal Dutch Academy of Arts and Sciences (KNAW).

Layout and cover design: Laura Steinbusch and Merlijn Meens

Copyright (C) 2011 LKM Steinbusch, Maastricht

Printed by: BOXPress BV || Proefschriftmaken.nl 


\title{
CD36; a target to restore cardiac function in type 2 diabetes
}

\author{
Proefschrift \\ Ter verkrijging van de graad van doctor aan de Universiteit Maastricht, \\ op gezag van de Rector Magnificus, Prof. Dr. G.P.M.F. Mols, \\ volgens het besluit van het college van decanen, \\ in het openbaar te verdedigen \\ op donderdag 13 oktober 2011 om 14:00 uur \\ door \\ Laura K.M. Steinbusch \\ geboren te Nijmegen op 30 november 1982
}




\section{Promotores:}

Prof. Dr. Jan F. C. Glatz

Prof. Dr. Michaela Diamant (VU University Medical Center, Amsterdam, Nederland)

\section{Copromotores:}

Dr. Joost J.F.P. Luiken

Dr. D.Margriet Ouwens (German Diabetes Center, Düsseldorf, Duitsland)

\section{Beoordelingscommissie:}

Prof. Dr. M.K.C. Hesselink (voorzitter)

Prof. dr. J. Eckel (German Diabetes Center, Düsseldorf, Duitsland)

Dr. J.J. Prompers (Technische Universiteit Eindhoven, Eindhoven, Nederland)

Prof. Dr. A.C. Nieuwenhuijzen Kruseman

Prof. Dr. H.P. Brunner-La Rocca

The studies presented in this thesis were supported by a grant of the Diabetes Foundation, project 2006.00.044.

Financial support by the Diabetes Foundation for publication of this thesis is gratefully acknowledged. 


\section{Contents}

$\begin{array}{lll}\text { Chapter } 1 & \text { General Introduction } & 7\end{array}$

Chapter 2 Subcellular trafficking of the substrate transporters

GLUT4 and CD36 in cardiomyocytes

Chapter 3 Differential regulation of cardiac glucose and fatty acid uptake by endosomal $\mathrm{pH}$ and actin filaments

Chapter $4 \quad$ CD36 inhibition prevents lipid accumulation and contractile dysfunction in rat cardiomyocyte cultures

Chapter 5 Overexpression of AMP-activated protein kinase or

Protein Kinase D independently prevent lipid-induced insulin resistance in cardiomyocytes

Chapter 6 Absence of fatty acid transporter CD36 protects against Western-type diet-related cardiac dysfunction following pressure overload in mice

Chapter 7 General discussion

Summary / Samenvatting

Curiculum Vitae

Dankwoord 

Chapter 1

General introduction 


\section{Normal structure and function of the heart}

Already in 1628 Sir William Harvey published "De Motu Cordis", or "Concerning the motion of the heart and blood", in which he described the pumping action of the heart and the blood circulation. The circulatory system serves to provide the organism's tissues with oxygen and nutrients in order to support function, growth and repair, and maintain homeostasis. The cardiac muscle is at the centre of this system, pumping blood throughout the body by timed contractions (1). The heart consists of four chambers (two atria and two ventricles) and several valves to avoid backflow of blood against the bloodstream (1). The systemic blood pressure ( 100 $\mathrm{mmHg}$ ) is much higher than the blood pressure in the pulmonary circuit ( $16 \mathrm{mmHg}$ ) while the total blood flow through the pulmonary circuit is the same as that through the systemic circulation (2). Therefore, the left ventricle needs more muscular force than the right ventricle, and thus has a thicker muscular wall.

\section{Substrate supply and utilization of cardiomyocytes}

The contractile units of the heart are the cardiomyocytes, which are striated like skeletal muscle and contract by the sliding filament mechanism. To sustain muscular activity, the heart, and the cardiomyocytes, obviously needs oxygen and nutrients for itself. This notion applies especially to the left ventricle which has to pump the blood into the systemic circulation. Therefore, the heart possesses its own blood supply, the coronary circulation (1). The aorta branches off into two coronary arteries, to the left for the systemic side of the heart, and to the right for the pulmonary side of the heart. Subsequently the arteries branch off into smaller ones.

With regard to their energy metabolism, cardiomyocytes are regarded omnivores that will metabolize all substrates as they are supplied with in order to keep up with the continuous blood demand of the body $(3,4)$. Cardiomyocytes will preferably utilize fatty acids (70\%), and then glucose $(30 \%)$, in order to spare glucose for the brain. If necessary, they will utilize lactate, and so remove lactate from the bloodstream when this is produced by working skeletal muscle (5).

The uptake of glucose and fatty acids by cardiomyocytes is facilitated by cell surface transporters, including the glucose transporter 4 (GLUT4) and the fatty acid transporter CD36 (Figure 1.1) (6). Under basal conditions these substrate transporters are cycling, in intracellular vesicles, between the sarcolemma and intracellular storage compartments. When energy demand increases, GLUT4 and CD36 presence at the sarcolemma will be elevated (7). Several extracellular signals and subcellular vesicle-associated trafficking proteins are involved in regulation of the presence of GLUT4 and/or CD36 at the sarcolemma. In particular, raised plasma 


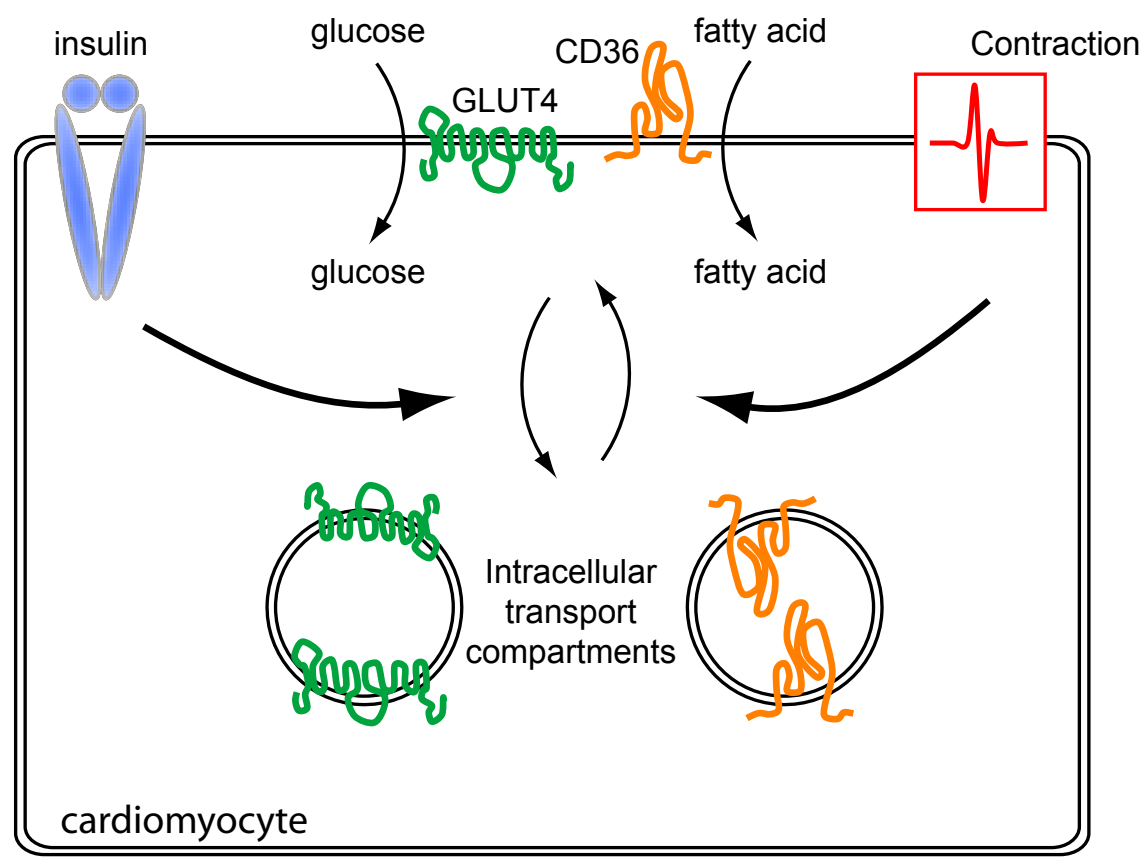

Figure 1.1: Membrane presence of the glucose transporter 4 (GLUT4) and the fatty acid transporter CD36 can be influenced by circulating blood insulin and increased cardiac work. Both stimuli affect reversible translocation of GLUT4 and CD36 from intracellular storage compartments towards the sarcolemma.

insulin concentrations and increased cardiac work will raise GLUT4 as well as CD36 presence at the cardiomyocyte membrane in order to increase glucose and fatty acid uptake, respectively (6). Additionally, insulin-mediated increase of GLUT4 presence at the sarcolemma is dependent on proper organisation of the actin cytoskeleton (8).

Insulin is a polypeptide hormone secreted by the $\beta$-cells of the pancreas when blood glucose levels, or amino acid levels, slightly increase. Insulin will lower blood glucose levels by stimulating glucose uptake by peripheral tissues (muscle, fat, liver) which can utilize glucose for their energy production or store it in the form of glycogen or triacylglycerols (9). It is important to keep blood glucose levels constant since glucose is an important energy source for many organs, especially the brain. Indeed, a counter regulatory hormone, glucagon, increases glucose secretion from the liver when blood glucose levels have dropped, and so insulin and glucagon act to preserve glucose homeostasis (Figure 1.2).

In cardiomyocytes, insulin acts by binding to the insulin receptor at the cell surface. 


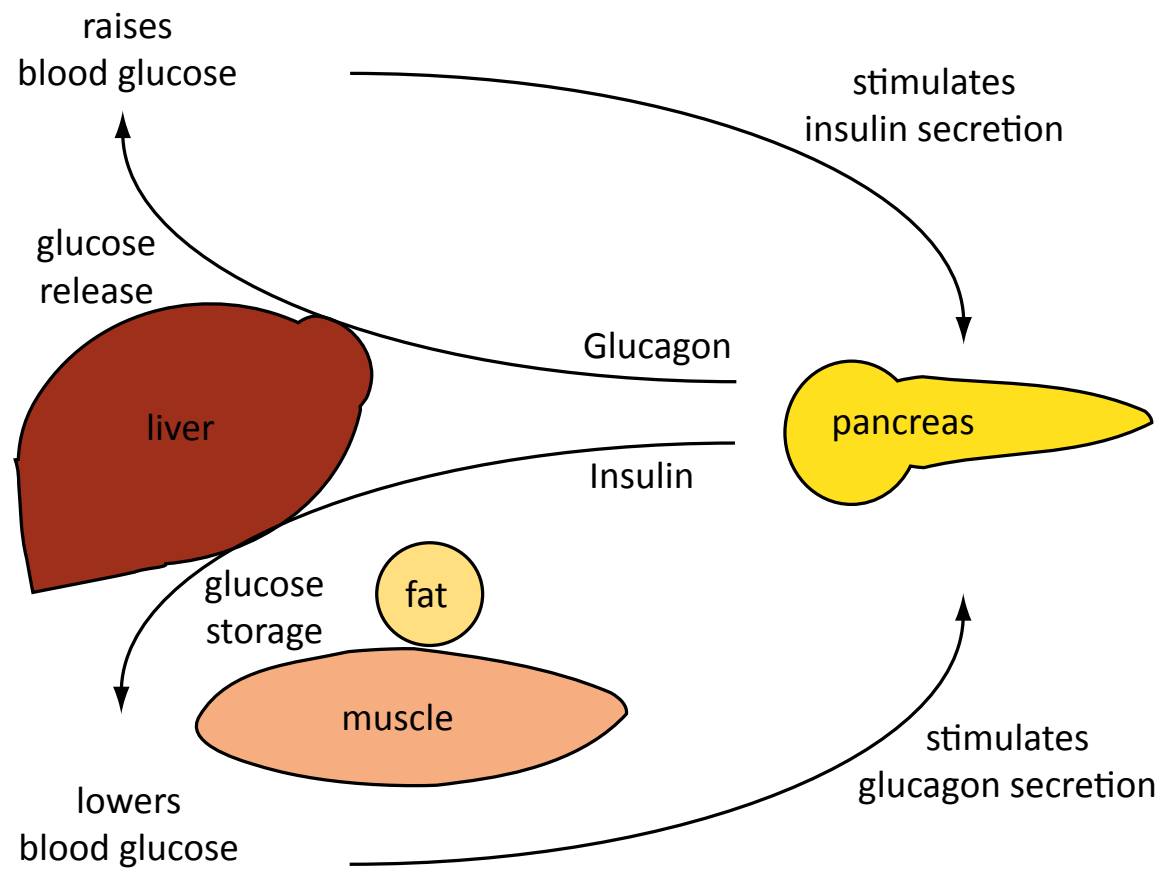

Figure 1.2: Regulation of blood glucose levels by insulin and glucagon. When blood glucose tends to increase, such as is the case in the postprandial phase, insulin is released from pancreatic $\beta$ cells, whereas in the fasting state, when glucose levels tend to be low, glucagon is released from pancreatic $\alpha$-cells. Both islet hormones try to normalize blood glucose levels. Insulin's action lowers blood glucose by stimulating glucose uptake by tissues, utilization and storage of glucose as glycogen in the liver and muscle. The opposing actions of glucagon aim to increase plasma glucose by stimulating glycogen breakdown into glucose and release into the bloodstream.

This will lead to activation of the tyrosine kinase domain of the insulin receptor, and insulin receptor substrate 1 (IRS-1). Tyrosine phosphorylated IRS1 leads to recruitment and activation of phosphatidylinositol-3-kinase (PI3K). The PI3K-mediated formation of PI-3,4,5-trisphosphate (PIP3) then activates 3-phosphoinositide-dependent protein kinase 1 (PDK1), which on its turn phosphorylates Akt/protein kinase $B$ (PKB) and protein kinase $C(P K C)-\lambda / \zeta$. Multiple studies have demonstrated that this pathway is critically involved in the translocation of both GLUT4 and CD36 to the sarcolemma (6).

Cardiomyocyte contraction also results in translocation of GLUT4 and CD36 to the sarcolemma, but this is mediated via another signalling pathway. Contraction raises the intracellular levels of adenosine-monophosphate (AMP) (changes the AMP: ATP ratio), cyclic AMP, reactive oxygen species (ROS) and calcium. Together, these 
second messengers activate a complex signalling system that involves AMP-activated protein kinase (AMPK), protein kinase A (PKA), atypical PKCs, protein kinase D (PKD), calcium-calmodulin-dependent protein kinases (CaMK), and the extracellularly regulated protein kinases (ERK) 1 and 2. Activation of AMPK induces both GLUT4 and CD36 translocation (10). Using isolated rodent cardiomyocytes, we have shown that PKD is also involved in cardiomyocyte GLUT4 translocation, but its role in CD36 translocation needs further investigation (11). Although the importance of CaMK and ERK1/2 in glucose and fatty acid uptake has been demonstrated for skeletal muscle (12-14), their relevance in cardiomyocytes still needs further investigation.

A detailed description of the regulation of the substrate utilization of cardiac metabolism is given in chapter 2 .

\section{Cardiac diseases and type 2 diabetes}

Despite many years of research and efforts to implement preventive measures, cardiometabolic diseases, including cardiovascular disease and type 2 diabetes, globally constitute an increasing health problem, not only in the Western world, but even to a greater extent in developing countries $(15,16)$. A cluster of metabolic risk factors, known as the metabolic syndrome, raises twice the risk of developing cardiovascular disease and five times the risk of developing type 2 diabetes. A patient is qualified for the metabolic syndrome when three out of the five risk factors are diagnosed. The risk factors include raised blood pressure, raised triglycerides, reduced high-density lipoproteins (HDL), central obesity and impaired fasting or postload plasma glucose (17). The metabolic syndrome is often present when cardiovascular disease or diabetes develops, and the number and severity of risk factors contributes to disease progression.

In the Netherlands, estimates indicate that approximately 1 million ( $6 \%$ ) people are currently affected by diabetes mellitus, of which $90 \%$ suffer from type 2 diabetes (18). It is estimated that by 20301.3 million people will have type 2 diabetes in the Netherlands (18) and 438 million (7.7\%) people will have type 2 diabetes worldwide (19). The incidence of type 2 diabetes increases with age and can be higher prevalent in specific ethnic groups $(18,20)$.

In 1889, Minkowski and von Mering were the first to demonstrate the importance of insulin in the control of blood glucose levels. Removing the pancreas from dogs caused, amongst others, hyperglycaemia, and lead to a syndrome resembling diabetes mellitus. Type 2 diabetes is characterized by decreased responsiveness of peripheral tissues towards insulin, which is also called insulin resistance. In the case of insulin resistance, glucose uptake into skeletal muscle, but also fat 
tissue, is impaired whereas hepatic glucose production is insufficiently inhibited. Initially, insulin resistance will be compensated for by increased insulin secretion (hyperinsulinemia). However, in the case of $\beta$-cell dysfunction, insulin secretion is insufficient and blood glucose levels start to rise, until these ultimately meet the diagnostic criteria of type 2 diabetes.

Hyperglycemia per se has been associated with the development of microangiopathy (21) which manifests itself clinically as diabetic retinopathy, nephropathy and neuropathy. Macrovascular disease, i.e. the major complication in diabetes, has been additionally attributed to factors such as dyslipidemia, insulin resistance and high blood pressure. Still, diabetes type 2 alone leads to a 2 times higher risk ratio for the development of cardiovascular disease (22) and more than half of the persons with diabetes will die from cardiovascular complications (23).

Type 2 diabetes patients can develop asymptomatic cardiac dysfunction, even in the absence of coronary artery disease and hypertension, which is ascribed to diabetic cardiomyopathy $(24,25)$. The concept of diabetic cardiomyopathy was first described by Rubler et al. (26) who reported four cases of patients with type 2 diabetes and cardiac failure without significant coronary artery disease. It is important to realize that diabetes associated changes are aggravated by the presence of co-morbidities such as hypertension or coronary artery disease (27). The development of cardiac dysfunction in diabetic cardiomyopathy is proposed to result from alteration of i) myocardial structure, e.g. cardiomyocyte hypertrophy, ii) myocardial function, e.g. impaired calcium release and reuptake and, iii) substrate supply and utilization, e.g. increased fatty acid supply and utilization $(3,25,28)$. Based on animal studies, alterations in cardiac metabolism in obesity and type 2 diabetes are attributed to myocardial glucolipotoxicity which may promote cardiac functional and structural changes as well as cell death (29). The importance of changes in myocardial substrate supply are underlined by research that demonstrated changes in skeletal and cardiac muscle lipid metabolism $(30,31)$, which were ascribed to potentially increased abundance of CD36 at the sarcolemma. Permanent relocation of CD36 to the sarcolemma, and increased fatty acid uptake, were strongly linked in cardiomyocytes and skeletal muscle in rodent models for insulin resistance (30, $32,33)$, and in skeletal muscle in obese humans $(30,34,35)$. Subsequently, reduced insulin-stimulated GLUT4 translocation and glucose uptake, and cardiac dysfunction, develop (36).

In humans, the importance of lipotoxicity in the development of the cardiac dysfunction, in relation to obesity and type 2 diabetes, has not been unequivocally proved. Magnetic resonance spectroscopy studies have confirmed the increased 
myocardial triacylglycerol content, and cardiac dysfunction, in obese and diabetic patients $(37,38)$. However, caloric restriction and exercise training improved, but also worsened, cardiac function (38-40). In addition, the current treatment for type 2 diabetes in the Netherlands - life-style intervention, metformin, sulphonylurea derivatives or thiazolidinediones (TZD) treatment (41) - has an unclear mechanism (42) or were shown to have unwanted side-effects $(41,43,44)$. Therefore, we have investigated novel strategies for targeting disturbed cardiac metabolism in cell systems and animal models for insulin resistance and type 2 diabetes.

A detailed description of the alterations in cardiac function and (the regulation) of cardiac metabolism in rodents and humans with insulin resistance or type 2 diabetes is given in chapter 2 .

\section{AIM OF THIS THESIS}

The research described in this thesis was designed to investigate the subcellular trafficking of CD36 as a target to prevent the development of cardiac dysfunction in cell systems and animal models of type 2 diabetes. Firstly, it was hypothesized that the chronic and continuous presence of CD36 at the sarcolemma contributes to the development of diabetes-related cardiac dysfunction. To address this, we have set up an in-vitro model for cardiomyocyte insulin resistance in which we could modulate the fatty acid uptake activity of CD36, and we have assessed the role of CD36 in the development of cardiac dysfunction in rodents exposed to metabolic and mechanophysical stress. In addition, we have tested if enhancement of glucose uptake could prevent the development of insulin resistance related to permanent CD36 translocation. Secondly, we hypothesized that interference with the trafficking of CD36 normalizes myocardial lipid metabolism and improves insulin resistance, which ultimately results in amelioration of cardiac dysfunction in the insulin resistant heart. To test this hypothesis, we have assessed the subcellular trafficking machinery underlying aberrant trafficking of GLUT4 and CD36 in insulin resistant cardiomyocytes.

\section{OUTLINE OF THE THESIS}

The project started with a pharmacological study to assess subcellular machinery involved in GLUT4 and/or CD36 trafficking in rat cardiomyocytes (Chapter 2 and 3). We concluded that GLUT4 and CD36 trafficking are differentially regulated with respect to their trafficking machinery (Chapter 3 ). This differential regulation suggested that aberrant trafficking components could result in the altered translocation of GLUT4 and CD36, which we had observed in earlier studies in insulin resistant cardiomyocytes $(31,45)$. We evaluated the present knowledge on 
subcellular trafficking of GLUT4 and CD36 in cardiomyocytes in a literature review (Chapter 2). Afterwards, we wanted to evaluate the involvement of these trafficking components in the aberrant translocation of GLUT4 and CD36 in in-vitro and in-vivo models for insulin resistance and type 2 diabetes (Chapter 7).

Being aware that we cannot directly test new treatment targets in patients, we set up a proof-of-concept in-vitro model to study the effects of genetic or pharmacological modulation of these targets. In this model adult rat cardiomyocytes were cultured for 48 hours in media that induce lipid storage and that reduce insulin sensitivity. Two studies were performed to prevent the development of lipotoxicity and insulin resistance in cultured rat cardiomyocytes. In the first study CD36-mediated fatty acid uptake was blocked by an antibody against CD36 (Chapter 4). In the second study two proteins involved in glucose uptake were over-expressed to enhance glucose uptake, prevent the excessive lipid accumulation, prevent alterations in insulin sensitivity, and restore the optimal balance between glucose and fat uptake (Chapter 5).

Most cardiac patients have diabetes and hypertension, whereas most research is dedicated to study these pathological processes separately. We aimed at studying the interaction of these two cardiac stresses and we wanted to obtain proof of principle for the role of CD36 in the development of cardiac dysfunction in this situation (Chapter 6). We showed that metabolic stress alone, e.g. western-type diet or ablation of CD36, does not affect cardiac function. However, the metabolic stress was exposed when pressure overload (mechanophysical stress) was added to the cardiac stresses. Metabolic stress and mechanophysical stress were found to interact and together to result in greater cardiac hypertrophy and cardiac dysfunction. Moreover, ablation of CD36 prevented the development of cardiac dysfunction in mice on a western-type diet.

Chapters 2 to 6 have been originally written as separate articles for publication in international peer-reviewed scientific journals, which is why some overlap between chapters could not be avoided. The last chapter provides an overall discussion and conclusion about this PhD thesis project (Chapter 7). 


\section{References}

1. Guyton AC, Hall JE. Medical Physiology. 10 ed.: W.B. Saunders Copmany; 2000.

2. Guyton AC, Hall JE. Textbook of Medical Physiology, Chapter 14: Overview of Circulation. 10 ed.; 2000.

3. Glatz JFC, Luiken JJFP, Bonen A. Membrane fatty acid transporters as regulators of lipid metabolism: implications for metabolic disease. Physiol Rev. 2010 Jan;90(1):367-417.

4. Lopaschuk GD, Ussher JR, Folmes CD, Jaswal JS, Stanley WC. Myocardial fatty acid metabolism in health and disease. Physiol Rev. 2010 Jan;90(1):207-58.

5. Marieb EN. Human Anatomy and Physiology, Chapter 9: Muscles and Muscle Tissue. 6 ed.; 2004.

6. Steinbusch LK, Schwenk RW, Ouwens DM, Diamant M, Glatz JF, Luiken JJ. Subcellular trafficking of the substrate transporters GLUT4 and CD36 in cardiomyocytes. Cell Mol Life Sci. 2011 May 6.

7. Schwenk RW, Luiken JJ, Bonen A, Glatz JF. Regulation of sarcolemmal glucose and fatty acid transporters in cardiac disease. Cardiovasc Res. 2008 Jul 15;79(2):249-58.

8. Patel N, Huang C, Klip A. Cellular location of insulin-triggered signals and implications for glucose uptake. Pflugers Arch. 2006 Jan;451(4):499-510.

9. Marieb EN. Human Anatomy and Physiology, Chapter 16: The Endocrine System. 2004. p. 603-43.

10. Habets DD, Coumans WA, El Hasnaoui M, Zarrinpashneh E, Bertrand L, Viollet B, et al. Crucial role for LKB1 to AMPKalpha2 axis in the regulation of CD36-mediated long-chain fatty acid uptake into cardiomyocytes. Biochim Biophys Acta. 2009 Mar;1791(3):212-9.

11. Luiken JJ, Vertommen D, Coort SL, Habets DD, El Hasnaoui M, Pelsers MM, et al. Identification of protein kinase $\mathrm{D}$ as a novel contraction-activated kinase linked to GLUT4-mediated glucose uptake, independent of AMPK. Cell Signal. 2008 Mar;20(3):543-56.

12. Chen HC, Bandyopadhyay G, Sajan MP, Kanoh Y, Standaert M, Farese RV, Jr., et al. Activation of the ERK pathway and atypical protein kinase $C$ isoforms in exercise- and aminoimidazole-4-carboxamide1-beta-D-riboside (AICAR)-stimulated glucose transport. J Biol Chem. 2002 Jun 28;277(26):2355462.

13. Farese RV, Sajan MP, Yang H, Li P, Mastorides S, Gower WR, Jr., et al. Muscle-specific knockout of PKC-lambda impairs glucose transport and induces metabolic and diabetic syndromes. J Clin Invest. 2007 Aug;117(8):2289-301.

14. Raney MA, Turcotte LP. Evidence for the regulation of contraction-induced fatty acid oxidation via extracellular signal-regulated kinase $1 / 2$ activation independent of changes in fatty acid uptake. Metabolism. 2007 Sep;56(9):1192-200.

15. Shaw JE, Sicree RA, Zimmet PZ. Global estimates of the prevalence of diabetes for 2010 and 2030. Diabetes Res Clin Pract. Jan;87(1):4-14.

16. Danaei G, Finucane MM, Lu Y, Singh GM, Cowan MJ, Paciorek CJ, et al. National, regional, and global trends in fasting plasma glucose and diabetes prevalence since 1980: systematic analysis of health examination surveys and epidemiological studies with 370 country-years and 2.7 million participants. Lancet. 2011 Jul 2;378(9785):31-40.

17. Alberti KG, Eckel RH, Grundy SM, Zimmet PZ, Cleeman JI, Donato KA, et al. Harmonizing the metabolic syndrome: a joint interim statement of the International Diabetes Federation Task Force on Epidemiology and Prevention; National Heart, Lung, and Blood Institute; American Heart Association; World Heart Federation; International Atherosclerosis Society; and International Association for the Study of Obesity. Circulation. 2009 Oct 20;120(16):1640-5.

18. Baan C, Poos M. Hoe vaak komt diabetes mellitus voor en hoeveel mensen sterven eraan? ; 2010 [updated 201024 juni 2009; cited 201128 April]; Available from: http://www.nationaalkompas.nl.

19. Federation ID. Global Burden: Prevalence and Projections, 2010 and 2030. 2010 [updated 2010; cited 201128 April]; Available from: http://www.diabetesatlas.org/content/diabetes-and-impairedglucose-tolerance.

20. Age- and sex-specific prevalences of diabetes and impaired glucose regulation in 13 European cohorts. Diabetes Care. 2003 Jan;26(1):61-9.

21. Giacco F, Brownlee M. Oxidative stress and diabetic complications. Circ Res. 2010 Oct 29;107(9):105870.

22. Sarwar N, Gao P, Seshasai SR, Gobin R, Kaptoge S, Di Angelantonio E, et al. Diabetes mellitus, fasting 
blood glucose concentration, and risk of vascular disease: a collaborative meta-analysis of 102 prospective studies. Lancet. 2010 Jun 26;375(9733):2215-22.

23. The Diabetes Atlas, Second Edition. International Diabetes Federation; 2003.

24. Stanley WC, Lopaschuk GD, McCormack JG. Regulation of energy substrate metabolism in the diabetic heart. Cardiovasc Res. 1997 Apr;34(1):25-33.

25. Boudina S, Abel ED. Diabetic cardiomyopathy, causes and effects. Rev Endocr Metab Disord. 2010 Mar;11(1):31-9.

26. Rubler S, Dlugash J, Yuceoglu YZ, Kumral T, Branwood AW, Grishman A. New type of cardiomyopathy associated with diabetic glomerulosclerosis. Am J Cardiol. 1972 Nov 8;30(6):595-602.

27. Hayat SA, Patel B, Khattar RS, Malik RA. Diabetic cardiomyopathy: mechanisms, diagnosis and treatment. Clin Sci (Lond). 2004 Dec;107(6):539-57.

28. An D, Rodrigues B. Role of changes in cardiac metabolism in development of diabetic cardiomyopathy. Am J Physiol Heart Circ Physiol. 2006 Oct;291(4):H1489-506.

29. Wende AR, Abel ED. Lipotoxicity in the heart. Biochim Biophys Acta. 2009 Mar;1801(3):311-9.

30. Aguer C, Mercier J, Man CY, Metz L, Bordenave S, Lambert K, et al. Intramyocellular lipid accumulation is associated with permanent relocation ex vivo and in vitro of fatty acid translocase (FAT)/CD36 in obese patients. Diabetologia. 2010 Jun;53(6):1151-63.

31. Ouwens DM, Diamant M, Fodor M, Habets DD, Pelsers MM, El Hasnaoui M, et al. Cardiac contractile dysfunction in insulin-resistant rats fed a high-fat diet is associated with elevated CD36-mediated fatty acid uptake and esterification. Diabetologia. 2007 Sep;50(9):1938-48.

32. Coort SL, Luiken JJ, van der Vusse GJ, Bonen A, Glatz JF. Increased FAT (fatty acid translocase)/CD36mediated long-chain fatty acid uptake in cardiac myocytes from obese Zucker rats. Biochem Soc Trans. 2004 Feb;32(Pt 1):83-5.

33. Carley AN, Atkinson LL, Bonen A, Harper ME, Kunnathu S, Lopaschuk GD, et al. Mechanisms responsible for enhanced fatty acid utilization by perfused hearts from type 2 diabetic $\mathrm{db} / \mathrm{db}$ mice. Archives of physiology and biochemistry. $2007 \mathrm{Apr} ; 113(2): 65-75$.

34. Bonen A, Parolin ML, Steinberg GR, Calles-Escandon J, Tandon NN, Glatz JF, et al. Triacylglycerol accumulation in human obesity and type 2 diabetes is associated with increased rates of skeletal muscle fatty acid transport and increased sarcolemmal FAT/CD36. Faseb J. 2004 Jul;18(10):1144-6.

35. Bonen A, Tandon NN, Glatz JF, Luiken JJ, Heigenhauser GJ. The fatty acid transporter FAT/CD36 is upregulated in subcutaneous and visceral adipose tissues in human obesity and type 2 diabetes. Int J Obes (Lond). 2006 Jun;30(6):877-83.

36. Severson DL. Diabetic cardiomyopathy: recent evidence from mouse models of type 1 and type 2 diabetes. Canadian journal of physiology and pharmacology. 2004 Oct;82(10):813-23.

37. Rijzewijk LJ, van der Meer RW, Lamb HJ, de Jong HW, Lubberink M, Romijn JA, et al. Altered myocardial substrate metabolism and decreased diastolic function in nonischemic human diabetic cardiomyopathy: studies with cardiac positron emission tomography and magnetic resonance imaging. J Am Coll Cardiol. 2009 Oct 13;54(16):1524-32.

38. Schrauwen-Hinderling VB, Hesselink MK, Meex R, van der Made S, Schar M, Lamb H, et al. Improved ejection fraction after exercise training in obesity is accompanied by reduced cardiac lipid content. J Clin Endocrinol Metab. 2010 Apr;95(4):1932-8.

39. Hammer S, Snel M, Lamb HJ, Jazet IM, van der Meer RW, Pijl H, et al. Prolonged caloric restriction in obese patients with type 2 diabetes mellitus decreases myocardial triglyceride content and improves myocardial function. J Am Coll Cardiol. 2008 Sep 16;52(12):1006-12.

40. van der Meer RW, Hammer S, Smit JW, Frolich M, Bax JJ, Diamant M, et al. Short-term caloric restriction induces accumulation of myocardial triglycerides and decreases left ventricular diastolic function in healthy subjects. Diabetes. 2007 Dec;56(12):2849-53.

41. Yki-Jarvinen H. Thiazolidinediones. N Engl J Med. 2004 Sep 9;351(11):1106-18.

42. Rijzewijk LJ DM. Diabetic Gluco-lipotoxic Cardiomyopathy - Amendable by Metabolic Manipulation? European Endocrinology. 2008;4(2).

43. Kohlroser J, Mathai J, Reichheld J, Banner BF, Bonkovsky HL. Hepatotoxicity due to troglitazone: report of two cases and review of adverse events reported to the United States Food and Drug Administration. Am J Gastroenterol. 2000 Jan;95(1):272-6.

44. Nissen SE, Wolski K. Effect of rosiglitazone on the risk of myocardial infarction and death from 
cardiovascular causes. N Engl J Med. 2007 Jun 14;356(24):2457-71.

45. Coort SL, Hasselbaink DM, Koonen DP, Willems J, Coumans WA, Chabowski A, et al. Enhanced sarcolemmal FAT/CD36 content and triacylglycerol storage in cardiac myocytes from obese zucker rats. Diabetes. 2004 Jul;53(7):1655-63. 


\section{Chapter 2}

\section{Subcellular trafficking of the substrate transporters GLUT4 and CD36 in cardiomyocytes}

Laura K.M. Steinbusch ${ }^{1}$, Robert W. Schwenk ${ }^{1}$, D. Margriet Ouwens ${ }^{2}$, Michaela Diamant $^{3}$, Jan F.C. Glatz ${ }^{1}$, Joost J.F.P. Luiken ${ }^{1}$

1 Department of Molecular Genetics, Maastricht University, Maastricht, NL

2 Institute of Clinical Biochemistry and Pathobiochemistry, German Diabetes Center, Düsseldorf, DE

3 Department of Endocrinology, Diabetes Centre, VU University Medical Centre, Amsterdam, NL

Cell Mol Life Sci. 2011 Aug;68(15):2525-38 


\begin{abstract}
Cardiomyocytes use glucose as well as fatty acids for ATP production. These substrates are transported into the cell by glucose transporter 4 (GLUT4) and the fatty acid transporter CD36. Besides being located at the sarcolemma GLUT4 and CD36 are stored in intracellular compartments. Raised plasma insulin concentrations and increased cardiac work will stimulate GLUT4 as well as CD36 to translocate to the sarcolemma. As far as studied, signalling pathways that regulate GLUT4 translocation similarly affect CD36 translocation. During the development of insulin resistance and type 2 diabetes CD36 becomes permanently localized at the sarcolemma, whereas GLUT4 internalizes. This juxtaposed positioning of GLUT4 and CD36 is important for aberrant substrate uptake in the diabetic heart, chronically increased fatty acid uptake at the expense of glucose. To explain the differences in subcellular localization of GLUT4 and CD36 in type 2 diabetes, recent research focused on the role of proteins involved in trafficking of cargo between subcellular compartments. Several of these proteins appear to be similarly involved in both GLUT4 and CD36 translocation. Others, however, have different roles in either GLUT4 or CD36 translocation. These trafficking components, which are differently involved in GLUT4 or CD36 translocation, may be considered novel targets for the development of therapies to restore the imbalanced substrate utilization that occurs in obesity, insulin resistance and diabetic cardiomyopathy.
\end{abstract}




\section{Introduction}

We previously reported that known signalling mechanisms, such as insulin and contraction, similarly affect myocyte GLUT4 and CD36 trafficking [1]. However, in insulin resistance and type 2 diabetes CD36 permanently relocates to the sarcolemma, while GLUT4 internalizes [2,3]. As a corollary there must be mechanisms which selectively recruit either GLUT4 or CD36. Therefore, we began to investigate distinct intracellular processes involved in vesicular transport to uncover mechanisms that are differently involved in GLUT4 and CD36 trafficking [4,5]. We revealed coatproteins, actin filaments, the cellular $\mathrm{pH}$ gradient and vesicle-associated membrane proteins (VAMPs) to be involved in GLUT4 and CD36 trafficking and, importantly, indeed found mechanisms that are differently involved in glucose and fatty acid uptake in cardiomyocytes.

In this review we first describe how cardiac glucose and fatty acid uptake are regulated and which alterations occur during insulin resistance and type 2 diabetes. Thereafter, we address signalling pathways and subcellular trafficking components that are involved in GLUT4 and CD36 translocation. Finally, we focus on components that are differently involved in glucose and fatty acid uptake and descrive novel targets to restore metabolic disturbance in type 2 diabetes.

\section{Regulation of cardiac glucose and fatty acid uptake}

Glucose and fatty acids are of fundamental importance for energy production in all eukaryotic cells. In cardiomyocytes the continuous supply of both substrates is especially crucial to maintain contractile activity [6]. Cardiomyocytes are metabolically flexible, i.e., they preferably use fatty acids, but can also use glucose, ketone and lactate to produce ATP [7]. These different substrates cannot sufficiently enter cardiomyocytes by diffusion and thus have to be taken up by facilitated transport. Glucose uptake into cells involves a family of glucose transport proteins called GLUTs - which shuttle sugars across plasmalemmal membranes through their aqueous pore [8]. The GLUT family consists of several members which are expressed by various cell types [9]. In cardiomyocytes, GLUT family members 1 and 4 fulfil this function. While GLUT1 is mainly involved in basal glucose uptake, GLUT4 translocates to the plasma membrane to enhance glucose uptake in response to extracellular stimuli like insulin or increased cardiac work. Cellular fatty acid uptake is facilitated by several membrane proteins with high-affinity binding sites for fatty acids [1], but the exact mechanisms by which these proteins mediate transmembrane passage of fatty acids is not known [10]. In cardiomyocytes the most important fatty acid transporters are fatty acid translocase (FAT), also referred to as CD36 [10,11], and two members of the family of 6 fatty acid transport proteins (FATP), i.e., FATP 1 [12] 


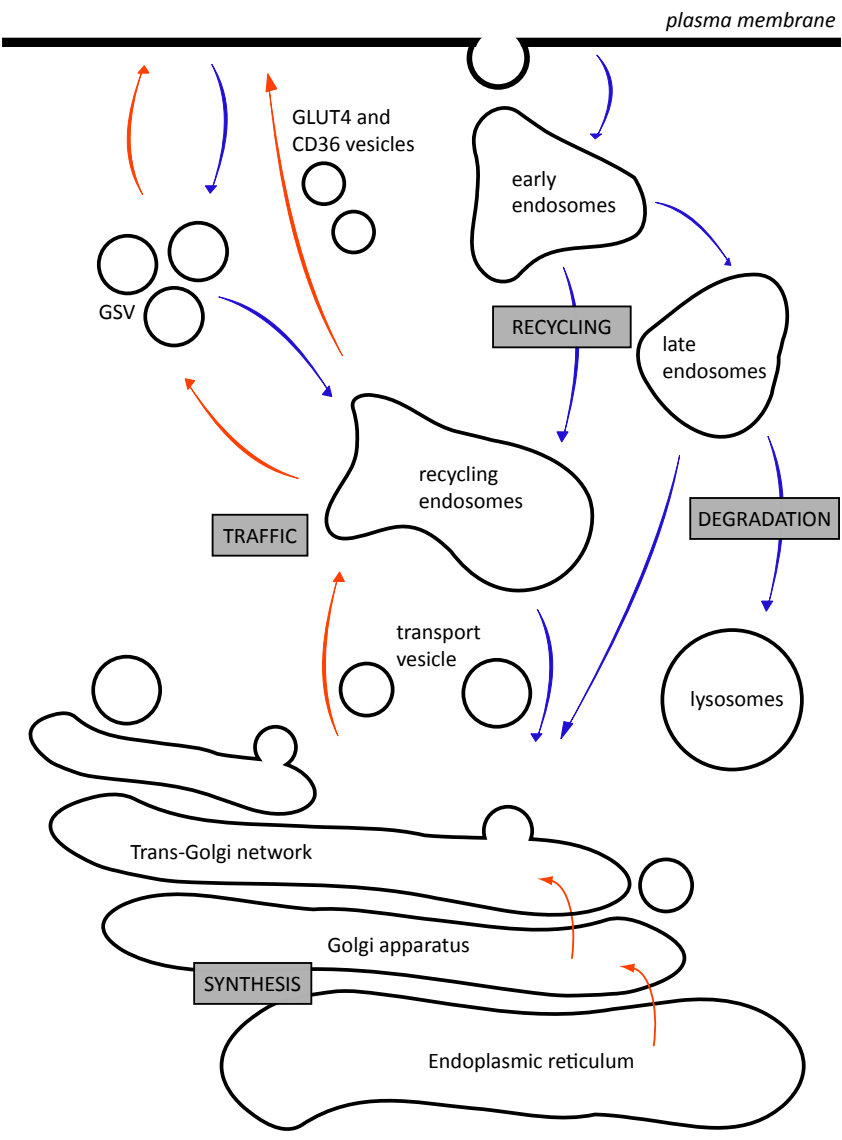

Figure 2.1: The endomembrane system of cardiomyocytes consists of several functionally different compartments. In the translocation process (red arrows) proteins are synthesized in the endoplasmic reticulum and further modified in the Golgi apparatus. There the budding of transport vesicles occurs and vesicles are transported to the endosomal system. GLUT4 is further transported to specific insulin-responsive GLUT4 storage vesicles (GSV). GLUT4 and CD36 can be stimulated to translocate from their compartments to the sarcolemma. In the endocytosis process (blue arrows) sarcolemmal proteins are taken up into the cell again and transported through the early endosomes and directed towards lysosomes for protein breakdown or towards the recycling endosomes for renewed use at the sarcolemma.

and 6 [13].

Both GLUT4 and CD36 are integral membrane proteins. GLUT4 consists of 12 transmembrane domains with both termini in the cytoplasm and one large intracellular and one large extracellular loop [14]. CD36 has a hairpin membrane structure with two transmembrane regions and both the $\mathrm{C}$-terminal and $\mathrm{N}$-terminal tail in the cytoplasm [1]. The translocation of both proteins from intracellular 
storage compartments to the plasma membrane, and vice versa, relies on a complex trafficking system, schematically represented in Figure 2.1 [15]. Immunoadsorption studies in rat cardiac myocytes showed that GLUT4 resides in two distinct pools, one of which is called GLUT4 storage vesicles (GSV) that does not contain CD36 and is sensitive to insulin [16]. On the other hand CD36 appears to reside in one subcellular pool which does not contain GLUT4 [16], suggesting that GLUT4 and CD36 are stored separately and travel independently.

Physiological stimuli, with circulating plasma insulin concentrations and increased cardiac work being the most important, stimulate the heart to quickly alter cardiac substrate utilization via reversible translocation of GLUT4 and CD36 from intracellular membrane compartments to the sarcolemma (Figure 2.2A) $[1,10]$. In contrast to CD36, the other fatty acid transporters FATP1 and FATP6 do not traffic between intracellular storage compartments and the sarcolemma in cardiomyocytes [17-19]. Therefore, FATP1 and FATP6 do not contribute to inducible fatty acid uptake. In addition, other studies have disclosed that these transporters also have a minor contribution to basal fatty acid uptake. From experiments with cardiomyocytes from wildtype and CD36 null mice it is known that the contribution of CD36 to fatty acid uptake is about 70\% [17]. In addition, in cardiomyocytes treated with the specific CD36 inhibitor sulfo- $N$-succinimydyl-oleate (SSO) the insulin/contraction-mediated increase in fatty acid uptake was totally blocked, meaning that CD36 is irreplaceable in stimulus-induced fatty acid uptake [20]. The system of regulated substrate uptake is crucial during exercise to supply cardiomyocytes with a sufficient amount of substrates, or to quickly replenish intracellular substrate storage pools after a meal. A dysfunction in this system of regulated glucose and fatty acid uptake into muscle, adipose tissue, beta cells and heart contributes to the development and progression of type 2 diabetes $[10,21]$.

The amount of glucose and fatty acid transporters present at the sarcolemma is a major regulatory factor of cardiac glucose and fatty acid utilization [22]. This implicates that the metabolic machinery is more than adequately suited to process all incoming substrates. Accordingly, intracellular concentrations of fatty acids and glucose will remain low. This also is true for the diabetic heart in which intracellular concentrations of these substrates are not markedly increased $[1,23]$. Hence, in both the healthy and the diabetic heart, the sarcolemmal presence of GLUT4 and CD36 determines cardiac substrate flux [24].

\section{Alterations in transporter location in insulin resistance}

Obesity, insulin resistance and type 2 diabetes show a strong association with changes in lipid metabolism [2,25]. Permanent relocation of CD36 to the sarcolemma and 
A) Healthy cardiomyocyte

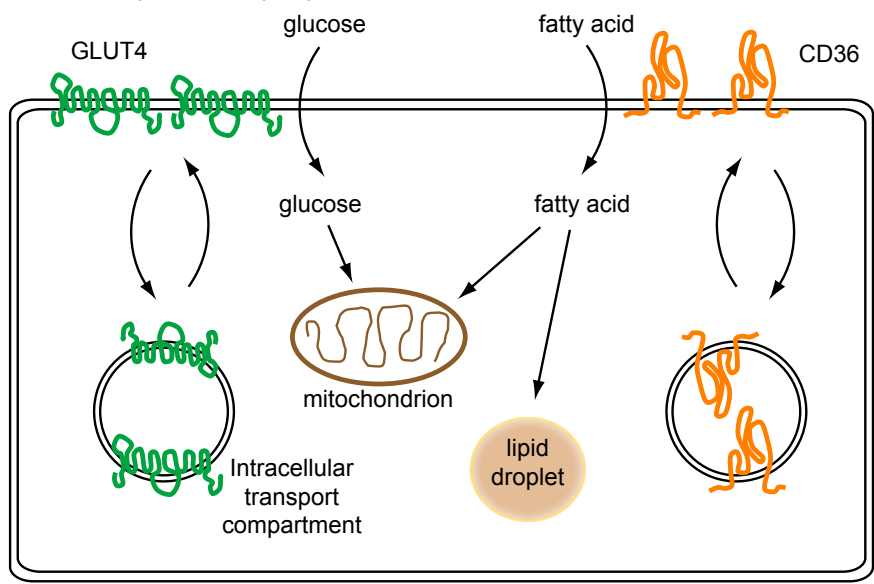

B) Diabetic cardiomyocyte

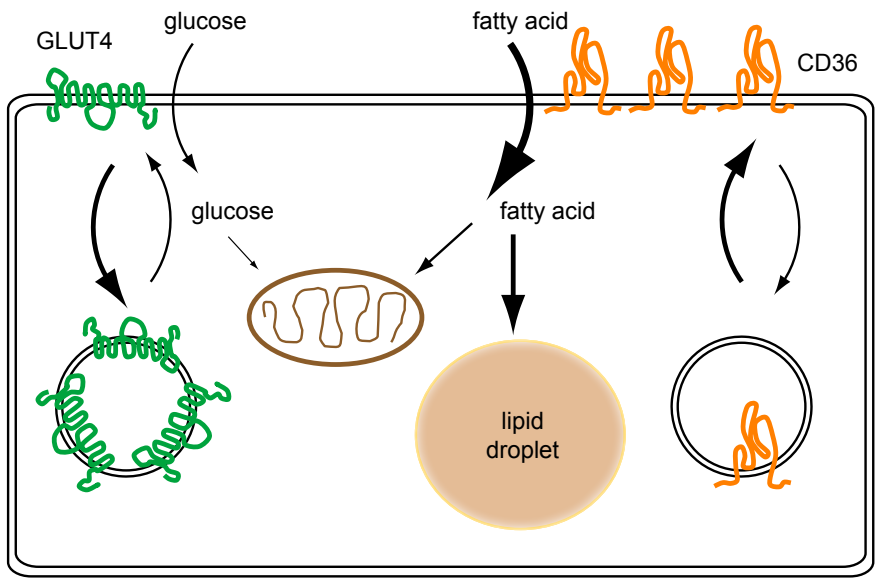

Figure 2.2: Alterations in transporter localisation in diabetic cardiomyocytes compared to healthy cardiomyocytes: A) Substrate uptake in healthy cardiomyocytes. The entry of glucose and fatty acids is facilitated by glucose transporter 4 (GLUT4) and fatty acid transporter CD36. The heart can acutely react to a change in energy demand by reversible translocation of these transporters from intracellular transport compartments. Once these substrates have entered the cell they can be used for ATP production by mitochondrial oxidation or they can be stored as glycogen (not shown) or in lipid droplets. B) Substrate uptake in diabetic cardiomyocytes: During the development of insulin resistance and type 2 diabetes, the localisation of GLUT4 and CD36 permanently alters. CD36 presence at the sarcolemma increases which associates with increased fatty acid uptake. In addition, fatty acid storage increases which is thought to associate with insulin-stimulated glucose uptake. 
increased fatty acid uptake were strongly linked in rodent models for insulin resistance $[2,26,27]$ and obese humans $[26,28,29]$. Furthermore, the sarcolemmal content of CD36 correlated well with increased uptake of fatty acids, increased intramuscular triacylglycerol $[30,31,28]$ and reduced insulin-stimulated GLUT4 translocation and glucose uptake [32]. Cardiac in-vivo positron-emission tomography (PET) in humans with type 2 diabetes showed increased fatty acid uptake and oxidation, and reduced insulin-stimulated glucose uptake, paralleled by decreased diastolic function as compared to age-matched healthy controls [33].

The increase in intramyocardial lipid concentrations cannot just be attributed to a reduction in mitochondrial fatty acid oxidation, since studies have shown that cardiac fatty acid oxidation remained unchanged, slightly reduced, or even increased in several rodent models of obesity and insulin resistance [10]. Inhibition of CD36-mediated fatty acid uptake with SSO normalized fatty acid utilization in different rodent models of insulin resistance [26]. This indicates that the increase in intramyocardial lipid concentrations in insulin resistant cardiomyocytes is caused by increased CD36-mediated fatty acid uptake. We and others showed that the surface presence of CD36 was increased in rodent models for insulin resistance and in skeletal muscle of obese humans $[2,3,32]$. The increase in surface presence of CD36 is not due to increased tissue expression but instead, to a permanent relocation from its intracellular storage compartment. This permanent CD36 relocation appears to be an early event in the sequence of maladaptive changes in the hearts of rodents with type 2 diabetes. We also obtained evidence that there is no decrease in cardiac mitochondrial function in this early pre-diabetic stage. However, it is very well possible that mitochondrial dysfunction develops at later stages which can lead to even more lipid storage. Moreover, it was shown that relocation of CD36 was specific for this fatty acid transporter because such changes were not observed for plasmalemmal FABP ${ }_{\text {pm }}$, FATP1 or FATP4 [10]. Thus, permanent relocation of CD36 to the sarcolemma is important in the development toward diabetic cardiomyopathy.

It is becoming increasingly evident that the increased intramyocardial triacylglycerol content is not the main contributor to the development of insulin resistance and cardiac dysfunction. Other lipid metabolites, such as ceramides and diacylglycerols, appear to be the main contributors to reduced insulin sensitivity ( see $[34,35]$ for excellent reviews on this topic).

Collectively, obesity, insulin resistance and type 2 diabetes impose metabolic stress on the heart [36-39], which may ultimately lead to cardiac metabolic inflexibility, lipotoxicity, and subsequent development of diabetic cardiomyopathy [3,32] (Figure 2.2B). 
A) Insulin-mediated signalling

insulin

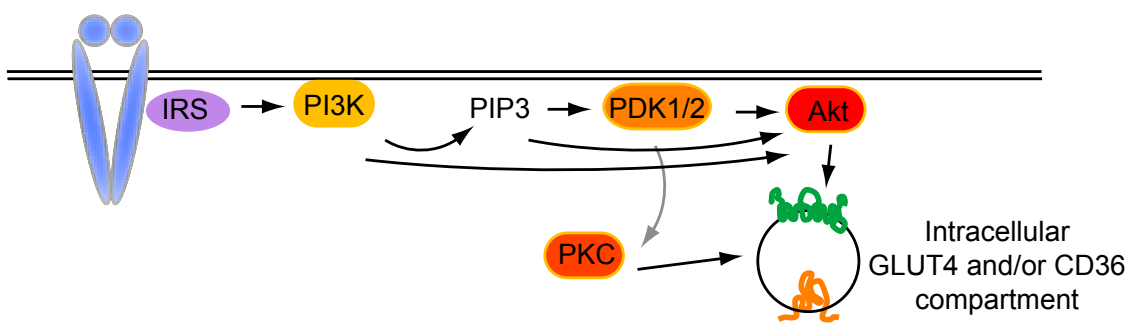

B) Contraction-mediated signalling
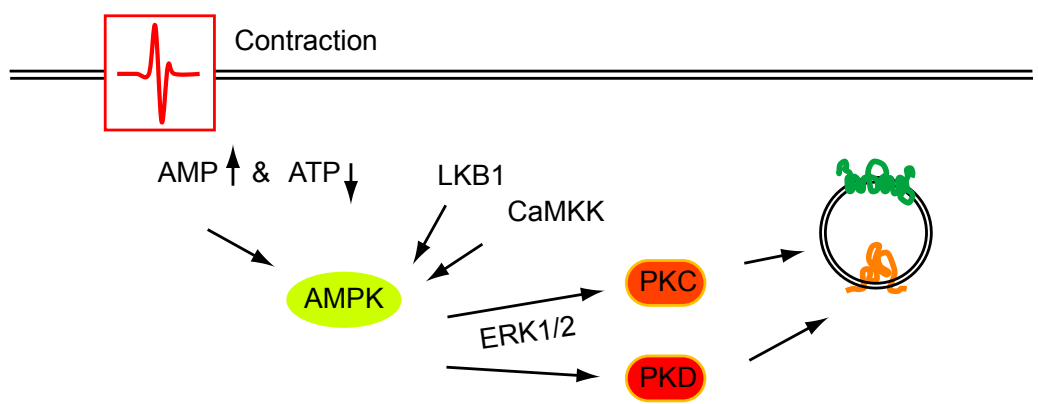

Figure 2.3: Signalling proteins involved in insulin-stimulated (A) and contraction-stimulated (B) induction of GLUT4 and CD36 trafficking: A) Upon binding of insulin to its receptor the downstream signalling axis (Akt axis) will be activated which induces the translocation of intracellular GLUT4 and CD36 vesicles. This signalling axis consists of insulin receptor substrate (IRS), phosphatidylinositol-3kinase (PI3K), PI-3-phosphate (PIP3), 3-phosphoinositide-dependent protein kinase (PDK), protein kinase $C$ (PKC) and Akt. B) When cardiac work increases the AMP/ATP-ratio and, subsequently, AMP-activated protein kinase (AMPK) activity increases. For full activation the action of upstream kinases, LKB1 or CaMKK, are warranted. Downstream of AMPK, ERK1/2, PKC and PKD are players in GLUT4 and CD36 translocation. For figure simplicity GLUT4 and CD36 are drawn in one transport compartment while we know that they are present in several different compartments.

\section{Signalling pathways involved in GLUT4 and CD36 translocation}

As mentioned above, postprandial increases in circulating plasma insulin levels and an elevated cardiac work are the most important physiological stimuli to enhance cardiac glucose and fatty acid uptake via induction of GLUT4 and CD36 translocation, respectively [1]. However, the metabolic fates of glucose and fatty acids are quite different during insulin-stimulation versus contraction-stimulation. Both substrates are preferentially stored under insulin-stimulated conditions, and preferentially oxidized upon increased contraction [1]. Since translocation of GLUT4 and CD36 are similarly induced by insulin and contraction, these translocation processes do not 
contribute to the different metabolic fates of both substrates during insulin- versus contraction-stimulation. Rather, upon intracellular trapping of both substrates (glucose via hexokinase and fatty acids via acetyl-CoA synthase (ACS)), the metabolic fates of glucose and fatty acids are determined by the activation state of key metabolic enzymes. Specifically, glucose and fatty acids are directed towards storage via insulin-induced activation of glycogen synthase (GS) and glycerol-3-phosphate acyltransferase (GPAT), respectively [1]. In addition, the contraction-induced drop in the intracellular ATP concentrations triggers phosphofructokinase, pyruvate dehydrogenase and TCA cycle progression for acceleration of glucose oxidation, and also carnitine-palmitoyl transferase-1 for acceleration of fatty acid oxidation [1]. Despite differential effects of insulin and contraction on the metabolic machinery, both stimuli similarly induce translocation of GLUT4 and CD36 to the sarcolemma [1]. This similarity in responsiveness of both transporters to both physiological stimuli suggests that similar signalling mechanisms are involved in GLUT4 and CD36 translocation. In addition it suggests that GLUT4 and CD36 migrate together to the sarcolemma in response to each of the stimuli. However, increasing numbers of studies report differences in the regulation of both substrate transporters, leading to a more differentiated understanding of GLUT4 and CD36 traffic.

Exactly how insulin and increased workload achieve increased abundance of GLUT4 and CD36 at the sarcolemma is unclear but there are two primary candidates; i.e. increasing exocytosis or inhibiting endocytosis [40-43]. Insulin is proposed to stimulate fusion of intracellular GLUT4 containing-vesicles with the plasma membrane in cardiac and skeletal myocytes while it does not affect the rate of endocytosis $[42,44,45]$. In myocytes, fusion of intracellular membranes with the plasmalemmal membrane is considered to be inducible, while endocytosis of GLUT4 and CD36 is regarded a housekeeping process which cannot be regulated. However it has been reported that decreased endocytosis in response to insulin regulates GLUT4 translocation in adipocytes [46]. Some studies found that, in line with the effect of insulin on GLUT4 translocation, contraction increases GLUT4 translocation $[44,45]$. In contrast, another study found that GLUT4 endocytosis is inhibited [42]. In summary, the exact mechanism by which insulin and contraction increase presence of CD36 and GLUT4 at the plasma membrane requires further studies aiming at the rate of endocytosis and/or the rat of translocation.

a)

Insulin-signalling

From all stimulus-induced transporter translocation processes, insulin-induced GLUT4 translocation is the most intensively studied [47]. Several of the kinases involved in insulin-induced GLUT4 translocation have been tested on their additional 
involvement in insulin-induced CD36 translocation. So far, these kinases seem to play a similar role in both translocation events, as detailed below. The insulin-signalling axis is initiated by the binding of insulin to its receptor and subsequent activation of insulin receptor substrate (IRS) 1 [48] IRS2 [49] (Figure 2.3A). This activates the regulatory subunit of phosphatidylinositol-3-kinase (PI3K), which consists of a catalytic $\mathrm{p} 110$ subunit and a regulatory $\mathrm{p} 85$ subunit [50]. Pharmacological inhibitors (most notably wortmannin) have greatly facilitated the investigation of the role of PI3K in GLUT4 and CD36 translocation, and pinpointed this lipid kinase as a key component [51-53]. The main phosphatidylinositol (PI)-phosphate generated by PI3K during insulin action is PI-3,4,5-trisphosphate (PIP3) [54]. Generation of PIP3 at the plasma membrane directly drives the activation of a number of different protein kinases with lipid binding pleckstrin homology domains [55]. Three of these kinases play an essential role in insulin-induced glucose uptake, 1) Akt/protein kinase $B(P K B)$-isoform 2, 2) protein kinase $C(P K C)-\lambda / \zeta$ and 3) 3-phosphoinositidedependent protein kinase (PDK) [56-59]. Akt/PKB-2 and PKC- $\lambda / \zeta$ have additionally been implicated in insulin-induced CD36 translocation [24,59].

Activation of Akt requires dual phosphorylation at Ser473 and Thr308 in addition to PI3K-mediated recruitment to the plasma membrane [1]. The Thr308 phosphorylation within the activation loop of Akt is mediated by PDK1 [60] and the Ser473 phosphorylation by a putative PDK2 [61]. Upon its activation, Akt phosphorylates TBC1D1 and TBC1D4, also referred to as AS160, as a final step to induce GLUT4 translocation [62,63]. Next to Akt, PDK1 also activates PKC- $\zeta$ upon unfolding of its pseudosubstrate domain and exposure of the activation loop [64]. The simultaneous and combined activation of Akt and PKC- $\lambda / \zeta$ is necessary for insulin-induced GLUT4 translocation in both heart [65] and skeletal muscle [66], and likely also essential for insulin-induced CD36 translocation.

To date, GLUT4 and CD36 translocation seem identically regulated by insulin. However, it is possible to translocate GLUT4 from insulin-responsive intracellular compartments in cardiomyocytes, without changes in subcellular CD36 localization using the thiol-modifying agent arsenite [67]. Hence, there are arsenite-sensitive proteins that contribute to insulin-induced GLUT4 translocation without affecting CD36 dynamics.

\section{b) Contraction-signalling}

Increased cardiac work results in a rapid rise of both glucose and fatty acid uptake in heart and muscle $[1,68]$. Upon increased contraction the intracellular concentration of adenosine-monophosphate (AMP), cyclic AMP, reactive oxygen species (ROS) and calcium increase. Together these second messengers activate a complex signalling 
system that involves AMP-activated protein kinase (AMPK), protein kinase A (PKA), atypical PKCs, protein kinase D (PKD), calcium-calmodulin-dependent protein kinases (CaMK), and the extracellularly-regulated protein kinases (ERK) 1 and 2 [68] (Figure 2.3B). Of all of these, AMPK, PKD and CaMK have been studied for their effects on metabolic processes.

AMPK is a heterotrimer consisting of a catalytic $\alpha$-domain, a glycogen-binding regulatory $\beta$-domain and an AMP-binding regulatory $\nu$-domain. Binding of AMP to the regulatory $\gamma$-subunit of AMPK leads to a conformational change of the kinase, which makes it accessible for upstream AMPK kinases (AMPKK). These, phosphorylate AMPK at the threonine-172 and consequently activate this kinase. In the heart activation of the $\alpha 2$ isoform of AMPK is essential for contraction-induced GLUT4 and CD36 translocation [69]. Kinases with suggested AMPKK activity include CaMK-kinase (CaMKK) and the tumour suppressor protein LKB1 [70]. In LKB1-null mice contraction-induced GLUT4 and CD36 translocation are completely abrogated, indicating that LKB1 is essential for both translocation processes [69]. Additionally, LKB1 is involved in hypoxia-induced AMPK-mediated cardiac GLUT4 translocation [71].

CaMK-kinase (CaMKK) is described as an alternative upstream kinase of AMPK [72]. However, evidence for the physiological importance of CaMKK in cardiomyocyte metabolism is scarce. One study reported basal activity and phosphorylation of AMPK in LKB1-deficient cells that could be further stimulated by calcium ionophores [72]. Another study, in which CaMKK $\beta$ was overexpressed or pharmacologically inhibited, showed that AMPK can also be activated by CaMKK [73]. In addition it was shown that CaMKK is important for contraction-mediated GLUT4 and CD36 translocation in skeletal muscle [74]. However, the importance of CaMKK in cardiac GLUT4 and CD36 translocation remains to be established.

Downstream events of AMPK involve atypical PKCs, ERK1/2, TBC1D1 and TBC1D4. It was shown that exercise increases glucose transport in skeletal muscle via AMPK through atypical PKCs. Furthermore, these effects of atypical PKCs were dependent on the ERK1/2 pathway, activation of proline-rich tyrosine kinase-2 (PYK2), and phospholipase D (PLD) [75]. In a muscle-specific knock out mouse model for the atypical PKC PKC $\lambda$, glucose transport was impaired and mice developed the metabolic syndrome [76]. In rat skeletal muscle, ERK1/2 inhibitors decreased contraction-induced fatty acid uptake and CD36 translocation [77]. Hence, atypical PKCs and ERKs are involved in contraction-stimulated substrate uptake in skeletal muscle. However, their function in substrate uptake of the heart still needs to be disclosed. 
We recently identified involvement of the contraction-activated protein PKD to in contraction-induced GLUT4 translocation and glucose uptake [78]. Pharmacological inhibition of PKD1 in cardiomyocytes inhibited contraction-stimulated GLUT4 translocation and glucose uptake [78]. Furthermore, contraction-stimulated PKD1 activation was still able to induce GLUT4 translocation and glucose uptake in AMPKa2 knockout mice suggesting that PKD1 acts independently of AMPK [78]. These findings suggest that contraction-mediated translocation of GLUT4 is a dual input mechanism which needs both the input of AMPK and PKD. Future experiments should reveal the role of PKD in contraction-induced CD36 translocation and fatty acid uptake. Additionally, upstream and downstream proteins of PKD1 have not been elucidated yet.

Surprisingly, the two Akt substrates TBC1D1 and TBC1D4 are also substrates of activated AMPK and therefore also part of the contraction signalling cascade $[66,79]$. Although these data suggest a complementary role of both TBC1D isoforms, the high expression of TBC1D1 in muscle compared to fat tissue indicates a pivotal role of this protein in contractile tissue [79]. Still, further research is needed to unravel i) whether the two isoforms are physiologically relevant and, ii) whether they fulfil similar functions in CD36 translocation.

In summary, GLUT4 and CD36 translocation seem identically regulated by increased workload, but the roles of CaMKK and PKD in contraction-induced CD36 translocation still await exploration.

\section{Trafficking machinery involved in GLUT4 and CD36 translocation}

The trafficking machinery involved in GLUT4 translocation [45,80-85], especially in adipocytes and muscle cells, has gained much more attention than the trafficking machinery involved in CD36 translocation [4,5]. The isolation of GLUT4 vesicles revealed approximately 50 proteins that regulate vesicle fission, -transport and fusion, as well as the specificity of GLUT4 transport [86]. CD36-containing vesicles have been isolated [16], but not extensively studied with a proteomics approach, so far.

Cellular protein traffic generally involves three major steps: a) Vesicle fission: At the donor compartment, the membranes will be curved into a budd that will subsequently excise. This process is dependent on bilayer destabilizing proteins, coat proteins, Rab GTPases and a number of adaptor proteins forming a fission complex. b) Subcellular vesicle transport: These newly formed transport vesicles move along one of the cytoskeletal networks with the aid of motor proteins which are regulated by Rab GTPases. c) Vesicle fusion: At the acceptor compartment the vesicle membranes 

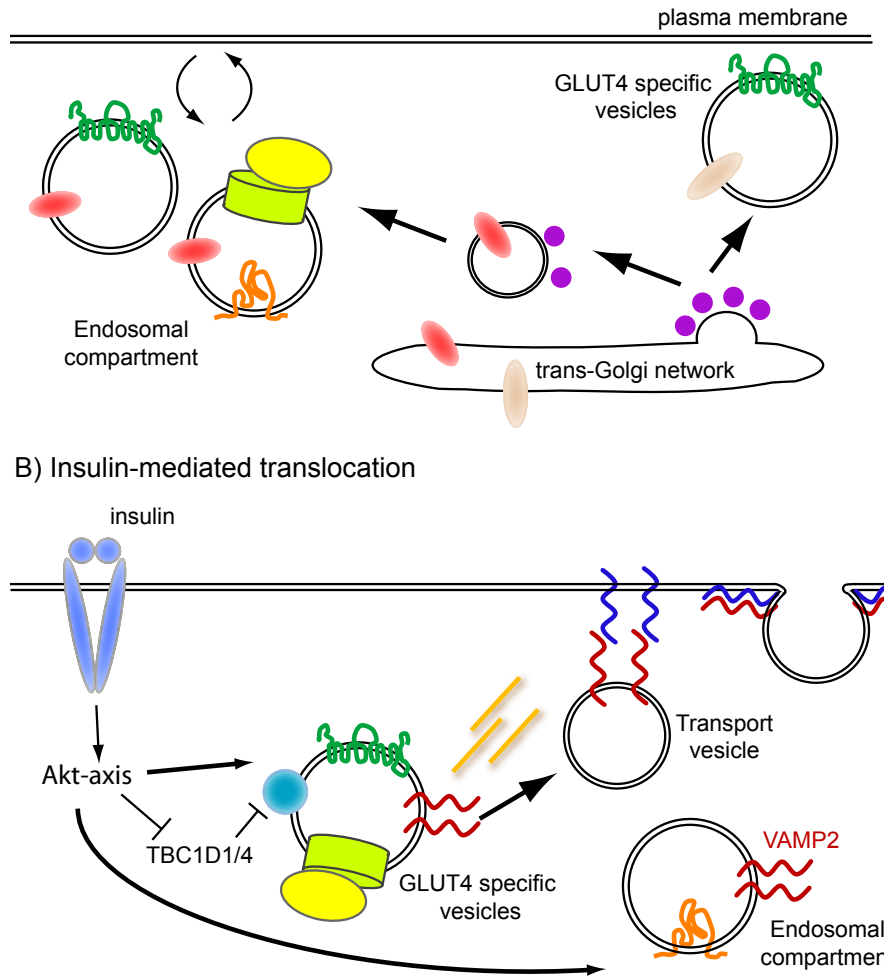

C) Contraction-mediated translocation

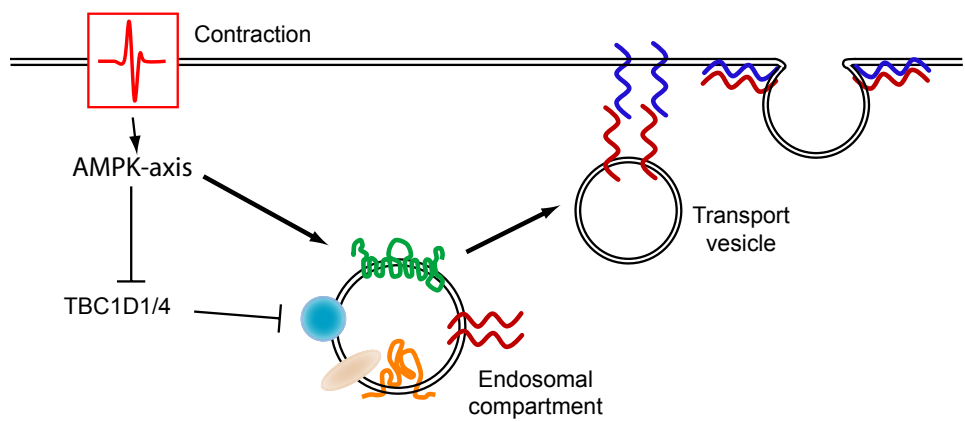

Figure 2.4: Signalling-pathways and subcellular trafficking components involved in GLUT4 and CD36 translocation in cardiomyocytes. A) Basal recycling: During basal recycling of endosomal vesicles GLUT4 is directed towards an insulin-responsive GLUT4 specific vesicle which also contains IRAP. Coat proteins and the transferrin receptor are found in GLUT4 and CD36 vesicles in the endosomal compartment. V-ATPase is only involved in basal recycling of $\mathrm{CD} 36$ containing vesicles. B) insulin-mediated translocation (Akt-axis): Insulin releases the vesicles from the inhibitory action of TBC1D1/4 and acts on VAMP2 containing GLUT4 and CD36 vesicles. V-ATPase is only involved in insulin-mediated GLUT4 translocation - and C) contractionmediated translocation (AMPK-axis): Contraction also affects functioning of TBC1D1/4. Furthermore, VAMP3 is involved in contraction-mediated translocation of GLUT4 and CD36. 
fuse with the acceptor lipid bilayer requiring the formation of a SNARE complex and is modulated by Rab GTPases. Both translocation and endocytotic routes between endosomes and the sarcolemma proceed accordingly (Figures 2.1 and 2.4).

Although it is generally believed that GLUT4 and CD36 translocation are vesiclemediated endosomal processes, GLUT4 localization overlaps only for 30-40\% with markers of this endocytosis system, e.g. the transferrin receptor and Rabs. In addition, chemical ablation of endosomes does not fully block insulin-stimulated GLUT4 translocation in adipocytes [87]

Recently, posttranslational modification of GLUT4 by ubiquitination was found to be important for its intracellular sorting [88]. CD36 can also be ubiquitinated, but in this case ubiquitination affects protein expression rather than localization [89].

Recent data, which will be discussed below, have revealed the role of these trafficking components in GLUT4 and CD36 translocation.

a) Coat proteins

Coat proteins are essential players in vesicle fission and fusion. To inititate vesicle fission these proteins are recruited to membrane spots where cargo is concentrated by adaptor proteins. There, coat proteins form a 'bulb' in the membrane and thus start budding of a vesicle. Once the vesicle is formed and detached from the organelle the coat proteins are released. The following protein families are known to function as coat proteins: coat protein complex (COP), clathrin and caveolin, which reside in specific subcellular compartments $[15,90]$.

COPI and II are involved in transport from the ER to the Golgi apparatus, where sorting receptors couple specific cargo to COPI and COPII transport vesicles [15,91]. Much of the knowledge on COPI vesicle formation is derived from pharmacological studies using brefeldin-A as a non competitive inhibitor of Arf1 [92,93], although it has also been reported that brefeldin A affects clathrin functioning [94]. Treatment of cells with brefeldin-A results in rapid fusion of the Golgi apparatus with the ER, which suggests an important role of these coat proteins in the maintenance of the distinct organelles [92]. However, the use of brefeldin-A in rat adipocytes could not clearly prove an involvement of COPI in insulin-stimulated GLUT4 translocation to the plasma memmrane [95-98]. Studies performed in cardiomyocytes show that COP proteins and/or clathrin function in stimulus-induced glucose and fatty acid uptake in cardiomyocytes [4]. Hence, GLUT4 and CD36 translocation in cardiomyocytes both are closely related vesicle-mediated processes (Figures 2.1 and 2.4).

Caveolins - caveolin-1, -2 and -3 - reside in cholesterol-enriched lipid rafts of 
the plasma membrane called caveolae. Caveolins could play a role in plasmalemmal docking of GLUT4- or CD36-containing vesicles, and could be involved in GLUT4 or CD36 internalization $[99,100]$. Caveolin-1 $[101,102]$ has been proposed to play a role in initiation of GLUT4 endocytosis in adipocytes, but in skeletal muscle the musclespecific isoform caveolin-3 does not colocalize with GLUT4 [103]. Hence, the role of caveolins in GLUT4 trafficking is unclear. Caveolin-1 has been shown to be involved in CD36 localization and function in smooth muscle cells [104] and fibroblast [105]. However, caveolin-3 does not seem to play a role in CD36 translocation in muscle cells because regulation of cardiac LCFA uptake was not altered in caveolin-3 knockout mice. In conclusion, there is evidence that caveolin-1 is involved in GLUT4 and CD36 translocation in non-muscle cells, but caveolin-3 most likely does not play a role in translocation of both transporters in (cardiac) myocytes.

\section{b) Cytoskeletal filaments}

It is well established that reorganization of filamentous actin beneath the plasma membrane plays a role in insulin-induced GLUT4 translocation [83,106-108]. Insulin signalling bifurcates at the level of PI3K towards Akt and Rac. Insulin activates GTP loading of Rac within 5 minutes and then induces reorganization of actin. It has been shown that agents that disturb actin polymerization, e.g. latrunculin B or cytochalasin D, inhibit insulin-induced GLUT4 translocation in adipocytes, skeletal muscle cells and cardiomyocytes $[4,82,83,109]$. Findings obtained by these pharmacological approaches were confirmed by overexpression of a dominant negative Rac mutant [110] or siRNA-mediated knock down of Rac [111]. Recently it was shown that Arp2/3 is a downstream effector of Rac and that cofilin regulates actin depolymerization which again proposes that active actin cycling is essential for insulin-stimulated GLUT4 translocation [83]. In contrast, latrunculin B did not inhibit stimulus-induced CD36 translocation in cardiomyocytes [4]. Hence, actin filaments are involved in GLUT4 translocation, but not in CD36 translocation in the heart.

Microtubule involvement in GLUT4 translocation has mainly been studied in adipocytes. Controversy exists about their role in stimulus-induced GLUT4 translocation. Some groups reported that microtubule-disrupting agents inhibited insulin-induced GLUT4 translocation in 3T3-adippocytes [81,112], while others did not find any effect on this process [113]. However, microtubules do not seem to play a role in stimulus-induced GLUT4 or CD36 translocation in skeletal muscle and cardiomyocytes $[4,114]$.

Although the cytoskeleton clearly is involved in GLUT4 and CD36 translocation in cardiomyocytes, its role in the altered transporter localization in diabetes has not been studied yet. However, investigators in other fields of research have 
studied the cytoskeleton in the diabetic heart. For example, in ventricular cells from streptozotocin-induced diabetic rats impairment of cytoskeletal function and structure - actin and microtubules - was found. In their study, the insulin-deficient conditions affected the cardiac potassium-current in a cytoskeleton-dependent manner [115] suggesting that this may also affect insulin-dependent GLUT4 translocation.

\section{c) Endosomal $\mathrm{pH}$}

The acidity of intracellular compartments, such as endosomes, is essential for various cellular processes, including endosomal function and vesicular trafficking $[116,117]$. Endosomal acidification is regulated by vacuolar-ATPase (v-ATPase or V1V0-ATPase), a large multisubunit complex that functions as an ATP driven proton pump. It has a similar build up as the $\mathrm{F}_{1} \mathrm{~F}_{0}$-ATPase located at the mitochondrial membrane, however it needs ATP to pump protons whereas the $F_{1} F_{0}$ needs protons to produce ATP [118].

Surprisingly, not much is known about the role of endosomal acidity in trafficking of GLUT4 or CD36. The role of V-ATPases in GLUT4 translocation has been studied in 3T3-L1 adipocytes [119], and in cardiomyocytes [120]. Upon inhibition of v-ATPase with bafilomycin A1 in 3T3-L1 adipocytes insulin-stimulated glucose uptake was disrupted and GLUT4 accumulated in intracellular membranes, while Akt and IRS1 signalling were still intact. From these data it was concluded that proper regulation of endosomal $\mathrm{pH}$ is important for the formation of small insulin-responsive vesicles [119]. This has also been studied in cardiomyocytes and in these cells v-ATPases in the GLUT4-containing vesicles may play a role in insulin-stimulated increase of GLUT4 translocation and glucose uptake $[120,121]$. When examining GLUT1 in mouse mammary epithelial cells it was found that endosomal acidification was important

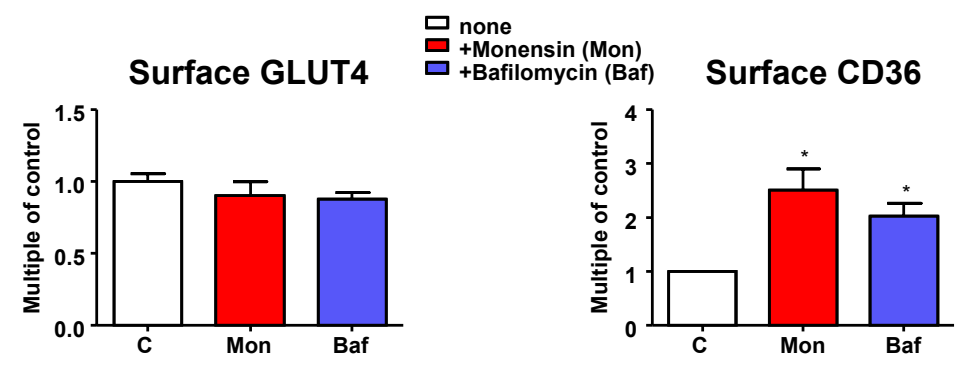

Figure 2.5: Endosomal $\mathrm{pH}$ is important for cardiomyocyte transporter translocation. Isolated rat cardiomyocytes were treated with $\mathrm{pH}$ gradient disturbing agents, monensin (Mon) and bafilomycin A (Baf). Afterwards, GLUT4 and CD36 presence at the cell surface were assayed. During basal recycling disturbance of the $\mathrm{pH}$ gradient only affects CD36 translocation [4]. 
for directed trafficking of GLUT1 [122].

We recently used the specific V-ATPase inhibitor bafilomycin $A$ and the proton ionophore monensin to study the role of endosomal acidification in CD36 translocation. While reducing glucose uptake only in the acutely stimulated state, both compounds already increased basal CD36 translocation and subsequent fatty acid uptake [4]. Thus, v-ATPase seems to be involved in stimulus-induced, but not in basal, GLUT4 translocation. This seems to be opposite for CD36 translocation, where v-ATPase is involved in basal, but not in stimulus-induced processes (Figures 2.4 and 2.5). A novel function of v-ATPase is the modulation of protein traffic between early and late endosomes. Here, vATPase acts as a $\mathrm{pH}$ sensor interacting with proteins such as small GTPases of the Arf-family and their regulatory proteins [123]. Whether this function of the v-ATPases is involved in GLUT4 and CD36 translocation is not known yet. However, the proton pump function of the v-ATPases clearly is important since bafilomycin A and monensin similarly affect GLUT4 and CD36 localisation.

Taken together, regulation of the endosomal $\mathrm{pH}$ seems an interesting target to restore the metabolic substrate balance in type 2 diabetes.

\section{d) Rab proteins}

Rab-GTPases are regulators of multiple steps of vesicular transport ( e.g. like vesicle formation, transport along the actin- and microtubule-based cytoskeleton and fusion with target membranes) by facilitation the formation of SNARE complexes [124,125]. Therefore, Rab-GTPases are considered to play a key role in the control of GLUT4 and CD36 vesicle trafficking [126]. Adding to the complexity, 19 isoforms of the more than 60 currently known Rabs are present on GLUT4 vesicles [62]. Examples are Rab4 and Rab11a, which are involved in the intracellular GLUT4 sequestration and endocytosis of both GLUT4 and CD36, respectively [127-129]. Interestingly, Rab11a was activated and recruited to GLUT4 vesicles upon insulin stimulation $[130,131]$. In this context it was also observed, that Rab11a shifted from microsomal fractions to the plasma membrane after insulin stimulation. In addition, Rab4 GTP-loading is also stimulated by insulin and this complex is known to bind syntaxin4, which function in the docking and fusion of vesicles with the plasma membrane [132,133]. Two proteins interacting with Rab11a, i.e., FIP2 and Rip11, have been investigated for their role in GLUT4 and CD36 recycling. FIP2, which functions as an adaptor for interaction of Rab11 with the motor protein myosin- $\mathrm{Vb}$ [134], mediates endocytosis of both GLUT4 and CD36 in cardiac myoblast cultures [128]. In the same cell system, Rip11, which colocalizes with Rab11 in endosomal membranes [135], is involved in CD36 endocytosis, but does not influence GLUT4 dynamics [128]. However, in cultured adipocytes Rip11 does influence GLUT4 traffic, indicating a cell type specific 
function of this Rab11a regulator [136].

Rab-GTPase activating proteins (Rab-GAPs) silence Rab activity by keeping them in an inactive state [137]. TBC1D1 and TBC1D4, two proteins mentioned as Akt- and AMPK substrates in section IV, are Rab-GAPs that silence Rab-function on GLUT4 translocation $[62,138]$. By doing so, they retrain GLUT4 in its intracellular stores under basal conditions. Insulin releases this brake on GLUT4 translocation by stimulating Akt-mediated phosphorylation and inactivation of TBC1D1 and 4. This will promote the formation of GLUT4 transport vesicles and eventually their translocation to the plasma membrane $[63,139]$. As detailed in section IVb, under conditions of increased contractions, activated AMPK acts analogous to Akt, indicating a common mechanism of GLUT4 mobilization that is shared by different signalling pathways [140]. Which Rab isoforms are regulated by TCB1D1 and TBC1D4, respectively? Invitro Rab-GAP assays revealed a strong activity of both GAPs against Rab2a, $-8,-10$ and -14 , and no activity against the above mentioned Rab4 and Rab11a $[62,63]$. Still, identifying one Rab protein to be the crucial isoform for GLUT4 translocation remains challenging, as Rab8a, -10 and -13 all appear to be essential for complete insulin-dependent GLUT4 translocation to plasma membrane [141-143]. In addition, if and how TBC1D1, TBC1D4 and Rabs are involved in CD36 translocation needs further study.

\section{e) SNARE proteins}

Integration of vesicular GLUT4 and CD36 into the plasma membrane is regulated by soluble N-ethylmaleimide-sensitive factor attachment protein receptors (SNAREs), the mechanistic core complexes of membrane fusion [144]. Subtypes of the SNARE proteins have been classified depending on the amino acid residues within the SNARE motifs which is either a glutamine (Q-SNAREs) or an arginine (R-SNAREs) [145]. When the vesicle-associated R-SNAREs interact with a specific subset of QSNAREs at the target membrane, a hetero-oligomeric SNARE complex is formed which catalyzes the fusion of the vesicle with the target membrane [145].

It is well accepted that insulin-stimulated translocation of GLUT4 in adipocytes, skeletal- and cardiac myocytes involves the R-SNARE VAMP2 [146], which interacts with the Q-SNAREs syntaxin4 and SNAP23 at the plasma membrane (Figure 2.4) $[147,148]$. We could recently show that insulin-stimulated CD36 translocation is also dependent on VAMP2 [5]. Another VAMP isoform, VAMP3, links contraction signalling to GLUT4 and CD36 translocation, disclosing a strong resemblance of the mechanisms of GLUT4 and CD36 trafficking [5]. Although present on GLUT4 vesicles, VAMP3 does not translocate to the plasma membrane upon increased contraction, pinpointing to a rather unclear function of this VAMP isoform in GLUT4 translocation 
[149]. However, other VAMP isoforms, like VAMP4 and VAMP7, are differentially involved in the regulation of GLUT4 and CD36 traffic and could be the basis for selective regulation of transporter distribution [5]. Still, their physiological function needs to be disclosed.

\section{Concluding remarks}

A complex interplay between signaling pathways and trafficking compontents is involved in the regulation of GLUT4 and CD36 translocation (Figure 2.4). The signalling pathways appear to similarly affect GLUT4 and CD36 translocation and thus are unsuitable targets for restoring the improper subcellular localization of both substrate transporters in the diabetic heart, for example by bringing GLUT4 to the cell surface and internalizing CD36. However, the subcellular trafficking machinery is able to discriminate between regulation of GLUT4 and CD36 translocation, and therefore could form the basis of a novel approach to restore cardiac substrate preference in metabolic diseases with altered substrate utilization. Coat proteins are similarly involved in GLUT4 and CD36 translocation. Other trafficking components are differentially involved in both processes. In detail, actin organisation and vATPase are specifically involved in GLUT4 translocation, while v-ATPase is specifically involved in CD36 endocytosis. Future experiments should explore the possible disturbance of these subcellular trafficking components in animal models and in biopsies from patients with type 2 diabetes.

Importantly, all these trafficking components that differentiate between GLUT4 and CD36 translocation are novel targets for the development of therapies to restore the metabolic balance in cardiomyocytes during disease characterized by unbalanced substrate usage (e.g. insulin resistance, diabetic cardiomyopathy and heart failure). Another advantage in therapeutically targeting the GLUT4 and CD36 trafficking machineries is that this can be achieved in a tissue-specific manner because many members of the major trafficking protein families display a tissuespecific distribution pattern [144,150]. Future research will undoubtedly unmask more GLUT4 and CD36-dedicated trafficking proteins that could be added to the list of novel anti-diabetic targets.

\section{Acknowledgments}

This work was supported by the Dutch Diabetes Research Foundation (Grant: 2006.00.044) and the EU European Cooperation in the field of Scientific and Technical Research (COST) Action BM0602 (Adipose tissue: A key target for prevention of the metabolic syndrome). 


\section{References}

1. Glatz JF, Luiken JJ, Bonen A (2010) Membrane fatty acid transporters as regulators of lipid metabolism: Implications for metabolic disease. Physiol Rev 90 (1):367-417.

2. Ouwens DM, Diamant M, Fodor M, Habets DD, Pelsers MM, El Hasnaoui M, Dang ZC, van den Brom CE, Vlasblom R, Rietdijk A, Boer C, Coort SL, Glatz JF, Luiken JJ (2007) Cardiac contractile dysfunction in insulin-resistant rats fed a high-fat diet is associated with elevated cd36-mediated fatty acid uptake and esterification. Diabetologia 50 (9):1938-1948.

3. van den Brom CE, Huisman MC, Vlasblom R, Boontje NM, Duijst S, Lubberink M, Molthoff CF, Lammertsma AA, van der Velden J, Boer C, Ouwens DM, Diamant M (2009) Altered myocardial substrate metabolism is associated with myocardial dysfunction in early diabetic cardiomyopathy in rats: Studies using positron emission tomography. Cardiovasc Diabetol 8:39.

4. Steinbusch LK, Wijnen W, Schwenk RW, Coumans WA, Hoebers NT, Ouwens DM, Diamant M, Bonen A, Glatz JF, Luiken JJ (2010) Differential regulation of cardiac glucose and fatty acid uptake by endosomal ph and actin filaments. Am J Physiol Cell Physiol 298 (6):C1549-1559.

5. Schwenk RW, Dirkx E, Coumans WA, Bonen A, Klip A, Glatz JF, Luiken JJ (2010) Requirement for distinct vesicle-associated membrane proteins in insulin- and amp-activated protein kinase (ampk)-induced translocation of glut4 and cd36 in cultured cardiomyocytes. Diabetologia 53 (10):2209-2219.

6. Russell LK, Finck BN, Kelly DP (2005) Mouse models of mitochondrial dysfunction and heart failure. J Mol Cell Cardiol 38 (1):81-91.

7. Hue L, Taegtmeyer H (2009) The randle cycle revisited: A new head for an old hat. Am J Physiol Endocrinol Metab 297 (3):E578-591.

8. Shepherd PR, Kahn BB (1999) Glucose transporters and insulin action--implications for insulin resistance and diabetes mellitus. N Engl J Med 341 (4):248-257.

9. Watson RT, Pessin JE (2001) Intracellular organization of insulin signaling and glut4 translocation. Recent Prog Horm Res 56:175-193.

10. Schwenk RW, Luiken JJ, Bonen A, Glatz JF (2008) Regulation of sarcolemmal glucose and fatty acid transporters in cardiac disease. Cardiovasc Res 79 (2):249-258.

11. Abumrad NA, el-Maghrabi MR, Amri EZ, Lopez E, Grimaldi PA (1993) Cloning of a rat adipocyte membrane protein implicated in binding or transport of long-chain fatty acids that is induced during preadipocyte differentiation. Homology with human cd36. J Biol Chem 268 (24):17665-17668.

12. Chiu HC, Kovacs A, Blanton RM, Han X, Courtois M, Weinheimer CJ, Yamada KA, Brunet S, Xu H, Nerbonne JM, Welch MJ, Fettig NM, Sharp TL, Sambandam N, Olson KM, Ory DS, Schaffer JE (2005) Transgenic expression of fatty acid transport protein 1 in the heart causes lipotoxic cardiomyopathy. Circ Res 96 (2):225-233.

13. Gimeno RE, Ortegon AM, Patel S, Punreddy S, Ge P, Sun Y, Lodish HF, Stahl A (2003) Characterization of a heart-specific fatty acid transport protein. J Biol Chem 278 (18):16039-16044.

14. Olson AL, Pessin JE (1996) Structure, function, and regulation of the mammalian facilitative glucose transporter gene family. Annu Rev Nutr 16:235-256.

15. Russell C, Stagg SM (2009) New insights into the structural mechanisms of the copii coat. Traffic 11 (3):303-310.

16. Muller H, Deckers K, Eckel J (2002) The fatty acid translocase (fat)/cd36 and the glucose transporter glut4 are localized in different cellular compartments in rat cardiac muscle. Biochem Biophys Res Commun 293 (2):665-669.

17. Habets DD, Coumans WA, Voshol PJ, den Boer MA, Febbraio M, Bonen A, Glatz JF, Luiken JJ (2007) Ampkmediated increase in myocardial long-chain fatty acid uptake critically depends on sarcolemmal cd36. Biochem Biophys Res Commun 355 (1):204-210.

18. Habets DDJ (2008) Thesis: Regulation of cardiac long-chain fatty acid and glucose utilization, chapter 5: Aicar stimulates long-chain fatty acid uptake and oxidation in mouse heart independent of cd36.89-101.

19. Chabowski A, Coort SL, Calles-Escandon J, Tandon NN, Glatz JF, Luiken JJ, Bonen A (2005) The subcellular compartmentation of fatty acid transporters is regulated differently by insulin and by aicar. FEBS Lett 579 (11):2428-2432.

20. Coort SL, Willems J, Coumans WA, van der Vusse GJ, Bonen A, Glatz JF, Luiken JJ (2002) Sulfo-n- 
succinimidyl esters of long chain fatty acids specifically inhibit fatty acid translocase (fat/cd36)mediated cellular fatty acid uptake. Mol Cell Biochem 239 (1-2):213-219.

21. McGarry JD (2002) Banting lecture 2001: Dysregulation of fatty acid metabolism in the etiology of type 2 diabetes. Diabetes 51 (1):7-18.

22. Glatz JF, Bonen A, Ouwens DM, Luiken JJ (2006) Regulation of sarcolemmal transport of substrates in the healthy and diseased heart. Cardiovasc Drugs Ther 20 (6):471-476.

23. Shulman GI (1999) Cellular mechanisms of insulin resistance in humans. Am J Cardiol 84 (1A):3J-10J.

24. Luiken JJ, Coort SL, Koonen DP, van der Horst DJ, Bonen A, Zorzano A, Glatz JF (2004) Regulation of cardiac long-chain fatty acid and glucose uptake by translocation of substrate transporters. Pflugers Arch 448 (1):1-15.

25. Sharma S, Adrogue JV, Golfman L, Uray I, Lemm J, Youker K, Noon GP, Frazier OH, Taegtmeyer H (2004) Intramyocardial lipid accumulation in the failing human heart resembles the lipotoxic rat heart. FASEB J 18 (14):1692-1700.

26. Coort SL, Hasselbaink DM, Koonen DP, Willems J, Coumans WA, Chabowski A, van der Vusse GJ, Bonen A, Glatz JF, Luiken JJ (2004) Enhanced sarcolemmal fat/cd36 content and triacylglycerol storage in cardiac myocytes from obese zucker rats. Diabetes 53 (7):1655-1663.

27. Carley AN, Atkinson LL, Bonen A, Harper ME, Kunnathu S, Lopaschuk GD, Severson DL (2007) Mechanisms responsible for enhanced fatty acid utilization by perfused hearts from type 2 diabetic $\mathrm{db} / \mathrm{db}$ mice. Arch Physiol Biochem 113 (2):65-75.

28. Aguer C, Mercier J, Man CY, Metz L, Bordenave S, Lambert K, Jean E, Lantier L, Bounoua L, Brun JF, Raynaud de Mauverger E, Andreelli F, Foretz M, Kitzmann M (2010) Intramyocellular lipid accumulation is associated with permanent relocation ex vivo and in vitro of fatty acid translocase (fat)/cd36 in obese patients. Diabetologia 53 (6):1151-1163.

29. Chabowski A, Chatham JC, Tandon NN, Calles-Escandon J, Glatz JF, Luiken JJ, Bonen A (2006) Fatty acid transport and fat/cd36 are increased in red but not in white skeletal muscle of zdf rats. Am J Physiol Endocrinol Metab 291 (3):E675-682.

30. Bonen A, Parolin ML, Steinberg GR, Calles-Escandon J, Tandon NN, Glatz JF, Luiken JJ, Heigenhauser GJ, Dyck DJ (2004) Triacylglycerol accumulation in human obesity and type 2 diabetes is associated with increased rates of skeletal muscle fatty acid transport and increased sarcolemmal fat/cd36. Faseb J 18 (10):1144-1146.

31. Bonen A, Tandon NN, Glatz JF, Luiken JJ, Heigenhauser GJ (2006) The fatty acid transporter fat/cd36 is upregulated in subcutaneous and visceral adipose tissues in human obesity and type 2 diabetes. Int J Obes (Lond) 30 (6):877-883.

32. Severson DL (2004) Diabetic cardiomyopathy: Recent evidence from mouse models of type 1 and type 2 diabetes. Can J Physiol Pharmacol 82 (10):813-823.

33. van der Meer RW, Rijzewijk LJ, de Jong HW, Lamb HJ, Lubberink M, Romijn JA, Bax JJ, de Roos A, Kamp O, Paulus WJ, Heine RJ, Lammertsma AA, Smit JW, Diamant M (2009) Pioglitazone improves cardiac function and alters myocardial substrate metabolism without affecting cardiac triglyceride accumulation and high-energy phosphate metabolism in patients with well-controlled type 2 diabetes mellitus. Circulation 119 (15):2069-2077.

34. Holland WL, Knotts TA, Chavez JA, Wang LP, Hoehn KL, Summers SA (2007) Lipid mediators of insulin resistance. Nutr Rev 65 (6 Pt 2):S39-46.

35. DeFronzo RA (2010) Insulin resistance, lipotoxicity, type 2 diabetes and atherosclerosis: The missing links. The claude bernard lecture 2009. Diabetologia 53 (7):1270-1287.

36. Hubert HB, Feinleib M, McNamara PM, Castelli WP (1983) Obesity as an independent risk factor for cardiovascular disease: A 26-year follow-up of participants in the framingham heart study. Circulation 67 (5):968-977.

37. Taha M, Lopaschuk GD (2007) Alterations in energy metabolism in cardiomyopathies. Ann Med 39 (8):594-607.

38. Kusminski CM, Shetty S, Orci L, Unger RH, Scherer PE (2009) Diabetes and apoptosis: Lipotoxicity. Apoptosis 14 (12):1484-1495.

39. van Dis I, Kromhout D, Geleijnse JM, Boer JM, Verschuren WM (2009) Body mass index and waist circumference predict both 10-year nonfatal and fatal cardiovascular disease risk: Study conducted in 20000 dutch men and women aged 20-65 years. Eur J Cardiovasc Prev Rehabil. 
40. Rudich A, Klip A (2003) Push/pull mechanisms of glut4 traffic in muscle cells. Acta Physiol Scand 178 (4):297-308.

41. Zeigerer A, McBrayer MK, McGraw TE (2004) Insulin stimulation of glut4 exocytosis, but not its inhibition of endocytosis, is dependent on rabgap as160. Mol Biol Cell 15 (10):4406-4415.

42. Yang J, Holman GD (2005) Insulin and contraction stimulate exocytosis, but increased amp-activated protein kinase activity resulting from oxidative metabolism stress slows endocytosis of glut4 in cardiomyocytes. J Biol Chem 280 (6):4070-4078.

43. Klip A (2009) The many ways to regulate glucose transporter 4. Appl Physiol Nutr Metab 34 (3):481487.

44. Fazakerley DJ, Lawrence SP, Lizunov VA, Cushman SW, Holman GD (2009) A common trafficking route for glut4 in cardiomyocytes in response to insulin, contraction and energy-status signalling. J Cell Sci 122 (Pt 5):727-734.

45. Tremblay F, Dubois MJ, Marette A (2003) Regulation of glut4 traffic and function by insulin and contraction in skeletal muscle. Front Biosci 8:d1072-1084.

46. Lee W, Ryu J, Spangler RA, Jung CY (2000) Modulation of glut4 and glut1 recycling by insulin in rat adipocytes: Kinetic analysis based on the involvement of multiple intracellular compartments. Biochemistry 39 (31):9358-9366.

47. Bryant NJ, Govers R, James DE (2002) Regulated transport of the glucose transporter glut4. Nat Rev Mol Cell Biol 3 (4):267-277.

48. Kaburagi Y, Satoh S, Tamemoto H, Yamamoto-Honda R, Tobe K, Veki K, Yamauchi T, Kono-Sugita E, Sekihara H, Aizawa S, Cushman SW, Akanuma Y, Yazaki Y, Kadowaki T (1997) Role of insulin receptor substrate-1 and pp60 in the regulation of insulin-induced glucose transport and glut4 translocation in primary adipocytes. J Biol Chem 272 (41):25839-25844.

49. Fasshauer M, Klein J, Ueki K, Kriauciunas KM, Benito M, White MF, Kahn CR (2000) Essential role of insulin receptor substrate- 2 in insulin stimulation of glut4 translocation and glucose uptake in brown adipocytes. J Biol Chem 275 (33):25494-25501.

50. Cantley LC (2002) The phosphoinositide 3-kinase pathway. Science 296 (5573):1655-1657.

51. Le Marchand-Brustel Y, Gautier N, Cormont M, Van Obberghen E (1995) Wortmannin inhibits the action of insulin but not that of okadaic acid in skeletal muscle: Comparison with fat cells. Endocrinology 136 (8):3564-3570.

52. Luiken JJ, Dyck DJ, Han XX, Tandon NN, Arumugam Y, Glatz JF, Bonen A (2002) Insulin induces the translocation of the fatty acid transporter fat/cd36 to the plasma membrane. Am J Physiol Endocrinol Metab 282 (2):E491-495.

53. Luiken JJ, Koonen DP, Willems J, Zorzano A, Becker C, Fischer Y, Tandon NN, Van Der Vusse GJ, Bonen A, Glatz JF (2002) Insulin stimulates long-chain fatty acid utilization by rat cardiac myocytes through cellular redistribution of fat/cd36. Diabetes 51 (10):3113-3119.

54. Shisheva A (2008) Phosphoinositides in insulin action on glut4 dynamics: Not just ptdins $(3,4,5)$ p3. Am J Physiol Endocrinol Metab 295 (3):E536-544.

55. Shepherd PR (2005) Mechanisms regulating phosphoinositide 3-kinase signalling in insulin-sensitive tissues. Acta Physiol Scand 183 (1):3-12.

56. Cho H, Mu J, Kim JK, Thorvaldsen JL, Chu Q, Crenshaw EB, 3rd, Kaestner KH, Bartolomei MS, Shulman GI, Birnbaum MJ (2001) Insulin resistance and a diabetes mellitus-like syndrome in mice lacking the protein kinase akt2 (pkb beta). Science 292 (5522):1728-1731.

57. Mora A, Sakamoto K, McManus EJ, Alessi DR (2005) Role of the pdk1-pkb-gsk3 pathway in regulating glycogen synthase and glucose uptake in the heart. FEBS Lett 579 (17):3632-3638.

58. Bandyopadhyay G, Standaert ML, Galloway L, Moscat J, Farese RV (1997) Evidence for involvement of protein kinase c (pkc)-zeta and noninvolvement of diacylglycerol-sensitive pkcs in insulin-stimulated glucose transport in 16 myotubes. Endocrinology 138 (11):4721-4731.

59. Luiken JJ, Ouwens DM, Habets DD, van der Zon GC, Coumans WA, Schwenk RW, Bonen A, Glatz JF (2009) Permissive action of protein kinase c-zeta in insulin-induced cd36- and glut4 translocation in cardiac myocytes. J Endocrinol 201 (2):199-209.

60. Alessi DR, James SR, Downes CP, Holmes AB, Gaffney PR, Reese CB, Cohen P (1997) Characterization of a 3-phosphoinositide-dependent protein kinase which phosphorylates and activates protein kinase balpha. Curr Biol 7 (4):261-269. 
61. Dong LQ, Liu F (2005) Pdk2: The missing piece in the receptor tyrosine kinase signaling pathway puzzle. Am J Physiol Endocrinol Metab 289 (2):E187-196.

62. Miinea CP, Sano H, Kane S, Sano E, Fukuda M, Peranen J, Lane WS, Lienhard GE (2005) As160, the akt substrate regulating glut4 translocation, has a functional rab gtpase-activating protein domain. Biochem J 391 (Pt 1):87-93.

63. Roach WG, Chavez JA, Miinea CP, Lienhard GE (2007) Substrate specificity and effect on glut4 translocation of the rab gtpase-activating protein tbc1d1. Biochem J 403 (2):353-358.

64. Liu XJ, Yang C, Gupta N, Zuo J, Chang YS, Fang FD (2007) Protein kinase c-zeta regulation of glut4 translocation through actin remodeling in cho cells. J Mol Med 85 (8):851-861.

65. Kovacic S, Soltys CL, Barr AJ, Shiojima I, Walsh K, Dyck JR (2003) Akt activity negatively regulates phosphorylation of amp-activated protein kinase in the heart. J Biol Chem 278 (41):39422-39427.

66. Kramer HF, Witczak CA, Fujii N, Jessen N, Taylor EB, Arnolds DE, Sakamoto K, Hirshman MF, Goodyear LJ (2006) Distinct signals regulate as160 phosphorylation in response to insulin, aicar, and contraction in mouse skeletal muscle. Diabetes 55 (7):2067-2076.

67. Luiken JJ, Momken I, Habets DD, El Hasnaoui M, Coumans WA, Koonen DP, Glatz JF, Bonen A (2006) Arsenite modulates cardiac substrate preference by translocation of glut4, but not cd36, independent of mitogen-activated protein kinase signaling. Endocrinology 147 (11):5205-5216.

68. Luiken JJ, Coort SL, Koonen DP, Bonen A, Glatz JF (2004) Signalling components involved in contractioninducible substrate uptake into cardiac myocytes. Proc Nutr Soc 63 (2):251-258.

69. Habets DD, Coumans WA, El Hasnaoui M, Zarrinpashneh E, Bertrand L, Viollet B, Kiens B, Jensen TE, Richter EA, Bonen A, Glatz JF, Luiken JJ (2009) Crucial role for Ikb1 to ampkalpha2 axis in the regulation of cd36-mediated long-chain fatty acid uptake into cardiomyocytes. Biochim Biophys Acta 1791 (3):212-219.

70. Hawley SA, Boudeau J, Reid JL, Mustard KJ, Udd L, Makela TP, Alessi DR, Hardie DG (2003) Complexes between the lkb1 tumor suppressor, strad alpha/beta and mo25 alpha/beta are upstream kinases in the amp-activated protein kinase cascade. J Biol 2 (4):28.

71. Sakamoto K, Zarrinpashneh E, Budas GR, Pouleur AC, Dutta A, Prescott AR, Vanoverschelde JL, Ashworth A, Jovanovic A, Alessi DR, Bertrand L (2006) Deficiency of lkb1 in heart prevents ischemiamediated activation of ampkalpha2 but not ampkalpha1. Am J Physiol Endocrinol Metab 290 (5): E780-788.

72. Hawley SA, Pan DA, Mustard KJ, Ross L, Bain J, Edelman AM, Frenguelli BG, Hardie DG (2005) Calmodulin-dependent protein kinase kinase-beta is an alternative upstream kinase for ampactivated protein kinase. Cell Metab 2 (1):9-19.

73. Woods A, Dickerson K, Heath R, Hong SP, Momcilovic M, Johnstone SR, Carlson M, Carling D (2005) $\mathrm{Ca} 2+$ /calmodulin-dependent protein kinase kinase-beta acts upstream of amp-activated protein kinase in mammalian cells. Cell Metab 2 (1):21-33.

74. Abbott MJ, Edelman AM, Turcotte LP (2009) Camkk is an upstream signal of amp-activated protein kinase in regulation of substrate metabolism in contracting skeletal muscle. Am J Physiol Regul Integr Comp Physiol 297 (6):R1724-1732.

75. Chen HC, Bandyopadhyay G, Sajan MP, Kanoh Y, Standaert M, Farese RV, Jr., Farese RV (2002) Activation of the erk pathway and atypical protein kinase $c$ isoforms in exercise- and aminoimidazole-4carboxamide-1-beta-d-riboside (aicar)-stimulated glucose transport. J Biol Chem 277 (26):2355423562.

76. Farese RV, Sajan MP, Yang H, Li P, Mastorides S, Gower WR, Jr., Nimal S, Choi CS, Kim S, Shulman GI, Kahn CR, Braun U, Leitges M (2007) Muscle-specific knockout of pkc-lambda impairs glucose transport and induces metabolic and diabetic syndromes. J Clin Invest 117 (8):2289-2301.

77. Raney MA, Turcotte LP (2007) Evidence for the regulation of contraction-induced fatty acid oxidation via extracellular signal-regulated kinase $1 / 2$ activation independent of changes in fatty acid uptake. Metabolism 56 (9):1192-1200.

78. Luiken JJ, Vertommen D, Coort SL, Habets DD, El Hasnaoui M, Pelsers MM, Viollet B, Bonen A, Hue L, Rider $\mathrm{MH}$, Glatz JF (2008) Identification of protein kinase $d$ as a novel contraction-activated kinase linked to glut4-mediated glucose uptake, independent of ampk. Cell Signal 20 (3):543-556.

79. Chen S, Murphy J, Toth R, Campbell DG, Morrice NA, Mackintosh C (2008) Complementary regulation of tbc1d1 and as160 by growth factors, insulin and ampk activators. Biochem J 409 (2):449-459. 
80. Kanzaki M, Pessin JE (2001) Insulin-stimulated glut4 translocation in adipocytes is dependent upon cortical actin remodeling. J Biol Chem 276 (45):42436-42444.

81. Olson AL, Trumbly AR, Gibson GV (2001) Insulin-mediated glut4 translocation is dependent on the microtubule network. J Biol Chem 276 (14):10706-10714.

82. Torok D, Patel N, Jebailey L, Thong FS, Randhawa VK, Klip A, Rudich A (2004) Insulin but not pdgf relies on actin remodeling and on vamp2 for glut4 translocation in myoblasts. J Cell Sci 117 (Pt 22):54475455.

83. Chiu TT, Patel N, Shaw AE, Bamburg JR, Klip A (2010) Arp2/3- and cofilin-coordinated actin dynamics is required for insulin-mediated glut4 translocation to the surface of muscle cells. Mol Biol Cell.

84. Baus D, Heermeier K, De Hoop M, Metz-Weidmann C, Gassenhuber J, Dittrich W, Welte S, Tennagels N (2008) Identification of a novel as160 splice variant that regulates glut4 translocation and glucoseuptake in rat muscle cells. Cell Signal 20 (12):2237-2246.

85. St-Denis JF, Cushman SW (1998) Role of snare's in the glut4 translocation response to insulin in adipose cells and muscle. J Basic Clin Physiol Pharmacol 9 (2-4):153-165.

86. Larance M, Ramm G, Stockli J, van Dam EM, Winata S, Wasinger V, Simpson F, Graham M, Junutula JR, Guilhaus M, James DE (2005) Characterization of the role of the rab gtpase-activating protein as 160 in insulin-regulated glut4 trafficking. The Journal of biological chemistry 280 (45):37803-37813.

87. Martin LB, Shewan A, Millar CA, Gould GW, James DE (1998) Vesicle-associated membrane protein 2 plays a specific role in the insulin-dependent trafficking of the facilitative glucose transporter glut4 in 3t3-I1 adipocytes. J Biol Chem 273 (3):1444-1452.

88. Lamb CA, McCann RK, Stockli J, James DE, Bryant NJ (2010) Insulin-regulated trafficking of glut4 requires ubiquitination. Traffic 11 (11):1445-1454.

89. Su X, Abumrad NA (2009) Cellular fatty acid uptake: A pathway under construction. Trends Endocrinol Metab 20 (2):72-77.

90. Chidlow JH, Jr., Sessa WC (2010) Caveolae, caveolins, and cavins: Complex control of cellular signalling and inflammation. Cardiovasc Res 86 (2):219-225.

91. Dancourt J, Barlowe C (2010) Protein sorting receptors in the early secretory pathway. Annu Rev Biochem 79:777-802.

92. Beck R, Rawet M, Wieland FT, Cassel D (2009) The copi system: Molecular mechanisms and function. FEBS Lett 583 (17):2701-2709.

93. Whitney JA, Gomez M, Sheff D, Kreis TE, Mellman I (1995) Cytoplasmic coat proteins involved in endosome function. Cell 83 (5):703-713.

94. Chakrabarti R, Buxton J, Joly M, Corvera S (1994) Insulin-sensitive association of glut-4 with endocytic clathrin-coated vesicles revealed with the use of brefeldin a. J Biol Chem 269 (11):7926-7933.

95. Lachaal M, Moronski C, Liu H, Jung CY (1994) Brefeldin a inhibits insulin-induced glucose transport stimulation and glut4 recruitment in rat adipocytes. J Biol Chem 269 (38):23689-23693.

96. Martin S, Ramm G, Lyttle CT, Meerloo T, Stoorvogel W, James DE (2000) Biogenesis of insulin-responsive glut4 vesicles is independent of brefeldin a-sensitive trafficking. Traffic 1 (8):652-660.

97. Kono-Sugita E, Satoh S, Suzuki Y, Egawa M, Udaka N, Ito T, Sekihara H (1996) Insulin-induced glut4 recycling in rat adipose cells by a pathway insensitive to brefeldin a. Eur J Biochem 236 (3):10331037.

98. Bao S, Smith RM, Jarett L, Garvey WT (1995) The effects of brefeldin a on the glucose transport system in rat adipocytes. Implications regarding the intracellular locus of insulin-sensitive glut4. J Biol Chem 270 (50):30199-30204.

99. Watson RT, Pessin JE (2001) Subcellular compartmentalization and trafficking of the insulin-responsive glucose transporter, glut4. Exp Cell Res 271 (1):75-83.

100. Pohl J, Ring A, Korkmaz U, Ehehalt R, Stremmel W (2005) Fat/cd36-mediated long-chain fatty acid uptake in adipocytes requires plasma membrane rafts. Mol Biol Cell 16 (1):24-31.

101. Ros-Baro A, Lopez-Iglesias C, Peiro S, Bellido D, Palacin M, Zorzano A, Camps M (2001) Lipid rafts are required for glut4 internalization in adipose cells. Proc Natl Acad Sci U S A 98 (21):12050-12055.

102. Shigematsu S, Watson RT, Khan AH, Pessin JE (2003) The adipocyte plasma membrane caveolin functional/structural organization is necessary for the efficient endocytosis of glut4. J Biol Chem 278 (12):10683-10690.

103. Ralston E, Ploug T (1999) Caveolin-3 is associated with the t-tubules of mature skeletal muscle fibers. 
Exp Cell Res 246 (2):510-515.

104. Mattern HM, Raikar LS, Hardin CD (2009) The effect of caveolin-1 (cav-1) on fatty acid uptake and cd36 localization and lipotoxicity in vascular smooth muscle (vsm) cells. Int J Physiol Pathophysiol Pharmacol 1 (1):1-14.

105. Ring A, Le Lay S, Pohl J, Verkade P, Stremmel W (2006) Caveolin-1 is required for fatty acid translocase (fat/cd36) localization and function at the plasma membrane of mouse embryonic fibroblasts. Biochim Biophys Acta 1761 (4):416-423.

106. Brozinick JT, Jr., Hawkins ED, Strawbridge AB, Elmendorf JS (2004) Disruption of cortical actin in skeletal muscle demonstrates an essential role of the cytoskeleton in glucose transporter 4 translocation in insulin-sensitive tissues. J Biol Chem 279 (39):40699-40706.

107. Condrescu M, Reeves JP (2006) Actin-dependent regulation of the cardiac na(+)/ca(2+) exchanger. Am J Physiol Cell Physiol 290 (3):C691-701.

108. Tong P, Khayat ZA, Huang C, Patel N, Ueyama A, Klip A (2001) Insulin-induced cortical actin remodeling promotes glut4 insertion at muscle cell membrane ruffles. J Clin Invest 108 (3):371-381.

109. Olson AL, Eyster CA, Duggins QS, Knight JB (2003) Insulin promotes formation of polymerized microtubules by a phosphatidylinositol 3-kinase-independent, actin-dependent pathway in 3t3-l1 adipocytes. Endocrinology 144 (11):5030-5039.

110. Khayat ZA, Tong P, Yaworsky K, Bloch RJ, Klip A (2000) Insulin-induced actin filament remodeling colocalizes actin with phosphatidylinositol 3-kinase and glut4 in 16 myotubes. J Cell Sci 113 Pt 2:279290.

111. JeBailey L, Rudich A, Huang X, Di Ciano-Oliveira C, Kapus A, Klip A (2004) Skeletal muscle cells and adipocytes differ in their reliance on tc10 and rac for insulin-induced actin remodeling. Mol Endocrinol 18 (2):359-372.

112. Huang J, Imamura T, Babendure JL, Lu JC, Olefsky JM (2005) Disruption of microtubules ablates the specificity of insulin signaling to glut4 translocation in 3t3-I1 adipocytes. J Biol Chem 280 (51):4230042306.

113. Shigematsu S, Khan AH, Kanzaki M, Pessin JE (2002) Intracellular insulin-responsive glucose transporter (glut4) distribution but not insulin-stimulated glut4 exocytosis and recycling are microtubule dependent. Mol Endocrinol 16 (5):1060-1068.

114. Ai H, Ralston E, Lauritzen HP, Galbo H, Ploug T (2003) Disruption of microtubules in rat skeletal muscle does not inhibit insulin- or contraction-stimulated glucose transport. Am J Physiol Endocrinol Metab 285 (4):E836-844.

115. Shimoni Y, Rattner JB (2001) Type 1 diabetes leads to cytoskeleton changes that are reflected in insulin action on rat cardiac k(+) currents. Am J Physiol Endocrinol Metab 281 (3):E575-585.

116. Sun-Wada GH, Wada Y, Futai M (2004) Diverse and essential roles of mammalian vacuolar-type proton pump atpase: Toward the physiological understanding of inside acidic compartments. Biochim Biophys Acta 1658 (1-2):106-114.

117. Forgac M (2007) Vacuolar atpases: Rotary proton pumps in physiology and pathophysiology. Nat Rev Mol Cell Biol 8 (11):917-929.

118. Merkulova M, Bakulina A, Thaker YR, Gruber G, Marshansky V (2010) Specific motifs of the v-atpase a2-subunit isoform interact with catalytic and regulatory domains of arno. Biochim Biophys Acta 1797 (8):1398-1409.

119. Chinni SR, Shisheva A (1999) Arrest of endosome acidification by bafilomycin a1 mimics insulin action on glut4 translocation in 3t3-I1 adipocytes. Biochem J 339 ( Pt 3):599-606.

120. Yang J, Gillingham AK, Hodel A, Koumanov F, Woodward B, Holman GD (2002) Insulin-stimulated cytosol alkalinization facilitates optimal activation of glucose transport in cardiomyocytes. Am $J$ Physiol Endocrinol Metab 283 (6):E1299-1307.

121. Choi YO, Park JH, Song YS, Lee W, Moriyama Y, Choe H, Leem CH, Jang YJ (2007) Involvement of vesicular h+-atpase in insulin-stimulated glucose transport in 3t3-f442a adipocytes. Endocr J 54 (5):733-743.

122. Riskin A, Nannegari VH, Mond Y (2008) Acute effectors of glut1 glucose transporter subcellular targeting in cit3 mouse mammary epithelial cells. Pediatr Res 63 (1):56-61.

123. Hurtado-Lorenzo A, Skinner M, El Annan J, Futai M, Sun-Wada GH, Bourgoin S, Casanova J, Wildeman A, Bechoua S, Ausiello DA, Brown D, Marshansky V (2006) V-atpase interacts with arno and arf6 in 
early endosomes and regulates the protein degradative pathway. Nat Cell Biol 8 (2):124-136.

124. Schimmoller F, Simon I, Pfeffer SR (1998) Rab gtpases, directors of vesicle docking. J Biol Chem 273 (35):22161-22164.

125. Takai Y, Sasaki T, Matozaki T (2001) Small gtp-binding proteins. Physiol Rev 81 (1):153-208.

126. Cormont M, Le Marchand-Brustel Y (2001) The role of small g-proteins in the regulation of glucose transport (review). Mol Membr Biol 18 (3):213-220.

127. Cormont M, Bortoluzzi MN, Gautier N, Mari M, van Obberghen E, Le Marchand-Brustel Y (1996) Potential role of rab4 in the regulation of subcellular localization of glut4 in adipocytes. Mol Cell Biol 16 (12):6879-6886.

128. Schwenk RW, Luiken JJ, Eckel J (2007) Fip2 and rip11 specify rab11a-mediated cellular distribution of glut4 and fat/cd36 in h9c2-hir cells. Biochem Biophys Res Commun 363 (1):119-125.

129. Uhlig M, Passlack W, Eckel J (2005) Functional role of rab11 in glut4 trafficking in cardiomyocytes. Mol Cell Endocrinol 235 (1-2):1-9.

130. Kessler A, Tomas E, Immler D, Meyer HE, Zorzano A, Eckel J (2000) Rab11 is associated with glut4containing vesicles and redistributes in response to insulin. Diabetologia 43 (12):1518-1527.

131. Schwenk RW, Eckel J (2007) A novel method to monitor insulin-stimulated gtp-loading of rab11a in cardiomyocytes. Cell Signal $19(4): 825-830$.

132. Shibata H, Omata W, Kojima I (1997) Insulin stimulates guanine nucleotide exchange on rab4 via a wortmannin-sensitive signaling pathway in rat adipocytes. J Biol Chem 272 (23):14542-14546.

133. Li L, Omata W, Kojima I, Shibata H (2001) Direct interaction of rab4 with syntaxin 4. J Biol Chem 276 (7):5265-5273.

134. Hales CM, Vaerman JP, Goldenring JR (2002) Rab11 family interacting protein 2 associates with myosin vb and regulates plasma membrane recycling. J Biol Chem 277 (52):50415-50421.

135. Prekeris R, Klumperman J, Scheller RH (2000) A rab11/rip11 protein complex regulates apical membrane trafficking via recycling endosomes. Mol Cell 6 (6):1437-1448.

136. Welsh GI, Leney SE, Lloyd-Lewis B, Wherlock M, Lindsay AJ, McCaffrey MW, Tavare JM (2007) Rip11 is a rab11- and as160-rabgap-binding protein required for insulin-stimulated glucose uptake in adipocytes. J Cell Sci 120 (Pt 23):4197-4208.

137. Grosshans BL, Ortiz D, Novick P (2006) Rabs and their effectors: Achieving specificity in membrane traffic. Proceedings of the National Academy of Sciences of the United States of America 103 (32):11821-11827.

138. Sakamoto K, Holman GD (2008) Emerging role for as160/tbc1d4 and tbc1d1 in the regulation of glut4 traffic. Am J Physiol Endocrinol Metab 295 (1):E29-37.

139. Sano H, Kane S, Sano E, Miinea CP, Asara JM, Lane WS, Garner CW, Lienhard GE (2003) Insulinstimulated phosphorylation of a rab gtpase-activating protein regulates glut 4 translocation. The Journal of biological chemistry 278 (17):14599-14602.

140. Thong FS, Bilan PJ, Klip A (2007) The rab gtpase-activating protein as160 integrates akt, protein kinase c, and amp-activated protein kinase signals regulating glut4 traffic. Diabetes 56 (2):414-423.

141. Randhawa VK, Ishikura S, Talior-Volodarsky I, Cheng AW, Patel N, Hartwig JH, Klip A (2008) Glut4 vesicle recruitment and fusion are differentially regulated by rac, as160, and rab8a in muscle cells. The Journal of biological chemistry 283 (40):27208-27219.

142. Sun Y, Bilan PJ, Liu Z, Klip A (2010) Rab8a and rab13 are activated by insulin and regulate glut4 translocation in muscle cells. Proc Natl Acad Sci U S A 107 (46):19909-19914.

143. Sano H, Roach WG, Peck GR, Fukuda M, Lienhard GE (2008) Rab10 in insulin-stimulated glut4 translocation. Biochem J 411 (1):89-95.

144. Hong W (2005) Snares and traffic. Biochim Biophys Acta 1744 (3):493-517.

145. Jahn R, Scheller RH (2006) Snares--engines for membrane fusion. Nat Rev Mol Cell Biol 7 (9):631643.

146. Chen Y, Gan BQ, Tang BL (2010) Syntaxin 16: Unraveling cellular physiology through a ubiquitous snare molecule. J Cell Physiol 225 (2):326-332.

147. Randhawa VK, Bilan PJ, Khayat ZA, Daneman N, Liu Z, Ramlal T, Volchuk A, Peng XR, Coppola T, Regazzi R, Trimble WS, Klip A (2000) Vamp2, but not vamp3/cellubrevin, mediates insulin-dependent incorporation of glut4 into the plasma membrane of 16 myoblasts. Molecular biology of the cell 11 (7):2403-2417. 
148. Kawanishi M, Tamori Y, Okazawa H, Araki S, Shinoda H, Kasuga M (2000) Role of snap23 in insulininduced translocation of glut4 in 3t3-I1 adipocytes. Mediation of complex formation between syntaxin4 and vamp2. The Journal of biological chemistry 275 (11):8240-8247.

149. Rose AJ, Jeppesen J, Kiens B, Richter EA (2009) Effects of contraction on localization of glut4 and vsnare isoforms in rat skeletal muscle. Am J Physiol Regul Integr Comp Physiol.

150. McMahon HT, Mills IG (2004) Cop and clathrin-coated vesicle budding: Different pathways, common approaches. Curr Opin Cell Biol 16 (4):379-391. 


\section{Chapter 3}

\section{Differential regulation of cardiac glucose and fatty acid uptake by endosomal $\mathrm{pH}$ and actin filaments}

Laura K.M. Steinbusch ${ }^{1}$, Wino Wijnen ${ }^{1}$, Robert W. Schwenk ${ }^{1}$, Will A. Coumans ${ }^{1}$, Nicole T. H. Hoebers ${ }^{1}$, D. Margriet Ouwens ${ }^{2}$, Michaela Diamant ${ }^{3}$, Arend Bonen $^{4}$, Jan F.C. Glatz ${ }^{1}$, Joost J.F.P. Luiken ${ }^{1}$

1 Department of Molecular Genetics, Maastricht University, NL-6200 MD Maastricht, the Netherlands

2 German Diabetes Center Düsseldorf, Germany

3 Department of Endocrinology, Diabetes Center, VU University Medical Centre, Amsterdam, the Netherlands

4 Department of Human Health and Nutritional Science, University of Guelph, Guelph, Ontario, Canada N1G 2W1

Am J Physiol Cell Physiol. 2010 Jun;298(6):C1549-59 


\begin{abstract}
Insulin and contraction stimulate both cardiac glucose and long-chain fatty acid (LCFA) uptake via translocation of the substrate transporters GLUT4 and CD36, respectively, from intracellular compartments to the sarcolemma. Little is known about the role of vesicular trafficking elements in insulin- and contraction-stimulated glucose and LCFA uptake in the heart, especially whether certain trafficking elements are specifically involved in GLUT4 versus CD36 translocation. Therefore, we studied the role of coat-proteins, actin- and microtubule-filaments and endosomal $\mathrm{pH}$ on glucose and LCFA uptake into primary cardiomyocytes under basal conditions and during stimulation with insulin or oligomycin (contraction-like AMP-activated protein kinase activator). Inhibition of coat-protein targeting to Golgi/endosomes decreased insulin/oligomycin-stimulated glucose (-42\%/-51\%) and LCFA (-39\%/$68 \%)$ uptake. Actin disruption decreased insulin/oligomycin-stimulated glucose uptake (-41\%/-75\%), while not affecting LCFA uptake. Microtubule disruption did not affect substrate uptake under any condition. Endosomal alkalinization increased basal sarcolemmal CD36 (2-fold), but not GLUT4, content, and concomitantly decreased basal intracellular membrane GLUT4 and CD36 content (-60\% and $62 \%$, respectively), indicating successful CD36 translocation and incomplete GLUT4 translocation. Additionally, endosomal alkalinization elevated basal LCFA uptake (1.4-fold) in a non-additive manner to insulin/oligomycin, and decreased insulin/oligomycin-stimulated glucose uptake (-32\%/-68\%). In conclusion, (i) CD36 translocation, just like GLUT4 translocation, is a vesicle-mediated process depending on coat-proteins, and (ii) GLUT4 and CD36 trafficking are differentially dependent on endosomal $\mathrm{pH}$ and actin filaments. The latter conclusion suggests novel strategies to alter cardiac substrate preference as part of metabolic modulation therapy.
\end{abstract}




\section{Introduction}

Glucose and LCFA are the major fuels for cardiac contractile activity. GLUT4 is the major glucose transporter in the heart, and a number of LCFA transporters have been implicated in cardiac LCFA uptake such as CD36 (35), fatty acid transporter protein (FATP)1 (7) and FATP6 (16). To adequately respond to rapidly varying metabolic demands, the heart is able to acutely regulate the uptake of both substrates, i.e., via reversible translocation of GLUT4 and CD36 from intracellular membrane compartments (endosomes) to the sarcolemma (35). In contrast to CD36, FATP1 and FATP6 do not traffic between intracellular storage compartments and the sarcolemma in the heart, and only have a minor contribution to basal LCFA uptake $(18,19)$. In addition, FATP1 has been shown to translocate to the cell surface of adipocytes (38), showing that trafficking processes are tissue-specific. The most important physiological stimuli to induce cardiac GLUT4 and CD36 translocation are (i) a rise in circulating levels of insulin and (ii) an increase in contraction frequency. Hence, the processes of GLUT4 and CD36 translocation bear close resemblance to each other, based on their responsiveness to these same physiological stimuli, and also to various pharmacological stimuli (25). Additionally, the same signaling enzymes are involved in the translocation of both transporters. Specifically, phosphatidylinositol3 kinase $(\mathrm{PI} 3 \mathrm{~K})$ and $\mathrm{Akt} /$ protein kinase $\mathrm{B}$ (PKB) are involved in insulin-stimulated translocation of both GLUT4 and CD36, and AMP-activated protein kinase (AMPK) as well as its upstream kinase the tumor suppressor protein LKB1, are involved in their contraction-stimulated translocation (17). Whether this similarity between GLUT4 and CD36 translocation also extends to the subcellular machineries involved in translocation of each of these transporters remains unexplored.

Because stimulus-induced GLUT4 translocation has been described since the early eighties, and stimulus-induced CD36 translocation has only recently begun to be examined, there is much more information about the subcellular machinery involved in GLUT4 translocation $(4,32)$ compared to the CD36 translocation machinery, of which essentially nothing is known (35). Parts of the subcellular GLUT4 translocation machinery are formed by (i) coat proteins, involved in packaging of GLUT4 vesicles during their budding from the endosomal membranes, (ii) cytoskeletal filaments along which the subcellular GLUT4 vesicles migrate towards the cell surface, and (iii) the recycling endosomes, involved in storage of GLUT4.

Several coat proteins have been proposed to function in GLUT4 recycling: caveolin, clathrin and $\beta$-COP. Caveolin $(33,37)$ and clathrin $(2)$, predominantly plasmalemmal, have been proposed to play a role in initiation of GLUT4 endocytosis, although this has been disputed by others (31). The fungal metabolite brefeldin-A is known to 
interfere with the retrograde transport from the Golgi apparatus to the endoplasmic reticulum through inhibition of coat-proteins, e.g. $\beta$-COP and Arf1p, involved in formation of transport vesicles resulting in impaired sorting from this network (14, 41). Also mistargeting of clathrin/adaptor protein (AP) complexes might play a role in this process (23) In addition to the Golgi, the endosomal compartment, presumably involved in storing GLUT4 and CD36, also depends on COP proteins and clathrin for its structural organization, and will collapse upon brefeldin-A treatment (45). The use of brefeldin-A in studying insulin-stimulated GLUT4 translocation in rat adipocytes also yielded controversial observations: inhibition (22), or no inhibition (21). Hence, the issue as to which coat-proteins are necessary for regulation of GLUT4 translocation and what their role is in cardiomyocytes is yet unresolved. To date, brefeldin-A has not yet been used to investigate the regulation of GLUT4 and CD36 translocation in the heart.

It is well established that cortical filamentous actin plays a role in insulin-induced GLUT4 translocation $(9,43)$. Specifically, insulin-induced GLUT4 translocation depends on continuous cycles of actin polymerization/depolymerization, as both actin stabilizing and destabilizing agents are inhibitory to this process (20). Actin structures support ruffling of the plasma membrane, important for local concentration of t-SNAREs (42). Controversy exists about the role of the microtubules in GLUT4 translocation, as microtubule-disrupting agents have been reported to inhibit insulin-induced GLUT4 translocation (29) and not to affect this process (1, 36). None of these filament disruptors have been used to examine insulin-induced GLUT4 translocation in cardiomyocytes, or contraction-induced GLUT4 translocation or stimulus-induced CD36 translocation in any cell type.

One of the key features of endosomes is their acidic interior, a feature which they share with lysosomes, but not (or, to a lesser extent) with other organelles (15, 40). Therefore, this low endosomal $\mathrm{pH}$ is thought to be important for endosomal functioning, as has been established in receptor-mediated endocytosis. Endosomal acidification is achieved by the proton-pumping action of the vesicular-type ATPase (v-ATPase or V1V0-ATPase), a large multisubunit complex specifically localized to endosomes and lysosomes (15). Based on pharmacological agents able to disrupt the $\mathrm{pH}$ gradient between endosomes and cytoplasm, as investigated in adipocytes, skeletal muscle and heart, the role of endosomal $\mathrm{pH}$ in regulation of subcellular GLUT4 localization is controversial. For example, it has been reported that bafilomycin-A, a specific inhibitor of the v-ATPase, stimulates (6) or inhibits GLUT4 translocation $(8,46)$. Furthermore, dissipation of the endosomal/cytoplasmic $\mathrm{pH}$ gradient with the proton ionophore monensin did not affect insulin-induced GLUT4 translocation 
(32). However, no studies have yet been undertaken to assess the role of endosomal functioning in contraction-induced GLUT4 translocation in the heart. With respect to CD36, the sole piece of evidence about the role of endosomes in CD36 translocation comes from our earlier work in skeletal muscle, in which we detected an intracellular membrane fraction enriched in CD36 and the transferrin receptor, an established component of the recycling endosomes (3).

The present study was designed to examine the involvement of components of the vesicular trafficking machinery, i.e., vesicular coat-proteins, cytoskeletal filaments and endosomal $\mathrm{pH}$, in the regulation of LCFA uptake (through CD36 translocation), and evaluate the possible similarities and/or differences with the regulation of glucose uptake (through GLUT4 translocation). We chose a pharmacological approach to interfere with the functioning of coat proteins (using brefeldin-A), cytoskeletal proteins (using latrunculin-B and colchicine) and endosomal v-ATPase (using bafilomycin-A and monensin) rather than a genetic approach. We chose this approach because (i) brefeldin- $A$, latrunculin- $B$, colchicine, bafilomycin- $A$ and monensin are frequently used established inhibitors, and (ii) coat proteins, cytoskeletal proteins and endosomal v-ATPase are involved in multiple crucial cellular functions, so that their genetic ablation would seriously hamper cell viability. In contrast to a genetic approach, a pharmacological approach to block functioning of selected trafficking proteins can be undertaken in a relative short time-span $(\leq 60$ $\min$ ) without detrimental effects on cell survival.

The involvement of these trafficking components in the regulation of substrate uptake was studied in regard to insulin as well as contraction-stimulation. In order to mimic contraction signaling, we used the $F_{1} F_{0}$-ATPase inhibitor oligomycin, which, just like increased muscular work, induces AMPK activation through an increase of the AMP/ATP ratio (25). Given that different signaling routes appear to be involved in contraction-induced versus insulin-induced transporter translocation, we also analyzed whether these differences can be attributed to vesicular coat proteins, cytoskeletal filaments or the endosomal $\mathrm{pH}$. For this purpose, it was investigated whether agents disrupting $\beta$-COP functioning (brefeldin-A), actin filaments (latrunculin B) and microtubules (colchicine) or endosomal $\mathrm{pH}$ (monensin and bafilomycin A), were able to alter insulin- and oligomycin-induced glucose and LCFA uptake.

\section{Materials and Methods}

\section{Materials}

Palmitic acid and $\left[{ }^{3} \mathrm{H}\right]$ deoxyglucose were obtained from GE Healthcare (Little Chalfont, UK). $\left[{ }^{3} \mathrm{H}\right]$ chloroquine was from Moravek Biochemicals (Brea, USA). Laminin, insulin, oligomycin, monensin, bafilomycin-A, 
brefeldin-A, latrunculin-B and colchicine were purchased from Sigma (Saint Louis, USA). Bovine serum albumin (BSA) (fraction V), dependent on the application, was derived from MP Biomedicals (Irvine, USA) (for cell isolation and incubation purposes), or from Sigma (other purposes). Collagenase type II was from Worthington (Freehold, USA). CD36 was detected with a monoclonal antibody (MO25) directed against human CD36, kindly provided by Dr. N. Tandon (Otsuka Pharmaceuticals, Bethesda, USA). Rabbit anti-mouse immunoglobulin horseradish peroxidase and swine anti-rabbit immunoglobulin horseradish peroxidase were obtained from DAKO (Glostrup, Denmark). Non-fat dry milk and Western blot reagents were from Bio-Rad Laboratories (Hercules, USA) and the enhanced chemiluminescence (ECL) kit was from Amersham Pharmacia Biotech (Buckingham, UK). The fluorescently labeled monoclonal antibody against the Golgi matrix $130 \mathrm{kDa}$ protein (GM-130) was from BD Biosciences (San Jose, USA), and the anti- $\alpha$ tubulin antibody from lowa Hybridomabank (clone E7) (lowa City, USA). Texas red-conjugated phalloidin and DAPI were from Molecular Probes (Eugene, USA) and goat-anti-mouse-TRITC was purchased from DAKO (Glostrup, Denmark). Sulfo- $N$-succinimidyloleate (SSO) is routinely synthesized in our laboratory, as has been previously described (39). Purity of these compounds was confirmed with infrared spectroscopy (kindly performed by Dr. van Genderen, Eindhoven Technical University, Eindhoven, the Netherlands).

\section{Isolation of cardiomyocytes followed by measurement of substrate uptake}

Cardiomyocytes were isolated from male Lewis rats (200-250 g) using a Langendorff perfusion system, as previously described (28). Only when $>80 \%$ of the cells had a rod-shaped appearance and excluded trypan blue, were they used for subsequent tracer uptake studies. Uptake of $\left[1-{ }^{14} \mathrm{C}\right]$ palmitate (in complex with $\mathrm{BSA})$ and $\left[{ }^{3} \mathrm{H}\right]$ deoxyglucose into cardiomyocytes incubated in cell-incubation medium was measured as previously described (28). Substrate uptake was modulated by insulin and various pharmacological inhibitors (see figure legends for exact concentrations and incubation times). All these inhibitors were dissolved in DMSO, which final concentration in the cell suspensions never exceeded $0.5 \%$. At this concentration, DMSO did not affect cellular substrate utilization. All agents were added $15-45$ min prior to measurement of substrate uptake at the minimal concentration at which they exerted the maximal effect. None of these agents, alone or in combination and including SSO were found to affect the percentage of cells that (i) were rod-shaped and (ii) excluded trypan blue, as parameters of cellular integrity.

\section{Isolation of giant vesicles followed by measurement of substrate uptake}

Giant vesicles were prepared from rat heart, as described previously (27). Uptake of $\left[9,10-{ }^{3} \mathrm{H}\right]$ palmitate (in complex with BSA) and [ $\left.{ }^{3} \mathrm{H}\right] \mathrm{D}$-glucose were measured as described previously (27). All pharmacological inhibitors used were added to giant vesicles 20 min prior to determination of palmitate or glucose uptake (see figure legends for exact concentrations and incubation times).

\section{$\left[{ }^{3} \mathrm{H}\right]$ chloroquine uptake assay}

Cardiomyocytes (0.5 - $1.0 \mathrm{mg}$ wet mass $/ \mathrm{ml})$ were pre-incubated with or without pharmacological agents similarly as in the substrate uptake assay. At the start of the incubation $4 \mu{ }^{3} \mathrm{H}$-chloroquine $(250 \mu \mathrm{Ci} / \mathrm{ml}$ diluted 1:125 in milliQ) was added. After a 30 min incubation period, $1.5 \mathrm{ml}$ cell suspension was pulse centrifuged. The supernatant was aspirated and the lower part of the cup, containing the cell pellet, was snipped and vortexed in $5 \mathrm{ml}$ Opti-Fluor (Perkin Elmer, Massachusetts, USA) until the pellet was completely dissolved. Samples were counted with a Wallace liquid scintillation counter.

\section{Microscopy}

Cells were seeded on laminin-coated coverslips. After attachment, cells were washed and incubated with the corresponding inhibitors in cell-incubation medium. Cells were fixed with (ice cold) methanol, washed for 15 min with $0.2 \%$ Triton X-100 in PBS and blocked with 2\% BSA in PBS. Fluorescent dyes or primary antibodies (GM-130 (1:100), phalloidin TexasRED (1:100) and $\alpha$-tubulin (1:50)) were incubated for 1 hour at room temperature in PBS with $2 \%$ BSA. For the detection of tubulin the cells were subsequently washed with PBS and incubated for 1 hour with goat-anti-mouse-TRITC (1:100) in PBS with 1\% BSA. Cells were washed and mounted with Glycerol DABCO from Sigma. Nuclei were stained with DAPI (1:8000 in PBS). Cells were evaluated with a Zeiss confocal microscope with a BioRad laser. Image analysis was performed with ImageJ. 


\section{Surface detection of $C D 36$}

Directly after isolation, cell suspensions of cardiomyocytes (100.000 cells/well) were plated in laminincoated $(20 \mu \mathrm{g} / \mathrm{ml}) 35 \mathrm{~mm}$ culture plates and were allowed to attach to the plates for $1 \mathrm{~h}$. Afterwards, the cells were incubated with $0.35 \%$ DMSO or with the pharmacological agents as described for the substrate uptake assay. As previously described (44), cells were biotinylated with the cell membrane-impermeable reagent sulfo-NHS-LC-biotin in bicarbonate medium at a final concentration of $1 \mathrm{mg} / \mathrm{ml}$ for $45 \mathrm{~min}$ at $4^{\circ} \mathrm{C}$ while shaking. The reaction was quenched with ice-cold glycine in bicarbonate medium (100mM). After a brief wash with ice-cold bicarbonate medium, cells were lysed by scraping in $250 \mu$ lysis buffer. Lysates were incubated at $4{ }^{\circ} \mathrm{C}$ for $1 \mathrm{~h}$ while rotating, and centrifuged for $10 \mathrm{~min}$ at $13,000 \mathrm{~g}$ at $4^{\circ} \mathrm{C}$. 15 $\mu \mathrm{l}$ supernatant was used as total lysate sample and $200 \mu \mathrm{l}$ supernatant was incubated overnight with streptavidin beads. Samples were briefly centrifuged, and beads were washed twice with lysis buffer. Biotinylated proteins were eluted by incubation of the streptavidin beads for $5 \mathrm{~min}$ at $95^{\circ} \mathrm{C}$ in sample buffer. Samples were subjected to SDS-polyacrylamide gel electrophoresis, followed by Western blotting, as previously described (25).

\section{Cellular fractionation of rat cardiomyocytes}

Freshly isolated cardiomyocytes were incubated with oligomycin or trafficking inhibitors similarly to the substrate uptake experiments. Subsequently, cell suspensions were processed according to the fractionation procedure as previously described (26).

Other procedures

Cellular wet mass was obtained from cell samples taken during the incubation period and determined after centrifugation for 2-3 s at maximal speed in a microcentrifuge and subsequent removal of the supernatant. Protein was quantified with the Bicinchichonic acid protein assay (Pierce, Rockford, IL, USA) according to manufacturer's instructions.

Data presentation and statistics

All data are presented as means \pm S.E.M. for the indicated number of myocyte preparations. Statistical difference between groups of observations was evaluated by ANOVA or Student's $t$-test. $P$ values equal to or less than 0.05 were considered significant.

\section{Results}

Verification of the disrupting actions of brefeldin- $A$, latrunculin- $B$ and colchicine at the ultrastructural level in cardiomyocytes

One of the reported cellular effects of brefeldin-A treatment is fragmentation of the Golgi-apparatus (13). To evaluate the effectiveness of brefeldin-A on Golgi disruption in cardiomyocytes, cells were treated, fixed and stained for Golgi-marker130, a Golgi-localized protein. The Golgi-apparatus was detectable as an elongated structure stretching from the vicinity of the nucleus through the sarcoplasmic reticulum, parallel along the contractile fibers. With brefeldin-A, this staining became less intense and more dispersed. The lack of high intensity staining after brefeldin-A treatment indicates that the Golgi-apparatus, and likely also the endosomes, have been fragmented (Fig. 3.1A).

Latrunculin-B has been used as an inhibitor of actin polymerization and thereby as a destabilizing agent for actin filaments (20). Treatment with latrunculin-B was 
Chapter 3

A. Golgi staining

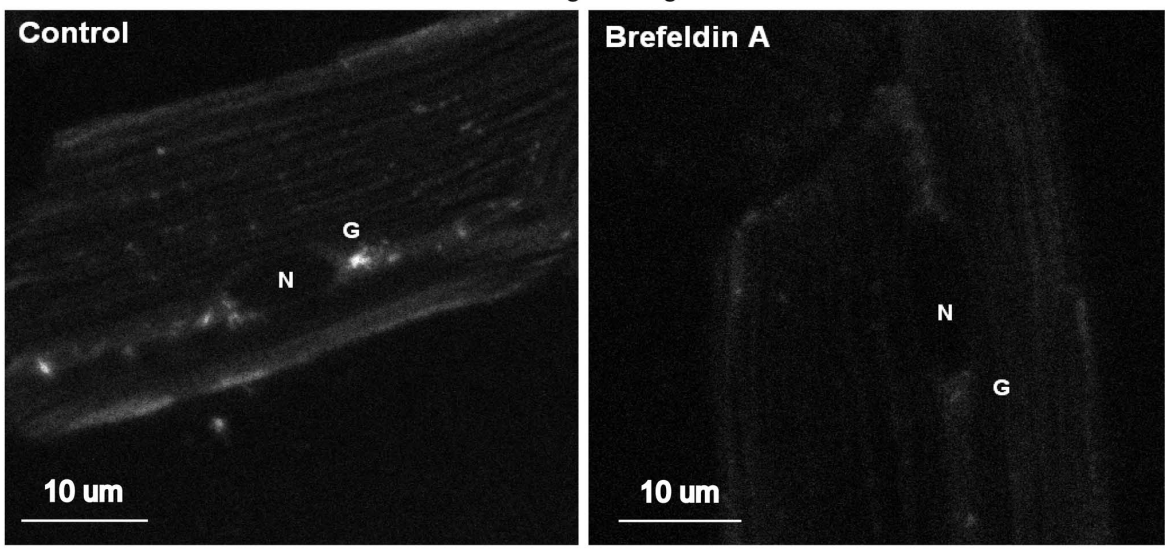

B. actin staining

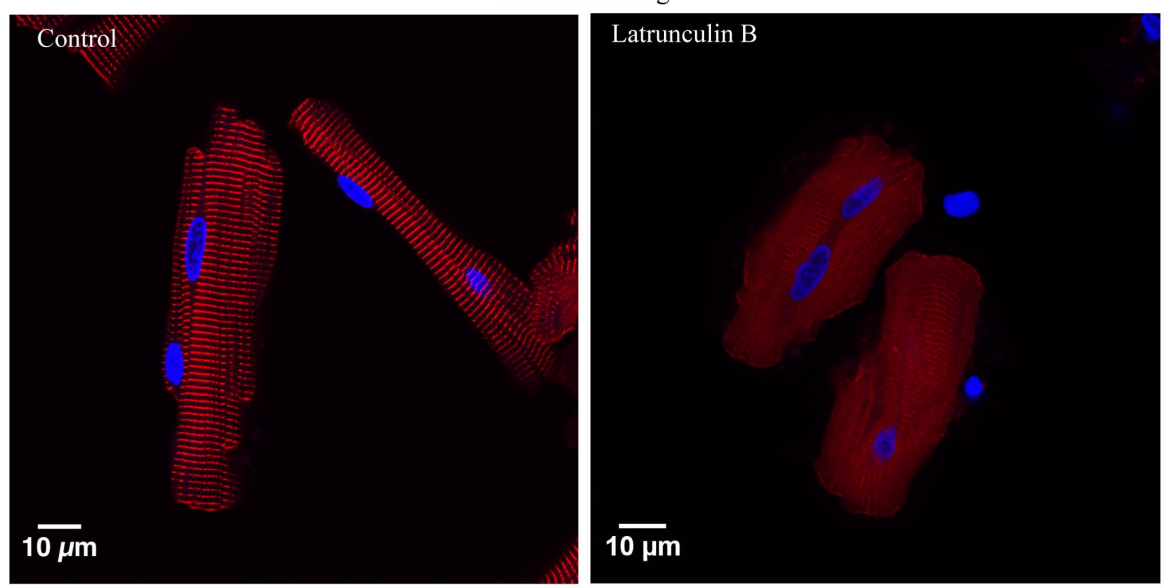

C. Microtubule staining

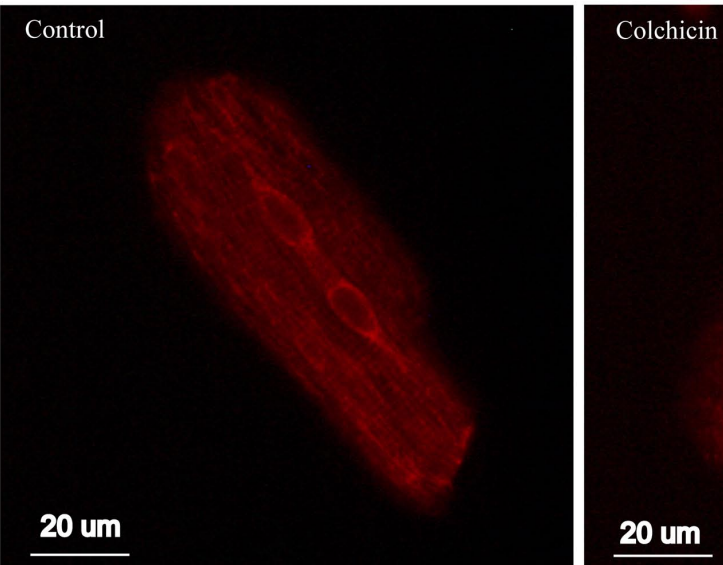




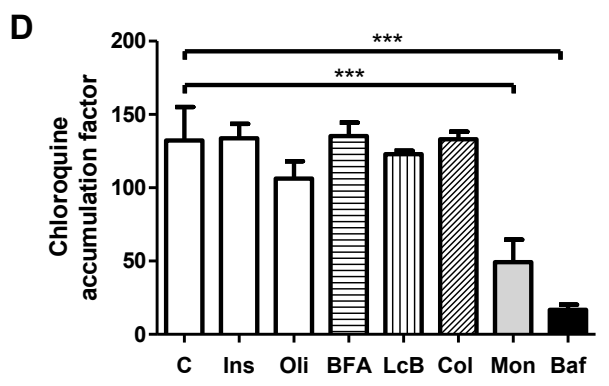

Figure 3.1 (also on previous page): Effect of trafficking inhibitors on cardiomyocyte morphology and endosomal function. (A) Cardiomyocyte suspensions were incubated without or with $20 \mu \mathrm{g} / \mathrm{ml}$ brefeldin-A (45 min) prior to fixation and Golgi staining with GM-130. (B) Cardiomyocyte suspensions were incubated without or with $20 \mu \mathrm{g} / \mathrm{ml}$ latrunculin-B (45 min) prior to fixation and actin staining with Phalloidin TexasRED. (C) Cardiomyocyte suspensions were incubated without or with $1 \mu \mathrm{M}$ colchicine (45 min) prior to fixation and staining of microtubules with $\alpha$-tubulin. (D) Cardiomyocyte suspensions were incubated without or with $100 \mathrm{nM}$ insulin $(20 \mathrm{~min}), 5 \mu \mathrm{M}$ oligomycin $(20 \mathrm{~min}), 20 \mu \mathrm{g} / \mathrm{ml}$ brefeldinA (45 min), $20 \mu \mathrm{g} / \mathrm{ml}$ latrunculin-B (45 min), $1 \mu \mathrm{M}$ colchicine (45 min), $100 \mathrm{nM}$ monensin (25 min), or $100 \mathrm{nM}$ bafilomycin-A (25 $\mathrm{min})$ at the time periods indicated prior to incubation (30 $\mathrm{min})$ with trace amounts of $[3 \mathrm{H}]$ chloroquine for assessment of endosomal function. Data are means \pm S.E.M. of 4-6 experiments carried out with different cardiomyocyte preparations. *Significantly different from cardiomyocytes without additions $(P<0.05)$. Control=C, insulin=Ins, oligomycin=Oli, brefeldin$A=B F A$, latrunculin $-B=L C B$, colchicine $=C o l$, monensin= Mon and bafilomycin $-A=B a f$.

evaluated by actin staining with phalloidin-TexasRed. The striated actin pattern, a characteristic feature of cardiomyocytes, was markedly less pronounced and more dispersed upon treatment with $20 \mu \mathrm{M}$ latrunculin-B. In addition, black holes appeared in between the actin striations of latrunculin-B-treated cardiomyocytes, indicating that the actin cytoskeleton has ruptured at several intracellular locations. Finally, cell morphology altered from rod shaped with rectangular ends to a shorter and rounder appearance (Fig. 3.1B). Hence, the subcellular actin network was damaged by latrunculin-B treatment.

Colchicine is a disruptor of the microtubule network (1). Optimal concentrations were established using immunefluorescence staining of control and colchicine treated cardiomyocytes. Incubation of cardiomyocytes for $1 \mathrm{~h}$ in the presence of $1 \mu \mathrm{M}$ colchicine induced structural changes in the microtubule network. The peri-nuclear staining became less prominent and the overall organization of the microtubules was disrupted as indicated by a more diffuse staining pattern in treated cells (Fig. 3.1C). Another well-established colchicine-induced change in cell morphology is the loss of cell shape (34). Clearly, colchicine treatment of cardiomyocytes caused a metamorphosis from the characteristic rod-shaped appearance into a more spreadout less defined cell shape.

Taken together, we could verify the effectiveness of brefeldin-A, latrunculin-B and colchicine in cardiomyocytes. 
Deoxyglucose uptake

Palmitate uptake

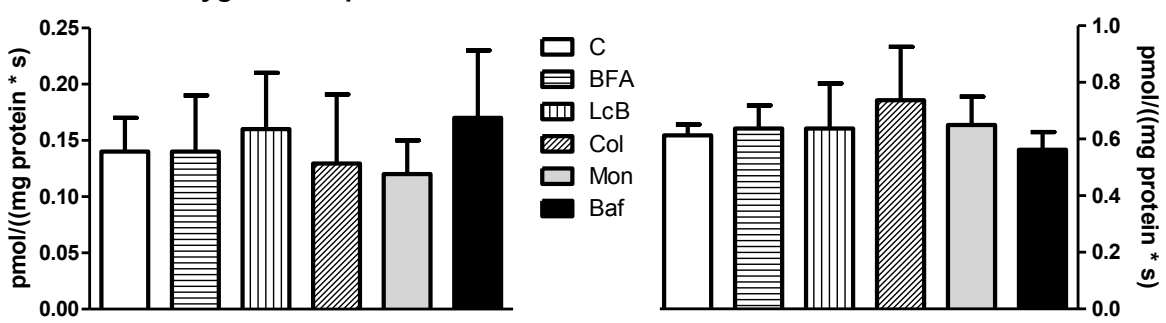

Figure 3.2: Effects of trafficking inhibitors on intrinsic activity of substrate transporters in heartderived giant vesicles. Giant vesicle suspensions were incubated without or with $20 \mu \mathrm{g} / \mathrm{ml}$ brefeldinA, $20 \mu \mathrm{g} / \mathrm{ml}$ latrunculin-B, $1 \mu \mathrm{M}$ colchicine, $100 \mathrm{nM}$ monensin, or $100 \mathrm{nM}$ bafilomycin-A prior to execution of glucose uptake studies $(2 \mathrm{~min}$ ) or palmitate uptake studies (15 sec). Data are means \pm S.E.M. of 3-4 experiments carried out with different cardiomyocyte preparations. Control=C, brefeldin- $A=B F A$, latrunculin $-B=L C B$, colchicine $=C$ ol, monensin=Mon and bafilomycin $-A=B$ af.

\section{Verification of alkalizing action of monensin and bafilomycin-A in cardiomyocytes}

Intracellular accumulation of divalent weak bases, such as chloroquine, is a sensitive $\mathrm{pH}$ indicator of the interior of acidic organelles (12). In non-treated cardiomyocytes, the chloroquine accumulation factor was $133 \pm 22$-fold, which was not influenced by addition of insulin, oligomycin, brefeldin-A, latrunculin-B, or colchicine (Fig.3.1D). In contrast, elevation of the endosomal $\mathrm{pH}$ by monensin or bafilomycin-A markedly decreased chloroquine accumulation (Fig.3.1D). Hence, monensin and bafilomycinA effectively interfere with endosomal functioning via alkalinization of the acidic lumen.

\section{Excluding direct effects of trafficking-inhibiting agents on GLUT4 and CD36}

The possibility exists that the used trafficking inhibitors would affect glucose or LCFA uptake into cardiomyocytes through direct interaction with GLUT4 or CD36 at the plasma membrane. We investigated this option by preparation of giant vesicles which solely consist of sarcolemmal membranes encapsulating soluble cytoplasm. Intracellular organelles such as the endosomal recycling compartment are absent (27), so that translocation of transporters cannot occur. Hence, during incubation of giant vesicles with selected stimuli the amount of GLUT4 and CD36 present at the vesicular membrane remains fixed, and therefore, alterations in transport rates can only be due to changes in the activities of these substrate transporters. We observed that none of the used trafficking inhibitors altered the uptake rates of glucose and LCFA into giant vesicles (Fig. 3.2), indicating that in case of an inhibitory effect of these agents on regulation of substrate uptake into cardiomyocytes it cannot be ascribed to a direct inhibition of sarcolemmal GLUT4 or CD36. 


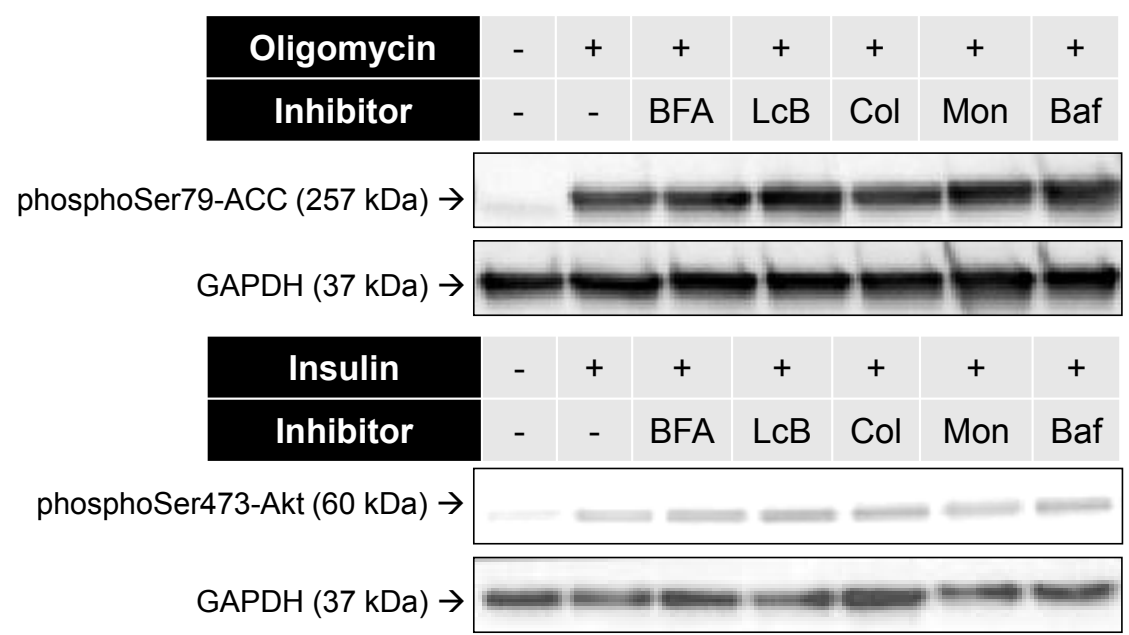

Figure 3.3. Effect of trafficking inhibitors on phosphorylation of signaling proteins in insulin and AMPK (contraction) signaling. Cardiomyocyte suspensions were pre-incubated without or with $20 \mu \mathrm{g} / \mathrm{ml}$ brefeldin-A (45 min), $20 \mu \mathrm{g} / \mathrm{ml}$ latrunculin-B (45 min), $1 \mu \mathrm{M}$ colchicine (45 min), $100 \mathrm{nM}$ monensin (25 min), or $100 \mathrm{nM}$ bafilomycin-A (25 min), at the time periods indicated, and subsequently incubated with or without $100 \mathrm{nM}$ insulin or $5 \mu \mathrm{M}$ oligomycin for $15 \mathrm{~min}$. Subsequently samples were processed for detection of phosphoSer79-ACC, phosphoSer473-Akt by western blotting. Control=C, insulin=Ins, oligomycin=Oli, brefeldin-A=BFA, latrunculin $-B=L c B$, colchicine $=\mathrm{Col}$, monensin=Mon and bafilomycin $-\mathrm{A}=\mathrm{Baf}$.

Excluding non-specific effects of trafficking-inhibiting agents on insulin- and AMPK signaling

To demonstrate that the cytoskeleton disruptors, brefeldin-A and latrunculin-B, did not interfere with oligomycin-induced AMPK activation, we evaluated Ser79phosphorylation of the AMPKsubstrateACC by western blotting (Fig3A). Symmetrically, we determined insulin-induced Akt-Ser473 phosphorylation (Fig.3.3B). Insulin and oligomycin enhanced phosphorylation of Akt and ACC by $>10$-fold (Fig.3.3), in agreement with earlier observations in cardiomyocytes $(23,28)$. However, none of the used trafficking inhibitors were observed to alter the phosphorylation states of these markers of insulin and AMPK signaling (Fig. 3.3). Hence, any effects of these agents on regulation of substrate uptake into cardiomyocytes cannot be attributed to non-specific effects of these compounds on insulin- and AMPK signaling.

Effects of trafficking-inhibiting agents on substrate uptake into cardiomyocytes

Insulin and oligomycin were used to stimulate cardiac substrate uptake. As displayed in Fig. 3.4, insulin and oligomycin treatment increased glucose uptake by 5 - to 12-fold and 1.7 - to 2.5 -fold, respectively, and LCFA uptake by 1.3 - to 1.5 -fold and 

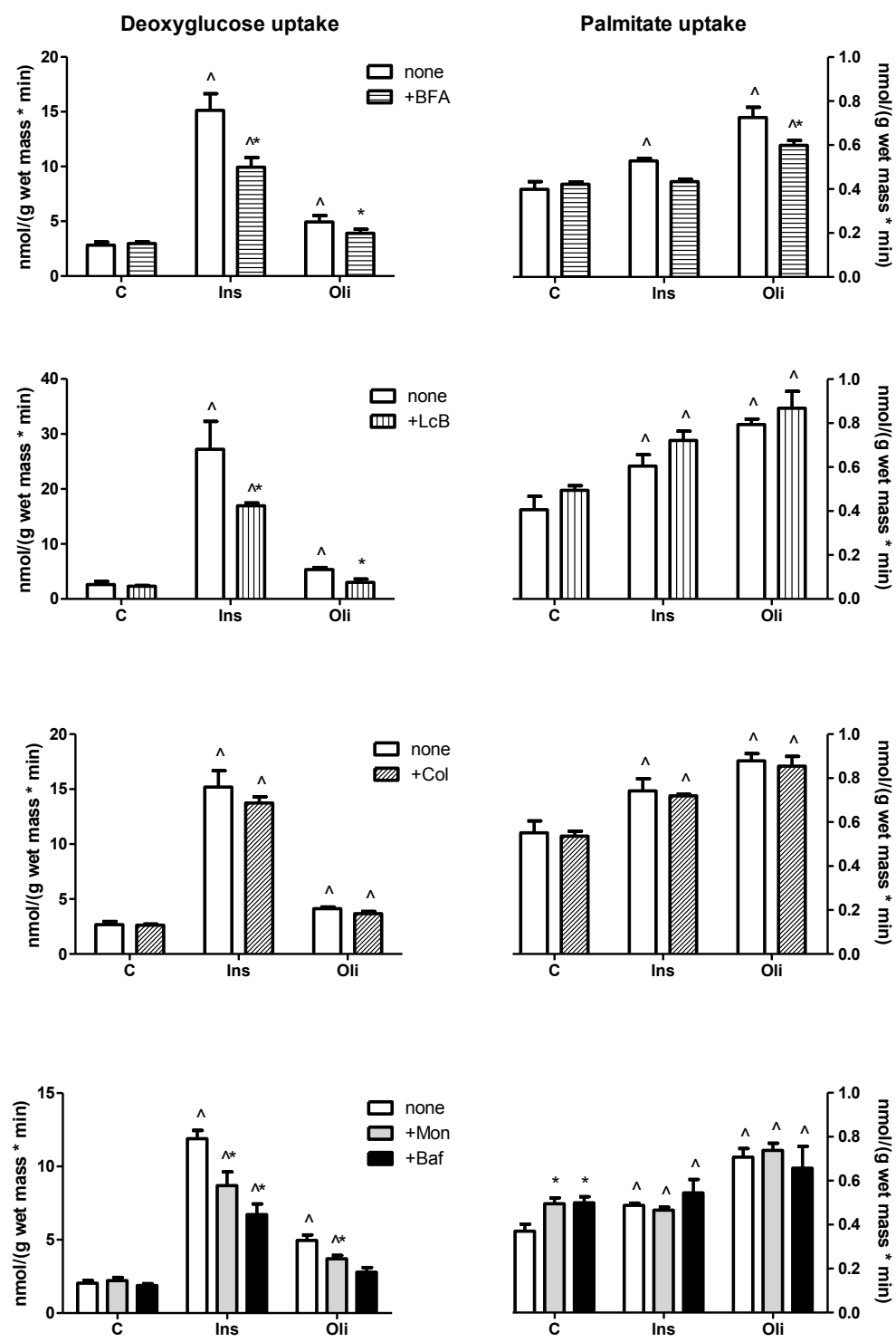

Figure 3.4. Effects of trafficking inhibitors on glucose and LCFA uptake into cardiomyocytes. Cardiomyocyte suspensions were pre-incubated without or with $20 \mu \mathrm{g} / \mathrm{ml}$ brefeldin-A (45 min), $20 \mu \mathrm{g} / \mathrm{ml}$ latrunculin-B (45 min), $1 \mu$ M colchicine (45 min), $100 \mathrm{nM}$ monensin ( $25 \mathrm{~min}$ ), or $100 \mathrm{nM}$ bafilomycin-A ( $25 \mathrm{~min}$ ), at the time periods indicated, and subsequently incubated with or without $100 \mathrm{nM}$ insulin or $5 \mu \mathrm{M}$ oligomycin for $15 \mathrm{~min}$ prior to execution of palmitate uptake studies ( $3 \mathrm{~min}$ ) or deoxyglucose uptake studies ( $3 \mathrm{~min}$ ). Data are means \pm S.E.M. of 4-12 experiments carried out with different cardiomyocyte preparations. *Significantly different from cardiomyocytes stimulated with insulin or oligomycin in the absence of trafficking inhibitors $(P<0.05)$, ^significantly different from cardiomyocytes without trafficking inhibitor $(p<0.05)$. Control=C, insulin=Ins, oligomycin=Oli, brefeldin $-A=B F A$, latrunculin $-B=L C B$, colchicine $=C o l$, monensin=Mon and bafilomycin-A=Baf. 
1.7- to 2.0-fold, respectively, in agreement with our earlier observations $(25,26)$. Brefeldin-A treatment did not alter basal glucose and LCFA uptake, but markedly inhibited insulin-stimulated glucose uptake (-42\%), oligomycin-stimulated glucose uptake (-51\%) and oligomycin-stimulated LCFA uptake (-39\%), and largely inhibited insulin-stimulated LCFA uptake (-68\%; Fig. 3.4A). Latrunculin-B treatment did not alter basal glucose uptake and also did not alter LCFA uptake, neither under basal nor upon treatment of cardiomyocytes with insulin or oligomycin (Fig. 3.4B). In contrast, this actin filament disrupting agent markedly inhibited insulin-stimulated glucose uptake (-41\%) and largely inhibited oligomycin-stimulated glucose uptake (-75\%; Fig. 3.4B). Colchicine treatment neither influenced basal glucose and LCFA uptake nor insulin- or oligomycin-stimulated glucose and LCFA uptake (Fig. 3.4C). Monensin and bafilomycin-A exerted very similar effects on substrate uptake into cardiomyocytes, bolstering the notion that these agent act via the same mechanism, i.e., disruption of low endosomal pH. Specifically, monensin or bafilomycin-A did not alter basal glucose uptake, while simultaneously increasing basal LCFA uptake by 1.3- and 1.4-fold, respectively. Furthermore, monensin and bafilomycin-A markedly inhibited insulin-stimulated glucose uptake (-32\% and $-52 \%$, respectively) and largely inhibited oligomycin-stimulated glucose uptake (-49\% and $-68 \%$, respectively), but these agents had no effect on insulin- or oligomycin-stimulated LCFA uptake (Fig. 3.4D).

When combining the results obtained with all applied trafficking inhibitors, we conclude that insulin/oligomycin-stimulated glucose and LCFA uptake resemble each other in their similar dependence on coat-protein-mediated vesicle formation and their independence of microtubules. In contrast, the endosomal $\mathrm{pH}$ is differentially involved in basal and insulin/oligomycin-stimulated glucose and LCFA uptake. Moreover, insulin/oligomycin-stimulated glucose uptake, but not LCFA uptake, is dependent on actin filaments.

Involvement of $\mathrm{CD} 36$ in alterations seen in cardiomyocytes treated with alkalizing agents

We observed an increase in basal LCFA uptake in cardiomyocytes treated with alkalizing agents. To establish whether CD36 was involved in this process we applied the specific CD36 inhibitor SSO $(11,18)$. In agreement with earlier studies, SSO pretreatment partially inhibited LCFA uptake into non-stimulated cardiomyocytes (Control; -30\%) (26). Furthermore, SSO completely reduced the increase in basal LCFA uptake in monensin- and bafilomycin-A-treated cells, i.e., to the same residual level as observed for non-stimulated cardiomyocytes (Fig. 3.5A).This indicates that CD36 is necessary for the action of these endosomal pH-elevating agents on LCFA 
A

Palmitate uptake
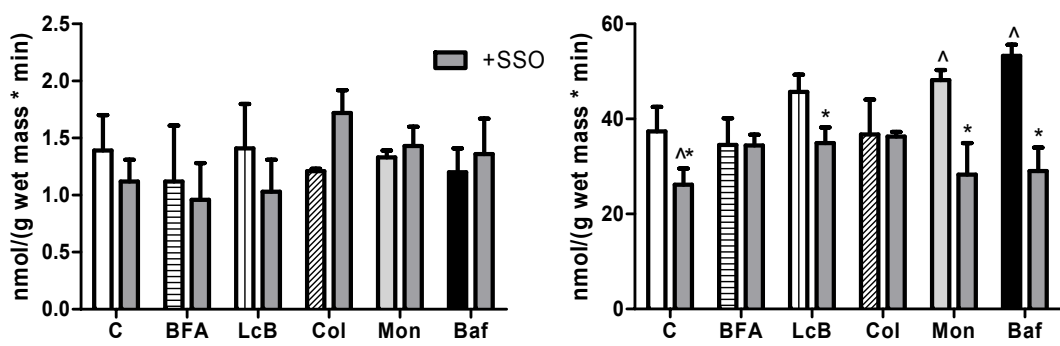

B
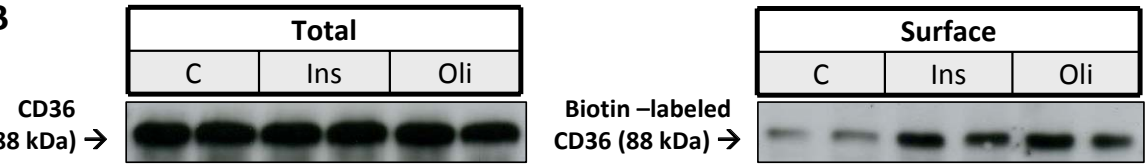

C
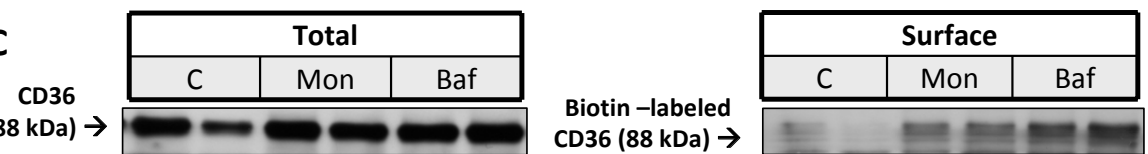

GLUT4
$(50 \mathrm{kDa}) \rightarrow$

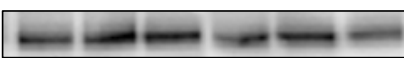

Biotin -labeled GLUT4 (50 kDa) $\rightarrow$

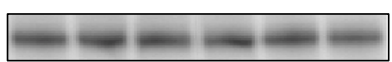

D
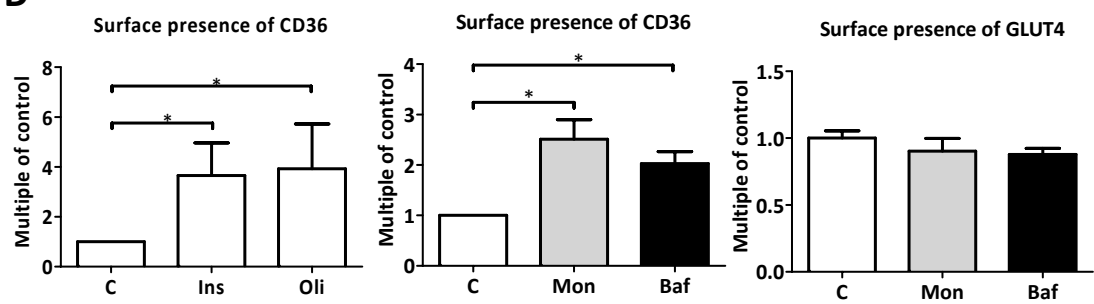

uptake into cardiomyocytes. SSO treatment did not affect glucose uptake into cardiomyocytes, confirming the specificity of this compound for CD36 (Fig. 3.5A). Additionally, none of the trafficking inhibitors decreased cardiomyocyte glucose uptake either in the absence or presence of SSO (Fig. 3.5A).

The involvement of CD36 in the increased basal LCFA uptake in monensin- and bafilomycin-A-treated cardiomyocytes suggests that both endosomal inhibitors induce CD36 translocation to the sarcolemma. To verify this, surface protein biotinylation was performed, allowing quantification of CD36-translocation to the cell surface. We found the amount of CD36 in the biotin-labeled fraction to be increased in insulin-(3.7-fold) or oligomycin-treated (4.0-fold) cardiomyocytes compared to 
Figure 3.5 (previous page): Involvement of CD36 in increased basal LCFA uptake into cardiomyocytes after monensin/bafilomycin-A treatment. (A) Modulation of the stimulatory effects of trafficking inhibitors on LCFA uptake by SSO. Cell suspensions were pre-incubated with DMSO (basal) or with $500 \mu \mathrm{M}$ SSO (dissolved in DMSO), after which the cells were washed twice, as described in Experimental procedures. Subsequently, cells were incubated with or without 100 $\mathrm{nM}$ monensin ( $25 \mathrm{~min}$ ), $100 \mathrm{nM}$ bafilomycin-A (25 min), $20 \mu \mathrm{g} / \mathrm{ml}$ brefeldin-A (45 min), $20 \mu \mathrm{g} / \mathrm{ml}$ latrunculin-B (45 min) or $1 \mu \mathrm{M}$ colchicines (45 min) prior to execution of palmitate uptake studies (3 $\mathrm{min}$ ) or deoxyglucose uptake studies (3 min). Data are means \pm S.E.M. of 3-4 experiments carried out with different cardiomyocyte preparations. *Significantly different from cardiomyocytes without SSO $(P<0.05)$, ^significantly different from cardiomyocytes without inhibitor $(\mathrm{p}<0.05)$. (B-D) Effect of trafficking inhibitors on CD36 surface presence: seeded cells were incubated with DMSO (control), $100 \mathrm{nM}$ insulin (20 min), $5 \mu \mathrm{M}$ oligomycin (20 min), $100 \mathrm{nM}$ monensin (25 min) or $100 \mathrm{nM}$ bafilomycin-A (25 min) prior to biotinylation and cell lysis. CD36 and GLUT4 were detected by Western blotting prior to biotinylation (Total) and after biotinylation (Surface). Values are relative to control presence of CD36 at the sarcolemma. Data are means \pm S.E.M. of 3-4 experiments carried out with different cardiomyocyte preparations. Representative Western blots are displayed. *Significantly different from myocytes without additions $(P<0.05)$. Control=C, brefeldin- $A=B F A$, latrunculin $-B=L C B$, colchicine $=C$ ol, monensin=Mon, bafilomycin $-A=B$ af, insulin=Ins and oligomycin=Oli.

non-stimulated cells (Fig. 3.5B and D). This confirmed earlier observations using this procedure in insulin- and oligomycin-stimulated $\mathrm{CHO}$ cells (44), and the suitability of this procedure to quantify the cell surface presence of recycling proteins. An increase in CD36 cell surface content was also observed upon treatment of cardiomyocytes with monensin (2.5-fold) or bafilomycin-A (2.0-fold), whereas no alterations were seen in GLUT4 surface presence (Fig. 3.5C-D). To assess whether the increase in sarcolemmal CD36 in monensin or bafilomycin-A treated cardiomyocytes was due to translocation from intracellular membrane compartments, subcellular fractionation was performed. First of all, this method confirmed the biotinylation experiments; the presence of CD36 in the sarcolemmal fraction was found to be increased upon cardiomyocyte treatment with monensin (1.3-fold, $p=0.07)$ or bafilomycin-A (1.2fold), but not upon brefeldin-A, latrunculin-B or colchicine treatment (Fig. 3.6). Importantly, the intracellular membrane content of CD36 was found to be decreased by monensin (-62\%), bafilomycin-A (-58\%) or latrunculin-B (-55\%) treatment, but not by brefeldin-A or colchicine (Fig. 3.6). This indicates that dissipation of endosomal $\mathrm{pH}$, but not disruption of assembly of coat proteins, actin filaments or microtubule, causes CD36 translocation from intracellular stores to the sarcolemma. In these same subcellular fractions we measured the content of the major cardiac glucose transporter GLUT4, which was not altered by any of the applied trafficking inhibitors, in agreement with the lack of an effect of monensin or bafilomycin-A on cell surface GLUT4 content, and in agreement with the lack of an effect of these inhibitors on basal glucose uptake. However, we found monensin (-60\%) or bafilomycin-A (-42\%) to reduce the GLUT4 content in the intracellular membrane fraction, i.e., whereas 


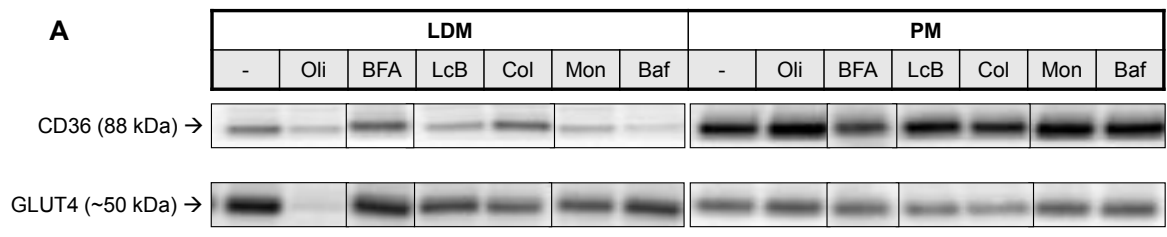

B

\section{GLUT4}
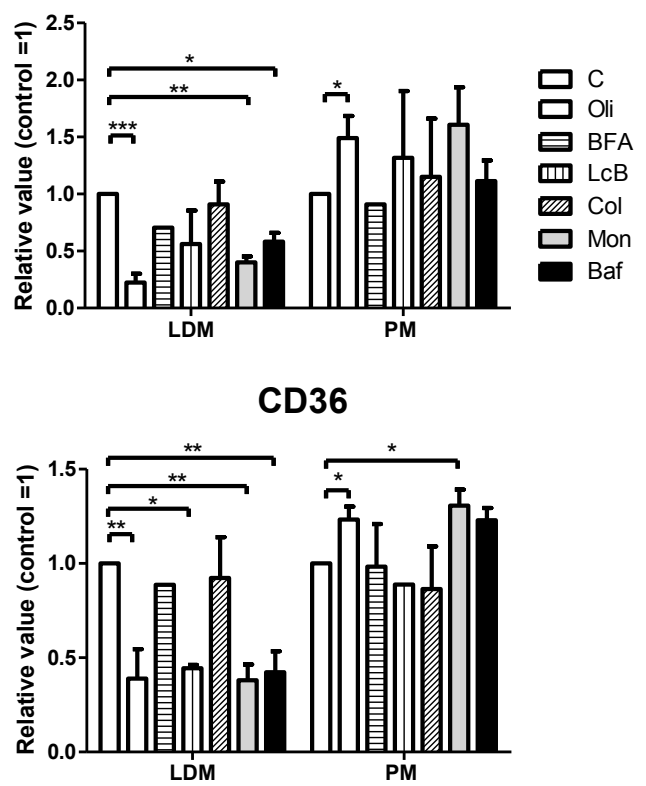

Figure 3.6: Effect of trafficking inhibitors on subcellular localization of GLUT4 and CD36.

Cardiomyocyte suspensions were incubated without or with $5 \mu \mathrm{M}$ oligomycin $(15 \mathrm{~min}), 20 \mu \mathrm{g} / \mathrm{ml}$ brefeldin-A (45 min), $20 \mu \mathrm{g} / \mathrm{ml}$ latrunculin-B ( $45 \mathrm{~min}$ ), $1 \mu \mathrm{M}$ colchicine (45 min), $100 \mathrm{nM}$ monensin (25 min), or $100 \mathrm{nM}$ bafilomycin-A (25 min). Afterwards cells were processed for fractionation and later detection of GLUT4 and CD36 by western blotting. Data are means \pm S.E.M. of 3-4 experiments carried out with different cardiomyocyte preparations. Representative Western blots are displayed. Lines indicate that samples were loaded on different blots. *Significantly different from myocytes without additions $(P<0.05)$. Control $=C$, oligomycin=Oli, brefeldin-A=BFA, latrunculin-B=LCB, colchicine $=\mathrm{Col}$, monensin=Mon, bafilomycin $A=B$ af, low density microsomal fraction=LDM, plasmalemmal fraction=PM.

brefeldin-A, latrunculin-B or colchicines were unsuccessful in this respect. Hence, it seems that monensin and bafilomycin induced an incomplete GLUT4 translocation event. In these subcellular fractionation experiments, oligomycin was used as positive control for CD36 and GLUT4 translocation. Oligomycin treatment was observed to increase sarcolemmal CD36 (1.2-fold) and GLUT4 (1.5-fold) content, and to decrease intracellular CD36 (-61\%) and GLUT4 (-77\%) content, confirming earlier data (25) 
and indicating the suitability of the subcellular fractionation method.

\section{Discussion}

Translocation of both GLUT4 and CD36 are pivotal processes by which the heart regulates its substrate uptake. In order to modulate cardiac substrate preference, e.g. to favor glucose over LCFA utilization, it would be of interest to identify subcellular components specifically involved in the translocation of either GLUT4 or of CD36. However, the signal transduction cascades, as far as these have been investigated, appear not to discriminate between translocation of GLUT4 and that of CD36 in cardiomyocytes (see introduction, and also ref. (35)).

In the present study, we have extended the comparison between the translocation of GLUT4 and that of CD36 in cardiomyocytes by investigating the possible similarities and differences in the reliance on trafficking structures. We applied compounds that disrupt selected components of the subcellular trafficking machinery, and have come to the following conclusions. (i) Glucose uptake and LCFA uptake, stimulated by either insulin or oligomycin, show similar dependence on coat proteins. (ii) Actin filaments do not play a role in LCFA uptake but are involved in glucose uptake stimulated by insulin or oligomycin, whereas microtubules are neither involved in insulin/oligomycin-stimulated glucose uptake nor in insulin/oligomycinstimulated LCFA uptake. (iii) Proper endosomal proton pumping is necessary for insulin/oligomycin-stimulated glucose uptake as well as for maintaining low basal LCFA uptake rates and intracellular retention of CD36.

Taken together, we have identified trafficking elements that are (i) similarly involved in the regulation of glucose and LCFA uptake (coat proteins), (ii) not involved in the regulation of uptake of both substrates (microtubules), and (iii) differentially involved in the regulation of glucose uptake versus LCFA uptake (actin filaments and endosomal $\mathrm{pH})$.

Involvement of coat proteins in regulation of substrate uptake into cardiomyocytes

This is the first study that has used brefeldin-A to investigate the role of coat proteins, in the regulation of cardiac substrate uptake. Under our experimental conditions, brefeldin-A treatment resulted in the disappearance of Golgi structures, confirming that this fungal inhibitor indeed affected coat protein-mediated processes in cardiomyocytes. Brefeldin-A did not alter basal glucose or LCFA uptake in cardiomyocytes, nor did it alter the subcellular localization of GLUT4 and CD36. This indicates that coat-proteins are not involved in the maintenance of a low surface content of GLUT4 and CD36 in non-stimulated cardiomyocytes. 
In contrast, brefeldin-A inhibited, at least partially, both insulin- and oligomycinstimulated glucose uptake, and insulin- and oligomycin-stimulated LCFA uptake. Hence, coat proteins are involved in stimulation of glucose and LCFA uptake upon insulin or oligomycin treatment of cardiomyocytes. Because brefeldin-A inhibits both COP and clathrin targeting to Golgi/endosomal membranes, it cannot be discriminated whether malfunctioning of $\beta$-COP versus clathrin is responsible for brefeldin-A-induced inhibition of insulin/oligomycin-stimulated glucose and LCFA uptake. Notwithstanding, the inhibition of stimulus-induced LCFA uptake by brefeldin-A provides the first evidence that CD36 translocation is a vesicle-mediated process dependent on coat proteins, just like GLUT4 translocation.

Involvement of cytoskeletal elements in regulation of substrate uptake into cardiomyocytes

Like brefeldin-A, inhibitors of actin filaments such as cytochalasin-D or latrunculin$B$, have not been used in the context of cardiac substrate uptake. We were able to confirm that latrunculin-B effectively disrupts the actin network in cardiomyocytes, indicating that this drug is suitable to study the involvement of the actin filaments in subcellular processes. Latrunculin-B did not affect basal glucose or LCFA uptake, nor did it alter basal presence of CD36 and GLUT4 at the sarcolemma, and the basal presence of GLUT4 in the intracellular compartments. Surprisingly, latrunculin-B decreased the basal presence of CD36 in the intracellular compartments, indicating that disruption of actin polymerization dynamics results in an initiation of CD36 translocation but not in completion of this process. The functional relevance of this failing CD36 translocation is presently incompletely understood.

More interestingly, latrunculin-B markedly inhibited insulin-stimulated glucose uptake and completely inhibited oligomycin-stimulated glucose uptake. The inhibition of insulin-stimulated glucose uptake is regarded as a classical latrunculin $B$ action in adipocytes as a result of actin filament disruption (24), and confirms the effectiveness of this drug in cardiomyocytes. In contrast, the inhibition of AMPKmediated glucose uptake by latrunculin- $B$, and the lack of an effect of latrunculin-B on basal or insulin/oligomycin-stimulated LCFA uptake are novel observations. This suggests that actin filaments are specifically involved in stimulus-induced GLUT4 translocation, and not in CD36 translocation.

Conversely, we found that colchicine, while successfully disrupting the microtubule network in cardiomyocytes, had no effect on subcellular GLUT4 and CD36 distribution and on glucose and LCFA uptake into cardiomyocytes under any condition. This indicates that, at least in the heart, this filamentous network does not provide the scaffolding system along which the intracellular GLUT4 and CD36 
vesicles recycle between the endosomal compartment and the cell surface.

In conclusion, this is the first study to identify a subcellular component, i.e., actin filaments, involved in selective translocation of one of the transporters, and to provide evidence that GLUT4 translocation and CD36 translocation are separate events. Combined with the brefeldin-A data, it appears that the processes of GLUT4 translocation and CD36 translocation depend on mutually shared trafficking structures, as well as on structures specifically dedicated to the translocation of either one of these substrate transporters.

Involvement of endosomal functioning in regulation of substrate uptake into cardiomyocytes

The role of the endosomal $\mathrm{pH}$ in translocation processes such as that of GLUT4, as investigated in adipocytes and skeletal muscle, is controversial (see Introduction). We used two structurally unrelated agents with different action modes to compare the role of endosomal $\mathrm{pH}$ in the regulation of glucose and LCFA uptake in cardiomyocytes. Monensin and bafilomycin-A both blocked intracellular accumulation of the divalent weak base chloroquine in cardiomyocytes, which confirms their dissipating effect on endosomal proton trapping. The other trafficking inhibitors used had no effect on chloroquine accumulation, indicating that there are no non-specific effects of these compounds on the endosomal $\mathrm{pH}$.

Our observations on the effects of both endosomal inhibitors on substrate uptake into cardiac myocytes revealed that endosomal $\mathrm{pH}$ plays an entirely different role in subcellular distribution of GLUT4 than of CD36. Namely, we observed that both inhibitors markedly increased basal LCFA uptake without altering basal glucose uptake. In agreement with this, two independent techniques for measurement of cell surface content of proteins show that both endosomal inhibitors increase the sarcolemmal content of CD36, but not that of GLUT4 (Fig. 3.5C-D and Fig. 3.6). These results suggest that monensin/bafilomycin-A-induced LCFA uptake is due to CD36 translocation, and that the lack of an effect of monensin and bafilomycin-A is due to a lack of an effect on GLUT4 translocation. Definite evidence that the selective action of monensin/bafilomycin-A on LCFA uptake is mediated via CD36 translocation from intracellular stores to the sarcolemma was provided by the sensitivity of monensin/ bafilomycin-enhanced LCFA uptake to inhibition by SSO. Surprisingly, monensin and bafilomycin-A reduced the GLUT4 content within the intracellular membrane fraction, suggesting that both alkalizing agents similarly induced the budding of GLUT4 and of CD36 vesicles from the endosomal compartment. However, only the CD36-containing vesicles are able to reach the cell surface upon endosomal alkalinization. 
A possible explanation for the role of endosomal alkalinization in budding of GLUT4 and CD36 vesicles from the endosomal membranes could include that one of the endosomal proteins regulating this budding process is repressed by low $\mathrm{pH}$, and becomes de-inhibited by a dissipation of the $\mathrm{pH}$ gradient. Furthermore, our results suggest that CD36-containing vesicles would travel directly to the sarcolemma upon budding from endosomal membranes, whereas GLUT4 containing vesicles might travel to the sarcolemma via a hypothetical endosomal GLUT4 transit compartment, in which GLUT4 would be unpacked and subsequently reloaded into different transport vesicles for further transport to the sarcolemma for some unknown reasons. However, in this intermediary station the proteins that regulate vesicle budding might be repressed by endosomal alkalinization, instead of activated in case of those in the original endosomal GLUT4 stores. Then, GLUT4 arriving in this compartment upon cardiomyocyte treatment with endosomal alkalinizing agents, would get stuck here.

Remarkably, this subcellular distribution of both substrate transporters, with CD36 being at the cell surface and GLUT4 intracellular during endosomal alkalinization, resembles that of the early insulin-resistant heart, as observed in young adult obese Zucker rats (10) and in rats fed a high-fat diet for 10 weeks (30). This suggests that endosomal alkalinization in the early insulin-resistant heart could result in selective cell surface accumulation of CD36, and hence might contribute to the development of insulin resistance through increased intra-myocellular LCFA accumulation. The loss of the endosomal to cytoplasmic $\mathrm{pH}$ gradient might possibly be due to a reduced energy reserve associated with mitochondrial dysfunction during insulin resistance (5). The remaining ATP produced would then only be used for the most necessary cellular processes, and less ATP would be made available for proton pumping into the endosomal compartment.

Another striking difference about the role of the endosomal $\mathrm{pH}$ in the regulation of glucose versus LCFA uptake is that-insulin/oligomycin-stimulated glucose uptake was partially blocked by monensin/bafilomycin-A treatment, while these compounds had no effect on insulin/oligomycin-stimulated LCFA uptake. The lack of an effect of monensin/bafilomycin-A on insulin/oligomycin stimulated LCFA uptake must be appreciated in view of their stimulatory action on basal LCFA uptake: namely, the effects of monensin/bafilomycin-A on one hand and insulin/oligomycin on the other were non-additive. Importantly, this non-additivity is regarded as kinetic evidence that all these factors use a common molecular mechanism to increase LCFA uptake. Because insulin and oligomycin themselves do not or only slightly alkalinize the endosomes (Fig. 3.1D), the effects of insulin and oligomycin on translocation must 
be downstream of the alkalinization process. Hence, insulin/oligomycin treatment might activate the same budding protein as endosomal alkalinization does, but then via phosphorylation.

The blockade of insulin/oligomycin-stimulated glucose uptake treatment of cardiomyocytes with endosomal alkalinizing agents is in agreement with earlier studies on insulin-stimulated GLUT4 translocation and glucose uptake in adipocytes (8) and cardiomyocytes (46). Perhaps, the hypothetical GLUT4 transit compartment with budding proteins inhibited by a rise in $\mathrm{pH}$ might not only offer an explanation for the incomplete GLUT4 translocation, but also for the inhibition of insulin/oligomycininduced GLUT4 translocation upon endosomal alkalinization. Namely, GLUT4 induced to translocate from the endosomal GLUT4 stores upon insulin/oligomycin treatment would not be further processed in this transit compartment when the $\mathrm{pH}$ gradient between this compartment and the cytoplasm has been dissipated by alkalinizing agents.

Nonetheless and irrespective of the provided possible explanations, it is clear that the endosomal $\mathrm{pH}$ plays a differential role in the regulation of cardiac glucose and LCFA uptake.

\section{Concluding remarks}

The ability of brefeldin-A to inhibit insulin- or oligomycin-stimulated LCFA uptake provides the first evidence for the vesicle-dependent nature of CD36 translocation upon stimulation of cardiomyocytes with hormonal and pharmacological stimuli. This demonstrates that the similarity in the regulation of translocation of GLUT4 and CD36 extends beyond the signaling pathways (as reviewed in (35)) to the vesicular trafficking machinery. However, actin filaments are solely involved in GLUT4 recycling, and the endosomal proton pump has differential roles in GLUT4 and CD36 recycling. With the actin filaments being specifically involved in GLUT4 recycling, it might be speculated that there is also a filamentous network entirely dedicated to CD36 recycling. However, such a candidate filament network is not provided by the microtubules.

Finally, the differential involvement of the endosomal proton pump and actin filaments in the regulation of GLUT4 and CD36 distribution in cardiomyocytes provides novel therapeutic strategies to alter substrate preference in metabolic disease. For instance, pharmacological inhibitors that are specifically targeted to the heart to disrupt actin polymerization dynamics (for inhibition of glucose uptake) could theoretically be used as therapeutic agents to correct substrate preference in the hypertrophied heart, which is characterized by excess glucose utilization. Conversely, 
in metabolic diseases such as type- 2 diabetes, cardiospecific pharmacological agents that stimulate v-ATPase activity would lower LCFA uptake in the lipid-overloaded heart and may thereby restore insulin-stimulated glucose uptake and prevent or reverse the development of metabolic cardiomyopathy.

\section{Acknowledgement}

The authors would like to thank Mr. M. El Hasnaoui, Mr. W.A. Coumans, N.Hoebers and J. Broers for their excellent technical assistance. This study was supported by the Dutch Diabetes Research Foundation (grant nr. 2006.00.044), the Netherlands Organisation for Health Research and Development (ZonMw grant nr. 912-04-075), the European Community (Integrated Project LSHM-CT-2004-005272, Exgenesis), the Natural Sciences and Engineering Research Council of Canada, and by the Heart and Stroke Foundation of Ontario. Antibody MO25 was kindly provided by Dr. N.N. Tandon, Thrombosis and Vascular Biology Laboratory, Otsuka America Pharmaceutical, Inc., Rockville, Maryland. Arend Bonen is the Canada Research Chair in Metabolism and Health. Jan F.C. Glatz is Netherlands Heart Foundation professor of cardiac metabolism. 


\section{References}

1. Ai H, Ralston E, Lauritzen HP, Galbo H, and Ploug T. Disruption of microtubules in rat skeletal muscle does not inhibit insulin- or contraction-stimulated glucose transport. Am J Physiol Endocrinol Metab 285: E836-844, 2003.

2. Antonescu CN, Diaz M, Femia G, Planas JV, and Klip A. Clathrin-dependent and independent endocytosis of glucose transporter 4 (GLUT4) in myoblasts: regulation by mitochondrial uncoupling. Traffic 9: 1173-1190, 2008.

3. Bonen A, Luiken JJ, Arumugam Y, Glatz JF, and Tandon NN. Acute regulation of fatty acid uptake involves the cellular redistribution of fatty acid translocase. J Biol Chem 275: 14501-14508, 2000.

4. Brozinick JT, Jr., Hawkins ED, Strawbridge AB, and Elmendorf JS. Disruption of cortical actin in skeletal muscle demonstrates an essential role of the cytoskeleton in glucose transporter 4 translocation in insulin-sensitive tissues. J Biol Chem 279: 40699-40706, 2004.

5. Bugger $\mathbf{H}$, and Abel ED. Molecular mechanisms for myocardial mitochondrial dysfunction in the metabolic syndrome. Clin Sci (Lond) 114: 195-210, 2008.

6. Chinni SR, and Shisheva A. Arrest of endosome acidification by bafilomycin A1 mimics insulin action on GLUT4 translocation in 3T3-L1 adipocytes. Biochem J 339 ( Pt 3): 599-606, 1999.

7. Chiu HC, Kovacs A, Blanton RM, Han X, Courtois M, Weinheimer CJ, Yamada KA, Brunet S, Xu H, Nerbonne JM, Welch MJ, Fettig NM, Sharp TL, Sambandam N, Olson KM, Ory DS, and Schaffer JE. Transgenic expression of fatty acid transport protein 1 in the heart causes lipotoxic cardiomyopathy. Circ Res 96: 225-233, 2005.

8. Choi YO, Park JH, Song YS, Lee W, Moriyama Y, Choe H, Leem CH, and Jang YJ. Involvement of vesicular H+-ATPase in insulin-stimulated glucose transport in 3T3-F442A adipocytes. Endocr J 54: 733-743, 2007.

9. Condrescu M, and Reeves JP. Actin-dependent regulation of the cardiac $\mathrm{Na}(+) / \mathrm{Ca}(2+)$ exchanger. Am J Physiol Cell Physiol 290: C691-701, 2006.

10. Coort SL, Hasselbaink DM, Koonen DP, Willems J, Coumans WA, Chabowski A, van der Vusse GJ, Bonen A, Glatz JF, and Luiken JJ. Enhanced sarcolemmal FAT/CD36 content and triacylglycerol storage in cardiac myocytes from obese zucker rats. Diabetes 53: 1655-1663, 2004.

11. Coort SL, Willems J, Coumans WA, van der Vusse GJ, Bonen A, Glatz JF, and Luiken JJ. Sulfo-Nsuccinimidyl esters of long chain fatty acids specifically inhibit fatty acid translocase (FAT/CD36)mediated cellular fatty acid uptake. Mol Cell Biochem 239: 213-219, 2002.

12. de Duve C, de Barsy T, Poole B, Trouet A, Tulkens P, and Van Hoof F. Commentary. Lysosomotropic agents. Biochem Pharmacol 23: 2495-2531, 1974.

13. Dinter A, and Berger EG. Golgi-disturbing agents. Histochem Cell Biol 109: 571-590, 1998.

14. Duden R, Griffiths G, Frank R, Argos P, and Kreis TE. Beta-COP, a 110 kd protein associated with nonclathrin-coated vesicles and the Golgi complex, shows homology to beta-adaptin. Cell 64: 649-665, 1991.

15. Forgac M. Vacuolar ATPases: rotary proton pumps in physiology and pathophysiology. Nat Rev Mol Cell Biol 8: 917-929, 2007.

16. Gimeno RE, Ortegon AM, Patel S, Punreddy S, Ge P, Sun Y, Lodish HF, and Stahl A. Characterization of a heart-specific fatty acid transport protein. J Biol Chem 278: 16039-16044, 2003.

17. Habets DD, Coumans WA, El Hasnaoui M, Zarrinpashneh E, Bertrand L, Viollet B, Kiens B, Jensen TE, Richter EA, Bonen A, Glatz JF, and Luiken JJ. Crucial role for LKB1 to AMPKalpha2 axis in the regulation of CD36-mediated long-chain fatty acid uptake into cardiomyocytes. Biochim Biophys Acta 1791: 212-219, 2009.

18. Habets DD, Coumans WA, Voshol PJ, den Boer MA, Febbraio M, Bonen A, Glatz JF, and Luiken JJ. AMPK-mediated increase in myocardial long-chain fatty acid uptake critically depends on sarcolemmal CD36. Biochem Biophys Res Commun 355: 204-210, 2007.

19. Habets DDJ. Thesis: Regulation of cardiac long-chain fatty acid and glucose utilization, chapter 5 : AICAR stimulates long-chain fatty acid uptake and oxidation in mouse heart independent of CD36. 89-101, 2008.

20. Kanzaki M, and Pessin JE. Insulin-stimulated GLUT4 translocation in adipocytes is dependent upon cortical actin remodeling. J Biol Chem 276: 42436-42444, 2001. 
21. Kono-Sugita E, Satoh S, Suzuki Y, Egawa M, Udaka N, Ito T, and Sekihara H. Insulin-induced GLUT4 recycling in rat adipose cells by a pathway insensitive to brefeldin A. Eur J Biochem 236: 1033-1037, 1996.

22. Lachaal M, Moronski C, Liu H, and Jung CY. Brefeldin A inhibits insulin-induced glucose transport stimulation and GLUT4 recruitment in rat adipocytes. J Biol Chem 269: 23689-23693, 1994.

23. Lippincott-Schwartz J. Bidirectional membrane traffic between the endoplasmic reticulum and Golgi apparatus. Trends Cell Biol 3: 81-88, 1993.

24. Liu XJ, Yang C, Gupta N, Zuo J, Chang YS, and Fang FD. Protein kinase C-zeta regulation of GLUT4 translocation through actin remodeling in $\mathrm{CHO}$ cells. J Mol Med 85: 851-861, 2007.

25. Luiken JJ, Coort SL, Willems J, Coumans WA, Bonen A, van der Vusse GJ, and Glatz JF. Contractioninduced fatty acid translocase/CD36 translocation in rat cardiac myocytes is mediated through AMPactivated protein kinase signaling. Diabetes 52: 1627-1634, 2003.

26. Luiken JJ, Koonen DP, Willems J, Zorzano A, Becker C, Fischer Y, Tandon NN, Van Der Vusse GJ, Bonen A, and Glatz JF. Insulin stimulates long-chain fatty acid utilization by rat cardiac myocytes through cellular redistribution of FAT/CD36. Diabetes 51: 3113-3119, 2002.

27. Luiken JJ, Turcotte LP, and Bonen A. Protein-mediated palmitate uptake and expression of fatty acid transport proteins in heart giant vesicles. J Lipid Res 40: 1007-1016, 1999.

28. Luiken JJ, van Nieuwenhoven FA, America G, van der Vusse GJ, and Glatz JF. Uptake and metabolism of palmitate by isolated cardiac myocytes from adult rats: involvement of sarcolemmal proteins. $J$ Lipid Res 38: 745-758, 1997.

29. Olson AL, Trumbly AR, and Gibson GV. Insulin-mediated GLUT4 translocation is dependent on the microtubule network. J Biol Chem 276: 10706-10714, 2001.

30. Ouwens DM, Diamant M, Fodor M, Habets DD, Pelsers MM, El Hasnaoui M, Dang ZC, van den Brom CE, Vlasblom R, Rietdijk A, Boer C, Coort SL, Glatz JF, and Luiken JJ. Cardiac contractile dysfunction in insulin-resistant rats fed a high-fat diet is associated with elevated CD36-mediated fatty acid uptake and esterification. Diabetologia 50: 1938-1948, 2007.

31. Ralston E, and Ploug T. Caveolin-3 is associated with the T-tubules of mature skeletal muscle fibers. Exp Cell Res 246: 510-515, 1999.

32. Romanek R, Sargeant R, Paquet MR, Gluck S, Klip A, and Grinstein S. Chloroquine inhibits glucose-transporter recruitment induced by insulin in rat adipocytes independently of its action on endomembrane pH. Biochem J 296 ( Pt 2): 321-327, 1993.

33. Ros-Baro A, Lopez-Iglesias C, Peiro S, Bellido D, Palacin M, Zorzano A, and Camps M. Lipid rafts are required for GLUT4 internalization in adipose cells. Proc Natl Acad Sci U S A 98: 12050-12055, 2001.

34. Samarakoon R, and Higgins PJ. MEK/ERK pathway mediates cell-shape-dependent plasminogen activator inhibitor type 1 gene expression upon drug-induced disruption of the microfilament and microtubule networks. J Cell Sci 115: 3093-3103, 2002.

35. Schwenk RW, Luiken JJ, Bonen A, and Glatz JF. Regulation of sarcolemmal glucose and fatty acid transporters in cardiac disease. Cardiovasc Res 79: 249-258, 2008.

36. Shigematsu S, Khan AH, Kanzaki M, and Pessin JE. Intracellular insulin-responsive glucose transporter (GLUT4) distribution but not insulin-stimulated GLUT4 exocytosis and recycling are microtubule dependent. Mol Endocrinol 16: 1060-1068, 2002.

37. Shigematsu S, Watson RT, Khan AH, and Pessin JE. The adipocyte plasma membrane caveolin functional/structural organization is necessary for the efficient endocytosis of GLUT4. J Biol Chem 278: 10683-10690, 2003.

38. Stahl A, Evans JG, Pattel S, Hirsch D, and Lodish HF. Insulin causes fatty acid transport protein translocation and enhanced fatty acid uptake in adipocytes. Dev Cell 2: 477-488, 2002.

39. Staros JV. N-hydroxysulfosuccinimide active esters: bis(N-hydroxysulfosuccinimide) esters of two dicarboxylic acids are hydrophilic, membrane-impermeant, protein cross-linkers. Biochemistry 21: 3950-3955, 1982.

40. Sun-Wada GH, Wada Y, and Futai $\mathbf{M}$. Diverse and essential roles of mammalian vacuolar-type proton pump ATPase: toward the physiological understanding of inside acidic compartments. Biochim Biophys Acta 1658: 106-114, 2004.

41. Tamura G, Ando K, Suzuki S, Takatsuki A, and Arima K. Antiviral activity of brefeldin A and verrucarin 
A. J Antibiot (Tokyo) 21: 160-161, 1968.

42. Tong P, Khayat ZA, Huang C, Patel N, Ueyama A, and Klip A. Insulin-induced cortical actin remodeling promotes GLUT4 insertion at muscle cell membrane ruffles. J Clin Invest 108: 371-381, 2001.

43. Torok D, Patel N, Jebailey L, Thong FS, Randhawa VK, Klip A, and Rudich A. Insulin but not PDGF relies on actin remodeling and on VAMP2 for GLUT4 translocation in myoblasts. J Cell Sci 117: 54475455, 2004.

44. van Oort MM, van Doorn JM, Bonen A, Glatz JF, van der Horst DJ, Rodenburg KW, and Luiken JJ. Insulin-induced translocation of CD36 to the plasma membrane is reversible and shows similarity to that of GLUT4. Biochim Biophys Acta 1781: 61-71, 2008.

45. Whitney JA, Gomez M, Sheff D, Kreis TE, and Mellman I. Cytoplasmic coat proteins involved in endosome function. Cell 83: 703-713, 1995.

46. Yang J, Gillingham AK, Hodel A, Koumanov F, Woodward B, and Holman GD. Insulin-stimulated cytosol alkalinization facilitates optimal activation of glucose transport in cardiomyocytes. Am J Physiol Endocrinol Metab 283: E1299-1307, 2002. antagonist and endothelinB-selective agonists. $J$ Biol Chem 268, 8547-8553 (1993).

42. Bouallegue, A., Daou, G.B. \& Srivastava, A.K. Endothelin-1-induced signaling pathways in vascular smooth muscle cells. Curr Vasc 
Chapter 4

\section{CD36 inhibition prevents lipid accumulation and contractile dysfunction in rat cardiomyocyte cultures}

Laura K.M. Steinbusch ${ }^{1 *}$, Yeliz Angin ${ }^{1 *}$, Peter J. Simons ${ }^{2}$, Kim Douma ${ }^{1,}$ Sabrina Greulich ${ }^{4}$, Nicole T.H. Hoebers ${ }^{1}$, Will A. Coumans ${ }^{1}$, Wino Wijnen ${ }^{1}$, Michaela Diamant $^{3}$, D.Margriet Ouwens ${ }^{4}$, Jan F.C. Glatz ${ }^{1}$, Joost J.F.P. Luiken ${ }^{1}$

${ }^{1}$ CARIM, Maastricht University, Maastricht, NL

${ }^{2}$ Bioceros BV, Utrecht, NL

${ }^{3}$ Diabetes Center, VUMC, Amsterdam, NL

${ }^{4}$ German Diabetes Center, Düsseldorf, DE

*These authors contributed equally

Submitted 


\begin{abstract}
Background: increased cardiac fatty acid supply and increased sarcolemmal presence of CD36 each is associated with and contributes to impaired cardiac insulin sensitivity and function. We aimed at preventing the development of insulin resistance and contractile dysfunction in cardiomyocytes by blocking CD36-mediated palmitate uptake.
\end{abstract}

Methods: Insulin resistance and contractile dysfunction were induced in primary cardiomyocytes by $48 \mathrm{~h}$ incubation in media containing $100 \mathrm{nM}$ insulin (high insulin; $\mathrm{HI}$ ) or $200 \mu \mathrm{M}$ palmitate (high palmitate; HP). CD36-blocking peptides or antibodies were tested for their ability to inhibit palmitate uptake into cardiomyocytes. Thereafter, basal and insulin-stimulated substrate uptake, insulin signaling, sarcolemmal CD36 presence, lipid content and contractile parameters were determined in cells exposed to $\mathrm{HI}$ or HP media with/without CD36-inhibiting compounds.

Results: Culturing cardiomyocytes in HI or HP medium abrogated or markedly reduced insulin-stimulated glucose uptake and Akt-phosphorylation. Furthermore, cardiomyocytes cultured in each medium displayed increased basal palmitate uptake, lipid accumulation, elevated sarcolemmal CD36 content, and decreased sarcomere shortening. CD36 inhibition enhanced basal glucose uptake and prevented elevated basal palmitate uptake, triacylglycerol accumulation, and contractile dysfunction in cardiomyocytes cultured in each medium. Additionally, CD36 inhibition prevented loss of insulin signaling in cells cultured in HP, but not in HI medium.

Conclusions: CD36 inhibition prevents lipid accumulation and lipid-induced contractile dysfunction in cardiomyocytes, but likely independently of effects on insulin signaling. Nonetheless, pharmacological CD36 inhibition may be considered as a treatment strategy to counteract impaired functioning of the lipid-loaded heart. 


\section{Introduction}

Increasedcardiaclipidcontenthas beenassociated with a number ofpathophysiological conditions like cardiac insulin resistance and contractile dysfunction which may lead to the development of diabetic cardiomyopathy [1-3]. Cardiac lipid accumulation may occur as a result of elevated fatty acid supply [4] and/or increased uptake of long chain fatty acids (LCFA) [5-7]. Excessive entry of LCFA into cardiomyocytes will provide increased substrates for mitochondrial fatty acid oxidation. When the flux of incoming fatty acids exceeds the mitochondrial $\beta$-oxidation capacity, LCFA will be increasingly stored as triacylglycerols and converted into other metabolites. Notably, there is a strong correlation between triacylglycerol storage and insulin resistance $[8,9]$.

Fatty acids and glucose are the major energy substrates for the heart. Cardiac substrate uptake is dependent on plasma glucose and fatty acid concentrations, as well as the sarcolemmal presence of glucose and fatty acid transporters $[7,10]$. The main glucose transporter (GLUT) in the heart is GLUT4, whereas LCFA uptake is largely mediated by CD36 [11]. Also other fatty acid transporters have been found to be present in the heart such as members of the family of fatty acid transporter proteins (FATPs), but these proteins have a minor role in bulk uptake of LCFA into the heart [7]. Both cardiac glucose and fatty acid uptake are regulated by reversible translocation of GLUT4 and CD36 from intracellular compartments to the sarcolemma [11].

In insulin resistant rodent models, the expression of CD36 in the heart is not changed in comparison to healthy rodents, but this transporter has been shown to permanently relocate from intracellular stores to the sarcolemma. This CD36 relocation will cause chronically elevated LCFA uptake into the heart, followed by myocellular lipid accumulation, and consequently insulin resistance [7, 12, 13]. Ultimately, permanent sarcolemmal CD36 relocation may lead to cardiac dysfunction [12]. Accordingly, ablation of CD36 has been shown to preserve cardiac function in Western diet-fed mice [14], and also in mice suffering from PPAR $\alpha$ overexpressioninduced lipotoxicity [15]. Taken together, CD36 and its increased abundance at the sarcolemma play a key role in the development of high-fat diet-induced cardiac dysfunction.

CD36 is a multifactorial protein and has different functions in different cell types. Several endogenous CD36-ligands (LCFA, thrombospondin-1, oxidized low-density lipoproteins) with different binding regions on the extracellular domain of CD36 are known [16-18]. In addition, synthetic CD36-specific binding molecules (sulfo-Nsuccinimydyl oleate (SSO), hexarelin, EP80317) and antibodies have been introduced $[19,20]$. Sulfo-N-succinimidyl esters of LCFA have proven to block initial LCFA uptake 
into heart and muscle [21]. However, they are not useful in long-term experiments because of their chemical instability [20]. In search for other CD36 ligands that interfere with the fatty acid transport function of CD36, we first tested whether hexarelin, EP80317 and anti-CD36 monoclonal antibodies (mAb) would inhibit shortterm LCFA uptake into cardiomyocytes prior to testing their protective potential against the detrimental effects of cardiomyocytic lipid overload.

To test the putative preventive effect of CD36 ligands on lipid accumulation, insulin resistance and contractile dysfunction of cardiomyocytes, we first needed suitable culturing conditions in which cardiomyocytes develop excessive lipids storage and loss of insulin signaling and contractile function. For this, we chronically exposed rat primary cardiomyocytes to a medium containing a high concentration of insulin (HI), because insulin is known to induce CD36 translocation to the sarcolemma, and thereby increase LCFA uptake and lipid accumulation. Besides, it is known that chronic insulin-treatment induces loss of insulin signaling in cardiomyocytes [22]. In addition, we exposed cardiomyocytes to a medium containing a high concentration of palmitate (HP), which is known to reduce contractile function [23]. In this study, cardiomyocytes were cultured in a $\mathrm{HI}$ or a HP containing medium with/without antiCD36 monoclonal antibody (mAb) clone 63 (or its solvent, as a control). Then, we evaluated the cultured cardiomyocytes on surface CD36 presence, substrate uptake, insulin signaling, myocellular lipid content and contractile function. We describe here that inhibition of CD36-mediated LCFA uptake by clone 63 prevents lipid accumulation and loss of sarcomere shortening in these cardiomyocyte cultures.

\section{Materials and Methods}

\subsection{Materials}

[14C]Palmitic acid and [3H]deoxy-glucose were obtained from GE Healthcare (Little Chalfont, UK). $[3 \mathrm{H}]$ chloroquine was from Moravek Biochemicals (Brea, USA). Laminin and insulin were purchased from Sigma (Saint Louis, USA). Bovine serum albumin (BSA) (fraction V), dependent on the application, was derived from MP Biomedicals (Irvine, USA) (for cell isolation and incubation purposes), or from Sigma (other purposes). Collagenase type II was from Worthington (Freehold, USA). (SSO was synthesized in our laboratory [24], EP80317 was from Bio-Connect (special production by Peptides International, Kentucky, USA), hexarelin was a gift from Prof. Dr. Heemskerk (Maastricht, NL), anti-CD36 mAb clone 63 (also known as clone CRF D2717) was from BD Biosciences (Franklin Lakes, NJ, USA), and kindly provided by Bioceros BV, (Utrecht, NL).

\subsection{Experimental animals}

Male Lewis rats, 200-250 gram, were purchased from Charles River laboratories and used for cardiomyocyte isolation. All animals were fed ad libitum. All procedures were approved by the Experimental Animal Committee of Maastricht University, NL.

\subsection{Cardiomyocyte isolation and culturing}

Cardiomyocyte isolations were performed as described previously [25] with the only difference being the sterile conditions that were taken into account for subsequent culturing. After isolation of cardiomyocytes, 
200,000 cells/well were routinely seeded in laminin coated 6-well plates $(9.6 \mathrm{~cm} 2)$, unless otherwise specified. After 90 min adhesion in modified Krebs-Ringer medium [26] supplemented with $0.45 \%$ BSA, the adhesion medium was replaced with control medium (based on M199 supplemented with 5 $\mathrm{mM}$ creatine monohydrate, $3.2 \mathrm{mM}$ carnitine hydrochloride, $3.1 \mathrm{mM}$ taurine, $100 \mathrm{U} / \mathrm{ml}$ penicillin and streptomycin, $20 \mu \mathrm{M}$ palmitate (palmitate:BSA 0.3:1)) HI medium (control medium supplemented with $100 \mathrm{nM}$ insulin) or HP medium (control medium with more palmitate; $200 \mu \mathrm{M}$, palmitate:BSA 3:1). Cells were cultured for $48 \mathrm{~h}$ and in case of measurements of short-term insulin effects cardiomyocytes were washed with modified Krebs-Ringer supplemented with $0.45 \% \mathrm{BSA}$ and $1 \mathrm{mM} \mathrm{CaCl} 2$ (medium A) and left untreated for 30 minutes (explained in detail in Results section 3.2).

\subsection{Measurement of substrate uptake}

We measured uptake of [1-14C]palmitate (in complex with BSA) and [3H]deoxyglucose into freshly isolated cardiomyocytes [26] as well as into cardiomyocytes in culture [27], as previously described. With respect to freshly isolated cardiomyocytes, cells were pre-incubated with anti-CD36-specific binding molecules (500 $\mathrm{MM}$ SSO, $100 \mu \mathrm{M}$ EP80317, $1 \mu \mathrm{M}$ hexarelin, 0.825 $\mathrm{g} / \mathrm{ml}$ anti-CD36 mAb clone 63 ) at $37^{\circ} \mathrm{C}$ while shaking for $20 \mathrm{~min}$, and subsequently incubated with oligomycin $(5 \mu \mathrm{M})$ for an additional $20 \mathrm{~min}$. Then, a mixture of [3H]glucose and [14C]palmitate was added the last 5 min of incubation and radioactivity was measured in scintillation fluid (Opti-Fluor) Perkin Elmer, Waltham, USA.

With respect to two days-cultured cardiomyocytes, a mixture of [3H]glucose and [14C]palmitate was added for $10 \mathrm{~min}$ directly following a $15 \mathrm{~min}$ incubation period with/without insulin (100 $\mathrm{nM})$. Then, cells

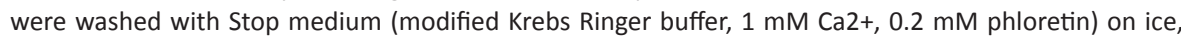
lysed in sample buffer (40\% glycerol, 0.25 M Tris, 1 M DTT, 20\% mercaptoethanol) and radioactivity was measured in scintillation fluid (Opti-Fluor, Perkin Elmer, Waltham, USA).

\subsection{Detection of phosphorylation of enzymes within the insulin signaling network}

Following a 15 min treatment with/without insulin (100 nM), cells were lysed in sample buffer (40\% glycerol, 0.25 M Tris, 1 M DTT, 20\% mercaptoethanol, bromo-phenol-blue) and used for protein detection by SDS-polyacrylamide gel electrophoresis ( $20 \mu \mathrm{g}$ protein per lane), followed by Western blotting, as previously described [28]. Antibodies against phospho-Ser473-Akt, Akt, phospho-Ser9-GSK3 $\beta$ were purchased from Cell Signalling Technologies (Danvers, MA), phospho-AS160 from Upstate (Millipore) (Billerica, MA), CD36 from GenTex Inc. (San Antonio, TX, USA), GLUT4 and GAPDH from Abcam (Cambridge, USA) and caveolin3 from BD Transduction laboratories (Franklin Lakes, USA). Western blot images were analyzed with a Molecular Imager (ChemiDoc XRS, BioRad) and quantified with Quantity One ${ }^{\circledR}$ (BioRad).

\subsection{Measurement of sarcomere shortening and Ca2+-fluxes}

For measurement of sarcomere shortening and Ca2+-fluxes, cells were cultured on $35 \mathrm{~mm}$ high dishes with elastic surface from Ibidi GmBH (München,Germany). After two days of culturing, cells were preloaded with Fura-2 AM (Merck chemicals (Darmstadt, Germany) for 25 min at room temperature, washed twice with control medium 199 and then incubated for 20 min with medium 199. Subsequently, contractile function and Ca2+-transients were analyzed in cells showing an intact rod-shaped morphology and sarcomere length $>1.6 \mu \mathrm{m}$ as described previously [29]. Before measurement was started, cells were electrically pre-stimulated for $5 \mathrm{~min}$ with $1 \mathrm{~Hz}$ to reach a steady-state level for sarcomere shortening and Fura-2 fluorescence. Then, cells were paced with bipolar pulses of $5 \mathrm{~ms}$ duration at $1 \mathrm{~Hz}$. The cytosolic $\mathrm{Ca} 2+$ concentration was monitored as a ratio of the fluorescence emission peaks at 340 and $380 \mathrm{~nm}$. In each experimental condition, data files were recorded of 10 consecutive beats for at least eight different cells. Sarcomere shortening and $\mathrm{Ca} 2+$-transients were measured with a fluorescence system from IonOptix (Dublin, Ireland) and calculated using lonWizard (IonOptix).

\subsection{Triacylglycerol stores}

For measurement of intramyocellylar lipid content, cardiomyocytes were cultured in $78.55 \mathrm{~cm} 2$ glass petridishes with $1 \times 106$ cell density. Intramyocellular lipids were determined after 2 days of culturing as described previously [30]. In short, samples containing $400 \mu \mathrm{g}$ of protein were used for intracellular 
lipid extraction in methanol/chloroform, and an internal standard and water were added. Afterwards thin-layer chromatography was used to separate lipids. Bands were resolved with a hexane/diethylether/ propanol (87:10:3) resolving solution and triacylglycerol bands were detected with a Molecular Imager (ChemiDoc XRS, BioRad) and analyzed with Quantity One ${ }^{\circledR}$ (BioRad).

\subsection{Sarcolemmal CD36 presence}

Following a 15 min treatment with/without insulin (100 nM), cells were incubated for 10 min with $2 \mu \mathrm{g} /$ $\mathrm{ml}$ mouse anti-mouse CD36 mAb clone 63, which is known to cross-react with rat CD36, and FITC labeled rabbit-anti-mouse IgA secondary antibodies (1:500; Rockland, USA). Cardiomyocytes were washed with adhesion medium and then the viable cardiomyocytes were imaged using the Leica SP5 imaging platform in two-photon mode (Leica Microsystems, Wetzlar, Germany) with the emission filters optimized for FITCdetection. Images were processed with ImageJ. Cardiomyocytes were kept at $37{ }^{\circ} \mathrm{C}$ during incubation and imaging.

\subsection{Statistics}

Differences among the data obtained from five to eight experiments are presented as means \pm S.E.M. Statistical difference between groups of observations was evaluated by unpaired Student's t-test, oneWay ANOVA or 2-Way ANOVA, depending on the groups compared. P values equal to or less than 0.05 were considered significant.

\section{Results}

3.1 Anti-CD36 mAb clone 63 treatment inhibits palmitate uptake in freshly isolated cardiomyocytes

Our first aim was to select a CD36 ligand that would inhibit LCFA uptake into cardiomyocyte cultures. Expectedly, the putative LCFA uptake-blocking effects of the selected CD36 ligands can be best appreciated under conditions in which CD36 has a large contribution to the cardiomyocytic LCFA uptake rate. Therefore, we tested the ability of these CD36 ligands to inhibit LCFA uptake into cardiomyocytes treated with the F1F0-ATPase inhibitor oligomycin, because oligomycin treatment is known to

\section{Palmitate Uptake}

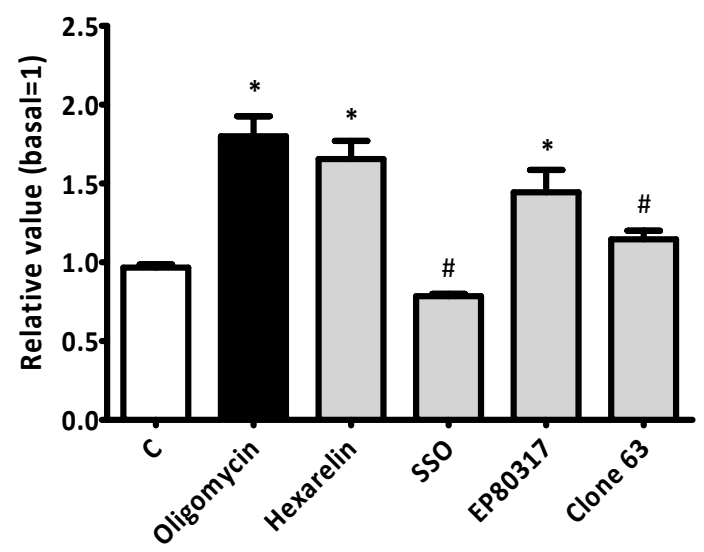

Figure 4.1: The effects of selected CD36 ligands on oligomycinstimulated LCFA uptake into cardiomyocytes. Cardiomyocytes were pre-incubated with CD36 ligands for $20 \mathrm{~min}$. (blank, $20 \mu \mathrm{M}$ hexarelin, $0.5 \mathrm{mM}$ SSO, $100 \mu \mathrm{M}$ EP80317, $0.8 \mu \mathrm{g} / \mathrm{ml}$ Clone 63). Next, oligomycin $(5 \mu \mathrm{M})$ was added for $20 \mathrm{~min}$, followed by (5 min) measurement of uptake of [3H]glucose and [14C]palmitate. Values are displayed as mean +/S.E.M ( $n=5) . *$ vs. control; \# vs. oligomycin $(p<0.05)$. 
Glucose uptake

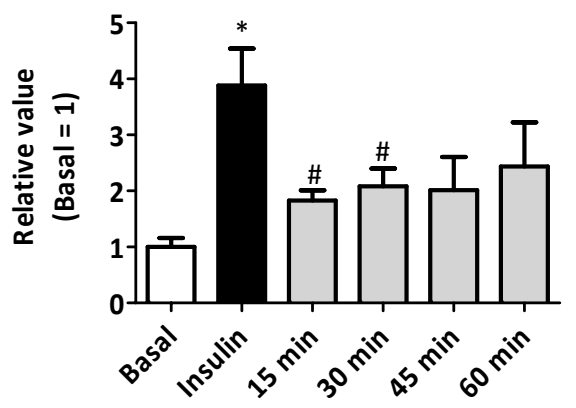

Palmitate uptake

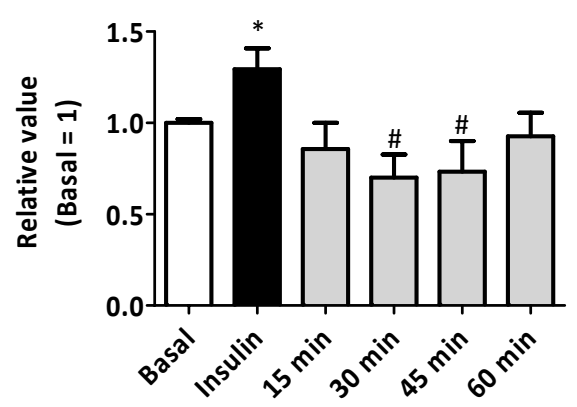

Figure 4.2: Disappearance of acute insulin effects on glucose and palmitate uptake into cardiomyocytes. 90 min after seeding, cardiomyocytes were stimulated with insulin for 15 minutes, and uptake of [3H]glucose and [14C]palmitate was measured directly hereafter, or at indicated time points after insulin removal. Values are displayed as mean +/- S.E.M ( $n=5)$. * vs. basal, \# vs. insulin $(\mathrm{p}<0.05)$.

enhance the contribution of CD36 to total LCFA uptake into rat cardiomyocytes from about $56 \%$ to $>79 \%$ [24]. In agreement with our previous results [20], SSO markedly decreased oligomycin-stimulated LCFA uptake (Fig. 4.1). When added at $100 \mu \mathrm{M}$, the oligopeptides EP80317 and hexarelin were without effect. At higher concentrations, these compounds affected cell viability (data not shown). Clone 63 inhibited oligomycin-stimulated palmitate uptake by 64 \% (Fig. 4.1). Because SSO is unsuited as a long-term blocker of LCFA uptake [20], we selected Clone 63 to chronically inhibit palmitate uptake into primary cardiomyocyte cultures.

\subsection{Short-term insulin effect on substrate uptake disappears after 30 minutes}

To assay insulin-stimulated glucose and LCFA uptake, we treated cardiomyocytes with insulin for 15 min prior to substrate uptake measurements. However, in case of culturing cardiomyocytes in $\mathrm{HI}$ medium for two days, chronic and short-term insulin effects might be present at the same time. To fully appreciate the chronic effects of insulin on Akt phosphorylation and substrate uptake, the short-term effect of insulin must have completely faded out. Therefore, we determined the disappearance time of short-term insulin effects on glucose and, for comparison, on LCFA uptake into basally cultured cardiomyocytes. Cardiomyocytes were stimulated with insulin (100 nM) and directly assayed for substrate uptake or, the stimulus medium containing insulin was washed away and substrate uptake was measured after several time-points (Fig. 4.2). Firstly, insulin significantly increased both glucose and palmitate uptake (Fig. 4.2). Secondly, glucose uptake returned to basal levels after $15 \mathrm{~min}$ and palmitate uptake returned to basal levels after $30 \mathrm{~min}$. Therefore, 
A

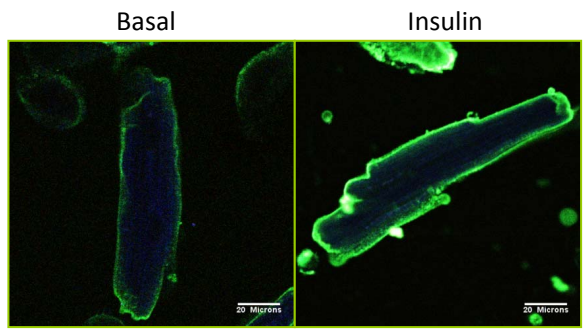

B Control High Insulin High Palmitate

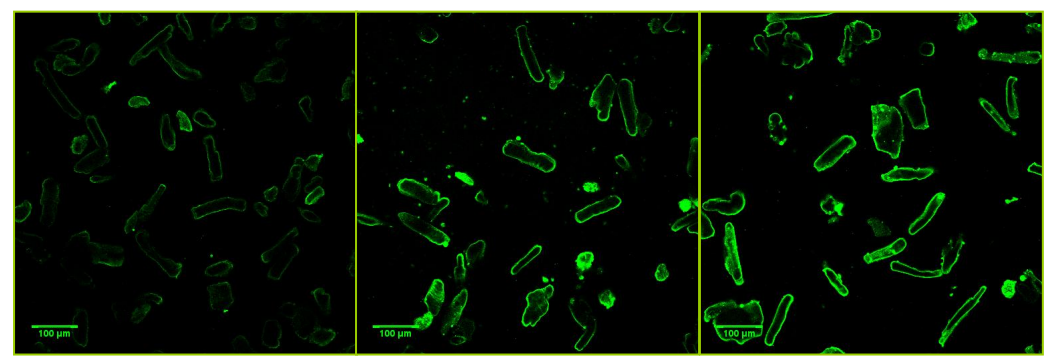

C

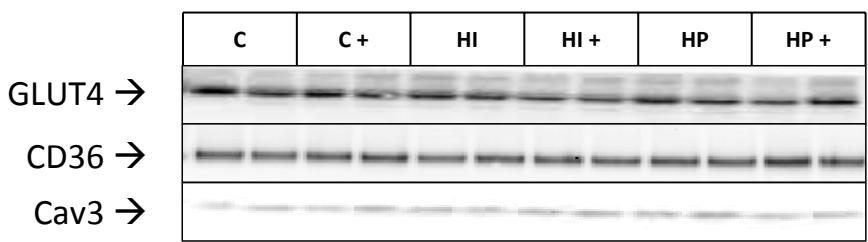

Figure 4.3: Figure 3: Effects of culturing under insulin resistance-inducing conditions on cell surface content and total expression levels of CD36 in cardiomyocytes. (A) For verification of the suitability of 2-photon microscopy to visualize changes in cell surface localization of CD36, cells were shortterm (15 min) treated with $100 \mathrm{nM}$ insulin to positively confirm the well-described insulin-induced CD36 translocation event. CD36 was detected upon FITC labeling (green). Representative images are shown $(n=3)(B)$ Cardiomyocytes were cultured in control medium (C), or in media containing high insulin or high palmitate concentrations for 48 hours, and then used for microscopical detection of CD36. $n=3$. (B). Protein expression of GLUT4 and CD36, and caveolin3 (Cav3; loading control) was measured in cell lysates from cardiomyocytes cultured in control medium (C), high insulin (HI) medium or high palmitate (HP) without or with (+) anti-CD36 monoclonal antibody clone 63 (C). Representative blots are shown $(n=3)$.

for each experiment, after 48 hours of culturing cells were washed, control medium was added to all wells, and we waited for 30 min before starting insulin-sensitivity measurements.

\subsection{Establishment of lipid loaded and insulin resistant cardiomyocytes with decreased contractile activity}

Cardiomyocytes were exposed to HI or HP containing medium to induce myocellular 
insulin resistance. One of the initial steps in acquisition of myocellular insulin resistance is the permanent relocation of CD36 to the sarcolemma [31]. Sarcolemmal CD36 presence was measured in viable cells by two-photon microscopy. First, it was confirmed that this method could be successfully applied in our experimental setting, because short-term (15 $\mathrm{min}$ ) insulin treatment of basally cultured cardiomyocytes promoted the well-recognized increase in CD36 presence at the sarcolemma, which is due to translocation from intracellular stores (Fig. 4.3A). Additionally, $\mathrm{HI}$ and $\mathrm{HP}$ media enhanced sarcolemmal CD36 presence (Fig. 4.3B). However, total (i.e. sum

A

\section{Glucose Uptake}

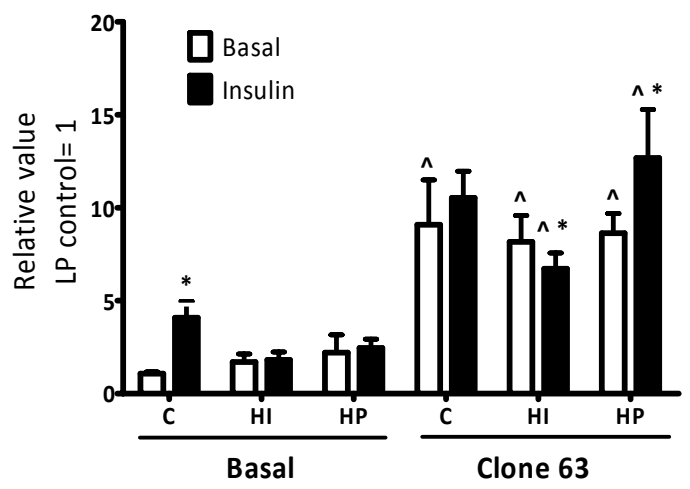

B

Palmitate Uptake

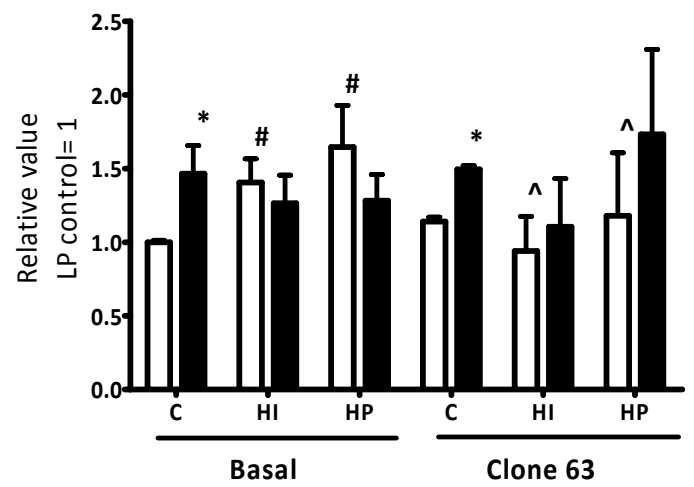

Figure 4.4: Effect of anti-CD36 mAb clone 63 on substrate uptake into cardiomyocytes cultured under insulin resistance-inducing conditions. Cardiomyocytes were cultured in control medium (C), or in media containing high insulin (HI) or high palmitate (HP) concentrations in the absence (Basal) or presence of clone 63. Upon 2 days culturing, cells were washed and after a 30 min waitin period short-term (15 min) insulin (100 nM) effects were measured by uptake of [3H]glucose (A) and [14C]palmitate (B). Values are displayed as mean +/- S.E.M ( $n=5) .{ }^{*}$ insulin effect, \# medium effect, $\wedge$ clone 63 effect $(p<0.05)$. 


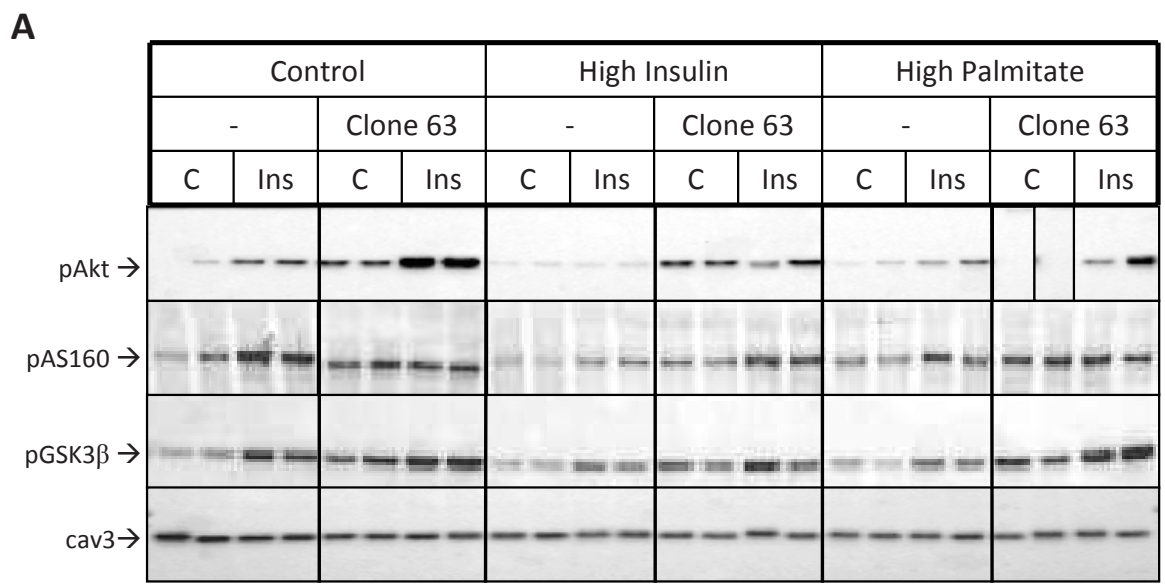

B

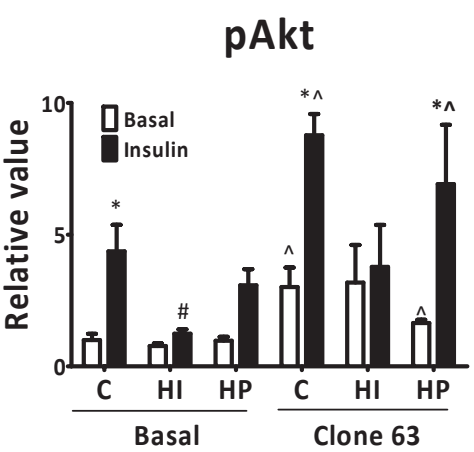

D

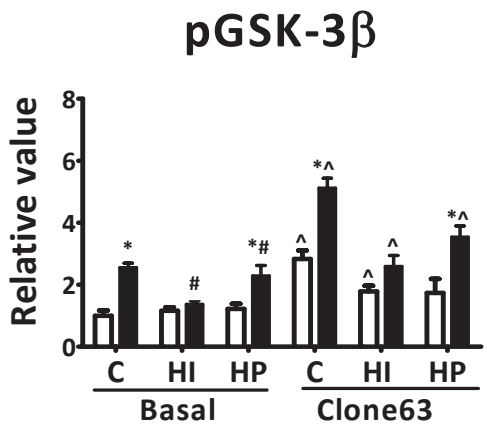

C

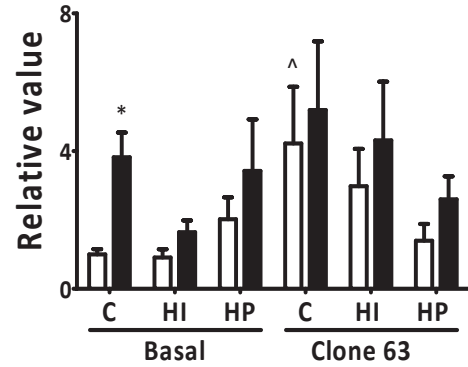

Figure 4.5: Effect of anti-CD36 mAb clone 63 on insulin signaling in cardiomyocytes cultured under insulin resistance-inducing conditions. Cardiomyocytes were cultured in control medium (C), or in media containing high insulin (HI) or high palmitate (HP) concentrations in the absence (Basal) or presence of clone 63. Upon 2 days culturing, cells were washed and after a $30 \mathrm{~min}$ waiting period short-term (15 min) insulin (100 $n M)$ effects were measured by Western analysis of phosphorylation of Akt (pAkt), AS160 (pAS160) and GSK3B (pGSK3B). (A) Representative blots are shown in (A). Quantification of the signals is shown in (B), (C) and (D). Values are displayed as mean +/- S.E.M ( $n=5)$. * insulin effect, \# medium effect, ^ clone 63 effect $(p<0.05)$. 
of intracellular and sarcolemmal) CD36 protein expression was not altered after culturing of cardiomyocytes in HI or HP media (Fig. 4.3C), implicating that upon either of insulin resistance-inducing conditions CD36 is permanently relocated from intracellular stores to the sarcolemma. Additionally, both insulin resistance-inducing media did not alter myocellular GLUT4 expression (Fig. 4.3C).

Basally cultured cardiomyocytes displayed a 3.8-fold increase in glucose uptake and a 1.5-fold increase in palmitate uptake upon insulin treatment. Cardiomyocytes cultured in either $\mathrm{HI}$ or HP medium showed no change in basal glucose uptake (Fig. 4.4A). In contrast, these cardiomyocytes exhibited elevated basal LCFA uptake (amounting to 1.4-fold and 1.6-fold, respectively) compared to basally cultured cells. In addition, cardiomyocytes cultured in either HI or HP media displayed a loss of insulin-stimulated glucose and LCFA uptake (Fig. 4.4B).

For evaluation of insulin signaling, phosphorylation of Akt and its two direct substrates AS160 and GSK3 $\beta$ were assessed. In basally cultured cardiomyocytes, shortterm insulin addition increased Akt-Ser473 phosphorylation, AS160 phosphorylation and GSK3 $\beta$-Ser9 phosphorylation by 4.4 -fold, 3.8-fold and 2.5-fold, respectively (Fig. 4.5B). Insulin-stimulated signaling was completely lost in cardiomyocytes cultured in high insulin medium, and largely reduced in cardiomyocytes cultured in high palmitate medium: only a residual 3.1-fold insulin-stimulation of Akt-Ser473 phosphorylation was observed (Fig. 4.5B), while induction of GSK3 and AS160 was completely abrogated (Fig. 4.5C and Fig. 4.5D).

With respect to myocellular lipid accumulation, cardiomyocytes cultured in high insulin or high palmitate medium displayed increased triacylglycerol (TAG) content

\section{Triacylglycerol}

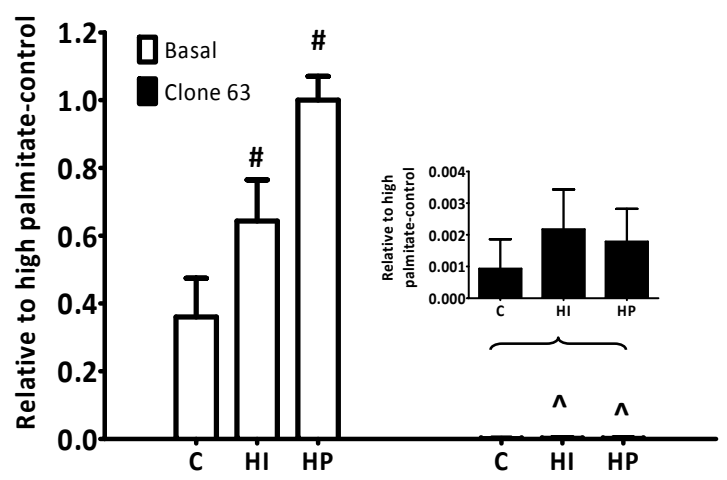

Figure 4.6: Effect of anti-CD36 mAb clone 63 on lipid accumulation in cardiomyocytes cultured under insulin resistance-inducing conditions. Cardiomyocytes were cultured in control medium (C) or in media containing high insulin (HI) or high palmitate (HP) concentrations in the absence (Basal) or presence of anti-CD36 monoclonal antibody clone 63. After 2 days culturing, cardiomyocytes were lysed, and used for measurement of triacylglycerol content via HPTLC. Values are displayed as mean +/S.E.M ( $n=5)$. \# medium effect, $\wedge$ clone 63 effect $(p<0.05)$. 
(2.0-fold, and 4.4-fold, respectively) compared to basally cultured cardiomyocytes (Fig. 4.6). However, we did not observe changes in diacylglycerol stores (data not shown).

To investigate whether exposure to $\mathrm{HI}$ or HP media leads to physiological dysfunction of cardiomyocytes, we analyzed the kinetics and amplitude of the contraction, shortening and relengthening rates, as well as peak sarcomere shortening. Compared to basally cultured cardiomyocytes, peak sarcomere shortening decreased by $38 \%$ and $62 \%$ during culturing in $\mathrm{HI}$ and $\mathrm{HP}$ media, respectively [Fig. 4.7A-B]. Departure velocity and return velocity of contraction were also reduced by culturing in $\mathrm{HI}$ and $\mathrm{HP}$ media (departure velocity: $-45 \%$ and $-62 \%$, respectively, return velocity: $-65 \%$ and $-70 \%$, respectively). Intracellular Ca2+ fluxes (velocity of $\mathrm{Ca} 2+$ increases and decreases, and peak Fura-2 fluorescence signal) were unchanged in cardiomyocytes cultured in either medium (Fig. 4.7D-F).

Thus, cardiomyocytes cultured in $\mathrm{HI}$ or $\mathrm{HP}$ media displayed elevations in sarcolemmal CD36 presence, basal LCFA uptake and myocellular TAG content. In addition, cardiomyocytes cultured in either medium showed loss of insulin-stimulated substrate uptake, insulin signaling and sarcomere shortening, and hence, displayed hallmark features of lipid-induced insulin resistance and contractile dysfunction.

3.4 Effects of anti-CD36 treatment on prevention of lipid accumulation and development of insulin resistance

Anti-CD36 mAb clone 63 was used to evaluate the effects of a blockade of CD36mediated LCFA uptake on prevention of the development of insulin resistance and contractile dysfunction in cardiomyocytes cultured in HI or HP media. Clone 63 was added at the start of the 2 days culturing of cardiomyocytes under basal or insulin resistance-inducing conditions, and was removed prior to the measurements of short-term palmitate and glucose uptake. The lack of an effect of clone 63 on basal and insulin-stimulated palmitate uptake into basally cultured cardiomyocytes (Fig. 4.4) indicates that these anti-CD36 antibodies have effectively been washed away, and that there has been no compensatory upregulation of CD36 (as shown in Fig. 4.1C), but also not of other LCFA transporters. Furthermore, clone 63-treatment increased basal glucose uptake into cardiomyocytes by 8.5 -fold under all three culturing conditions, and short-term insulin treatment did not further stimulate glucose uptake (Fig. 4.4). Notably, clone 63 treatment prevented the increase in basal LCFA uptake in cardiomyocytes cultured in high insulin or high palmitate media. On the other hand, insulin-stimulated LCFA uptake was not fully restored by clone 63 treatment, although there was a trend to increased palmitate uptake upon-short term insulin addition to cardiomyocytes cultured in high palmitate media (1.4-fold, 
A

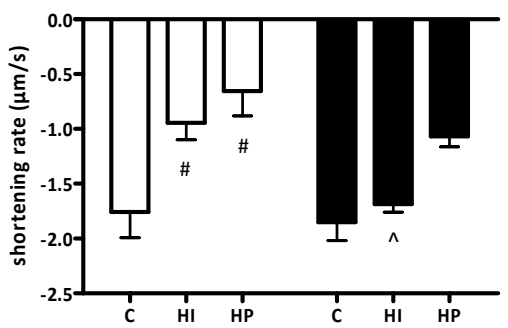

D

B

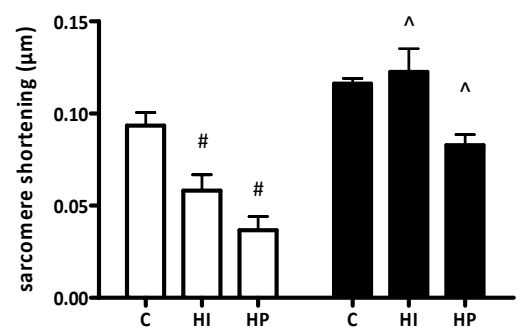

C

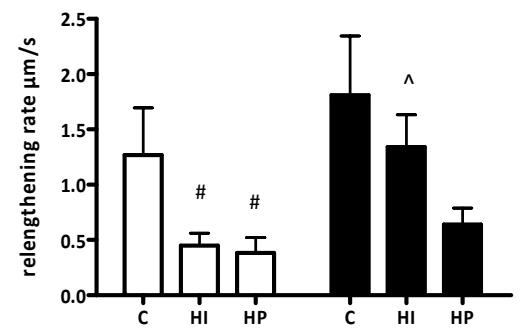

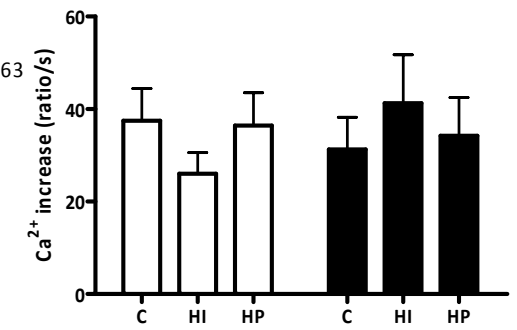

E

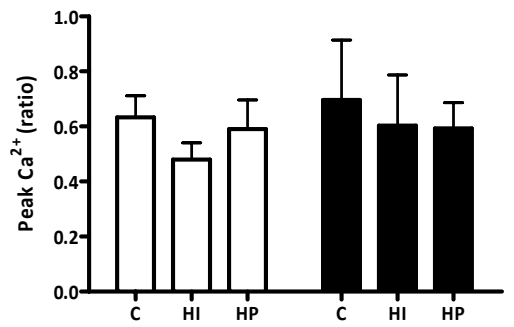

$\mathbf{F}$

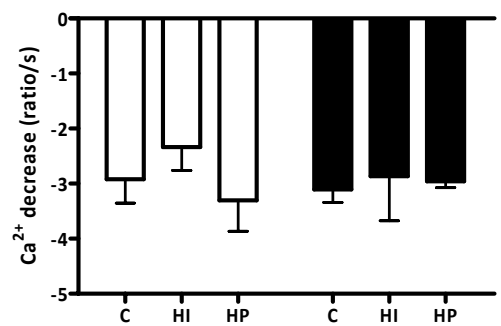

Figure 4.7: Effect of anti-CD36 mAb clone 63 treatment on contractile function of cardiomyocytes cultured under insulin resistance-inducing conditions. Cardiomyocytes were cultured in control medium (C) or in media containing high insulin (HI) or high palmitate (HP) concentrations in the absence (Basal) or presence of anti-CD36 monoclonal antibody clone 63. After 2 days culturing, cardiomyocytes were used for analysis of parameters of sarcomere shortening and Ca2+-fluxes. The following parameters are displayed: $(A)$ departure velocity of contraction; (B) peak sarcomere shortening; (C) return velocity of contraction; (D) velocity of cytosolic Ca2+ increases, (E) peak Fura2 fluorescence signal, and (F) velocity of cytosolic Ca2+ decreases. Values are displayed as mean + /- S.E.M of at least 10 independent experiments. \# medium effect, ^ clone $^{\circ} 3$ effect $(p<0.05)$. 
$\mathrm{p}>0.05)$.

Clone 63 treatment increased basal Akt-Ser473 phosphorylation in all three culturing conditions (basal: 3.0-fold; high insulin medium: 3.2-fold; high palmitate medium: 1.7-fold) (Fig. 5A-B). Clone 63 treatment did not alter insulin-stimulated Akt phosphorylation, and prevented the loss of insulin-stimulated Akt phosphorylation in cardiomyocytes cultured in HP medium. However, clone 63 treatment did not prevent loss of insulin-stimulated Akt phosphorylation in cardiomyocytes cultured in $\mathrm{HI}$ medium. Overall, changes in Akt-Ser473 phosphorylation were largely reflected by changes in GSK3 $\beta$-Ser9 phosphorylation, and to a lesser extent by changes in AS160 phosphorylation.

With respect to intramyocellular lipid accumulation, clone 63 treatment robustly reduced TAG content in cardiomyocytes cultured in control medium, and completely decreased TAG storage in cardiomyocytes cultured in high insulin or high palmitate media (Fig. 4.6).

With respect to parameters of contractile function, clone 63 treatment had no effect on sarcomere shortening in basally cultured cardiomyocytes. Treatment of primary cardiomyocytes with clone 63 totally prevented peak sarcomere shortening upon $\mathrm{HI}$, and partially rescued this contractile parameter in HP cultured cardiomyocytes (Fig 4.7A-C). Additionally, the shortening and relengthening rates were partially retained upon clone 63 treatment of HI-cultured cardiomyocytes. In contrast, intracellular Ca2+ oscillations were not altered by clone 63 treatment (Fig. 4.7).

\section{Discussion}

This is the first study to describe the preventive action of blockade of LCFA uptake in the development of insulin resistance and contractile dysfunction in cardiomyocytes. Although there are many studies reporting on the mechanism by which lipids induce insulin resistance in the development of diabetic cardiomyopathy, none of them have proposed to restore these maladaptive changes by blocking LCFA entry into the heart. In the present study, we investigated the suitability of CD36 as a target to restore insulin sensitivity and contractile parameters in cultures of cardiomyocytes exposed to insulin resistance-inducing conditions. Firstly, a variety of structurally unrelated compounds reported to inhibit CD36 function, were screened for their ability to inhibit LCFA uptake into primary cardiomyocytes. Secondly, we established that cardiomyocytes cultured in HI or HP containing medium displayed key features of lipid-induced insulin resistance [31]. Finally, we demonstrated that inhibition of CD36-mediated LCFA uptake was able to prevent lipid accumulation and 
contractile dysfunction in cardiomyocytes cultured under insulin resistance-inducing conditions.

\subsection{Anti-CD36 mAb potently inhibits LCFA uptake into primary cardiomyocytes}

Sulfo-N-succinimydyl oleate (SSO) is the most widely established inhibitor of CD36mediated LCFA uptake, but its use in long-term incubations is not feasible because of its relatively short half-life [20]. Nonetheless, the use of SSO in short-term LCFA uptake studies confirmed that maximally stimulated LCFA uptake in these primary cardiomyocytes is largely CD36-dependent. The CD36-specific thrombospondinbinding peptide inhibitors hexarelin and EP80317 did not affect LCFA uptake demonstrating that the thrombospondin-binding domain of CD36 is not involved in LCFA transport or does not overlap with the LCFA-binding pocket of CD36 [32, 33]. Hence, both peptides are likely to be unsuited for protection against myocellular lipid-overload. The use of a CD36-specific mAbs proved to be more promising in terms of blocking LCFA uptake. Specifically, anti-CD36 mAb clone 63 treatment inhibited maximally stimulated LCFA uptake by $>30 \%$ (Fig. 4.1). However, frequently used anti-CD36 mAbs, like clone MO25 and clone OKM5 [34], did not appear to affect LCFA uptake. Whereas SSO inhibited LCFA uptake by $>70 \%$ [35] in heart giant sarcolemmal vesicles, both these latter anti-CD36 mAbs were without effect on LCFA uptake in these vesicles (Luiken \& Bonen, 1999, unpublished results). Taken together, clone 63 is a valuable in vitro tool to test whether CD36-mediated LCFA uptake would be a target for offering protection to lipid-overloaded cardiomyocytes against the development of insulin resistance and contractile dysfunction.

\subsection{Development of a cardiomyocyte model as a lipid-induced insulin resistance}

Long-term incubation of cell lines or primary cell cultures with saturated LCFA species has been shown to induce insulin resistance at the level of decreased insulin signaling or decreased insulin-stimulated glucose uptake [36-38]. However, long-term effects on fatty acid transport, transporters and storage have not been investigated yet. Chronic insulin stimulation has also been used to induce insulin resistance in cardiomyocyte cultures [22], but again, LCFA transport and transporters were not measured. In the present study, chronic insulin treatment as well as chronic palmitate treatment of cardiomyocyte cultures enhanced the presence of CD36 at the sarcolemma in concordance with elevated basal LCFA uptake and LCFA accumulation. Simultaneously, insulin-stimulated phosphorylation of proteins involved in the insulin signaling cascade and insulin-stimulated glucose and LCFA uptake were lost or markedly reduced in chronic insulin or palmitate treated cardiomyocytes. These results indicate that both chronic conditions induce key features of insulin resistance in this in vitro cardiomyocyte model. Yet, there are some subtle differences in insulin- 
treated and palmitate-treated cardiomyocytes concerning these features of insulin resistance: lipid accumulation in palmitate-treated cells is 2 -fold greater than in insulin-treated cells, but inhibition of insulin signaling is less extensive in palmitatetreated cells and inhibition of insulin-stimulated substrate uptake is almost identical in both insulin- and palmitate-treated cardiomyocytes. This demonstrates that there is no linear relationship between lipid accumulation and insulin resistance.

With respect to cardiomyocyte contractility, culturing of cardiomyocytes in $\mathrm{HI}$ or HP containing media impaired contractile amplitude. This is in agreement with recent findings that exposure of freshly isolated adult mouse cardiomyocytes to palmitate rapidly reduced unloaded fractional cell shortening [23], and in line with the currently accepted notion that insulin resistance is causal to contractile dysfunction [39]. There is more controversy about the association of insulin resistance with disturbance of Ca2+ dynamics. In our experiments calcium oscillations were unchanged in cultured cells with $\mathrm{HI}$ and $\mathrm{HP}$ containing media. This is in agreement with the lack of changes in kinetics and amplitude of $\mathrm{Ca} 2+$ transients in cardiomyocytes from mice fed a high fat diet [40]. However, cardiomyocytes from insulin resistant sucrose-fed mice and ob/ob mice displayed decreased Ca2+ oscillations [41, 42]. Nonetheless, sarcomere shortening is considered as a better marker of mechanical output for evaluating cardiomyocyte function [43]. Interestingly, the alterations in contractile function were proportional to the amount of myocellular TAG accumulation, because high palmitate-cultured cardiomyocytes showed greater dysfunction and greater TAG accumulation than in high-insulin cultured cells. This supports the concept that myocellular accumulation of lipids is causal to contractile dysfunction.

In conclusion, both $\mathrm{HI}$ and HP containing media provide suitable culturing conditions for inducing insulin resistance and contractile dysfunction in cardiomyocytes via myocellular lipid overload.

4.3 Inhibition of CD36-mediated LCFA uptake prevents reduction of insulin sensitivity and contractile function in lipid-overloaded cardiomyocytes

The main purpose of this study was to prevent the development of lipid-induced insulin resistance and contractile dysfunction by inhibition of CD36-mediated LCFA uptake. Clone 63 treatment of basally cultured cardiomyocytes enhanced basal glucose uptake and insulin did not further stimulate glucose uptake, suggesting that insulin-stimulated glucose uptake contributes to increased basal glucose uptake in CD36-inhibited cardiomyocytes. Chronic inhibition of CD36 induced a substrate switch towards increased glucose utilization. This substrate switch occurred in the absence of changes in GLUT4 expression, suggesting that enhanced sarcolemmal GLUT4 levels might explain the adaptation of the myocytes to low LCFA availability. The increase 
in basal glucose uptake was accompanied by an increase in phosphorylation of Akt and its direct target AS160, thereby relieving the intracellular retention of GLUT4 by AS160. However, in contrast to the loss of insulin-stimulated glucose uptake, insulinstimulated Akt phosphorylation was retained in clone 63-treated cardiomyocytes. Perhaps in clone 63-treated basally cultured cardiomyocytes, GLUT4 is already completely depleted from the intracellular storage compartments, including the insulin-responsive stores, so that extra Akt and AS160-phosphorylation upon insulin addition would be futile in this respect.

How treatment with clone 63 could trigger basal Akt phosphorylation in cardiomyocytes is a matter of speculation. Interestingly, it has been shown that ligand binding to CD36 (thrombospondin, oxidized LDL, LCFA) in platelets or in taste cells alters intracellular signaling via the Src-family of protein tyrosine kinases (Fyn, Lyn, Yes and/or Syk) [16, 44-46]. Ablation of CD36 in mice reduced CD36 signaling to c-Jun-N-terminal kinase (JNK) and subsequent Ser-phosphorylation of the insulinreceptor substrate (IRS), thereby activating downstream insulin signaling and Akt activation under basal conditions [17]. Further research is needed to elucidate the molecular mechanisms behind increased basal Akt phosphorylation in clone 63treated cardiomyocytes.

Clone 63 treatment induced a similar substrate switch towards glucose in cells cultured under insulin resistance-inducing conditions as in basally cultured cardiomyocytes. Again, this was accompanied by increased basal Akt/GSK3 $\beta$ phosphorylation, suggesting a causal relationship between Akt activation and increased glucose uptake. Remarkably, clone 63 treatment prevented the loss of insulin stimulated Akt/GSK3 $\beta$ phosphorylation in cardiomyocytes cultured in HP medium but was not able to retain insulin signaling in cardiomyocytes cultured in $\mathrm{HI}$ medium. We have no explanation for these selective preventive effects of clone 63 on insulin signaling and insulin-stimulated glucose uptake in one model of insulin resistant cardiomyocytes but not in the other. However, we may only conclude that these preventive effects of clone 63 are model-related and not generally applicable to $\mathrm{HI}$ containing medium induced insulin resistant cardiomyocytes.

Nonetheless, the finding that clone 63 prevents the reduction in contractile function in cardiomyocytes cultured under both insulin resistance-inducing conditions provides powerful evidence that CD36 offers a suitable target to prevent the onset of cardiomyocyte dysfunction under these adverse conditions. Possibly, the reduction in TAG might directly explain clone-63-mediated preservation of contractile function. Namely the increased depositioning of lipid droplets in between the contractile fibers could directly inhibit contraction mechanics, which is then prevented by blocking 
CD36-mediated LCFA uptake. However, we cannot exclude the possibility that clone 63 binding to CD36 activates intracellular signaling (e.g., Akt activation) that would directly or indirectly preserve contractile function of cardiomyocytes.

Taken together, increased basal glucose uptake and prevention of lipid accumulation associate with prevention of contractile dysfunction upon clone 63 treatment of cardiomyocytes cultured under both insulin resistance-inducing conditions. Further research is needed to clarify the exact mechanism by which clone 63 treatment prevents deterioration of contraction in cardiomyocytes cultured under insulin resistance-inducing conditions.

\subsection{Conclusion}

In summary, the blockade of CD36-mediated LCFA uptake caused a substrate switch towards glucose and prevented increases in LCFA uptake, lipid accumulation and decreases in contractile function in two in vitro models of lipid-induced cardiac insulin resistance. Increased cardiac glucose uptake is known to be involved in the development of cardiomyocyte hypertrophy, suggesting that proper titration of anti-CD36 treatment is necessary to avoid a total shift of cardiomyocyte metabolism towards glucose utilization.

In addition, it has been speculated that the LCFA binding pocket in the extracellular domain of CD36 is mainly not overlapping with the docking sites of thrombospondin and oxLDL [32]. Therefore the non-overlapping regions of this LCFA binding pockets might be the subject of a novel drug design strategy to specifically block the CD36 transport function.

Altogether, these findings clearly confirm that CD36-mediated LCFA uptake plays a key role in the development of lipid-induced insulin resistance and cardiac dysfunction. Furthermore, in vivo blockade of the transport function of CD36 might provide an attractive therapeutic strategy to prevent the development of diabetic cardiomyopathy in humans.

\section{Acknowledgements}

This work was supported by the Dutch Diabetes Research Foundation (Grant: 2006.00.044), the EU European Cooperation in the field of Scientific and Technical Research (COST) Action BM0602 (Adipose tissue: A key target for prevention of the metabolic syndrome), and CTMM, the Center for Translational Molecular Medicine, project PREDICCt (grant 01C-104), and supported by the Netherlands Heart Foundation, Dutch Diabetes Research Foundation, and Dutch Kidney Foundation. The authors would like to thank Lei Ding, Jurriaan Hodzelmans and Pascal Vroemen for their technical assistance. 


\section{References}

[1] Rodrigues B, Cam MC, McNeill JH. Metabolic disturbances in diabetic cardiomyopathy. Mol Cell Biochem. 1998 Mar; 180(1-2): 53-7.

[2] Stanley WC, Lopaschuk GD, McCormack JG. Regulation of energy substrate metabolism in the diabetic heart. Cardiovasc Res. 1997 Apr; 34(1): 25-33.

[3] Carley AN, Severson DL. Fatty acid metabolism is enhanced in type 2 diabetic hearts. Biochim Biophys Acta. 2005 May 15; 1734(2): 112-26.

[4] Menard SL, Croteau E, Sarrhini O, Gelinas R, Brassard P, Ouellet R, et al. Abnormal in vivo myocardial energy substrate uptake in diet-induced type 2 diabetic cardiomyopathy in rats. Am J Physiol Endocrinol Metab. 2010 May; 298(5): E1049-57.

[5] Tomita T, Wilson L, Chiga M. Idiopathic dilated cardiomyopathy--an evidence of abnormal lipid accumulation accumulation in myocardium. Am J Cardiovasc Pathol. 1990; 3(1): 81-5.

[6] Chavez JA, Knotts TA, Wang LP, Li G, Dobrowsky RT, Florant GL, et al. A role for ceramide, but not diacylglycerol, in the antagonism of insulin signal transduction by saturated fatty acids. J Biol Chem. 2003 Mar 21; 278(12): 10297-303.

[7] Glatz JFC, Luiken JJFP, Bonen A. Membrane fatty acid transporters as regulators of lipid metabolism: implications for metabolic disease. Physiol Rev. 2010 Jan; 90(1): 367-417.

[8] Bonen A, Parolin ML, Steinberg GR, Calles-Escandon J, Tandon NN, Glatz JF, et al. Triacylglycerol accumulation in human obesity and type 2 diabetes is associated with increased rates of skeletal muscle fatty acid transport and increased sarcolemmal FAT/CD36. Faseb J. 2004 Jul; 18(10): 1144-6.

[9] Holloway GP, Benton CR, Mullen KL, Yoshida Y, Snook LA, Han XX, et al. In obese rat muscle transport of palmitate is increased and is channeled to triacylglycerol storage despite an increase in mitochondrial palmitate oxidation. Am J Physiol Endocrinol Metab. 2009 Apr; 296(4): E738-47.

[10] Lopaschuk GD, Ussher JR, Folmes CD, Jaswal JS, Stanley WC. Myocardial fatty acid metabolism in health and disease. Physiol Rev. 2010 Jan; 90(1): 207-58.

[11] Steinbusch LK, Schwenk RW, Ouwens DM, Diamant M, Glatz JF, Luiken JJ. Subcellular trafficking of the substrate transporters GLUT4 and CD36 in cardiomyocytes. Cell Mol Life Sci. 2011 May 6.

[12] Coort SL, Luiken JJ, van der Vusse GJ, Bonen A, Glatz JF. Increased FAT (fatty acid translocase)/ CD36-mediated long-chain fatty acid uptake in cardiac myocytes from obese Zucker rats. Biochem Soc Trans. 2004 Feb; 32(Pt 1): 83-5.

[13] Ouwens DM, Diamant M, Fodor M, Habets DD, Pelsers MM, El Hasnaoui M, et al. Cardiac contractile dysfunction in insulin-resistant rats fed a high-fat diet is associated with elevated CD36-mediated fatty acid uptake and esterification. Diabetologia. 2007 Sep; 50(9): 1938-48.

[14] Steinbusch LK, Luiken JJ, Vlasblom R, Chabowski A, Hoebers NT, Coumans WA, et al. Absence of fatty acid transporter CD36 protects against Western-type diet-related cardiac dysfunction following pressure overload in mice. Am J Physiol Endocrinol Metab. 2011 Jun 28.

[15] Yang J, Sambandam N, Han X, Gross RW, Courtois M, Kovacs A, et al. CD36 deficiency rescues lipotoxic cardiomyopathy. Circ Res. 2007 Apr 27; 100(8): 1208-17.

[16] Collot-Teixeira S, Martin J, McDermott-Roe C, Poston R, McGregor JL. CD36 and macrophages in atherosclerosis. Cardiovasc Res. 2007 Aug 1; 75(3): 468-77.

[17] Kennedy DJ, Kuchibhotla S, Westfall KM, Silverstein RL, Morton RE, Febbraio M. A CD36dependent pathway enhances macrophage and adipose tissue inflammation and impairs insulin signalling. Cardiovasc Res. 2011 Feb 15; 89(3): 604-13.

[18] Sun B, Boyanovsky BB, Connelly MA, Shridas P, van der Westhuyzen DR, Webb NR. Distinct mechanisms for OxLDL uptake and cellular trafficking by class B scavenger receptors CD36 and SR-BI. J Lipid Res. 2007 Dec; 48(12): 2560-70.

[19] Pettersson I, Muccioli G, Granata R, Deghenghi R, Ghigo E, Ohlsson C, et al. Natural (ghrelin) and synthetic (hexarelin) GH secretagogues stimulate H9c2 cardiomyocyte cell proliferation. J Endocrinol. 2002 Oct; 175(1): 201-9.

[20] Coort SL, Willems J, Coumans WA, van der Vusse GJ, Bonen A, Glatz JF, et al. Sulfo-N-succinimidyl 
esters of long chain fatty acids specifically inhibit fatty acid translocase (FAT/CD36)-mediated cellular fatty acid uptake. Mol Cell Biochem. 2002 Oct; 239(1-2): 213-9.

[21] Kusaka Y, Tanaka T, Okamoto F, Terasaki F, Matsunaga Y, Miyazaki H, et al. Effect of sulfo- $\mathrm{N}$ succinimidyl palmitate on the rat heart: myocardial long-chain fatty acid uptake and cardiac hypertrophy. Journal of molecular and cellular cardiology. 1995 Aug; 27(8): 1605-12.

[22] Bertrand L, Ginion A, Beauloye C, Hebert AD, Guigas B, Hue L, et al. AMPK activation restores the stimulation of glucose uptake in an in vitro model of insulin-resistant cardiomyocytes via the activation of protein kinase B. Am J Physiol Heart Circ Physiol. 2006 Jul; 291(1): H239-50.

[23] Haim TE, Wang W, Flagg TP, Tones MA, Bahinski A, Numann RE, et al. Palmitate attenuates myocardial contractility through augmentation of repolarizing Kv currents. Journal of molecular and cellular cardiology. 2010 Feb; 48(2): 395-405.

[24] Luiken JJ, Coort SL, Willems J, Coumans WA, Bonen A, van der Vusse GJ, et al. Contractioninduced fatty acid translocase/CD36 translocation in rat cardiac myocytes is mediated through AMP-activated protein kinase signaling. Diabetes. 2003 Jul; 52(7): 1627-34.

[25] Steinbusch LK, Wijnen W, Schwenk RW, Coumans WA, Hoebers NT, Ouwens DM, et al. Differential regulation of cardiac glucose and fatty acid uptake by endosomal $\mathrm{pH}$ and actin filaments. Am J Physiol Cell Physiol. 2010 Jun; 298(6): C1549-59.

[26] Luiken JJ, van Nieuwenhoven FA, America G, van der Vusse GJ, Glatz JF. Uptake and metabolism of palmitate by isolated cardiac myocytes from adult rats: involvement of sarcolemmal proteins. J Lipid Res. 1997 Apr; 38(4): 745-58.

[27] Schwenk RW, Dirkx E, Coumans WA, Bonen A, Klip A, Glatz JF, et al. Requirement for distinct vesicle-associated membrane proteins in insulin- and AMP-activated protein kinase (AMPK)induced translocation of GLUT4 and CD36 in cultured cardiomyocytes. Diabetologia. 2010 Oct; 53(10): 2209-19.

[28] Bonen A, Luiken JJ, Arumugam Y, Glatz JF, Tandon NN. Acute regulation of fatty acid uptake involves the cellular redistribution of fatty acid translocase. J Biol Chem. 2000 May 12; 275(19): 14501-8.

[29] Greulich S, De Wiza DH, Preilowksi S, Ding Z, Mueller H, Langin D, et al. Secretory products of guinea pig epicardial fat induce insulin resistance and impair primary adult rat cardiomyocyte function. J Cell Mol Med. 2011 Dec 9.

[30] Alkhateeb H, Chabowski A, Glatz JF, Luiken JF, Bonen A. Two phases of palmitate-induced insulin resistance in skeletal muscle: impaired GLUT4 translocation is followed by a reduced GLUT4 intrinsic activity. Am J Physiol Endocrinol Metab. 2007 Sep; 293(3): E783-93.

[31] Coort SL, Bonen A, van der Vusse GJ, Glatz JF, Luiken JJ. Cardiac substrate uptake and metabolism in obesity and type-2 diabetes: role of sarcolemmal substrate transporters. Mol Cell Biochem. 2007 May; 299(1-2): 5-18.

[32] Silverstein RL, Febbraio M. CD36, a scavenger receptor involved in immunity, metabolism, angiogenesis, and behavior. Sci Signal. 2009; 2(72): re3.

[33] Nergiz-Unal R, Rademakers T, Cosemans JM, Heemskerk JW. CD36 as a multiple-ligand signaling receptor in atherothrombosis. Cardiovasc Hematol Agents Med Chem. 2011 Jan; 9(1): 42-55.

[34] Yamamoto N, Ikeda H, Tandon NN, Herman J, Tomiyama Y, Mitani T, et al. A platelet membrane glycoprotein (GP) deficiency in healthy blood donors: Naka- platelets lack detectable GPIV (CD36). Blood. 1990 Nov 1; 76(9): 1698-703.

[35] Luiken JJ, Turcotte LP, Bonen A. Protein-mediated palmitate uptake and expression of fatty acid transport proteins in heart giant vesicles. J Lipid Res. 1999 Jun; 40(6): 1007-16.

[36] Dimopoulos N, Watson M, Sakamoto K, Hundal HS. Differential effects of palmitate and palmitoleate on insulin action and glucose utilization in rat $\mathrm{L} 6$ skeletal muscle cells. Biochem J. 2006 Nov 1; 399(3): 473-81.

[37] Pickersgill L, Litherland GJ, Greenberg AS, Walker M, Yeaman SJ. Key role for ceramides in mediating insulin resistance in human muscle cells. J Biol Chem. 2007 Apr 27; 282(17): 125839.

[38] Ragheb R, Shanab GM, Medhat AM, Seoudi DM, Adeli K, Fantus IG. Free fatty acid-induced muscle insulin resistance and glucose uptake dysfunction: evidence for PKC activation and oxidative stress-activated signaling pathways. Biochem Biophys Res Commun. 2009 Nov 13; 
389(2): 211-6.

[39] Ren J, Porter JE, Wold LE, Aberle NS, Muralikrishnan D, Haselton JR. Depressed contractile function and adrenergic responsiveness of cardiac myocytes in an experimental model of Parkinson disease, the MPTP-treated mouse. Neurobiol Aging. 2004 Jan; 25(1): 131-8.

[40] Howarth FC, Qureshi MA, Gbewonyo AJ, Tariq S, Adeghate E. The progressive effects of a fat enriched diet on ventricular myocyte contraction and intracellular $\mathrm{Ca} 2+$ in the $\mathrm{C57BL} / 6 \mathrm{~J}$ mouse. Mol Cell Biochem. 2005 May; 273(1-2): 87-95.

[41] Fauconnier J, Lanner JT, Zhang SJ, Tavi P, Bruton JD, Katz A, et al. Insulin and inositol 1,4,5trisphosphate trigger abnormal cytosolic $\mathrm{Ca} 2+$ transients and reveal mitochondrial $\mathrm{Ca} 2+$ handling defects in cardiomyocytes of ob/ob mice. Diabetes. 2005 Aug; 54(8): 2375-81.

[42] Dong F, Fang CX, Yang X, Zhang X, Lopez FL, Ren J. Cardiac overexpression of catalase rescues cardiac contractile dysfunction induced by insulin resistance: Role of oxidative stress, protein carbonyl formation and insulin sensitivity. Diabetologia. 2006 Jun; 49(6): 1421-33.

[43] McDonald KS. The interdependence of $\mathrm{Ca} 2+$ activation, sarcomere length, and power output in the heart. Pflugers Arch. $2011 \mathrm{Jul} ;$ 462(1): 61-7.

[44] Huang MM, Bolen JB, Barnwell JW, Shattil SJ, Brugge JS. Membrane glycoprotein IV (CD36) is physically associated with the Fyn, Lyn, and Yes protein-tyrosine kinases in human platelets. Proc Natl Acad Sci U S A. 1991 Sep 1; 88(17): 7844-8.

[45] Nergiz-Unal R, Lamers MM, van Kruchten R, Luiken JJ, Cosemans JM, Glatz JF, et al. Signaling role of CD36 in platelet activation and thrombus formation on immobilized thrombospondin or oxidized LDL. J Thromb Haemost. 2011 Jun 22.

[46] El-Yassimi A, Hichami A, Besnard P, Khan NA. Linoleic acid induces calcium signaling, Src kinase phosphorylation, and neurotransmitter release in mouse CD36-positive gustatory cells. J Biol Chem. 2008 May 9; 283(19): 12949-59. 


\section{Chapter 5}

\section{Overexpression of AMP-activated protein kinase or Protein Kinase D independently prevent lipid-induced insulin resistance in cardiomyocytes}

Laura K.M. Steinbusch ${ }^{1 *}$, Ellen Dirkx ${ }^{1^{*}}$, Nicole T.H. Hoebers ${ }^{1}$, Yeliz Angin ${ }^{1}$, Veronique Roelants ${ }^{2}$, Benoit Viollet ${ }^{3}$, Michaela Diamant ${ }^{5}$, Guillaume van Eys ${ }^{1}$, D. Margriet Ouwens ${ }^{6}$, Luc Bertrand ${ }^{2}$, Jan F.C. Glatz ${ }^{1}$, Joost J.F.P. Luiken ${ }^{1}$.

1CARIM, Maastricht University, Maastricht, NL,

2 Université catholique de Louvain, Institut de Recherche Expérimentale et Clinique, Pole of Cardiovascular Research, Brussels, Belgium.

3Pasteur Institute, CNRS, UMR8104, Univ Paris Descartes, Paris, France.

5Diabetes Center, VU University Medical Center, Amsterdam, Netherlands.

6German Diabetes Centre, Düsseldorf, Germany.

${ }^{*}$ These authors contributed equally

In preparation 


\begin{abstract}
During lipid oversupply, the heart becomes insulin resistant, as exemplified by defective insulin-stimulated glucose uptake, and will develop diastolic dysfunction. In the healthy heart, not only insulin but also increased contractile activity stimulate glucose uptake. Upon increased contraction both AMP-activated protein kinase (AMPK) and protein kinase D (PKD) are activated, and independently mediate the stimulation of glucose uptake into cardiomyocytes. Therefore, each of these kinases are potential therapeutic targets in the diabetic heart because they may serve to bypass defective insulin-stimulated glucose uptake.

To test the preventive potential of these kinases against loss of insulin-stimulated glucose uptake, AMPK or PKD each were adenovirally overexpressed in primary cultures of insulin resistant cardiomyocytes, and substrate uptake, insulin sensitivity and lipid accumulation were measured. To induce insulin resistance and lipid loading, rat primary cardiomyocytes were cultured in the presence of high insulin (100 nM; HI) or high palmitate (palmitate/BSA: 3/1; HP). HI and HP each reduced insulin sensitivity, and increased basal palmitate uptake and lipid storage. Overexpression of each of the kinases prevented loss of insulin-stimulated glucose uptake in both $\mathrm{HI}$ and HP cultured cardiomyocytes. Interestingly, overexpression of AMPK prevented loss of insulin signaling, but did not prevent lipid accumulation. In contrast, overexpression of PKD prevented lipid accumulation, but not loss of insulin signaling.

In conclusion, AMPK and PKD each prevent loss of insulin-stimulated glucose uptake into cardiomyocytes cultured under insulin resistance-inducing conditions but through different mechanisms.
\end{abstract}




\section{Introduction}

The insulin resistant heart is characterized by impaired cardiac function and altered substrate preference towards increased long chain fatty acid (LCFA) utilization at the expense of glucose [1]. The greater influx of LCFA exceeds the mitochondrial $\beta$-oxidative capacity [2]. This mismatch between LCFA uptake and oxidation results in the gradual intramyocellular build-up of triacylglycerols (TG) and various LCFA metabolites, leading to decreased insulin signaling and insulin-stimulated glucose uptake [3]. Over time, both lipid accumulation and insulin resistance contribute to altered energy metabolism and remodeling of the heart, which eventually, in the presence of cardiac stress such as ischemia, may lead to heart failure [4]. Strategies that stimulate glucose uptake, or reduce LCFA uptake, independent of insulin signaling, may normalize substrate uptake in the insulin resistant heart, and thereby protect against loss of contractile function $[5,6]$.

In the healthy heart, glucose and LCFA uptake are mainly regulated by reversible glucose transporter 4 (GLUT4) and fatty acid transporter CD36 translocation between intracellular storage compartments and the sarcolemma [1, 7]. Insulin, as well as increased contractile activity, independently stimulate glucose uptake into cardiomyocytes [8]. Since insulin signaling is blunted in the insulin resistant heart, recent research has focused on activation of contraction-induced signaling for stimulation of glucose uptake [9].

It is well documented that during contraction-induced signaling AMP-activated protein kinase (AMPK) is activated [9]. Activation of AMPK occurs through phosphorylation by upstream kinases, such as LKB1, in combination with binding of AMP to one of the regulatory subunits [9]. In mice overexpressing a dominantnegative mutant of AMPK $\alpha$, it has been demonstrated that AMPK is necessary for contraction-induced glucose and LCFA uptake [10]. Several AMPK-activating agents, such as the biguanide metformin and resveratrol, currently serve as blood-glucose lowering agents [11]. Although metformin improved glycemic control, it did not improve cardiac function in type 2 diabetes patients [12]. Activation of AMPK by resveratrol was shown to improve health and survival when given to mice on a highcaloric diet $[13,14]$.

Recently, we showed that also protein kinase $D(P K D)$ is contraction activated and stimulates glucose uptake in rat cardiomyocytes [15]. PKD catalytic activity becomes apparent by its autophosphorylation at Ser916 [16]. Pharmacological inhibition of PKD activity did not affect AMPK-Thr172-phosphorylation but reduced glucose uptake to basal levels [15]. In addition, it was shown that contraction-activated PKD does not affect LCFA uptake into cardiomyocytes (E. Dirkx, unpublished data). This 
makes PKD a new player in the regulation of cardiac metabolism with a different action independent of AMPK.

Because both AMPK and PKD mediate contraction-stimulated glucose uptake, both kinases are potential targets to restore glucose uptake in the insulin-resistant heart. How, and if, AMPK and PKD can restore cardiac lipid loading and insulin resistance, is not known yet. Based on their different involvement in glucose and fatty acid uptake, we propose that AMPK and PKD differently prevent development of insulin resistance and lipotoxicity. Therefore, cardiomyocytes were cultured under lipid overloading and insulin resistance-inducing conditions, and then subjected to adenoviral overexpression of AMPK or PKD.

\section{Materials and Methods}

\subsection{Materials}

Palmitic acid and $\left[{ }^{3} \mathrm{H}\right]$ deoxyglucose were obtained from GE Healthcare (Little Chalfont, UK). Laminin and insulin were purchased from Sigma (Saint Louis, USA). Bovine serum albumin (BSA) (fraction V), dependent on the application, was derived from MP Biomedicals (Irvine, USA) (for cell isolation and incubation purposes), or from Sigma (other purposes). Collagenase type II was from Worthington (Freehold, USA).

\subsection{Experimental animals}

Male Lewis rats, 200-250 gram, were purchased from Charles River laboratories and used for cardiomyocyte isolation. All animals were fed ad libitum. All procedures were approved by the Experimental Animal Committee of Maastricht University, NL.

\subsection{Cardiomyocyte isolation}

Cardiomyocyte isolations were performed as described previously [25] with the only difference being the sterile conditions that were taken into account for subsequent culturing.

\subsection{Adenovirus amplification}

Control adenovirus containing enhanced green fluorescent protein (GFP) (AdC), a recombinant adenovirus encoding a truncated form of AMPK $\alpha 2$ (AMPK $\alpha 2$ 1-312) and GFP (AdAMPK) [19, 20], and a recombinant adenovirus encoding full-length wild-type mouse PKD1 and EGFP (AdPKD) [21] were used. Adenoviruses were amplified amplified in $\mathrm{HEK} 293$ cells and purified over $\mathrm{CsCl}_{2}$ gradients as previously described by Luo et al. [22]. Optimal multiplicity of infection (MOI) was determined by fluorescence microscopy and western blotting for downstream targets of both AMPK and PKD (Suppl. Fig. 5.1-5.2). MOI 40 was chosen for AdAMPK and MOI 10 was chosen for AdPKD.

\subsection{Culturing of rat cardiomyocytes}

After isolation of cardiomyocytes, 200,000 cells/well were routinely seeded in laminin coated 6-well plates $(9.6 \mathrm{~cm} 2)$, unless otherwise specified. After $90 \mathrm{~min}$ adhesion in modified Krebs-Ringer medium [26] supplemented with $0.45 \% \mathrm{BSA}$, the adhesion medium was replaced with control medium (based on M199 supplemented with $5 \mathrm{mM}$ creatine monohydrate, $3.2 \mathrm{mM}$ carnitine hydrochloride, $3.1 \mathrm{mM}$ taurine, $100 \mathrm{U} / \mathrm{ml}$ penicillin and streptomycin, $20 \mu \mathrm{M}$ palmitate (palmitate:BSA 0.3:1)) $\mathrm{HI}$ medium (control medium supplemented with $100 \mathrm{nM}$ insulin) or HP medium (control medium with more palmitate; 200 $\mu \mathrm{M}$, palmitate:BSA 3:1). At that same moment, primary rat cardiomyocytes were infected with AdC, AdAMPK, or AdPKD. Cardiomyocytes were cultured for 48 hours because of optimal combination of MOI and transfection time (Suppl. Fig. 5.1-5.2) and in case of measurements of short-term insulin effects cardiomyocytes were washed with modified Krebs-Ringer supplemented with $0.45 \% \mathrm{BSA}$ and $1 \mathrm{mM}$ $\mathrm{CaCl} 2$ (medium A) and left untreated for 30 minutes (see chapter 4 for detailed description of wash/wait 
procedure).

\subsection{Measurement of substrate uptake}

Uptake of $\left[1-{ }^{14} \mathrm{C}\right]$ palmitate (in complex with BSA) and $\left[{ }^{3} \mathrm{H}\right]$ deoxyglucose into cardiac myocytes was measured as previously described for cardiomyocytes in culture [25]. A mixture of [3H]glucose and [14C]palmitate was added for 10 min directly following a 15 min incubation period with/without insulin

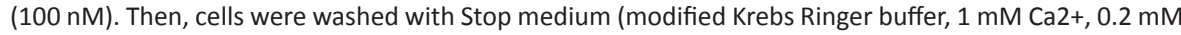
phloretin) on ice, lysed in sample buffer (40\% glycerol, 0.25 M Tris, 1 M DTT, 20\% mercaptoethanol) and radioactivity was measured in scintillation fluid (Opti-Fluor, Perkin Elmer, Waltham, USA).

\subsection{Triacylglycerol stores}

For measurement of intramyocellylar lipid content, cardiomyocytes were cultured in $78.55 \mathrm{~cm} 2$ glass petridishes with 1 × 106 cell density. Intramyocellular lipids were determined after 2 days of culturing as described previously [30]. In short, samples containing $400 \mu \mathrm{g}$ of protein were used for intracellular lipid extraction in methanol/chloroform, and an internal standard and water were added. Afterwards thin-layer chromatography was used to separate lipids. Bands were resolved with a hexane/diethylether/ propanol (87:10:3) resolving solution and triacylglycerol bands were detected with a Molecular Imager (ChemiDoc XRS, BioRad) and analyzed with Quantity One ${ }^{\circledR}$ (BioRad).

\subsection{Detection of protein amounts and phosphorylation of enzymes within the insulin signaling network}

Following a 15 min treatment with/without insulin (100 nM), cells were lysed in sample buffer (40\% glycerol, 0.25 M Tris, 1 M DTT, 20\% mercaptoethanol, bromo-phenol-blue) and used for protein detection by SDS-polyacrylamide gel electrophoresis (20 $\mu \mathrm{g}$ protein per lane), followed by Western blotting, as previously described [28]. Primary antibodies against phospho-Ser473-Akt, Akt, phospho-Thr172-AMPK and phospho-Ser22/23-Tnl from Cell Signaling (Danvers, MA), CD36 from GenTex Inc. (San Antonio, TX, USA), GLUT4 from Abcam (Cambridge, USA), phospho-Ser79-ACC from Upstate and caveolin3 from BD Transduction laboratories. Western blot images were analyzed with a Molecular Imager (ChemiDoc XRS, BioRad) and quantified with Quantity One ${ }^{\circledR}$ (BioRad).

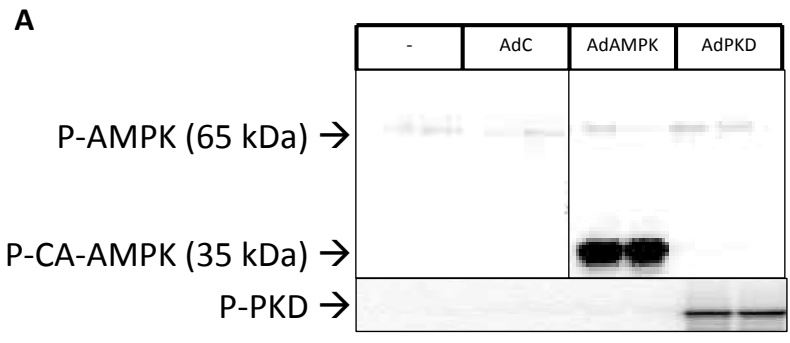

B

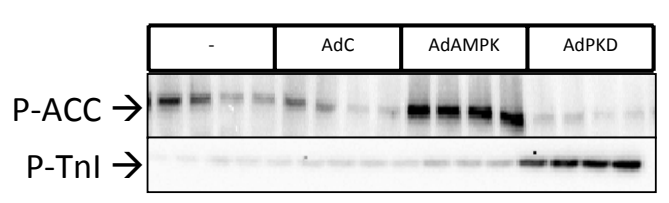

Figure 5.1: Western blot images of cultured primary rat cardiomyocytes transfected with adenovirus containing GFP ( $\mathrm{AdC}$ ), constitutively active AMP-activated protein kinase (AMPK) and protein kinase $D$ (PKD). (A) The truncated form of AMPK is present at $35 \mathrm{kDa}$, whereas endogenous $\mathrm{p}$-AMPK appears at its normal weight. PKD is only phosphorylated at Serine916 upon overexpression of AdPKD. (B) The downstream target of AMPK acyl-CoA carboxylase (ACC) was considerably stonger phosphorylated in cells transfected with AdAMPK. The downstream target of PKD troponinI (TnI) was only phosphorylated in cells transfected with AdPKD. 


\subsection{Statistics}

Differences among the data obtained from five to eight experiments are presented as means \pm S.E.M . Statistical difference between groups of observations was evaluated by unpaired Student's t-test, oneWay ANOVA or 2-Way ANOVA, depending on the groups compared. P values equal to or less than 0.05 were considered significant.

\section{Results and Discussion}

To test the putative preventive effect of AMPK or PKD activation in the lipid overloaded insulin resistant heart, rat primary cardiomyocytes were exposed to a high concentration of insulin ( $\mathrm{HI}$ medium) or to a high concentration of palmitate (HP medium) so as to induce lipotoxicity and insulin resistance by two different means. First, it was assessed how AdAMPK and AdPKD affect substrate uptake, insulin-sensitivity and lipid content in insulin sensitive cardiomyocytes.

3.1 Effect of AMPK or PKD overexpression on substrate uptake, insulin sensitivity and lipid storage in control cells

Cardiomyocytes were cultured for $48 \mathrm{~h}$ because of optimal combination of $\mathrm{MOI}$ and transfection time (Suppl. Fig. 5.1-5.2). Western blotting showed that no crossreactivity was present between AdAMPK and AdPKD (Fig. 5.1A-B). Overexpression of AMPK potently increased phosphorylation of its main subcellular target acetyl CoA carboxylase (ACC), but did not affect phosphorylation of the downstream substrate of PKD, troponin I (Tnl). Overexpression of PKD potently increased Tnl phosphorylation, but did not affect downstream signaling of AMPK ACC (Fig. 5.1B). This indicates that both kinases were successfully overexpressed in our cardiomyocyte cultures, and furthermore, confirms earlier findings that PKD and AMPK function independently [15].

Cardiomyocytes cultured for $48 \mathrm{~h}$ in control medium, and transduced with control adenovirus, displayed insulin-stimulated glucose (1.8-fold) and palmitate uptake (1.5-fold (Figures 5.2A-B), to a similar extent as previous short-term substrate uptake studies with suspensions of freshly isolated cardiomyocytes [29]. These results indicate that insulin sensitivity was maintained.

In line with previous work [10, 15], overexpression of either AMPK or PKD increased basal glucose uptake (Fig. 5.2A) (2.3-fold and 3.3-fold, respectively). The insulin-stimulated component of glucose uptake was retained upon overexpression of either kinase (Fig. 5.2A). AdAMPK, but not AdPKD, significantly increased basal palmitate uptake into cardiomyocytes, in agreement with earlier findings that AMPK is dedicated to both LCFA and glucose uptake, and that PKD is selective for glucose uptake [10,15] (Fig. 5.2B). However, the effect of insulin-stimulation on palmitate uptake was not reaching significance in AdAMPK and AdPKD-treated 
cells. This likely is an experimental limitation of palmitate uptake measurements in cultures of cardiomyocytes; in long-term cultures palmitate uptake rates are lower in comparison to freshly isolated cardiomyocyte suspensions, so that it is difficult to establish a moderate effect on top of another moderate effect. None of the alterations in substrate uptake can be ascribed to changes in protein presence of substrate transporters (data not shown), implicating that AdAMPK and AdPKD are likely to exert their relative effects on substrate uptake through translocation of these transporters rather than their expression. Hence, AdAMPK will induce both GLUT4 and CD36 translocation, and AdPKD solely GLUT4 translocation.

A

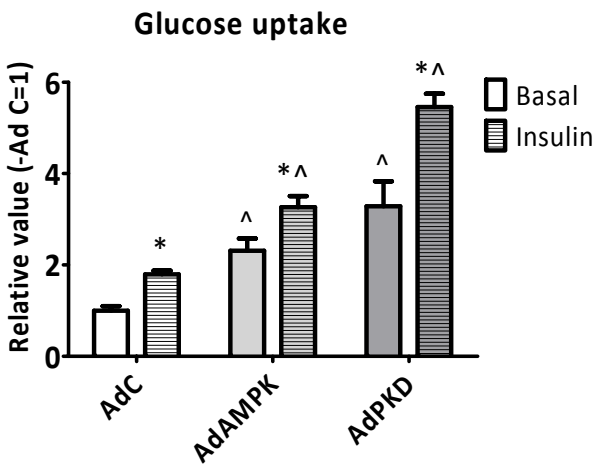

C

Phospho-Ser473-Akt

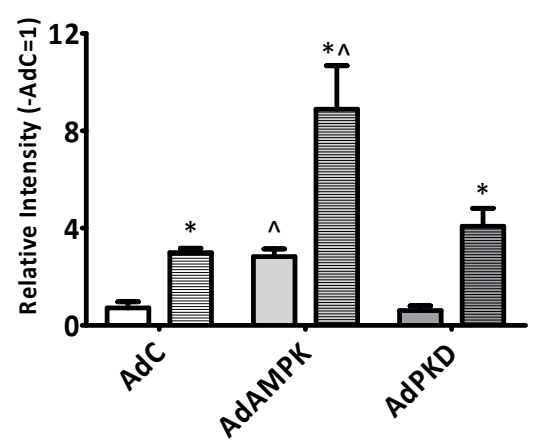

B

Palmitate uptake

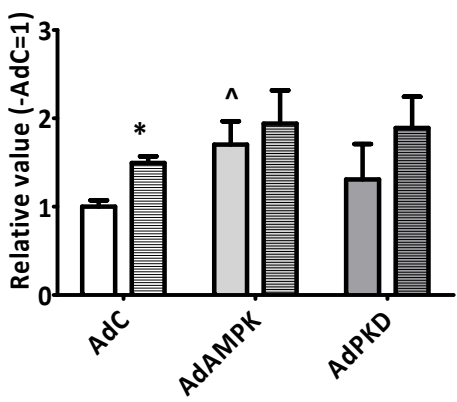

D

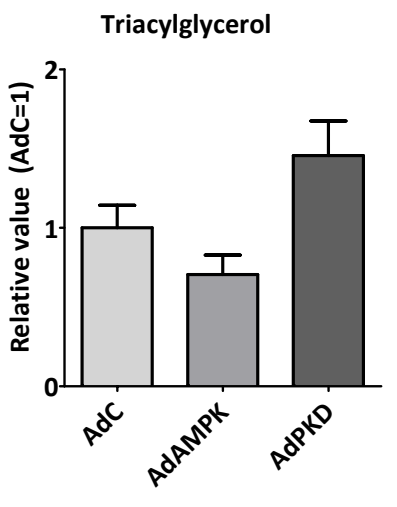

Figure 5.2: Effect of overexpression of adenoviral (Ad) constitutively active AMP-activated protein kinase (AMPK) or protein kinase $D$ (PKD) on metabolic parameters in cultured primary rat cardiomyocytes. (A) Glucose and (B) palmitate uptake measured by uptake of radioactive labelled substrates, basal (open bars) and insulin-stimulated (striped bars). (C-D) Akt-Ser473 and GSK3 $\beta$-Ser9 phosphorylation measured by western blotting, (E) triacylglycerol stores measured by HPTLC. Statistical analysis was done by One-Way with Bonferroni post-tests and Student t-test, * Insulin effect $p<0.05, \wedge$ adenovirus effect $p<0.05$. 
To examine insulin sensitivity at the level of the insulin-signaling cascade we measured insulin-stimulated Akt phosphorylation. Transducing cardiomyocytes with AdAMPK significantly increased basal and insulin-stimulated Akt phosphorylation (3.9 and 3.0-fold, respectively), which is in line with previous results from experiments with cardiomyocyte suspensions [30](Fig. 5.2C). In contrast, AdPKD was without an effect (Figure 5.2C-D). These changes in insulin-stimulated Akt phosphorylation could not be ascribed to alterations in total Akt protein presence (Suppl. Fig. 5.35.4). Similar AMPK-mediated effects on Akt phosphorylation have been obtained previously by using AMPK activators like metformin, phenformin or oligomycin [31,
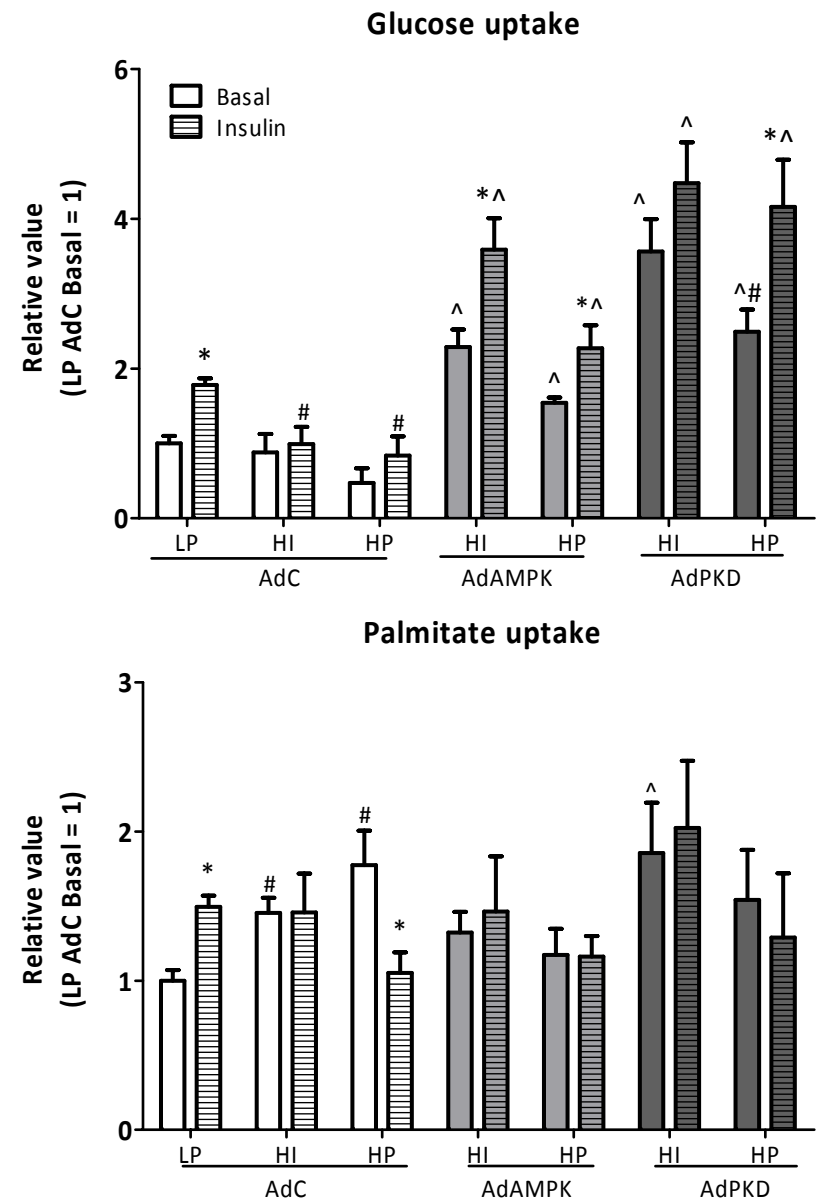

Figure 5.3: Glucose and palmitate uptake into rat primary cardiomyocytes cultured in control/low palmitate (LP), high insulin (HI) or high palmitate (HP) medium without or with the presence of adenovirus (Ad) containing constitutively active AMP-activated protein kinase (AMPK) or protein kinase D (PKD). Statistical analysis was done by One-Way ANOVA with Bonferroni post-tests and student $\mathrm{t}$-test, ${ }^{*}$ Insulin effect $\mathrm{p}<0.05, \wedge$ adenovirus effect $\mathrm{p}<0.05$, \# medium effect $\mathrm{p}<0.05$. 
32]. Transducing cardiomyocytes with control, AMPK or PKD adenoviruses did not significantly alter intramyocardial TG content (Fig. 5.2E) in normal insulin sensitive cardiomyocytes when there is only limited lipid storage.

Altogether these results show that AdAMPK and AdPKD each enhance glucose uptake into cardiomyocytes. In addition, AdAMPK, but not AdPKD, enhances LCFA uptake and Akt phosphorylation.

3.2 Effects of high insulin and high palmitate on substrate uptake, insulin sensitivity and lipid storage

For inducing myocellular insulin resistance, cardiomyocytes were exposed to a high insulin (HI) or a high palmitate (HP)-containing medium. HI or HP-medium-cultured cardiomyocytes showed no change in basal glucose uptake (Fig. 5.3A). However, they did show an increase in basal palmitate uptake (amounting to 1.5-fold and 1.8fold, respectively; Fig. 5.3B). In agreement with previous works [31, 32], HI-medium blocked insulin-stimulated glucose uptake entirely. Insulin-stimulated glucose uptake was also abrogated in cardiomyocytes cultured in HP-medium (Fig. 5.3). In addition, insulin-stimulated palmitate uptake was lost in HI- en HP-medium-cultured cardiomyocytes (Fig. 5.3).

With respect to insulin signaling, insulin-stimulated Akt phosphorylation was completely lost in HI-medium-cultured cardiomyocytes, and markedly reduced (by $42 \%, \mathrm{P}<0.05)$ in HP-medium-cultured cardiomyocytes cultured in high palmitate medium (Fig. 5.4). Both HI- and HP-media increased TG stores 1.9-fold and 2.9-fold, respectively (Fig. 5.5).

Taken together, both HI- and HP-media induce lipid accumulation and reduce insulin sensitivity in cardiomyocytes. A key underlying mechanism is the permanent relocation of the fattyacid transporterCD36from intracellularstores to the sarcolemma (Angin and Steinbusch et al., unpublished data), which causes chronically elevated basal LCFA uptake. The surplus of incoming LCFA will enhance their deposition into TGs and other LCFA metabolites leading to inhibition of insulin signaling downstream of the insulin-receptor substrate and, consequently, to inhibition of insulin-induced glucose and LCFA uptake, according to the lipid-induced insulin resistance theory of Shulman [33]. Hence, $\mathrm{HI}$ and HP-medium-cultured cardiomyocytes prove to be models for lipid overloaded insulin resistant cardiomyocytes.

3.3 Does AMPK overexpression prevent lipid accumulation and insulin resistance in cardiomyocytes cultured under insulin resistance-inducing conditions?

AdAMPK not only enhanced basal glucose uptake in both HI and HP-medium-cultured 
cardiomyocytes, but also prevented the loss in insulin-induced glucose uptake into cardiomyocytes cultured under both insulin resistance-inducing conditions (Fig. 5.3). However, AdAMPK did not decrease the elevated basal palmitate uptake in cells cultured in either experimental medium, nor was it able to retain the insulinstimulated component of palmitate uptake (Fig. 5.3B). It is not known yet why AdAMPK prevents the HP/HI-induced loss of insulin-stimulated glucose uptake but not that of insulin-stimulated LCFA uptake. However, it is known that in normal insulin-sensitive cardiomyocytes different subcellular components (e.g., soluble NSF attachment protein receptor (SNARE) proteins, and cytoskeletal actin, see [25, 34]) are involved in insulin-stimulated glucose versus LCFA uptake. For example, a recent study showed that berberine, an AMPK activator, was also able to enhance insulin-stimulated GLUT4 translocation and glucose uptake in insulin resistant cells by improvement of insulin-induced actin reorganization [35]. These studies suggest that subcellular trafficking components are involved in the regulation of cardiomyocyte metabolism and are able to discriminate between glucose and fatty acid uptake. Then, only those components specifically involved in insulin-stimulated glucose uptake would be a target of AMPK in insulin resistant cells.

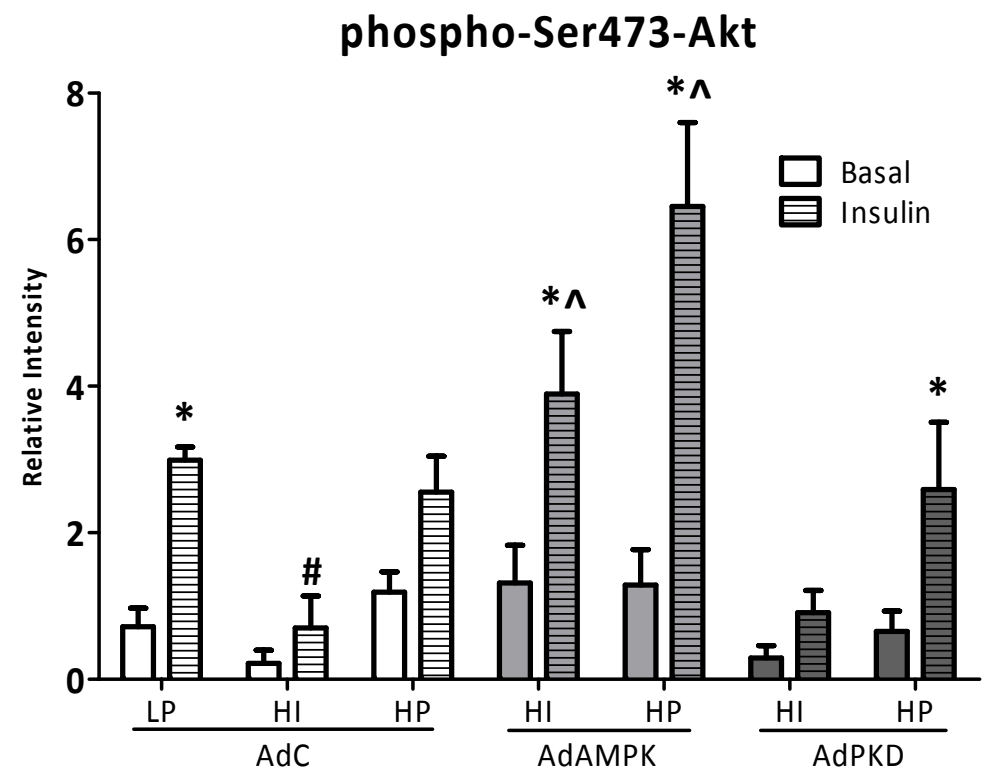

Figure 5.4: Quantification of western blot images for basal and insulin-stimulated Ser473Akt phosphorylation in cultured primary rat cardiomyocytes transfected with adenoviral (Ad) constitutively active AMP-activated protein kinase (AMPK) or protein kinase D (PKD). Statistical analysis was done by One-Way ANOVA with Bonferroni post-tests and Student t-test, * Insulin effect $p<0.05, \wedge$ adenovirus effect $p<0.05$. 
In addition to insulin-stimulated glucose uptake, culturing cardiomyocytes with AdAMPK maintained insulin-stimulated Akt-phosphorylation in both experimental media. Previously, it was shown that AMPK activation (by biguanides or oligomycin) or AMPK adenoviral-overexpression restores insulin-stimulated Akt-Ser473/Thr308phosphorylation and glucose uptake in cardiomyocytes cultured in HI-medium [31]. Here we show that AdAMPK treatment of cardiomyocytes cultured in HP-medium also prevents reduction of insulin sensitivity by increasing insulin stimulated Akt phosphorylation and glucose uptake (Fig. 5.4). It has been shown that mTOR inhibition of insulin-signalling is increased in insulin resistant cells, and that inhibiting mTOR signalling (via AMPK) is sufficient to increase insulin sensitivity in term of Akt phosphorylation [36].

Finally, AdAMPK treatment did not prevent TG accumulation in cardiomyocytes cultured in HP/HI-media. This is in line with the lack of an effect of AdAMPK on LCFA uptake in cardiomyocytes cultured in both insulin resistance-inducing media. AdAMPK treatment might additionally activate LCFA oxidation, which refrains the LCFA from being stored. As mentioned in the introduction, the greater influx of LCFA exceeds the mitochondrial $\beta$-oxidative capacity during lipid oversupply [37], and hence AdAMPK treatment is not able to further activate the mitochondria to oxidize more LCFA.

Altogether, we conclude that AdAMPK treatment preserves insulin sensitivity in cardiomyocytes cultured under insulin resistance-inducing conditions, but does not prevent lipid accumulation.

3.4 Effect of PKD overexpression on substrate uptake, insulin sensitivity and lipid storage

The effects of AdPKD treatment on glucose and palmitate uptake into HI/HP-mediacultured cardiomyocytes were similar to those of AdAMPK; increased basal glucose uptake and retention of insulin-stimulated glucose uptake, but no lowering of basal LCFA uptake and insulin-stimulated palmitate uptake (Fig. 5.3). This same action pattern of AdPKD and AdAMPK in cardiomyocytes cultured under insulin resistanceinducing conditions is surprising given the operability of each of these kinases in different signaling pathways. Nonetheless, PKD's specific effect on basal glucose uptake in cardiomyocytes cultured under insulin resistance-inducing conditions can be understood in view of its already described specific involvement in contractioninduced glucose uptake in insulin sensitive cardiomyocytes (E. Dirkx unpublished).

In line with the lack of an effect of AdPKD on basal and insulin-stimulated Akt phosphorylation in insulin sensitive cardiomyocytes (Fig. 5.2), AdPKD treatment did 
Figure 5.5: Triacylglycerol stores measured by HPTLCincell lysates from primary rat cardiomyocytes cultured in control/low palmitate (LP), high insulin (HI) or high palmitate (HP) medium in the presence of control (C) adenovirus (Ad), adenovirus containing constitutively active AMPactivated protein kinase (AMPK) or protein kinase D (PKD). Statistical analysis was done by 2-Way ANOVA with Bonferroni post-tests, $\mathrm{p}<0.05$, * vs. LP in the same group. ${ }^{\wedge}$ vs $\mathrm{AdC}$ in same medium group.

\section{Triacylglycerol}

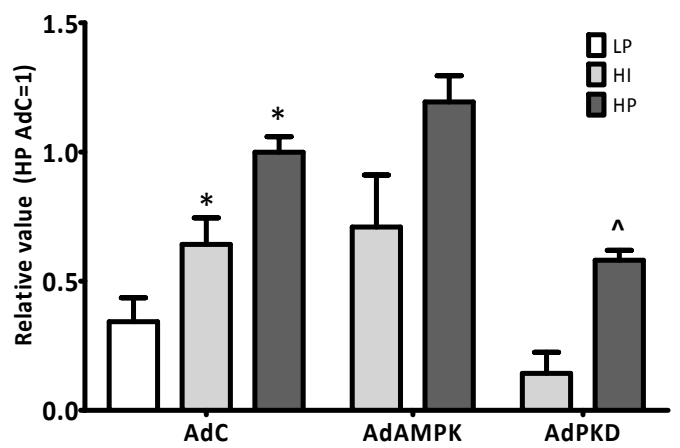

not alter Akt phosphorylation under both insulin-resistance inducing conditions (Fig. 5.4). These results suggest that the preventive action of AdPKD on insulin-stimulated glucose uptake could not be explained by altered Akt-phosphorylation.

AdPKD markedly reduced the storage of TG in cardiomyocytes cultured in both insulin resistance-inducing media (Fig. 5.5). However, this could not be explained by a reduction in basal palmitate uptake because this was not reduced by AdPKD treatment (Fig. 5.3). In addition, recent studies with cardiospecific PKD knockout mice showed that PKD is not involved in LCFA oxidation (E. Dirkx unpublished). Since the role of PKD in cellular metabolism is a relatively novel research subject, downstream PKD targets have been incompletely charted. Perhaps PKD would (in)directly activate TG hydrolysis, such as ATGL or HSL, although there is no support for this notion yet.

Taken together, it can be concluded that overexpression of PKD prevents the loss of insulin-stimulated glucose uptake via inhibition of lipid loading. How reduced lipid storage improves insulin-stimulated glucose uptake in cardiomyocytes cultured in $\mathrm{HP} / \mathrm{HI}$ media, without altering insulin-mediated Akt signaling remains an enigma. Yet it is known that SNARE proteins involved in insulin-stimulated GLUT4 translocation downstream of Akt-signaling, e.g. SNAP23 [38], also regulate the dynamics of lipid droplets [39]. Indeed, lipid droplets compete with the insulinstimulated GLUT4 translocation process for SNAP23 [39]. Then, reduction in lipid storage would make SNAP23 available to re-participate in insulin-stimulated GLUT4 translocation. Altogether, we conclude that in cardiomyocytes cultured under insulin resistance-inducing conditions, AdPKD treatment prevents lipid accumulation and insulin-induced glucose uptake, but does not prevent loss of insulin-mediated Akt signaling. 


\subsection{Conclusion}

In the present study, we explored the potential of AMPK or PKD overexpression to prevent loss of insulin-stimulated glucose uptake in cardiomyocytes incubated under insulin resistance-inducing conditions. The results can be summarized as follows; lipid loading and insulin resistance were induced by exposure to HI or HP medium. AdAMPK as well as AdPKD treatment prevented loss of insulin-stimulated glucose uptake in cardiomyocytes cultured in both culturing conditions, but they exert this beneficial effect through different mechanisms. AdAMPK, but not AdPKD, prevents the loss in insulin-mediated Akt signaling. Conversely, AdPKD, but not AdAMPK prevents lipid accumulation.

It is important to stress that all the effects of AdAMPK or AdPKD on substrate uptake, insulin sensitivity and lipid content in cardiomyocytes were observed in both culturing conditions, thereby suggesting that the beneficial effects of AdAMPK and AdAMPK on cardiomyocytic substrate uptake are not model-related but may be of general applicability in the insulin resistant setting.

A limitation of this study is that adenoviral transduction with AMPK and PKD results in a massive expression of these kinases. Normally such high levels of expression are in time counteracted by compensatory systems. However, these are acute experiments and therefore time for such a response lacks. Thus, these experiments provide insight on the di-rect respons to a strong rise in AMPK or PKD.

Future experiments should show if their combined action would be even more beneficial for preservation of cardiomyocyte substrate uptake under insulin resistance-inducing conditions. This further improvement could include retention of low basal LCFA uptake (thereby directly preventing lipid accumulation).

Finally it was revealed that not only AMPK, but also PKD, is a suitable target for prevention of maladaptive changes in cardiac substrate uptake leading to cardiomyopathy and loss of function. Next to the known AMPK activators (metformin, AICAR, resveratrol), perhaps also PKD activators would be potential insulin resistancepreventing/antagonizing therapeutics. Endothelin and phenylephrine have been shown to activate PKD via $\alpha$-adrenergic signaling in a G-protein coupled-receptor manner $[40,41]$. Hence, all these agents have a large spectrum of actions, in which PKD only forms a small component. Therefore, it would be of interest to search for pharmacological agents that would more specifically activate PKD.

In conclusion, AMPK and PKD each prevent loss of insulin-stimulated glucose uptake into cardiomyocytes cultured under insulin resistance-inducing conditions but they do so through different mechanisms. 


\section{Acknowledgments}

This work was supported by the Dutch Diabetes Research Foundation (Grant: 2006.00.044), and the EU European Cooperation in the field of Scientific and Technical Research (COST) Action BM0602 (Adipose tissue: A key target for prevention of the metabolic syndrome), by grants from the Fonds National de la Recherche Scientifique et Médicale, Belgium. LB is Research Associate of the Fonds National de la Recherche Scientifique, Belgium, by the Association Française contre les Myopathies (AFM) and Association pour l'Etude des Diabètes et des Maladies Métaboliques (ALFEDIAM). Disclosures: none declared. 


\section{References}

[1] Glatz JFC, Luiken JJFP, Bonen A. Membrane fatty acid transporters as regulators of lipid metabolism: implications for metabolic disease. Physiol Rev. 2010 Jan; 90(1): 367-417.

[2] Bonen A, Holloway GP, Tandon NN, Han XX, McFarlan J, Glatz JF, et al. Cardiac and skeletal muscle fatty acid transport and transporters and triacylglycerol and fatty acid oxidation in lean and Zucker diabetic fatty rats. Am J Physiol Regul Integr Comp Physiol. 2009 Oct; 297(4): R1202-12.

[3] Borradaile NM, Schaffer JE. Lipotoxicity in the heart. Current hypertension reports. 2005 Dec; 7(6): 412-7.

[4] Taegtmeyer H, McNulty P, Young ME. Adaptation and maladaptation of the heart in diabetes: Part I: general concepts. Circulation. 2002 Apr 9; 105(14): 1727-33.

[5] Steinbusch LK, Luiken JJ, Vlasblom R, Chabowski A, Hoebers NT, Coumans WA, et al. Absence of fatty acid transporter CD36 protects against Western-type diet-related cardiac dysfunction following pressure overload in mice. Am J Physiol Endocrinol Metab. 2011 Jun 28.

[6] Glatz JF, Bonen A, Ouwens DM, Luiken JJ. Regulation of sarcolemmal transport of substrates in the healthy and diseased heart. Cardiovasc Drugs Ther. 2006 Dec; 20(6): 471-6.

[7] Zorzano A, Sevilla L, Camps M, Becker C, Meyer J, Kammermeier H, et al. Regulation of glucose transport, and glucose transporters expression and trafficking in the heart: studies in cardiac myocytes. Am J Cardiol. 1997 Aug 4; 80(3A): 65A-76A.

[8] Lopaschuk GD, Ussher JR, Folmes CD, Jaswal JS, Stanley WC. Myocardial fatty acid metabolism in health and disease. Physiol Rev. 2010 Jan; 90(1): 207-58.

[9] Steinberg GR, Kemp BE. AMPK in Health and Disease. Physiol Rev. 2009 Jul; 89(3): 1025-78.

[10] Habets DD, Coumans WA, El Hasnaoui M, Zarrinpashneh E, Bertrand L, Viollet B, et al. Crucial role for LKB1 to AMPKalpha2 axis in the regulation of CD36-mediated long-chain fatty acid uptake into cardiomyocytes. Biochim Biophys Acta. 2009 Mar; 1791(3): 212-9.

[11] Hawley SA, Ross FA, Chevtzoff C, Green KA, Evans A, Fogarty S, et al. Use of cells expressing gamma subunit variants to identify diverse mechanisms of AMPK activation. Cell Metab. 2010 Jun 9; 11(6): 554-65.

[12] van der Meer RW, Rijzewijk LJ, de Jong HW, Lamb HJ, Lubberink M, Romijn JA, et al. Pioglitazone improves cardiac function and alters myocardial substrate metabolism without affecting cardiac triglyceride accumulation and high-energy phosphate metabolism in patients with well-controlled type 2 diabetes mellitus. Circulation. 2009 Apr 21; 119(15): 2069-77.

[13] Baur JA, Pearson KJ, Price NL, Jamieson HA, Lerin C, Kalra A, et al. Resveratrol improves health and survival of mice on a high-calorie diet. Nature. 2006 Nov 16; 444(7117): 337-42.

[14] Um JH, Park SJ, Kang H, Yang S, Foretz M, McBurney MW, et al. AMP-activated protein kinasedeficient mice are resistant to the metabolic effects of resveratrol. Diabetes. 2010 Mar; 59(3): 55463.

[15] Luiken JJ, Vertommen D, Coort SL, Habets DD, El Hasnaoui M, Pelsers MM, et al. Identification of protein kinase D as a novel contraction-activated kinase linked to GLUT4-mediated glucose uptake, independent of AMPK. Cell Signal. 2008 Mar; 20(3): 543-56.

[16] Rykx A, De Kimpe L, Mikhalap S, Vantus T, Seufferlein T, Vandenheede JR, et al. Protein kinase D: a family affair. FEBS Lett. 2003 Jul 3; 546(1): 81-6.

[17] Luiken JJ, van Nieuwenhoven FA, America G, van der Vusse GJ, Glatz JF. Uptake and metabolism of palmitate by isolated cardiac myocytes from adult rats: involvement of sarcolemmal proteins. J Lipid Res. 1997 Apr; 38(4): 745-58.

[18] Habets DD, Coumans WA, Voshol PJ, den Boer MA, Febbraio M, Bonen A, et al. AMPK-mediated increase in myocardial long-chain fatty acid uptake critically depends on sarcolemmal CD36. Biochem Biophys Res Commun. 2007 Mar 30; 355(1): 204-10.

[19] Foretz M, Ancellin N, Andreelli F, Saintillan Y, Grondin P, Kahn A, et al. Short-term overexpression of a constitutively active form of AMP-activated protein kinase in the liver leads to mild hypoglycemia and fatty liver. Diabetes. 2005 May; 54(5): 1331-9.

[20] Crute BE, Seefeld K, Gamble J, Kemp BE, Witters LA. Functional domains of the alpha1 catalytic subunit of the AMP-activated protein kinase. J Biol Chem. 1998 Dec 25; 273(52): 35347-54.

[21] Cuello F, Bardswell SC, Haworth RS, Yin X, Lutz S, Wieland T, et al. Protein kinase D selectively targets 
cardiac troponin I and regulates myofilament Ca2+ sensitivity in ventricular myocytes. Circ Res. 2007 Mar 30; 100(6): 864-73.

[22] Luo J, Deng ZL, Luo X, Tang N, Song WX, Chen J, et al. A protocol for rapid generation of recombinant adenoviruses using the AdEasy system. Nat Protoc. 2007; 2(5): 1236-47.

[23] Volz A, Piper HM, Siegmund B, Schwartz P. Longevity of adult ventricular rat heart muscle cells in serum-free primary culture. Journal of molecular and cellular cardiology. 1991 Feb; 23(2): 161-73.

[24] Eckel J, van Echten G, Reinauer H. Adult cardiac myocytes in primary culture: cell characteristics and insulin-receptor interaction. Am J Physiol. 1985 Aug; 249(2 Pt 2): H212-21.

[25] Schwenk RW, Dirkx E, Coumans WA, Bonen A, Klip A, Glatz JF, et al. Requirement for distinct vesicleassociated membrane proteins in insulin- and AMP-activated protein kinase (AMPK)-induced translocation of GLUT4 and CD36 in cultured cardiomyocytes. Diabetologia. 2010 Oct; 53(10): 220919.

[26] van Oort MM, van Doorn JM, Bonen A, Glatz JF, van der Horst DJ, Rodenburg KW, et al. Insulininduced translocation of CD36 to the plasma membrane is reversible and shows similarity to that of GLUT4. Biochim Biophys Acta. 2008 Jan-Feb; 1781(1-2): 61-71.

[27] Alkhateeb H, Chabowski A, Glatz JF, Luiken JF, Bonen A. Two phases of palmitate-induced insulin resistance in skeletal muscle: impaired GLUT4 translocation is followed by a reduced GLUT4 intrinsic activity. Am J Physiol Endocrinol Metab. 2007 Sep; 293(3): E783-93.

[28] Bonen A, Luiken JJ, Arumugam Y, Glatz JF, Tandon NN. Acute regulation of fatty acid uptake involves the cellular redistribution of fatty acid translocase. J Biol Chem. 2000 May 12; 275(19): 14501-8.

[29] Luiken JJ, Koonen DP, Willems J, Zorzano A, Becker C, Fischer Y, et al. Insulin stimulates long-chain fatty acid utilization by rat cardiac myocytes through cellular redistribution of FAT/CD36. Diabetes. 2002 Oct; 51(10): 3113-9.

[30] Steinbusch LK, Wijnen W, Schwenk RW, Coumans WA, Hoebers NT, Ouwens DM, et al. Differential regulation of cardiac glucose and fatty acid uptake by endosomal $\mathrm{pH}$ and actin filaments. Am J Physiol Cell Physiol. 2010 Jun; 298(6): C1549-59.

[31] Bertrand L, Ginion A, Beauloye C, Hebert AD, Guigas B, Hue L, et al. AMPK activation restores the stimulation of glucose uptake in an in vitro model of insulin-resistant cardiomyocytes via the activation of protein kinase B. Am J Physiol Heart Circ Physiol. 2006 Jul; 291(1): H239-50.

[32] Brindley DN, Kok BP, Kienesberger PC, Lehner R, Dyck JR. Shedding light on the enigma of myocardial lipotoxicity: the involvement of known and putative regulators of fatty acid storage and mobilization. Am J Physiol Endocrinol Metab. 2010 May; 298(5): E897-908.

[33] Shulman GI. Cellular mechanisms of insulin resistance. J Clin Invest. 2000 Jul; 106(2): 171-6.

[34] Steinbusch LK, Schwenk RW, Ouwens DM, Diamant M, Glatz JF, Luiken JJ. Subcellular trafficking of the substrate transporters GLUT4 and CD36 in cardiomyocytes. Cell Mol Life Sci. 2011 May 6.

[35] Liu LZ, Cheung SC, Lan LL, Ho SK, Xu HX, Chan JC, et al. Berberine modulates insulin signaling transduction in insulin-resistant cells. Mol Cell Endocrinol. 2010 Apr 12; 317(1-2): 148-53.

[36] Ginion A, Auquier J, Benton CR, Mouton C, Vanoverschelde JL, Hue L, et al. Inhibition of the mTOR/ p70S6K pathway is not involved in the insulin-sensitizing effect of AMPK on cardiac glucose uptake. Am J Physiol Heart Circ Physiol. 2011 May 20.

[37] Holloway GP, Benton CR, Mullen KL, Yoshida Y, Snook LA, Han XX, et al. In obese rat muscle transport of palmitate is increased and is channeled to triacylglycerol storage despite an increase in mitochondrial palmitate oxidation. Am J Physiol Endocrinol Metab. 2009 Apr; 296(4): E738-47.

[38] St-Denis JF, Cabaniols JP, Cushman SW, Roche PA. SNAP-23 participates in SNARE complex assembly in rat adipose cells. Biochem J. 1999 Mar 15; 338 ( Pt 3): 709-15.

[39] Bostrom P, Andersson L, Rutberg M, Perman J, Lidberg U, Johansson BR, et al. SNARE proteins mediate fusion between cytosolic lipid droplets and are implicated in insulin sensitivity. Nat Cell Biol. 2007 Nov; 9(11): 1286-93.

[40] Bossuyt J, Chang CW, Helmstadter K, Kunkel MT, Newton AC, Campbell KS, et al. Spatiotemporally distinct PKD activation in adult cardiomyocytes in response to phenylephrine and endothelin. J Biol Chem. 2011 Jul 27.

[41] Rozengurt E. Protein kinase d signaling: multiple biological function in health and disease. Physiology. 2011 Feb: 23-33. 
Supplemental data concerning chapter 5 
A

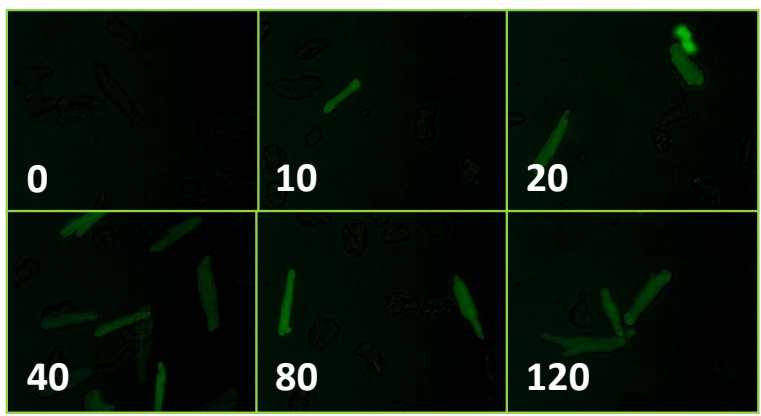

B
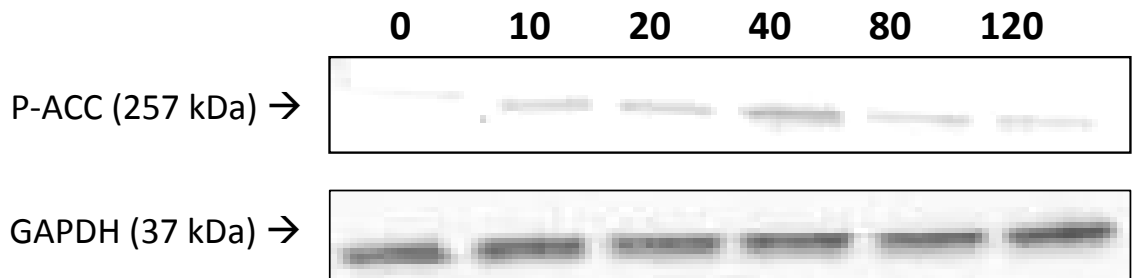

C

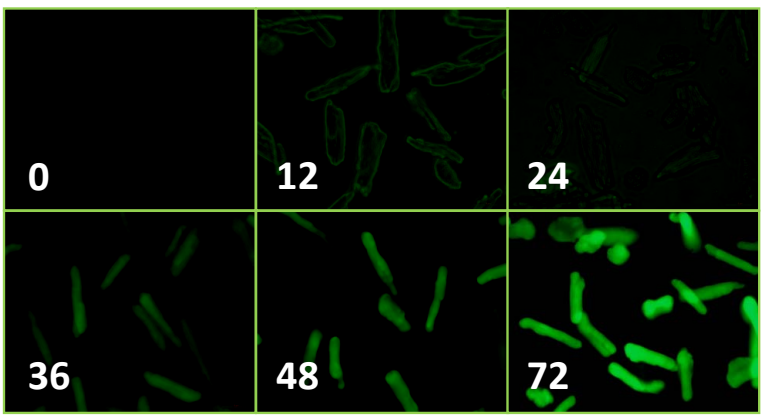

Supplemental Figure 5.1: $\mathrm{MOI}$ and time determination for transfection of cultured primary rat cardiomyocytes with adenoviral constitutively active AMP-activated protein kinase (AMPK) with a GFP tag. Fluorescent images (A) and wetern blot images (B) of rat cardiomyocytes cultured with adenoviral AMPK. GFP fluorescence appears with $\mathrm{MOI} 10$ and increases until $\mathrm{MOI} 40$, with higher $\mathrm{MOls}$ the cytotoxicity increases more than the transfection. $\mathrm{MOI} 40$ was used to determine the time frame of transfection (C) which already appears after 12 hours and increases until 72 hours. 
A
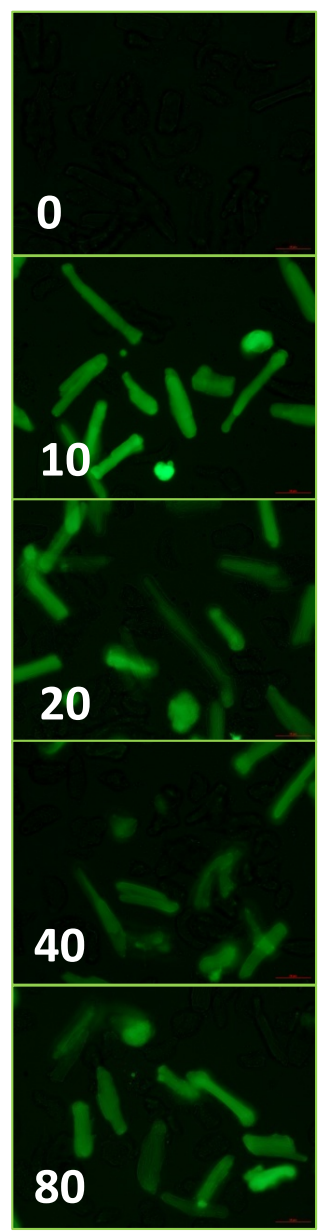

C

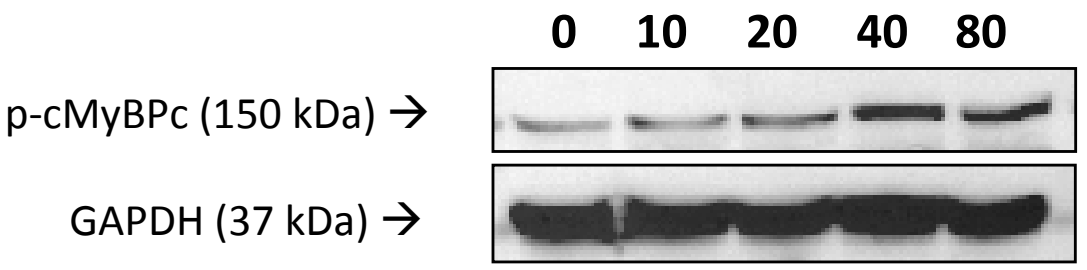

Supplemental Figure 5.2: $\mathrm{MOI}$ determination for transfection of cultured primary rat cardiomyocytes with adenoviral protein kinase D (PKD) with a EGFP tag. Fluorescent images (A), normal light images (B) and wetern blot images (C) of rat cardiomyocytes cultured with adenoviral PKD. EGFP fluorescence and phosphorylation of the downstream target of PKD (cardiac myosin binding protein c (cMyBPc) appears with $\mathrm{MOI} 10$ and increases until MOI 40. At MOIs of 20 and higher the cytotoxicity increases. $\mathrm{MOI} 10$ was chosen for experiments.

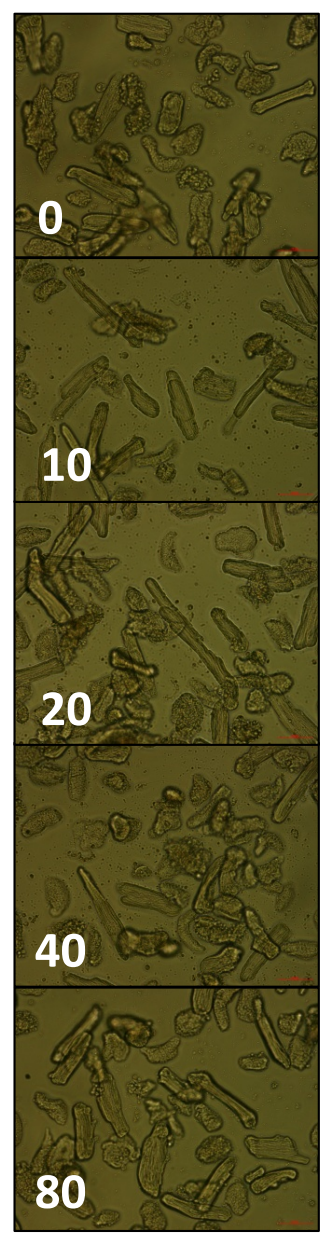

B 


\section{caveolin3}

\begin{tabular}{|c|c|c|c|c|}
\hline LP & $L P+A d C$ & LP+AdAMPK & LP+AdPKD & \\
\hline \multicolumn{5}{|c|}{ 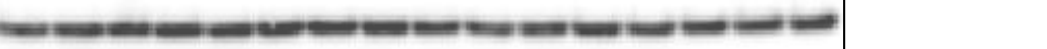 } \\
\hline LP & $\mathrm{HI}$ & $\mathrm{HI}+\mathrm{AdC}$ & HI+AdAMPK & $\mathrm{HI}+\mathrm{AdPKD}$ \\
\hline \multicolumn{5}{|c|}{ 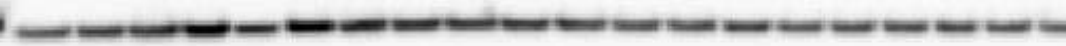 } \\
\hline LP & $\mathrm{HP}$ & $\mathrm{HP}+\mathrm{AdC}$ & HP+AdAMPK & HP+AdPKD \\
\hline
\end{tabular}

Supplemental Figure 5.3: Western blot images for the loading control caveolin3 in cultured primary rat cardiomyocytes cultured in low palmitate (LP), high insulin (HI) and high palmitate (HP) without adenovirus, with control adenovirus $(A d C)$, with constitutive active AMP-activated protein kinase (AdAMPK) or with protein kinase D (AdPKD). caveolin 3 was not altered by any culture condition.

\begin{tabular}{|c|c|c|c|c|c|c|}
\hline LP & LP+AdC & $\begin{array}{c}\text { LP+ } \\
\text { AdAMPK }\end{array}$ & $\begin{array}{c}\text { LP+ } \\
\text { AdPKD }\end{array}$ & HI & HI+AdC & $\begin{array}{c}\text { HI+ } \\
\text { AdAMPK }\end{array}$ \\
\hline
\end{tabular}

\section{Akt $\rightarrow$}

\begin{tabular}{|c|c|c|c|c|c|}
\hline LP & $\begin{array}{c}\text { HI+ } \\
\text { AdPKD }\end{array}$ & HP & HP+AdC & $\begin{array}{c}\text { HP+ } \\
\text { AdAMPK }\end{array}$ & $\begin{array}{c}\text { HP+ } \\
\text { AdPKD }\end{array}$ \\
\hline
\end{tabular}

\section{Akt $\rightarrow$}

Supplemental Figure 5.4: Western blot images for total Akt in cultured primary rat cardiomyocytes cultured in low palmitate (LP), high insulin (HI) and high palmitate (HP) without adenovirus, with control adenovirus (AdC), with constitutive active AMP-activated protein kinase (AdAMPK) or with protein kinase $D(A d P K D)$. Total Akt was not altered by any culture condition. 
Chapter 6

\section{Absence of fatty acid transporter CD36 protects against Western-type diet-related cardiac dysfunction following pressure overload in mice}

Laura K.M. Steinbusch ${ }^{1}$, Joost J.F.P. Luiken ${ }^{1}$, Ronald Vlasblom², Adrian Chabowski ${ }^{3}$, Nicole T.H. Hoebers ${ }^{1}$, Will A. Coumans ${ }^{1}$, Irene O.C.M. Vroegrijk ${ }^{4}$, Peter J. Voshol ${ }^{5}$, D.Margriet Ouwens ${ }^{6}$, Jan F.C. Glatz ${ }^{1}$, Michaela Diamant ${ }^{7}$

1 CARIM, Department of Molecular Genetics, Maastricht University Medical Center+, Maastricht, the Netherlands

2 Laboratory for Physiology, VU University Medical Center, Amsterdam, the Netherlands

3 Department of Physiology, Medical University Bialystok, Bialystok, Poland

4 Endocrinology and Metabolic Diseases, Leiden University Medical Center, Leiden, the Netherlands

5 University of Cambridge, Institute of Metabolic Science, Cambridge, United Kingdom

6 German Diabetes Center, Düsseldorf, Germany

7 Diabetes Center, Department of Internal Medicine, VU University Medical Center, Amsterdam, the Netherlands

Am J Physiol Endocrinol Metab. 2011 Jun 28. 


\begin{abstract}
Cardiac patients often are obese and have hypertension, but in most studies these conditions are investigated separately. Here, we aimed at, 1) elucidating the interaction of metabolic and mechanophysical stress in the development of cardiac dysfunction in mice and, 2) preventing this interaction by ablation of the fatty acid transporter CD36. Male Wildtype C57BI/6 (WT) mice and CD36-/- mice received chow or western-type diet (WTD) for 10 weeks, and then underwent a sham surgery or transverse aortic constriction (TAC) under anesthesia. After 6 weeks continuation of the diet, cardiac function, morphology, lipid profiles and molecular parameters were assessed. WTD administration affected body and organ weights of WT and CD36/- mice, but it only affected plasma glucose and insulin concentrations in WT mice. Cardiac lipid concentrations increased in WT mice receiving WTD, decreased in CD36/- on chow, and remained unchanged in CD36-/- receiving WTD. TAC induced cardiac hypertrophy in WT mice on chow, but did not affect cardiac function and cardiac lipid concentrations. WTD or CD36 ablation worsened the outcome of TAC. Ablation of CD36 protected against the WTD-related aggravation of cardiac functional and structural changes induced by TAC. In conclusion, cardiac dysfunction and remodeling worsen when the heart is exposed to two stresses, metabolic and mechanophysical, at the same time. CD36 ablation prevents the metabolic stress resulting from a WTD. Thus, metabolic conditions are a critical factor for the compromised heart and provide new targets for metabolic manipulation in cardioprotection.
\end{abstract}




\section{Introduction}

The healthy heart preferably utilizes long-chain fatty acids (60-70\%), but also glucose $(30-40 \%)$, lactate and ketone bodies $(29,37)$. Under normal conditions there is a distinctive and finely tuned utilization balance between these fuel substrates for ATP generation, such that high fatty acid supply inhibits glucose metabolism (14, $16,22)$. Under stressful conditions, such as ischemia or hypertension, glucose is the preferred substrate, as it requires less oxygen for its oxidation than an equimolar amount of carbons derived from fatty acids (16). Thus, the normal heart is able to switch between substrates according to the most favorable energetic yield needed for the prevailing cardiac condition (22).

Obesity, metabolic syndrome and type 2 diabetes are associated with an increased risk of cardiovascular disease and heart failure (29). In obesity and its related conditions plasma fatty acid and triglyceride (TG) concentrations are elevated and plasma glucose levels gradually increase in the presence of insulin resistance (38). Collectively these abnormalities impose metabolic stress on the heart $(21,27,40$, 45 ) which may ultimately lead to cardiac metabolic inflexibility, lipotoxicity (27), and subsequent development of metabolic cardiomyopathy both in rodents and humans $(19,29,33,34,40,44)$. Cardiac patients often are obese and have hypertension, but both conditions are mostly studied separately. In this study we aimed at clarifying the interaction of metabolic and mechanophysical stress in the development of cardiac dysfunction.

CD36 is the predominant cardiac fatty acid transporter and responsible for the majority of cardiac fatty acid uptake, as shown in studies with CD36-/- mice (18). In the normal heart, CD36 is equally distributed between the sarcolemma and intracellular membrane storage compartments. However, in rat models for obesity and insulin resistance, we and others have found that the fatty acid transporter CD36 is permanently relocated to the sarcolemma, thereby increasing the contribution of fatty acids to (cardiac) muscle energy metabolism $(1,10,32)$. This chronic increase in CD36-mediated fatty acid uptake caused 1) the gradual buildup of fatty acid metabolites, 2) reduced insulin-stimulated myocardial glucose uptake, measured by in-vivo positron-emission tomography (PET) (43) and cardiomyocyte glucose uptake $(10,32)$, as well as 3$)$ decreased cardiac contractile function $(32,43)$. In aging studies in mice, there was an association between CD36-mediated fatty acid uptake and ageinduced diabetes and cardiomyopathy (25). However, these studies could not make any strong conclusions on the possible causal relationship between CD36 presence at the sarcolemma and the development of diabetic cardiomyopathy.

Cardiac remodeling may occur as an adaptation to the metabolic stresses 
mentioned above, but also in response to mechanophysical and genetic stresses (41). Recent findings indicate that the consequences of chronic metabolic stress and the development of metabolic inflexibility may only become apparent in the presence of additional cardiac stress, such as ischemia and hypertension (23, 26, 31). Accordingly, it was shown that short-term lowering of plasma fatty acid levels by acipimox had no effect on cardiac function in normal controls while it did affect cardiac function in patients with heart failure (42). In summary, the effect of chronic metabolic stress on mechanophysical stress is not clear yet.

In this study we aimed at further elucidating the interaction of metabolism and function in the compromised heart. Firstly, we hypothesized that metabolic stress and mechanophysical stress interact in the development of cardiac dysfunction in mice. Secondly, we hypothesized that ablation of CD36 could prevent this interaction. Mechanophysical stress was induced by pressure overload after TAC, and metabolic stress resulted from exposure to a WTD.

\section{Experimental procedures}

Twelve-week-old male WT and CD36-/- mice were fed ad libitum either standard rodent diet (chow; 1206, Harlan Teklad, NL) or a WTD (D12079B, Open Source Research diets, NL). Ten weeks after initiation of the diet, mice were either sham-operated (5-8 for each group) or underwent TAC (7-10 for each group) to induce pressure overload (Fig.1A). Diet exposure was continued throughout the study. Six weeks after surgery, cardiac function was determined by echocardiography and mice were sacrificed by decapitation.

Experimental animals

CD36-/- mice were kindly provided by M. Febbraio (Cornell University, New York, USA) and bred at Leiden University Medical Center, Leiden, NL. Mice were generated by targeted homologous recombination and crossed back eight times to the C57BI/6 background (12). C57BI/6 controls were purchased from Charles River laboratories. All animal procedures were performed according to the Guide for the Care and Use of Laboratory Animals published by the European Commission Directive 86/609/EEC and in addition they were approved by the Experimental Animal Committees of Maastricht University and Leiden University Medical Center, the Netherlands.

\section{Diet composition}

Chow consisted of $330 \mathrm{kcal} / 100 \mathrm{~g}$ divided over 16\% proteins, 3.5\% fat (mostly palmitic and linoleic acid) and $60.89 \%$ carbohydrates (mainly starch). WTD contained $469 \mathrm{kcal} / 100$ g divided over $17 \%$ protein, $41 \%$ fat $(27.21 \%$ palmitic, $26.81 \%$ oleic, $12.41 \%$ stearic and $10.17 \%$ myristic acid) and $43 \%$ carbohydrates (primarily sucrose).

\section{Transverse aortic constriction}

TAC was performed as previously described (20). Mice were anesthetized (induction: ip ketamine/ xylazine, $100 \mathrm{mg} / \mathrm{kg}$ and $5 \mathrm{mg} / \mathrm{kg}$, respectively; maintenance isoflurane 1-2\%) and Temgesic $0.1 \mathrm{mg} / \mathrm{kg}$ was injected subcutaneous for pain relieve. The thorax was opened at the sternum and TAC was induced by ligation of the aortic branch around a 27 gauge needle using a 6.0 silk suture. Sham-operated mice underwent a similar operation without constricting the aorta.

\section{Echocardiography}

Trans-thoracic echocardiography was performed in anesthetized mice ( $3 \%$ isoflurane induction and 0.8 $1 \%$ maintenance) using an Aloka Terason $3000 \mathrm{cv}$. During B-mode and $\mathrm{M}$-mode recording heart rate was kept at 500 bpm by adjustment of isoflurane. Left ventricle (LV) fractional shortening (FS) was calculated 
as previously described (13). Echocardiography was performed by two persons who were blinded for experimental groups. Inter-individual differences in recordings were calculated and values were adjusted accordingly.

\section{Organ weight and blood glucose}

Body weight and blood glucose levels were determined at 12 weeks-of-age, after 10 weeks of diet intervention and 6 weeks after surgery. After 6 hours fasting, blood glucose was measured by glucosestrips and a glucometer from Bayer Ascensia Contour LINK, using tail bleeds. Afterwards organs were excised, weighed and processed for later analysis.

\section{Histology}

Deparaffinized LV sections ( $4 \mu \mathrm{m})$ were stained with hematoxylin-eosin to determine cardiomyocyte crosssectional-area (CsA). Only regions that included circular shaped cardiomyocytes with visible nuclei were analyzed. The mean CsA was determined from 60 to 100 cells for each mouse using QWin V3 software (Leica, The Netherlands). Macrophages were visualized by a Mac3 staining (Pharmigen \#553322) with alkaline phosphatase. The staining was scored on a 5 point scale.

A

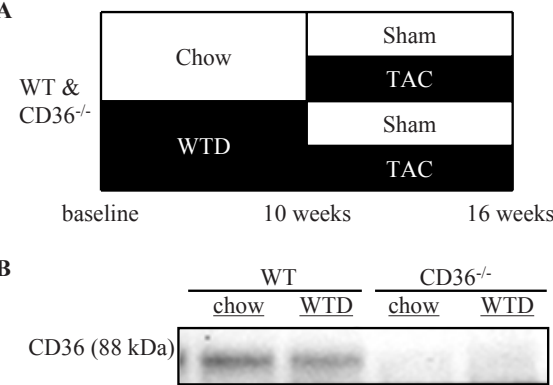

D

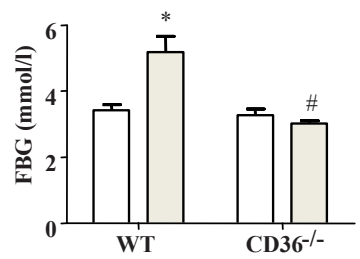

$\mathbf{F}$

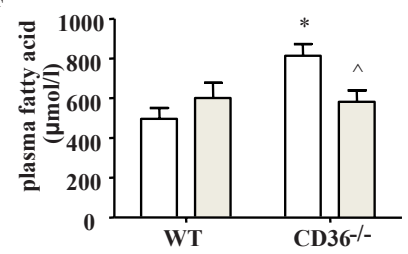

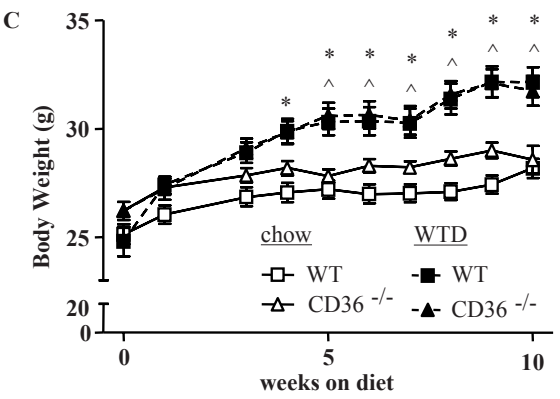

$\mathbf{E}$

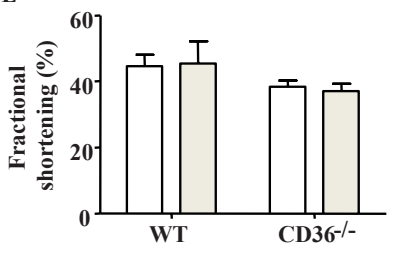

G

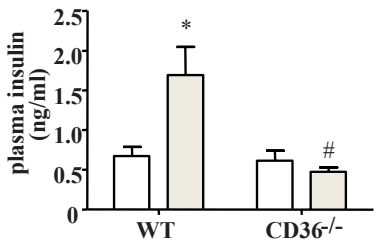

Figure 6.1: Experimental set-up and general parameters after 10 weeks of diet exposure: (A) Experimental set-up. (B) Western blot image of CD36 protein presence in WT and $\mathrm{CD}^{-1} 6^{-}$mice on chow or WTD. (C) Body-weight during 10 weeks of diet exposure. (D) Fasting blood glucose (FBG). (E) Cardiac function, Fractional shortening was measured by thoracic echocardiography in anesthetized mice. (F-G) Plasma fatty acid and plasma insulin concentrations after diet exposure. Data are mean \pm SEM from 20 mice on either diet for A-D and from 6-8 mice per group for E-F. Statistical analysis was done by 2 -Way ANOVA, * vs. WT chow, ^ ${ }^{\wedge}$ v. CD36 $\%$ chow, \# vs. WT/WTD. 
Heart Triglyceride, Diglyceride, and Ceramide Concentrations

Heart lipids were determined in snap frozen and freeze dried tissue samples as described previously (3). Intramyocardial lipids were extracted in methanol/chloroform and an internal standard and water were added. One portion of the chloroform layer was used for TG and diglyceride separation and another portion was used for ceramide determination. Afterwards thin-layer chromatography was used to separate lipids and samples were analyzed by gas-liquid chromatography.

\section{Gene expression}

Total RNA was isolated from heart tissue as described previously (39) and converted into first strand cDNA with iScript cDNA synthesis kit (Bio-Rad, USA) according to the manufacturer's instructions. Changes in gene expression were determined by quantitative-PCR as described previously (39). To standardize for the amount of cDNA, Hypoxanthine-phosphoribosyl-transferase (HPRT) was used as reference gene. Primer sets (Suppl. Table 6.1) were developed with Primer Express v1.5 (Applied Biosystems, Foster City, USA) using default settings. QPCR data was analyzed according to the relative standard curve method.

Protein detection

LV homogenates were used for protein detection by SDS-polyacrylamide gel electrophoresis, followed by Western blotting, as previously described (4). Antibodies were purchased at different companies or were kind gifts (Suppl. Table 6.2). Western blot images were analyzed with a Molecular Imager (ChemiDoc XRS, BioRad) and quantified with Quantity One ${ }^{\circledR}$ (BioRad).

\section{Data presentation and statistics}

Results are presented as means \pm SEM. Data were analyzed by two-way ANOVA with Bonferroni post-hoc test and Kaplan-Meier survival test using GraphPad Prism5.0. Two-sided values of $p<0.05$ were considered significant.

\section{Results}

\section{Characteristics at baseline and after 10 weeks of diet intervention}

At 12 weeks-of-age, WT and CD36-/- mice had a similar body weight and cardiac function (Suppl.Table 6.3), and CD36-/- mice showed no cardiac CD36 protein presence (Fig. 6.1B). After 10 weeks of diet intervention, mice exposed to WTD had gained significantly more body weight than those receiving chow, irrespective of the genotype (Fig. 6.1C). Six weeks after TAC surgery, mice receiving WTD continued to have a higher body weight than mice receiving chow, regardless of the genotype (Suppl.Table 6.4). Remarkably, WTD-induced increases in liver mass contributed to a markedly larger extent to the increase in body weight when comparing shamoperated CD36-/- mice to WT mice (Suppl. Table.6.4). WTD-induced alterations in fat pad weights were similar for both genotypes (Suppl. Table 6.4). This relates to the notion that the genetic ablation of CD36 shifts the lipid load to tissues, such as the liver, that do not rely on CD36 for uptake of fatty acids (17).

After 10 weeks of diet intervention, WT mice receiving WTD had higher fasting blood glucose levels than WT mice receiving chow (Fig. 6.1D), whereas fasting blood glucose concentrations did not change upon WTD administration in CD36-/- mice. Plasma fatty acid concentrations were elevated both in WT WTD mice and CD36-/chow mice (Fig. 6.1F). WTD administration in CD36-/- mice resulted in a decrease in 


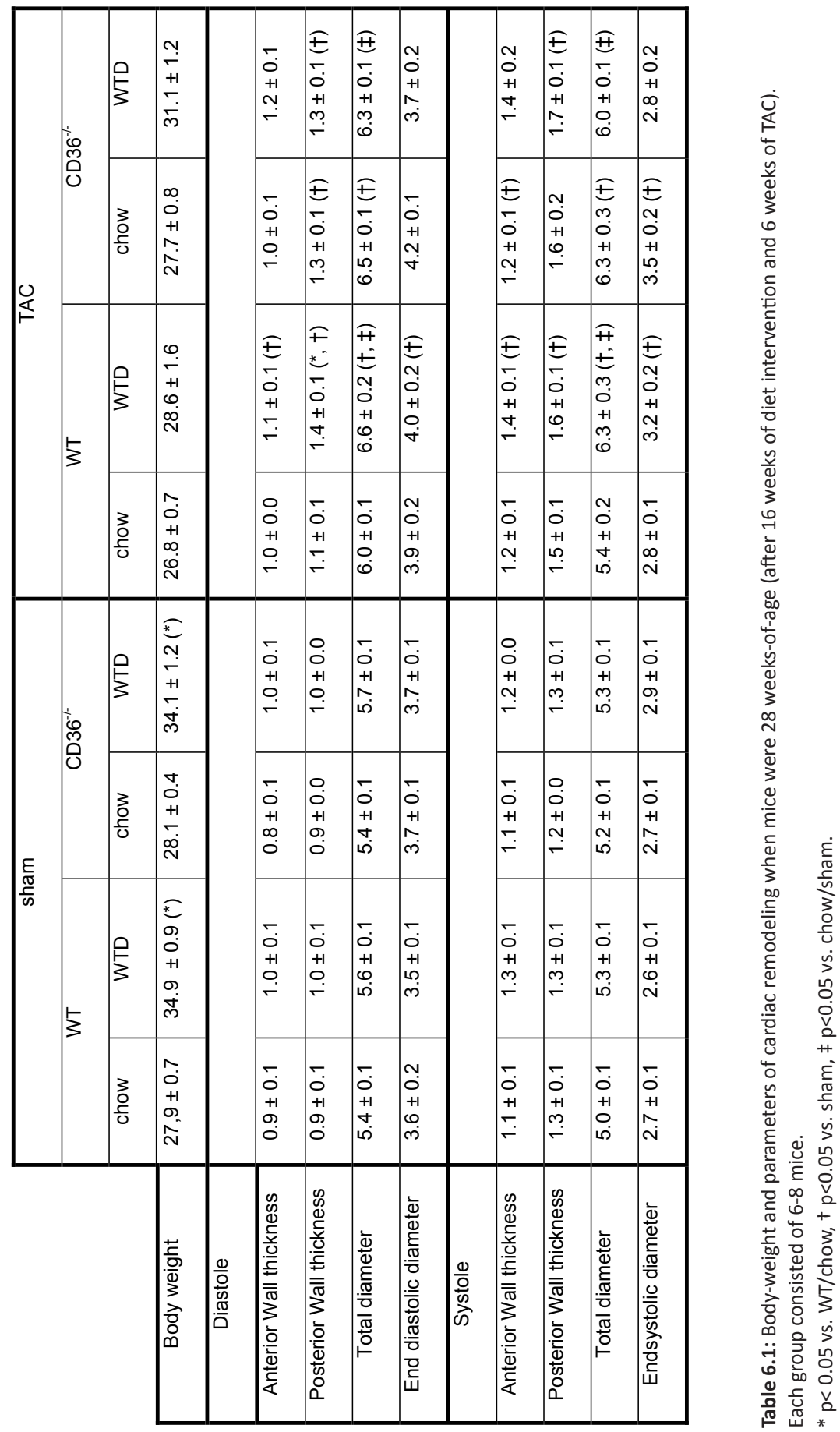


A

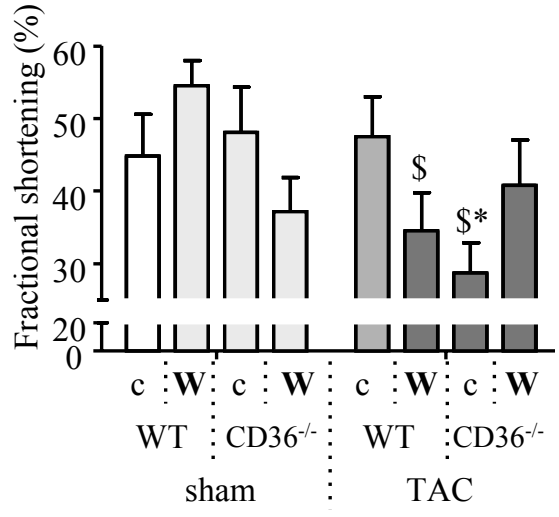

Figure 6.2: Cardiac function 6 weeks after TAC: (A) Fractional shortening, (B) left ventricle end-systolic diameter (LVESD) and (C) left ventricle end-diastolic diameter (LVEDD) were measured by thoracic echocardiography. Data are mean \pm SEM from 6-8 mice in each group. White bars = control group, light grey bars = metabolic stress (WTD, CD36 ablation or combination), grey bars = mechanophysical stress (TAC), dark grey bars = interaction of stresses. $\mathrm{C}=$ chow, $\mathrm{W}=$ WTD. Statistical analysis was done by 2 -Way ANOVA, * $p<0.05$ vs. WT chow, ^ $\mathrm{p}<0.05$ vs. CD36 $\%$ chow, $\$$ vs. sham.

B

C
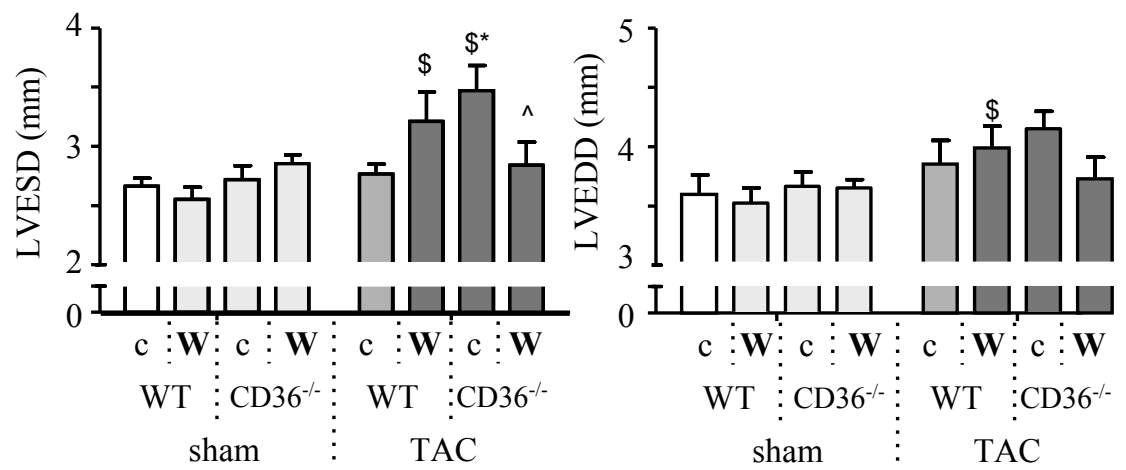

plasma fatty acid levels, suggesting that hepatic storage of fatty acid was increased. Plasma insulin levels were elevated in WT mice on a WTD in comparison to WT on a chow diet while no alterations were seen in CD36-/- mice (Fig. 6.1G), suggesting that CD36 ablation prevents the development of WTD-induced metabolic alterations. In agreement with this, WTD administration only altered genes important in fatty acid metabolism, e.g. long-chain acyl-CoA synthetase (Acsl), in hearts of WT mice but not in CD36-/- mice (Fig. 6.5). Interestingly, 10 weeks of WTD administration did not affect FS in any experimental group (Fig.1E). In conclusion, WT and CD36-/mice have similar bodyweight and cardiac function at 12 weeks-of-age. Ten weeks of metabolic stress affects body and organ weight, but not cardiac function, in both genotypes and, only affects blood glucose and insulin levels in WT mice. 
A

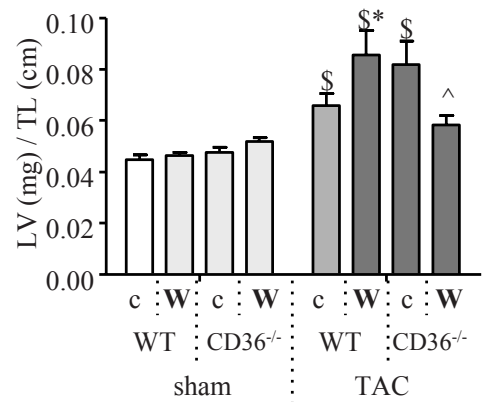

C

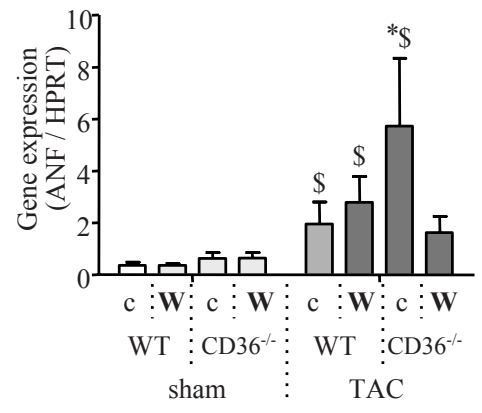

B

sham

TAC
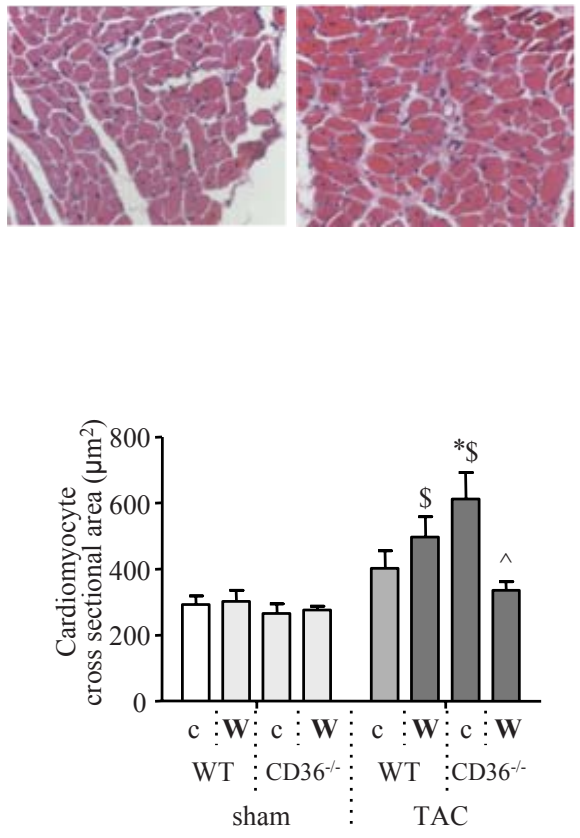

Figure 6.3: Cardiac parameters 6 weeks after TAC. (A) left ventricle (LV) weight corrected for tibialength. (B) Representative HE staining images of LV sections and analysis of cardiomyocyte crosssectional-area. (C) mRNA expression levels of ANF, corrected for HPRT as a housekeeping gene, measured by qPCR. Data are mean \pm SEM from 6-8 mice in each group. White bars = control group, light grey bars = metabolic stress (WTD, CD36 ablation or combination), grey bars = mechanophysical stress (TAC), dark grey bars = interaction of stresses. $\mathrm{C}=$ chow, $\mathrm{W}=$ WTD. Statistical analysis was done by 2 -Way ANOVA, ${ }^{*} p<0.05$ vs. WT chow, ${ }^{\wedge} p<0.05$ vs. CD36 $\%$ chow, \# $p<0.05$ vs. WT/WTD, $\$$ vs. sham.

\section{Parameters of cardiac function}

Surgery survival was $100 \%$ for sham-operated groups both for the acute phase and the remainder of the study. For the TAC group the survival was $69 \%$ for the acute phase of the TAC surgery and $73 \%$ for the remainder of the study. TAC resulted in a significant decrease in FS of $26 \%$ in WT mice receiving a WTD as well as a significant decrease in FS of 35\% in CD36-/- mice receiving chow (Fig. 6.2). These changes in FS mainly were reflected in increased left ventricular end systolic diameter (LVESD) (Fig.2B); a strong increase in both WT WTD mice and CD36-/- chow mice. Additionally, these changes in FS resulted from increased wall thicknesses and altered LV diameters in diastole (only for WT WTD) (Fig. 6.2C and Table 6.1). However, cardiac function was 
A

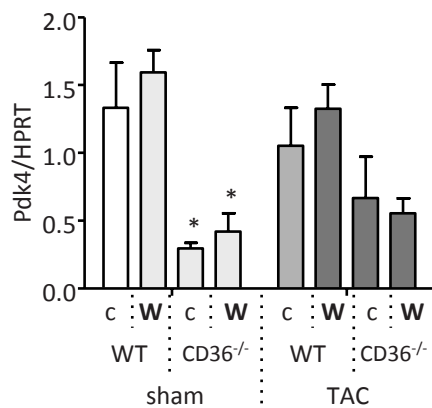

B

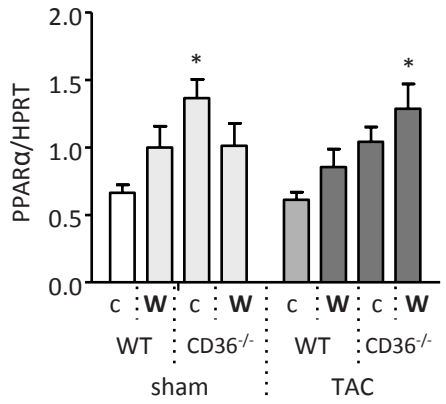

C

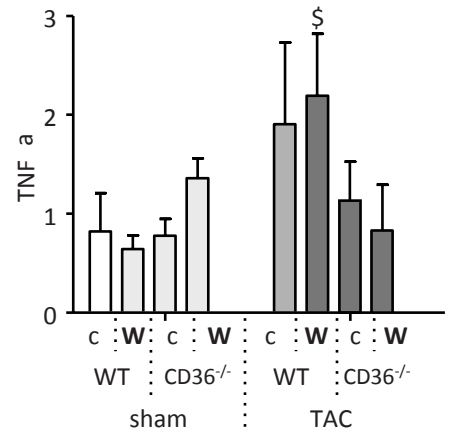

D

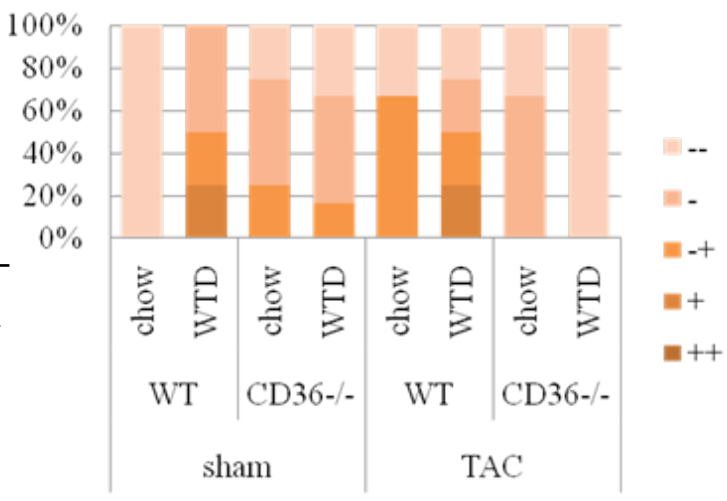

E

Score - -

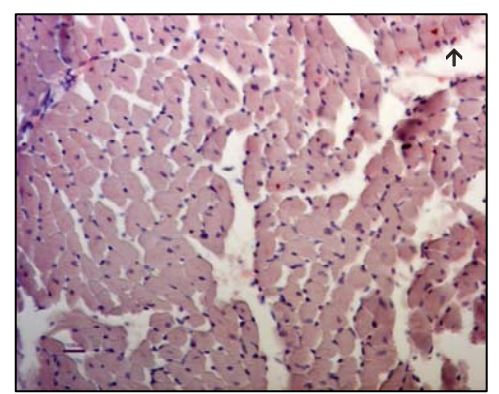

Score + +

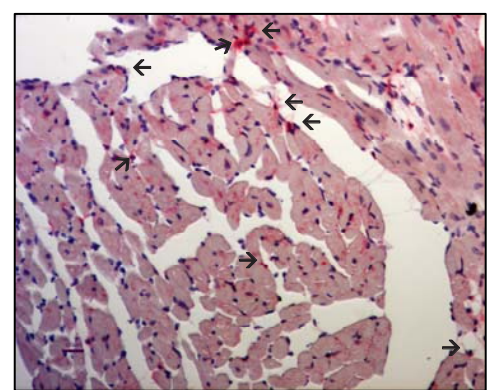

Figure 6.4: Metabolic and inflammation alterations. mRNA expression of (A) Pdk4 and (B) PPAR $\alpha$ 6 weeks after TAC. HPRT was used as a housekeeping gene. (C) Protein presence of TNF $\alpha$,(D) quantitation of macrophage infiltration in LV sections by Mac3 staining and (E) images of Mac3 staining scored - - (example from CD36-/- chow TAC) and + + (example from WT WTD sham), all 6 weeks after TAC. Data are mean \pm SEM from 6-8 mice in each group. White bars = control group, light grey bars = metabolic stress (WTD, CD36 ablation or combination), grey bars = mechanophysical stress (TAC), dark grey bars = interaction of stresses. $C=$ chow, $W=$ WTD. Statistical analysis was done by 2 -Way ANOVA. * vs. WT chow, p<0.05. 
preserved in CD36-/- on a WTD after TAC (Fig. 6.2), although their wall thickness was slightly increased (Table 6.1). No interaction of sham and WTD on cardiac function was found, regardless of the genetic background (Fig. 6.2), which is compatible with the lack of dietary effects in all animals prior to surgery (Suppl.Table 6.1, Fig. 6.1C). In summary, ablation of CD36 protects against WTD-related cardiac dysfunction.

\section{Parameters of cardiac remodeling}

Six weeks after TAC surgery, WT mice on chow showed marked signs of cardiac remodeling in comparison to sham-operated mice. Specifically, after TAC surgery WT mice on chow showed increments in heart weight (HW) (1.44-fold, $p<0.05$ : Suppl. Table 6.2), LV/TL (1.47-fold, $p<0.05$ : Fig. 6.3A), and cardiomyocyte cross-sectionalarea (1.38-fold, $p>0 / 05$, Fig. 6.3B). Even more pronounced cardiac hypertrophy was observed after TAC surgery in the WT mice receiving WTD (vs. sham: LV/TL; 1.87fold $p<0.001$ ) and CD36-/- mice receiving chow (vs. sham: LV/TL 1.71-fold, $p<0.001$ ) (Fig. 6.3A). The combination of WTD and CD36 ablation protected the hearts from TAC-related development of more pronounced cardiac hypertrophy, as observed in

A
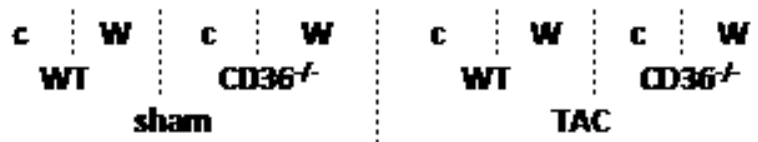

\section{Co36 [88 kDa)}

FATPG [70kDa]

FATP1 [63 kDa]

FABPpm [40 kDa]

caveclin3 (22 kDa)

$\mathbf{8}$

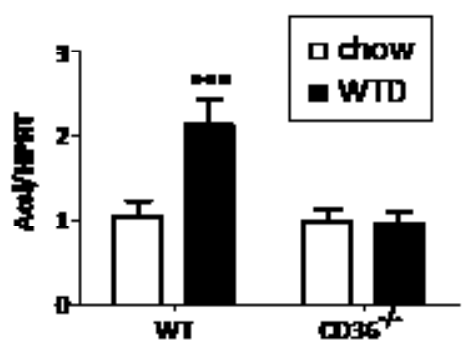

Figure 6.5: Fatty acid transporters and fatty acid handling proteins 6 weeks after TAC. (A) Representative western blot images of protein expression of CD36, fatty acid transporter (FATP) 6 and 1, plasmalemmal fatty acid binding protein (FABPpm) and caveolin3 as loading control in left ventricles from wildtype and CD36-/- mice on chow or WTD 6 weeks after surgery. $\mathrm{C}=$ chow, $\mathrm{W}=$ WTD. (B) mRNA expression of longchain acetyl CoA synthetase 6 weeks after TAC surgery. HPRT was used as a housekeeping gene. Statistics was performed by 2-Way ANOVA with Bonferroni posttests. ${ }^{* * *} \mathrm{p}<0.001$ compared to WT chow. 
A
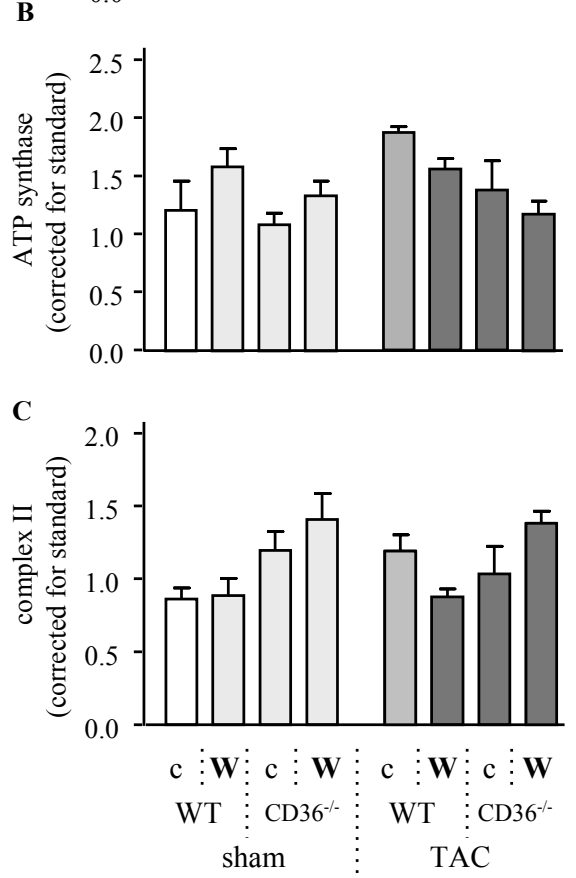

Figure 6.6: Alterations in mitochondrial genes and proteins. (A) mRNA expression levels of CPT1 measured by RT-PCR and (B-C) OXPHOS protein levels, measured by western blotting, all 6 weeks after TAC. Data are mean \pm SEM from 6-8 mice in each group. White bars = control group, light grey bars = metabolic stress (WTD, CD36 ablation or combination), grey bars $=$ mechanophysical stress (TAC), dark grey bars $=$ interaction of stresses. $\mathrm{C}=$ chow, $\mathrm{W}$ $=$ WTD. Statistical analysis was done by 2-Way ANOVA. * vs. WT chow, \$ vs. sham, $\mathrm{p}<0.05$.

WT mice on WTD and CD36-/- mice on a chow diet. All these changes in LV/TL were also reflected in alterations in cardiomyocyte cross sectional area (Fig. 6.3B). In comparison to sham-operated mice, TAC increased mRNA expression of ANF in heart tissue from chow and WTD-fed WT mice 5.4 and 7.6-fold (both $\mathrm{p}<0.05$ ) and even more marked in CD36-/-/chow mice (Fig. 6.3C; 9.1-fold, $\mathrm{p}<0.01)$. Only CD36-/- mice receiving a WTD showed no alteration in ANF mRNA expression after TAC surgery. In sham-operated mice there was no effect of either diet or genotype on the above-mentioned parameters of cardiac hypertrophy (Fig. 6.3A-C). In summary, ablation of CD36 protects against cardiac remodeling.

\section{Molecular alterations underlying cardiac dysfunction}

We investigated several genes that are important in cardiac metabolism and hypertrophy. Pdk4 is important in glucose metabolism; PPAR $\alpha$ and Acsl are involved in fatty acid metabolism, while ANF is regulated by cardiac hypertrophy. mRNA expression of Pdk4 was decreased by $78 \%(p<0.05)$ in hearts from CD36-/- mice (Fig. 6.4A). In addition, PPAR $\alpha$ mRNA expression changed only upon CD36 ablation; its expression increased in comparison to WT expression levels (Fig.4B) $(p<0.01)$. Administration of a WTD increased cardiac mRNA expression of the PPAR $\alpha$ response 
A

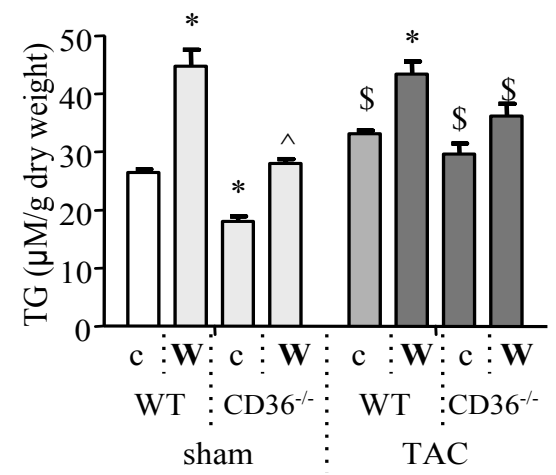

C

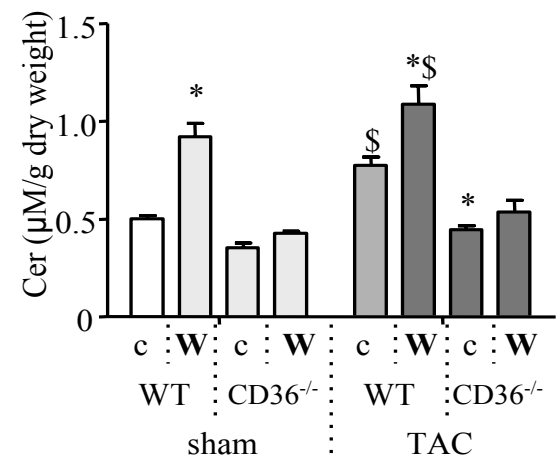

B

$\mathrm{C}$

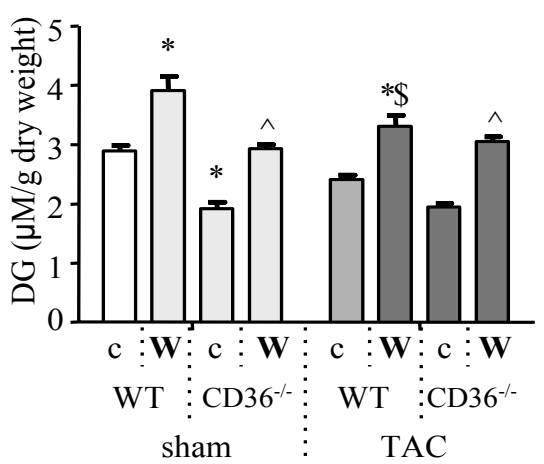

Figure 6.7: Lipid loading of the heart 6 weeks after TAC. (A) Triglyceride (TG), (B) diglyceride (DG) and (C) ceramide (Cer) contents in heart homogenates from sham and TAC-operated mice. Data are mean \pm SEM from 6-8 mice in each group. White bars = control group, light grey bars $=$ metabolic stress (WTD, CD36 ablation or combination), grey bars $=$ mechanophysical stress (TAC), dark grey bars $=$ interaction of stresses. $C=$ chow, W $=$ WTD. Statistical analysis was done by 2-Way ANOVA with Bonferroni post-tests, p $<0.05, *$ vs. WT chow, ^ vs. CD36 $\% /$ chow, \# vs. WT/WTD, \$ vs. sham.

gene Acsl ( $p<0.001)$ (Fig.5). In this way, the increased influx of fatty acids is rapidly directed to their metabolic destination and the cells are protected from the detergent effects of excess fatty acid levels (15). Cardiac mRNA expression of Pdk4 and PPAR $\alpha$ was not altered by WTD or by TAC (Fig.4A-B).

Cardiac protein expression of fatty acid transporter (FATP) 1, FATP6 and plasmalemmal fatty acid binding protein (FABPpm) were not altered in CD36-/- mice, in comparison to WT mice (Fig. 6.5). Additionally, in comparison to WT chow sham mice, WTD administration and/or TAC did not change the protein expression of any fatty acid transporter including CD36 (Fig. 6.5).

We measured CPT1 mRNA expression and protein expression of oxidative phosphorylation (OxPhos) proteins to determine possible alterations in mitochondrial oxidation, and metabolic inflexibility. mRNA expression of CPT1 (Fig. 6.6), the rate limiting enzyme in mitochondrial $\beta$-oxidation, and protein expression 
of mitochondrial ATP synthase and complex II in the electron transport chain (Fig. 6.6) were not changed upon CD36 ablation, WTD administration or TAC surgery. The other OxPhos complexes showed the same lack of changes (data not shown).

Inflammation is known to influence the development of cardiac dysfunction. (36) Both cardiac protein levels of the pro-inflammatory cytokine tumor necrosis factor $\alpha(T N F \alpha)$ as presence of macrophages in LV sections were upregulated after TAC in WT mice, on both diets, in comparison to CD36-/- mice (Fig. 6.4C-E). In shamoperated mice there was no effect of genotype or diet on TNF $\alpha$ protein expression (Fig.4C-E), whereas macrophage presence in LV sections was upregulated by WTD administration in WT mice. In conclusion, CD36 ablation protects against TAC-related increase of inflammation.

\section{Intramyocardial lipid concentrations}

In sham-operated mice, WT mice receiving a WTD showed higher cardiac TG (1.7fold, $p<0.05)$, DG (1.4-fold, $p<0.05)$ and ceramide $(1.8$-fold, $p<0.05)$ contents than WT mice receiving chow. This confirms that WTD promotes intramyocardial lipid accumulation (Fig. 6.7A-C). Sham-operated CD36-/- mice receiving chow showed lower intramyocardial TG $(-32 \%, \mathrm{p}<0.05)$ and DG $(-34 \%, \mathrm{p}<0.05)$ than shamoperated WT mice on a chow diet. WTD exposure in sham-operated CD36-/- mice resulted in less intramyocardial TG (TG: 1.6-fold, $p<0.05)$ and DG $(1.5$-fold, $p<0.05)$ accumulation and prevented ceramide accumulation compared to sham-operated WT mice receiving WTD. TAC increased intramyocardial TG, DG and ceramide levels (Fig. 6.7A-C) (1.2 to 1.6-fold, all p<0.05). The effects of WTD and CD36 ablation on intramyocardial levels of TG, DG and ceramide were similar in TAC compared to sham-operated mice. Lower ceramide levels could result in attenuated formation of toxic aldehydes such as 4 HNE. We have measured 4 HNE levels by western blotting but did not find differences between any of the groups (Suppl. Fig. 6.1). In summary, ablation of CD36 protected against WTD-related increase in cardiac lipid content.

\section{Discussion}

Here we demonstrate for the first time that metabolic stress appears an important denominator for TAC-induced mechanophysical stress to become evident. The deleterious effect of WTD-induced metabolic stress on TAC induced cardiac remodeling and dysfunction was prevented by ablation of the fatty acid transporter CD36. Furthermore, we revealed a tight association between intramyocellular lipid content and decreased cardiac function. 
Effects of metabolic stress on cardiac morphology and function

WTD resulted in a 1.7-fold increase in cardiac lipid content in WT mice (Fig.7), a similar degree of lipid accumulation as found in rats exposed to a similar diet for 10 weeks (32). However, WTD did not induce cardiomyopathy (Fig. 6.2-3).

WTD is known to cause a permanent relocation of CD36 to the sarcolemma and increased CD36-mediated fatty acid uptake into the heart $(1,9,32)$. In the present study WTD administration was not accompanied by increased expression of CD36, or of other fatty acid transporters (Fig. 6.5). Previous studies showed that a 2 -fold increase of FATP1 in hearts from CD36-/- mice did not result in enhanced fatty acid uptake in contraction-stimulated cardiomyocytes (18), suggesting that increased FATP expression cannot alter fatty acid uptake in the working heart.

A recent study showed that excessive cardiac lipid accumulation, induced by PPAR $\alpha$ overexpression, is a major causal factor for the development of cardiomyopathy (46). Ablation of CD36 proved to be protective against intramyocellular TG accumulation and cardiomyopathy. However, in our study WTD exposure did not alter PPAR $\alpha$ gene expression in WT mice or CD36-/- mice which strengthens our idea that PPAR $\alpha$ overexpression is a less physiological model to induce cardiac lipid oversupply than the use of a WTD.

CD36 ablation causes a metabolic stress opposite of that elicited by WTD, an undersupply of lipids to the heart $(12,18,26)$. Accordingly, we showed that accumulation of myocardial lipids and Pdk4 expression were markedly reduced by CD36 ablation, indicating that CD36-ablated hearts rely more on glucose metabolism than do WT hearts. However, CD36-/- mice had no cardiac phenotype. In line with this, transgenic mice with cardiospecific overexpression of the glucose transporter GLUT1 exhibited reduced intramyocardial lipid content without changes in cardiac function (28).

In addition, the excessive intramyocellular lipid accumulation upon a WTD was effectively prevented by CD36 ablation.

In summary, both a WTD and CD36 ablation evoked metabolic stress on the heart resulting in altered intramyocellular lipid concentrations when compared to WT mice on a chow diet, but these changes did not result in altered cardiac function. 


\section{Effects of mechanophysical stress on cardiac morphology and function}

TAC has been reported to increase LV pressure, to induce cardiac remodeling (20) and to provoke alterations in substrate utilization (35). In WT mice on a chow diet, we detected a $30 \%$ increase in cardiac mass due to hypertrophic growth of cardiomyocytes six weeks after TAC. This was accompanied by a large upregulation of ANF expression. However, this degree of hypertrophy was apparently insufficient to result in decreased function. Additionally, TAC had little or no effect on cardiac metabolic parameters, induced a slight increase in intramyocellular lipid concentrations and did not affect gene and protein expression levels of enzymes and transporters important in substrate utilization (Figs. 6.4-6.7).

In summary, TAC induced mechanophysical stress on the heart, resulting in adaptive cardiac remodeling accompanied by only minor changes in cardiac lipid content.

\section{Interaction between metabolic and mechanophysical stress}

Patients displaying obesity and hypertension often suffer from impaired cardiac function. In our mouse model we tried to mimic this combination by starting the mice on a WTD and performing TAC afterwards to induce pressure overload. We found that TAC in combination with a metabolic stress (either WTD or CD36 ablation) evoked a greater cardiac hypertrophy than TAC alone. Importantly, this greater cardiac hypertrophy was accompanied by loss of function as measured by LVESD and FS. This shows that metabolic stress, by itself not affecting cardiac fuction, aggravates the effect of mechanophysical stress on cardiac function.

In a previous study, C57BI/6 mice were exposed to a WTD or a standard diet after TAC surgery which did not affect cardiac remodeling $(2,7)$. However, in that study the role of existing cardiac metabolic stress interacting with cardiac remodeling and dysfunction was not studied. Here, we show that existing metabolic stress interacts with later induced cardiac mechanophysical stress.

\section{Absence of CD36 protects against interaction of stresses}

To test our hypothesis that CD36 ablation could modify the interaction between metabolic and mechanophysical stress we evaluated whether the TAC-induced cardiac dysfunction and greater cardiac remodeling that we had observed in WT mice exposed to a WTD was altered by CD36 ablation. Interestingly, CD36-/- mice that underwent TAC surgery during WTD administration did not develop cardiac dysfunction, nor did they develop adverse cardiac remodeling as observed in 
WT mice on a chow diet. Moreover, CD36 ablation prevented the WTD-induced intramyocellular lipid accumulation in TAC-treated mice. Intramyocellular lipid alteration alone did not affect cardiac function and morphology, but it augmented hypertrophic growth of the heart and development of cardiac dysfunction in response to pressure overload. This shows that when lipid accumulation is prevented by CD36 ablation, thus eliminating metabolic stress, mechanophysical stress is no longer able to affect cardiac function.

Inflammation is known to worsen the progression towards cardiac dysfunction (6). We observed that 6 weeks after TAC the pro-inflammatory cytokine TNF $\alpha$ and the presence of macrophages in LV sections were only upregulated in WT mice. This relates to the observation of Febbraio et al. who found in mice adipocytes and macrophages that CD36 is needed for signaling to genes coding for an inflammatory response $(8,24)$. This suggests that in the heart, ablation of CD36 not only prevents fatty acid uptake but also a detrimental inflammatory reaction.

It has become increasingly evident that mitochondrial dysfunction is an important mechanism contributing to the metabolic cardiomyopathy phenotype (5). We observed that neither CPT1 gene expression, nor protein expression of ATP synthase and complex II of the electron transport chain, was altered as a result of any of the stressors used. Although we did not measure mitochondrial oxidation, these observations suggest that cardiac mitochondrial function was not severely affected by the exposure to intramyocardial lipid levels resulting from WTD, CD36 ablation, or TAC.

\section{Conclusions}

In the presence of a mechanophysical stress, a decrease of $32 \%$ in intramyocardial lipid levels in CD36-/- mice, as well as an increase of 1.7-fold in intramyocardial lipid in WT mice elicited by WTD, are associated with impaired cardiac functioning. Combining these two observations eludes to the conclusion that for the compromised heart, the intramyocardial lipid content should be maintained within a narrow range to maintain cardiac function. Taken together, the intramyocardial milieu, especially the lipid concentration, is a crucial factor to determine the detrimental effects of TAC on cardiac function.

While WTD and CD36 ablation each interact with TAC in the development of cardiac dysfunction, the combination of these interventions did not impair cardiac function. On the contrary, they counterbalanced each other, thereby revealing the metabolic origin of these cardiac diseases. These metabolic roots of 
cardiac dysfunction (33) imply that treatment strategies should have a metabolic character. Because prevalence of the metabolic syndrome and type 2 diabetes are rising, inhibition of CD36 can be a potential approach for treatment of metabolic cardiomyopathy.

\section{Acknowledgements}

The authors would like to thank Mrs. L. Keersmaekers and Mrs. L. Ding for their excellent technical assistance and Biomedic for lending us the Aloka Terason $3000 \mathrm{cv}$.

\section{Grants}

This work was supported by the Dutch Diabetes Research Foundation (Grant number: 2006.00.044), and by the Netherlands Organization for Health Research and Development (NWO-ZonMw) (Grant number 912-04-075). I.O.C.M. Vroegrijk is supported by the 7th FP of the EU-funded "Lipidomics" (Grant number: 202272). D.M. Ouwens is supported by the EU European Cooperation in the field of Scientific and Technical Research (COST) Action BM0602 (Adipose tissue: a key target for prevention of the metabolic syndrome). 


\section{References}

1. Aguer C, Mercier J, Man CY, Metz L, Bordenave S, Lambert K, Jean E, Lantier L, Bounoua L, Brun JF, Raynaud de Mauverger E, Andreelli F, Foretz M, and Kitzmann M. Intramyocellular lipid accumulation is associated with permanent relocation ex vivo and in vitro of fatty acid translocase (FAT)/CD36 in obese patients. Diabetologia 53: 1151-1163, 2010.

2. Akki A, and Seymour AM. Western diet impairs metabolic remodelling and contractile efficiency in cardiac hypertrophy. Cardiovasc Res 81: 610-617, 2009.

3. Alkhateeb H, Chabowski A, Glatz JF, Luiken JF, and Bonen A. Two phases of palmitate-induced insulin resistance in skeletal muscle: impaired GLUT4 translocation is followed by a reduced GLUT4 intrinsic activity. Am J Physiol Endocrinol Metab 293: E783-793, 2007.

4. Bonen A, Luiken JJ, Arumugam Y, Glatz JF, and Tandon NN. Acute regulation of fatty acid uptake involves the cellular redistribution of fatty acid translocase. J Biol Chem 275: 14501-14508, 2000.

5. Boudina S, and Abel ED. Diabetic cardiomyopathy, causes and effects. Rev Endocr Metab Disord 11: 31-39, 2010.

6. Brasier AR. The nuclear factor-kappaB-interleukin-6 signalling pathway mediating vascular inflammation. Cardiovasc Res 86: 211-218, 2010.

7. Chess DJ, Lei B, Hoit BD, Azimzadeh AM, and Stanley WC. Effects of a high saturated fat diet on cardiac hypertrophy and dysfunction in response to pressure overload. J Card Fail 14: 82-88, 2008.

8. Collot-Teixeira S, Martin J, McDermott-Roe C, Poston R, and McGregor JL. CD36 and macrophages in atherosclerosis. Cardiovasc Res 75: 468-477, 2007.

9. Coort SL, Bonen A, van der Vusse GJ, Glatz JF, and Luiken JJ. Cardiac substrate uptake and metabolism in obesity and type-2 diabetes: role of sarcolemmal substrate transporters. Mol Cell Biochem 299: 5-18, 2007.

10. Coort SL, Hasselbaink DM, Koonen DP, Willems J, Coumans WA, Chabowski A, van der Vusse GJ, Bonen A, Glatz JF, and Luiken JJ. Enhanced sarcolemmal FAT/CD36 content and triacylglycerol storage in cardiac myocytes from obese zucker rats. Diabetes 53: 1655-1663, 2004.

11. Fabbri M, Di Meglio S, Gagliani MC, Consonni E, Molteni R, Bender JR, Tacchetti C, and Pardi R. Dynamic partitioning into lipid rafts controls the endo-exocytic cycle of the alphaL/beta2 integrin, LFA-1, during leukocyte chemotaxis. Mol Biol Cell 16: 5793-5803, 2005.

12. Febbraio M, Abumrad NA, Hajjar DP, Sharma K, Cheng W, Pearce SF, and Silverstein RL. A null mutation in murine CD36 reveals an important role in fatty acid and lipoprotein metabolism. J Biol Chem 274: 19055-19062, 1999.

13. Fontaine KR, Redden DT, Wang C, Westfall AO, and Allison DB. Years of life lost due to obesity. JAMA 289: 187-193, 2003.

14. Glatz JF, Bonen A, Ouwens DM, and Luiken JJ. Regulation of sarcolemmal transport of substrates in the healthy and diseased heart. Cardiovasc Drugs Ther 20: 471-476, 2006.

15. Glatz JF, and van der Vusse GJ. Intracellular transport of lipids. Mol Cell Biochem 88: 37-44, 1989.

16. Glatz JFC, Luiken JJFP, and Bonen A. Membrane fatty acid transporter as regulators of lipid metabolism: implications for metabolic disease. Physiol Rev 90: 367-417, 2010.

17. Goudriaan JR, Dahlmans VE, Teusink B, Ouwens DM, Febbraio M, Maassen JA, Romijn JA, Havekes LM, and Voshol PJ. CD36 deficiency increases insulin sensitivity in muscle, but induces insulin resistance in the liver in mice. J Lipid Res 44: 2270-2277, 2003.

18. Habets DD, Coumans WA, Voshol PJ, den Boer MA, Febbraio M, Bonen A, Glatz JF, and Luiken JJ. AMPK-mediated increase in myocardial long-chain fatty acid uptake critically depends on sarcolemmal CD36. Biochem Biophys Res Commun 355: 204-210, 2007.

19. Harmancey R, and Taegtmeyer H. The complexities of diabetic cardiomyopathy: lessons from patients and animal models. Curr Diab Rep 8: 243-248, 2008.

20. Hu P, Zhang D, Swenson L, Chakrabarti G, Abel ED, and Litwin SE. Minimally invasive aortic banding in mice: effects of altered cardiomyocyte insulin signaling during pressure overload. Am J Physiol Heart Circ Physiol 285: H1261-1269, 2003.

21. Hubert HB, Feinleib M, McNamara PM, and Castelli WP. Obesity as an independent risk factor for cardiovascular disease: a 26-year follow-up of participants in the Framingham Heart Study. 
Circulation 67: 968-977, 1983.

22. Hue L, and Taegtmeyer $\mathrm{H}$. The Randle cycle revisited: a new head for an old hat. Am J Physiol Endocrinol Metab 297: E578-591, 2009.

23. Irie H, Krukenkamp IB, Brinkmann JF, Gaudette GR, Saltman AE, Jou W, Glatz JF, Abumrad NA, and Ibrahimi A. Myocardial recovery from ischemia is impaired in CD36-null mice and restored by myocyte CD36 expression or medium-chain fatty acids. Proc Natl Acad Sci U S A 100: 6819-6824, 2003.

24. Kennedy DJ, Kuchibhotla S, Westfall KM, Silverstein RL, Morton RE, and Febbraio M. A CD36dependent pathway enhances macrophage and adipose tissue inflammation and impairs insulin signalling. Cardiovasc Res 89: 604-613, 2011.

25. Koonen DP, Febbraio M, Bonnet S, Nagendran J, Young ME, Michelakis ED, and Dyck JR. CD36 expression contributes to age-induced cardiomyopathy in mice. Circulation 116: 2139-2147, 2007.

26. Kuang M, Febbraio M, Wagg C, Lopaschuk GD, and Dyck JR. Fatty acid translocase/CD36 deficiency does not energetically or functionally compromise hearts before or after ischemia. Circulation 109: 1550-1557, 2004.

27. Kusminski CM, Shetty S, Orci L, Unger RH, and Scherer PE. Diabetes and apoptosis: lipotoxicity. Apoptosis 14: 1484-1495, 2009.

28. Liao R, Jain M, Cui L, D’Agostino J, Aiello F, Luptak I, Ngoy S, Mortensen RM, and Tian R. Cardiacspecific overexpression of GLUT1 prevents the development of heart failure attributable to pressure overload in mice. Circulation 106: 2125-2131, 2002.

29. Lopaschuk GD, Ussher JR, Folmes CD, Jaswal JS, and Stanley WC. Myocardial fatty acid metabolism in health and disease. Physiol Rev 90: 207-258, 2010.

30. Newton AC. Protein kinase C: structural and spatial regulation by phosphorylation, cofactors, and macromolecular interactions. Chem Rev 101: 2353-2364, 2001.

31. Opie LH, and Knuuti J. The adrenergic-fatty acid load in heart failure. J Am Coll Cardiol 54: 16371646, 2009.

32. Ouwens DM, Diamant M, Fodor M, Habets DD, Pelsers MM, El Hasnaoui M, Dang ZC, van den Brom CE, Vlasblom R, Rietdijk A, Boer C, Coort SL, Glatz JF, and Luiken JJ. Cardiac contractile dysfunction in insulin-resistant rats fed a high-fat diet is associated with elevated CD36-mediated fatty acid uptake and esterification. Diabetologia 50: 1938-1948, 2007.

33. Rijzewijk LJ DM. Diabetic Gluco-lipotoxic Cardiomyopathy - Amendable by Metabolic Manipulation? European Endocrinology 4: 2008.

34. Rijzewijk LJ, van der Meer RW, Lamb HJ, de Jong HW, Lubberink M, Romijn JA, Bax JJ, de Roos A, Twisk JW, Heine RJ, Lammertsma AA, Smit JW, and Diamant M. Altered myocardial substrate metabolism and decreased diastolic function in nonischemic human diabetic cardiomyopathy: studies with cardiac positron emission tomography and magnetic resonance imaging. J Am Coll Cardiol 54: 15241532, 2009.

35. Sambandam N, Lopaschuk GD, Brownsey RW, and Allard MF. Energy metabolism in the hypertrophied heart. Heart Fail Rev 7: 161-173, 2002.

36. Satoh M, Minami Y, Takahashi Y, and Nakamura M. Immune modulation: role of the inflammatory cytokine cascade in the failing human heart. Curr Heart Fail Rep 5: 69-74, 2008.

37. Schwenk RW, Luiken JJ, Bonen A, and Glatz JF. Regulation of sarcolemmal glucose and fatty acid transporters in cardiac disease. Cardiovasc Res 79: 249-258, 2008.

38. Severson DL. Diabetic cardiomyopathy: recent evidence from mouse models of type 1 and type 2 diabetes. Canadian journal of physiology and pharmacology 82: 813-823, 2004.

39. Shiri-Sverdlov R, Wouters K, van Gorp PJ, Gijbels MJ, Noel B, Buffat L, Staels B, Maeda N, van Bilsen $\mathrm{M}$, and Hofker $\mathrm{MH}$. Early diet-induced non-alcoholic steatohepatitis in APOE2 knock-in mice and its prevention by fibrates. J Hepatol 44: 732-741, 2006.

40. Taha M, and Lopaschuk GD. Alterations in energy metabolism in cardiomyopathies. Ann Med 39: 594-607, 2007.

41. Takeda N, Manabe I, Uchino Y, Eguchi K, Matsumoto S, Nishimura S, Shindo T, Sano M, Otsu K, Snider $\mathrm{P}$, Conway SJ, and Nagai R. Cardiac fibroblasts are essential for the adaptive response of the murine heart to pressure overload. J Clin Invest 120: 254-265.

42. Tuunanen $\mathrm{H}$, Engblom E, Naum A, Nagren K, Hesse B, Airaksinen KE, Nuutila P, lozzo P, Ukkonen H, 
Opie LH, and Knuuti J. Free fatty acid depletion acutely decreases cardiac work and efficiency in cardiomyopathic heart failure. Circulation 114: 2130-2137, 2006.

43. van den Brom CE, Huisman MC, Vlasblom R, Boontje NM, Duijst S, Lubberink M, Molthoff CF, Lammertsma AA, van der Velden J, Boer C, Ouwens DM, and Diamant M. Altered myocardial substrate metabolism is associated with myocardial dysfunction in early diabetic cardiomyopathy in rats: studies using positron emission tomography. Cardiovasc Diabetol 8: 39, 2009.

44. van der Meer RW, Rijzewijk LJ, de Jong HW, Lamb HJ, Lubberink M, Romijn JA, Bax JJ, de Roos A, Kamp O, Paulus WJ, Heine RJ, Lammertsma AA, Smit JW, and Diamant M. Pioglitazone improves cardiac function and alters myocardial substrate metabolism without affecting cardiac triglyceride accumulation and high-energy phosphate metabolism in patients with well-controlled type 2 diabetes mellitus. Circulation 119: 2069-2077, 2009.

45. van Dis I, Kromhout D, Geleijnse JM, Boer JM, and Verschuren WM. Body mass index and waist circumference predict both 10-year nonfatal and fatal cardiovascular disease risk: study conducted in 20000 Dutch men and women aged 20-65 years. Eur J Cardiovasc Prev Rehabil 2009.

46. Yang J, Sambandam N, Han X, Gross RW, Courtois M, Kovacs A, Febbraio M, Finck BN, and Kelly DP. CD36 deficiency rescues lipotoxic cardiomyopathy. Circ Res 100: 1208-1217, 2007. 
Supplemental data concerning chapter 6 


\section{HNE lane}

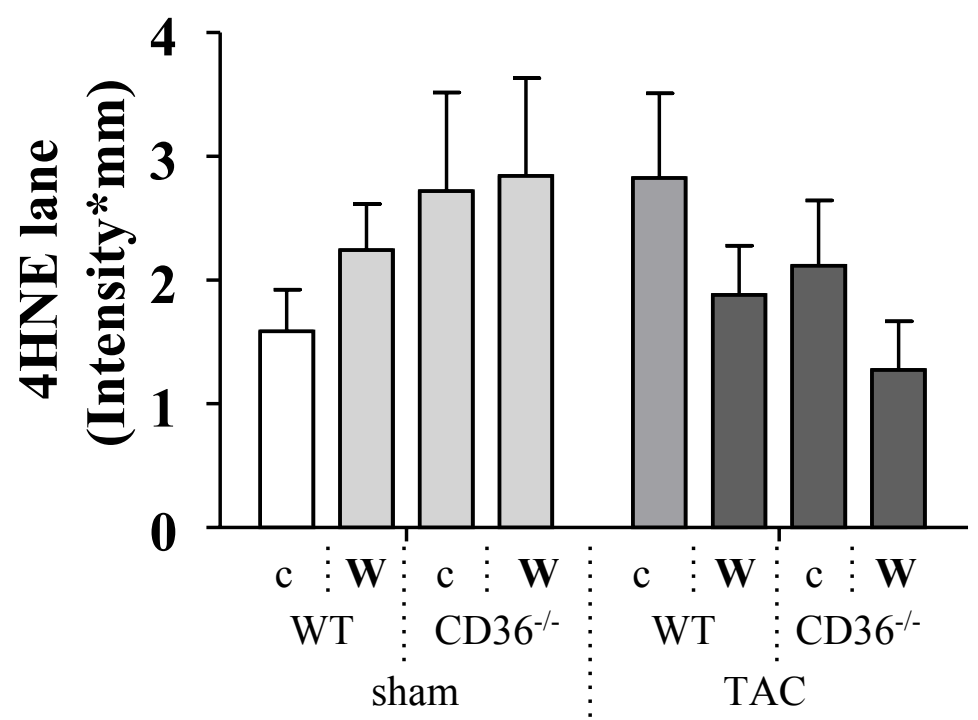

Supplementary figure 6.1: Western blot images of homogenates from left ventricles of all groups. 4-HNE adducts can appaer on any protein. Therefor,e the total lane of each sample was quantitated for band intensities. 4- HNE levels did not change significantly due to WTD, CD36 ablation or TAC. Statistical analysis was performed by 2-Way ANOVA and Bonferroni post-hoc tests. 


\begin{tabular}{|c|cc|}
\cline { 3 - 3 } \multicolumn{1}{c|}{} & \multicolumn{2}{c|}{ Primer } \\
Genename & \multicolumn{2}{c|}{ Reverse } \\
\cline { 3 - 3 } ANF & ATTGACAGGATTGGAGCCCAGAGT & TGACACACCACAAGGGCTTAGGAT \\
Cpt-1 & CCAAAACAGTATCCCAATCATCTG & CTGGGCGTTCGTCTCTGAA \\
Pdk4 & GCATTTCTACTCGGATGCTCATG & CCAATGTGGCTTGGGTTTCC \\
PPAR $\alpha$ & CCTCAGGGTACCACTACGGAGT & CAGCCGAATAGTTCGCCG \\
HPRT & AGCAGTACAGCCCCAAAATGG & TCCTTTTCACCAGCAAGCTTG \\
\hline
\end{tabular}

Supplementary table 6.1: Primersets for qPCRs.

\begin{tabular}{|l|l|}
\hline Protein of interest & Company \\
\hline CD36 & GenTex Inc. (San Antonio, TX, USA) \\
\hline FATP1 & Santa Cruz Biotech Inc. (Santa Cruz, USA) \\
\hline FATP6 & kind gifts from Dr. A. Stahl (Wake Forest University School of Medicine) \\
\hline FABPpm & $\begin{array}{l}\text { kind gifts from Dr. J. Calles-Escadron (Baptist Medical Center, Winston- } \\
\text { Salem, USA) }\end{array}$ \\
\hline Oxphos proteins & Mitosciences (Eugene, OR, USA) \\
\hline TNF $\alpha$ & Abcam (Abcam \#AB6671, Cambridge, UK) \\
\hline GAPDH & Abcam (Cambridge, USA) \\
\hline
\end{tabular}

Supplementary table 6.2: Antibodies for western blotting.

\begin{tabular}{|c|c|c|c|}
\hline & WT & CD36-/- & p-value \\
\hline Body weight (g) & $25.06 \pm 0.33$ & $25.88 \pm 0.22$ & 0.34 \\
\hline Fractional shortening (\%) & $43.83 \pm 3.19$ & $46.41 \pm 2.27$ & 0.62 \\
\hline
\end{tabular}

\section{Supplementary Table 6.3}

Body weight and fractional shortening at start of experiment when mice were 12 weeks-of-age: Wild-type (WT). Data are mean \pm SEM from 15 mice in each group. Statistical analysis was done by Student t-test. 

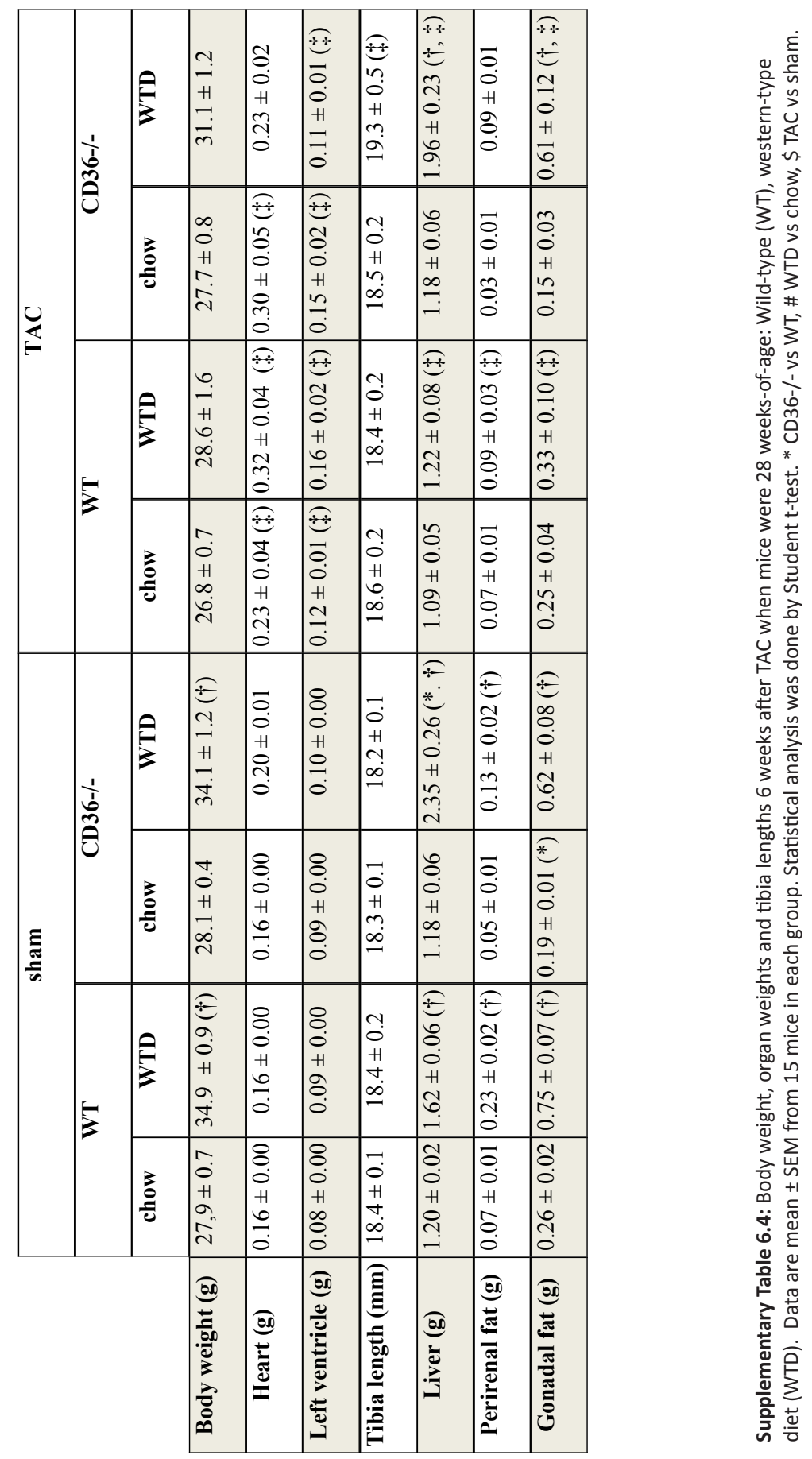
Chapter 6

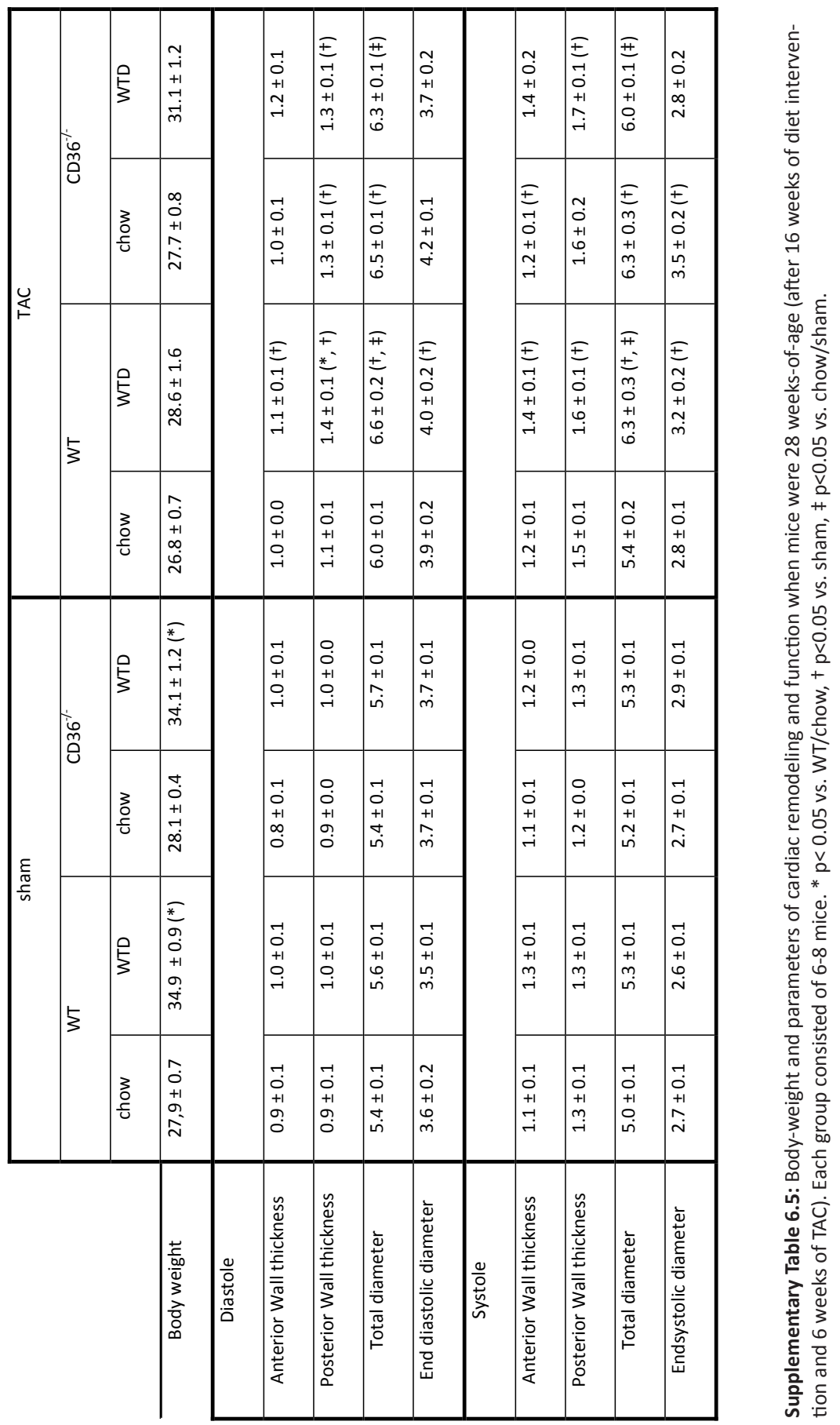


Chapter 7

General discussion 


\section{Introduction}

Currently, cardiometabolic diseases, including cardiovascular disease and type 2 diabetes, globally constitute an increasing health problem, not only in the Western world, but even to a greater extent in developing countries $(1,2)$. Although scientists have devoted many years of research and efforts to implement preventive measures, the world population suffering from cardiovascular disease and obesity and type 2 diabetes remains to rise (3). Studies, in which type 2 diabetes patients were compared to controls, have shown that substrate metabolism of the human heart shifts towards fatty acids for its ATP production at the expense of glucose utilization $(4,5)$. The greater influx of fatty acids exceeds the mitochondrial $\beta$-oxidative capacity (6) resulting in intramyocellular lipid accumulation and decreased insulinstimulated glucose uptake (7). In the presence of cardiac stress such as ischemia, these alterations may lead to heart failure (4). It was found that cardiomyocytes isolated from insulin-resistant rats take up more fatty acids, which correlated with increased sarcolemmal presence of the fatty acid transporter $\operatorname{CD} 36(8,9)$. Insulin, as well as increased cardiac work, stimulate glucose and fatty acid uptake, and glucose transporter 4 (GLUT4) and fatty acid transporter (CD36) translocation, suggesting that similar mechanisms regulate GLUT4 and CD36 translocation (10). However, glucose uptake and GLUT4 localization were altered differently from fatty acid uptake and CD36 localization in cardiomyocytes isolated from insulin-resistant rats. GLUT4 was found to reside more intracellularly, and insulin-stimulated glucose uptake and GLUT4 translocation were reduced (11). These results prompted us to hypothesize the existence of a regulatory mechanism that differentiates between GLUT4 and CD36 trafficking. Surprisingly, at the start of this project, all known regulatory mechanisms for GLUT4 and CD36 translocation were similar. Therefore, to contribute to a better understanding of the development of cardiac dysfunction in patients with obesity and type 2 diabetes, our project was designed to investigate the subcellular trafficking of CD36 as a target to prevent the development of cardiac dysfunction in cell systems and animal models of type 2 diabetes.

The first hypothesis stated that the chronic and continuous presence of CD36 at the sarcolemma contributes to the development of diabetes-related cardiac dysfunction. This was tested in two in-vitro models for cardiomyocyte insulin resistance, and in CD36 $\%$ mice exposed to a western type diet. In a proof-of-concept study it was found that blocking CD36-mediated fatty acid uptake, by an anti-CD36 antibody in isolated adult rat cardiomyocytes (Chapter 4), or genetic ablation of CD36 in a knock-out mouse (Chapter 6), prevented lipid accumulation and the development of insulin resistance and contractile dysfunction in cardiomyocytes (Figure 1). However, these 
preventive measures could not only be ascribed to inhibition of CD36-mediated fatty acid uptake but, also to alteration of CD36-mediated signaling. How the different functions of CD36 can affect the feasibility of CD36 as a treatment target will be further discussed below.

In addition, it was tested if bypassing defective insulin signaling via contractionmediated signaling could prevent the loss of insulin-stimulated glucose uptake related to permanent CD36 translocation. During contraction, not only AMP-activated protein kinase (AMPK), but also protein kinase $D(P K D)$, has been shown to be involved in contraction-induced stimulation of glucose uptake (12). Overexpression of these kinases in cultured adult rat cardiomyocytes enhanced basal and insulin-stimulated glucose uptake, and prevented the induction of insulin resistance in cultured adult rat cardiomyocytes exposed to medium containing a high concentration of insulin or palmitate (Chapter 5). However, AMPK and PKD appeared to achieve this through distinct pathways. How activation of AMPK or PKD might impact on the loss of insulin-stimulated glucose uptake in cardiomyocytes made insulin resistant by exposure to high insulin or high palmitate medium will be discussed in relation to recent literature.

Our second hypothesis stated that interference with the trafficking of CD36 normalizes myocardial lipid metabolism and improves insulin resistance, ultimately resulting in amelioration of cardiac dysfunction. To test this hypothesis, the subcellular trafficking machinery underlying aberrant trafficking of GLUT4 and CD36 in insulin resistant cardiomyocytes was first examined in insulin sensitive rat cardiomyocytes. We succeeded in finding subcellular trafficking components, the actin cytoskeleton and endosomal $\mathrm{pH}$, that are differently involved in GLUT4 and CD36 trafficking in rat cardiomyocytes (Chapters $\mathbf{2}$ and 3). Endosomal pH is regulated by the v-type ATPase, but how exactly the v-type ATPase is involved in the regulation of GLUT4 and CD36 translocation is not known yet. In addition, this differential regulation suggests that aberrant functioning of trafficking components may result in the altered translocation of GLUT4 and CD36 as observed in earlier studies in isolated cardiomyocytes from obese Zucker rats or rats exposed to a high-fat diet $(9,13)$. Hence, it is of interest to discuss this finding in relation to literature and to some preliminary results from invitro models for cardiomyocyte insulin resistance.

Inhibition of CD36-mediated fatty acid uptake as strategy to prevent cardiomyocyte insulin resistance and dysfunction

It has been shown that myocellular triacylglycerol accumulation and plasmalemmal CD36 presence precede the development of insulin resistance and type 2 diabetes in hearts from rodent models for insulin resistance $(9,14)$. In addition, it is known that 
CD36-/- mice display increased muscle insulin sensitivity (15), yet its effect on cardiac insulin sensitivity is not known yet. Results from human genetic profiling studies suggest that homozygous and heterozygous CD36 gene mutations differently affect metabolic and cardiac parameters. Homozygous mutations in the CD36 gene reduce cardiac LCFA uptake (16), and associate with type 2 diabetes in a Dutch cohort (17). On the contrary, heterozygous mutations indicated that down regulation of CD36 expression is protective against metabolic syndrome and insulin resistance (1719). The relation of CD36 gene mutations to cardiovascular risk are less equivocal; increases (20), and independent of cardiovascular risk (21).

Ablation of CD36 in mice proved to be protective against excessive cardiac lipid accumulation, induced by PPAR $\alpha$ overexpression, and cardiomyopathy (46). The hypothesis that the chronic and continuous presence of CD36 at the sarcolemma contributes to the development of diabetes-related cardiac dysfunction was tested in in-vitro models for cardiomyocyte insulin resistance (Chapter 4) and in CD36/- mice exposed to a western type diet (Chapter 6). Using cultures of isolated cardiomyocytes, we showed that blocking CD36-mediated fatty acid uptake prevented cardiomyocyte triacylglycerol accumulation and the development of insulin resistance and contractile dysfunction (Chapter 4), suggesting that blocking of CD36 indeed evokes insulin sensitizing actions (Figure 7.1). In addition, it was shown that ablation of CD36 prevents western-type diet related cardiac triacylglycerol, diacylglycerol and ceramide accumulation, and the development of cardiac dysfunction following pressure overload (Chapter 6), suggesting that ablation of CD36 also prevents the accumulation of fatty acid metabolites. Both anti-CD36 antibody treatment and CD36 ablation reduced lipid accumulation in the experimental conditions where cells, or mice, were exposed to a high amount of lipids. Anti-CD36 antibody treatment enhanced insulin-mediated Akt and GSK3 $\beta$-phosphorylation, suggesting an insulin sensitizing action of anti-CD36 antibody treatment. Cardiac insulin sensitivity per se was not studied in isolated cardiomyocytes from WT and CD36\% mice exposed to a western-type diet. Further research should reveal if in vivo ablation of CD36 has similar beneficial effects on cardiac insulin signaling as the in-vitro results from antiCD36 antibody treatment.

The signaling function of CD36 has first been studied in platelets, which was continued in other cell types later and led to the discovery of various ligands and other functions of CD36. In cardiomyocytes CD36 facilitates LCFA transport, in platelets, however, CD36 is known to bind thrombospondin-1 (22), in macrophages it functions as a scavenger receptor for oxidized low-density lipoproteins (oxLDL) and oxidized phospholipids (23-25), and in microglia it binds amyloid- $\beta$ (26) (Figure 

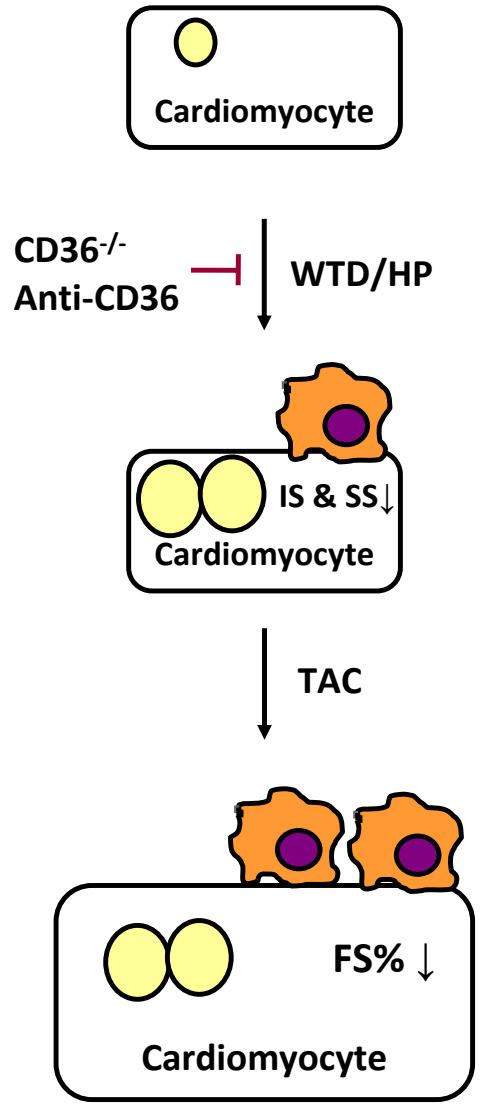

Figure 7.1: Summary of results from chapter 4 and 6. Western-type diet (WTD) administration to wildtype mice, or high palmitate (HP) medium administration to rat cardiomyocytes, resulted in increased intramyocellular lipid accumulation (yellow circles), infiltrating macrophages (orange cells) in the myocardium of mice, and reduced insulin sensitivity (IS) and sarcomere shortening (SS) in rat cardiomyocytes. Pressure overload, induced by transverse aortic constriction (TAC) induced cardiac hypertrophy, reduced fractional shortening, (FS\%) and lead to a further increase of lipid accumulation and macrophage infiltration. Ablation of the fatty acid transporter CD36, culturing in the presence of an antiCD36 antibody, prevented lipid accumulation in both studies, and macrophage infiltration in mouse hearts.
7.2). Already in the early nineties the signaling function of CD36 in human platelets has been reported to act through members (Fyn, Lyn, Yes and Syk) of the Src-family of protein-tyrosine kinases (22, $23,27,28)$. Thrombospondin-1 binding to CD36 mediates Src-kinase activation and subsequent inhibition of the cyclic-AMP/ protein kinase A (PKA) axis, which is an important inhibitor of platelet aggregation (22). Thrombospondin and oxLDL binding to CD36 can also affect platelet aggregation via Syk-induced Ca2+ fluxes (28). Recently, it was shown that Src-family kinases compete for association with CD36 in the process of microvascular development (29). In the presence of thrombospondin1, CD36 associated with Fyn, and in the absence of thrombospondin-1 CD36 associated with Src. It was hypothesized that thrombospondin-1 inhibits VEGFmediated Akt survival signaling by the recruitment of Fyn to CD36 (29). Further research in CD36-/- mice has shown that in white adipose tissue, the activity of the CD36-C-Jun N-terminal kinase (JNK)insulin receptor substrate (IRS) cascade was reduced, which enhanced insulinstimulated Akt-phosphorylation (24). We extrapolated that ablation of CD36 might enhance insulin signaling in the heart as well. It would be of interest to investigate if anti-CD36 treatment also reduces JNK and IRS phosphorylation in the in-vitro models for cardiomyocyte lipid accumulation and insulin resistance described in chapter 4 . Taken together, ligand binding to CD36 can affect Akt-phosphorylation, possibly by a 
reduction of the CD36-JNK-IRS cascade.

Inflammation is known to worsen the progression towards cardiac dysfunction (30). Recently, CD36-mediated intracellular signaling has attracted attention not only in the regulation of platelet coagulation (28), but also in macrophage migration (31) and inflammation (24). In microglia, i.e. macrophages of the brain, oxLDL binding to $\mathrm{CD} 36$ promotes $\mathrm{H}_{2} \mathrm{O}_{2}$ secretion and so mediate brain inflammation in Alzheimer's disease (32). It was found that oxLDL binding to CD36 on macrophages stimulates intracellular activation of the transcription factor nuclear factor $\mathrm{k} B$ (NFKB) and subsequent secretion of inflammatory cytokines (23). The expression of inflammatory cytokines such as TNF $\alpha$ and IL-6 are markedly reduced in CD36 1- macrophages (33). Previously, it had been shown that oxLDL-CD36 mediated signaling in macrophages resulted in activation of Src-tyrosine kinases (34) and macrophage trapping (31). The involvement of CD36 in these inflammatory cascades is in line with the reduced TNF $\alpha$ levels and macrophage infiltration that we have observed in left ventricle sections of $\mathrm{CD} 36^{-/}$exposed to a western-type diet and/or pressure overload (Chapter 6). Additionally, the use of $\mathrm{CD}^{-1-}$ mice has revealed that

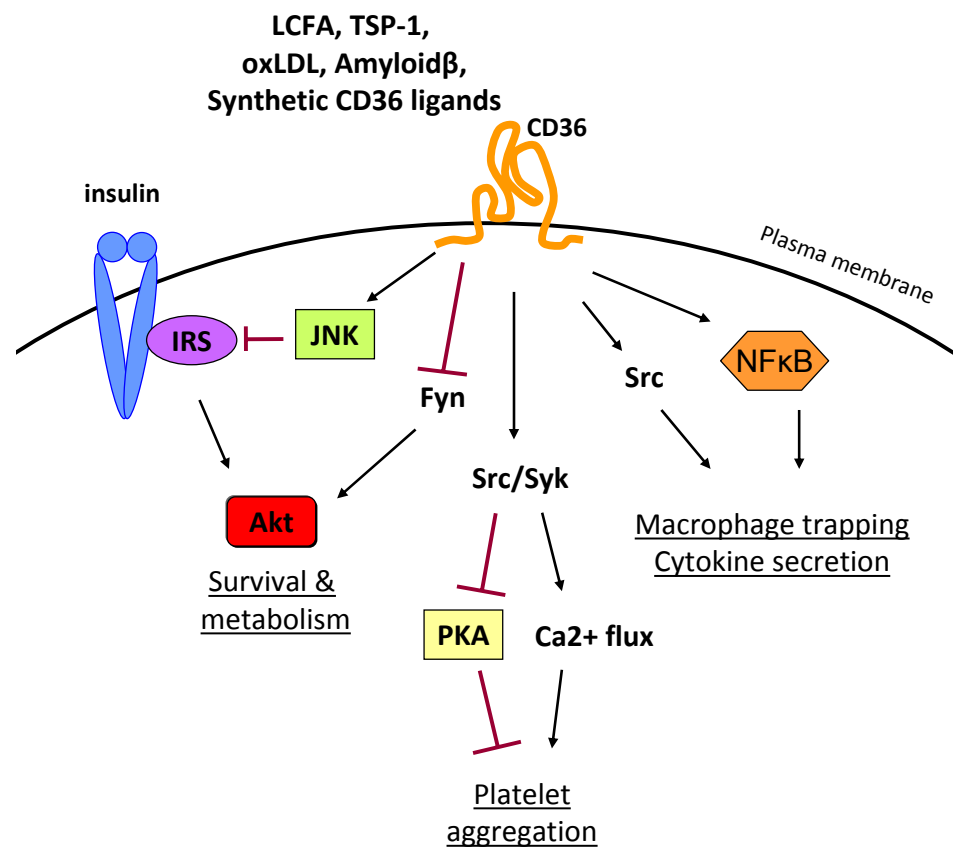

Figure 7.2: Tentative scheme of CD36-induced signalling as investigated in different cell types. Several Src-family tyrosine kinases may serve in CD36-induced activation of Jun- $\mathrm{N}$-terminal kinase (JNK), Akt, protein kinase A (PKA), Ca2+ signalling and Nuclear Factor K B (NFKB). 
macrophage presence of CD36 aggravates hepatic inflammation in a mouse model for non-alcoholic steatohepatitis (35), and brain inflammation in a mouse model for Alzheimer's disease (36). The role of these processes in humans remains to be elucidated. Altogether these studies suggest that CD36 may be a possible target to reduce the aggravating action of infiltrating macrophages and inflammation in experimental diabetic cardiomyopathy.

Where do lipids end up when CD36-mediated fatty acid is blocked by anti-CD36 treatment, and is this not inducing other pathological problems? In CD $36^{-/}$mice lipids are redirected to the liver (Chapter 6), whereafter the mice develop hepatic steatosis (15). In addition, they develop hepatic insulin resistance, while skeletal muscle insulin-sensitivity is increased. Thus, the increased peripheral insulin sensitivity may prevent the occurrence of fasting hyperglycaemia in this model. Additionally, studies in a mouse model for non-alcoholic steatohepatitis (NASH) have shown that hepatic steatosis is not a prerequisite for the development of hepatic inflammation (37). Studies have reported that the prevalence of hepatic steatosis is $20-40 \%$ in Western populations, while the prevalence of NASH is $2-4 \%(38,39)$. Why hepatic steatosis proceeds to NASH in one person, and not in the other, is not known yet. These data suggest that the liver can process increased fatty acid supply, but before applying antiCD36 treatment in humans more research should be done to reveal the alterations that trigger stable NAFLD to develop into NASH. When investigating cardiomyocytes it was shown that blocking CD36-mediated fatty acid uptake into cardiomyocytes not only reduces fatty acid uptake. It also increases basal glucose uptake, which is known to be involved in the development of cardiomyocyte hypertrophy. Combined, these findings suggest that proper titration of anti-CD36 treatment is necessary to avoid a total reliance on the liver for lipid processing, and to avoid a total shift of cardiomyocyte metabolism towards glucose utilization.

Taken together, CD36 ligands that inhibit fatty acid uptake, inflammatory reactions and JNK signaling would be feasible treatments for patients with diabetic cardiomyopathy. In addition, CD36-mediated intracellular signaling clearly is an interesting research topic which should be studied further to reveal its importance in cardiac metabolism and function.

Overexpression of contraction-mediated kinases as strategy to bypass defective insulin signaling

Insulin, as well as increased cardiomyocyte contraction, stimulate glucose uptake and GLUT4 translocation (40). Since insulin action is abrogated in the insulin resistant heart, and exercise is known to have insulin-sensitizing actions (41), activation of contraction-induced signaling proteins seemed a feasible strategy to bypass the 
defective insulin-signaling cascade $(12,42)$. Upon increased contraction both AMPactivated protein kinase (AMPK) and protein kinase $D$ (PKD) are activated, and mediate the stimulation of glucose uptake into cardiomyocytes. We showed that overexpression of AMPK or PKD differently prevented the loss of insulin-stimulated glucose uptake in cultured adult rat cardiomyocytes exposed to medium containing a high concentration of insulin or palmitate. AMPK seemed to enhance insulinsignaling directly, whereas overexpression of PKD seemed to enhance insulinsensitivity via a reduction of the lipid stores.

The preventive action of AMPK overexpression on alterations in substrate uptake might be explained by its effects on cytoskeletal elements. It is known that in normal insulin-sensitive cardiomyocytes different subcellular components (e.g., soluble NSF attachment protein receptor (SNARE) proteins, and cytoskeletal actin, see [25, 34]) are involved in insulin-stimulated glucose versus LCFA uptake. For example, insulin is known to induce reorganization of cytoskeletal actin which affects GLUT4 translocation and glucose uptake (10), whereas we have shown in chapter $\mathbf{3}$ that this process is not involved in CD36 translocation and fatty acid uptake. In addition, a recent study showed that berberine, an AMPK activator, was also able to enhance insulin-stimulated GLUT4 translocation and glucose uptake in insulin resistant cells by improvement of insulin-induced actin reorganization (43). Therefore, another mechanism by which AMPK activation may prevent the development of insulin resistance may be its effects on actin cytoskeleton reorganization.

In addition to insulin-stimulated glucose uptake, culturing cardiomyocytes with AdAMPK prevented inhibition of insulin-stimulated Akt-phosphorylation in both experimental media. Previously, it was shown that AMPK activation (by biguanides or oligomycin) or AMPK adenoviral-overexpression restores insulin-stimulated AktSer473/Thr308-phosphorylation and glucose uptake in cardiomyocytes cultured in medium containing a high concentration of insulin [31]. It is known that mTOR inhibition of insulin-signalling is increased in insulin resistant cells, and that inhibiting mTOR signalling (via AMPK activation) is sufficient to increase insulin sensitivity in term of Akt phosphorylation [36].

Therefore, it may be speculated that AMPK activation prevents both lipid-induced as well as insulin-induced reductions in insulin sensitivity by its effects on mTOR signaling (Figure 7.3). Future experiments may resolve if AMPK increases insulin sensitivity by affecting actin reorganization or by its effects on mTOR signaling, or both.

Overexpression of PKD in primary rat cardiomyocytes, cultured in medium containing a high concentration of insulin or palmitate, prevented the loss of insulin- 


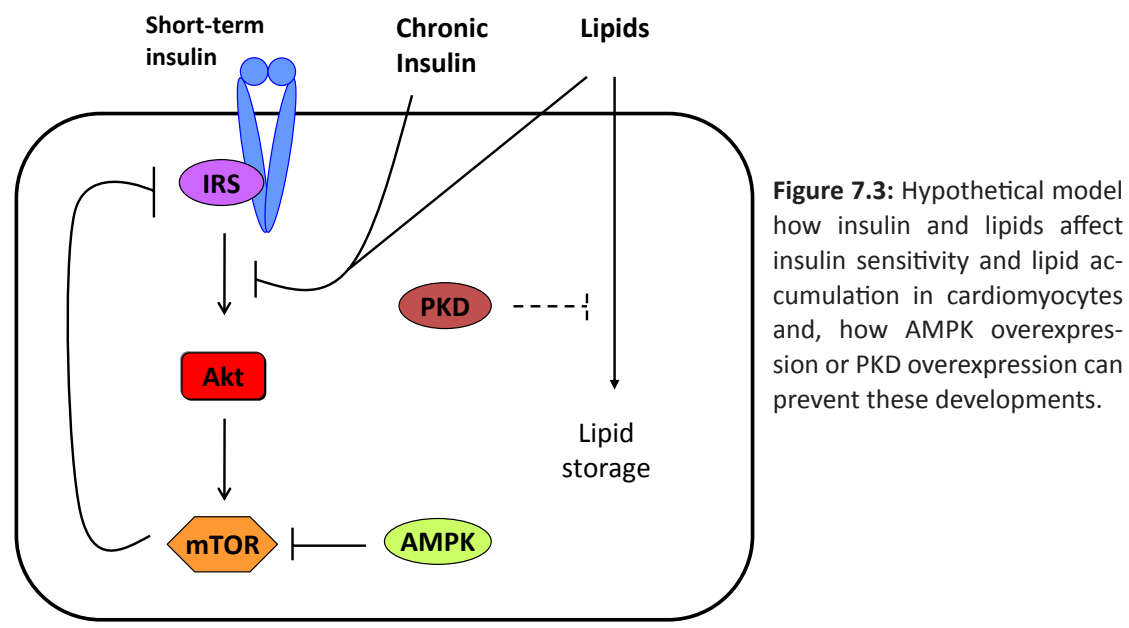

stimulated glucose uptake and triacylglycerol accumulation (chapter 5). How reduced lipid storage improves insulin-stimulated glucose uptake in these cardiomyocytes, without altering insulin-mediated Akt signaling, is not known yet. The role of PKD in cellular metabolism is a relatively novel research subject and downstream PKD targets have been incompletely evaluated. Possibly, PKD activates TG hydrolysis, although there is no support for this notion yet. Another possibility is an indirect action of PKD-mediated reduction of lipid stores. For example, it is known that lipid droplets compete for SNARE-associated proteins (SNAP) 23 with the insulinstimulated GLUT4 translocation process [39]. When lipid storage and lipid droplets reduce SNAP23 would be available to re-participate in insulin-stimulated GLUT4 translocation. Future experiments may resolve what the downstream targets of PKD are. The exact mechanism then how PKD affects lipid storage and prevents lipidinduced insulin resistance needs to be further investigated.

Bypassing defective insulin-signalling by AMPK or PKD activation appear interesting strategies to prevent loss of insulin-stimulated glucose uptake in cardiomyocytes. However, AMPK or PKD activation both enhanced basal glucose uptake into cardiomyocytes, which is known to be involved in the development of cardiomyocyte hypertrophy, suggesting that proper titration of specific AMPK or PKD activators is necessary to avoid a total shift of cardiomyocyte metabolism towards glucose utilization. Several AMPK-activating agents, such as the biguanide metformin and resveratrol, currently serve as blood-glucose lowering agents (44). Although metformin improved glycemic control, it did not improve cardiac function in type 2 diabetes patients (45), suggesting that improvement of glucose homeostasis per se is not enough to improve cardiac function. PKD activation could 
be an interesting novel strategy; however, specific PKD activators do not exist yet. Further research should investigate the exact mechanism by which PKD activation, in comparison to AMPK activation, prevents loss of insulin-stimulated glucose uptake into cardiomyocytes, and should reveal if AMPK and PKD activation are additive in their preventive action.

\section{Endosomal pH regulation is involved in subcellular trafficking of GLUT4 and CD36}

In chapter 3 we have described that endosomal pH plays a dissimilar role in subcellular distribution of GLUT4 and CD36, and glucose and fatty acid uptake (46). Endosomal alkalinization was involved in stimulus-induced, but not in basal, GLUT4 translocation. This was opposite for CD36 translocation; endosomal alkalinization was involved in basal, but not in stimulus-induced processes.

In all eukaryotic cells, and this in cardiomyocytes, $\mathrm{pH}$ gradients between cytosolic and intracellular compartments are controlled by the proton-pump action of the vtype ATPase $(5,47)$. This $\mathrm{H}^{+}$-ATPase uses the energy released during the cleavage of the $\gamma$-phosphate group of ATP to pump protons into the lumen of the endosomes and thus regulates the acidity of intracellular compartments [3, 5]. V-type ATPase has been localized to endosomes and lysosomes but also to the Golgi, small vesicles and the plasma membrane (47). The v-type ATPase is a multicomplex protein with two sectors, the integral membrane $\mathrm{V} 0$ part which constitutes the proton conducting domains, and the cytosolic V1 part which binds and hydrolyses ATP. The V0 sector (260 kDa) consists of subunits a, c, c', $d$ and e, and V1 consists (650 kDa) of subunits $A-H[6,8,9]$.

Bafilomycin $A$ is used as an inhibitor of v-type ATPase functioning (48). Some researchers debate the specificity of v-ATPase inhibitor bafilomycin A (48). Although we did show similar effects on glucose and fatty acid uptake with two structurally and functionally different compounds (bafilomycin A and monensin), confirmation of these findings by siRNA knock down of one of the subunits of v-type ATPase (subunit B2) in cardiomyocytes would strengthen our findings. Unfortunately, siRNA knock down is not possible in rat cardiomyocytes, but it is possible in a cardiomyocyte cell line, HL-1 cells, that express GLUT4 and CD36 and show similar regulation of substrate uptake as rat cardiomyocytes $(49,50)$. It was established that bafilomycin $A$ and monensin similarly reduced chloroquine accumulation in $\mathrm{HL}-1$ cells as in rat cardiomyocytes (Figure 7.4A-B). Both compounds reduced chloroquine accumulation in a dose responsive manner. Furthermore, subunit B2 was detected by western blotting in $\mathrm{HL}-1$ cells, as well as in rat cardiomyocytes (CMC) using rat brain as a positive control (Figure 7.4C). Finally, we searched for another method to visualize intracellular $\mathrm{pH}$ values. We have used lysosensor DND-189 to measure 
A

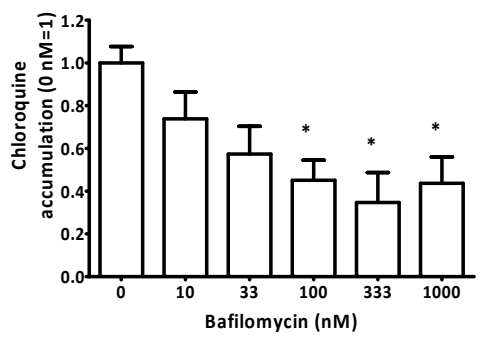

B

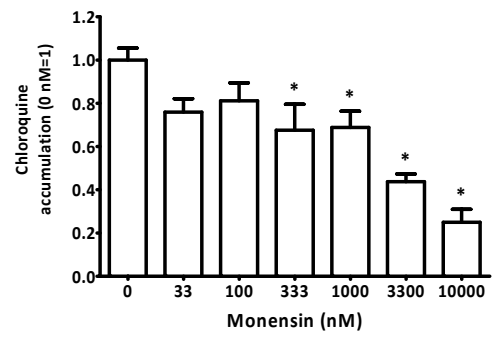

C

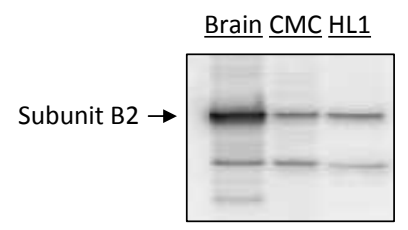

D

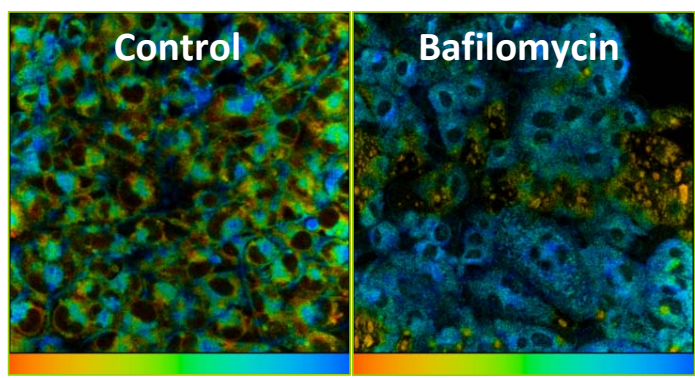

Figure 7.4: HL-1 cells are a suitable cardiomyocyte cell line (Schwenk (2010) Diabetologia) to study regulation of endosomal $\mathrm{pH}$. Dose response curves for the effect of bafilomycin $A(A)$ or monensin (B) on chloroquine accumulation in HL-1 cells. HL-1 cells were preincubated for 25 minutes with bafilomycin or monensin, whereafter the cardiomyocytes were incubated for 20 minutes with $3 \mathrm{H}-$ labelled chloroquine. Then cells were washed, lysed and radioactivity was measured. Mean -/+ SEM are shown from 3-5 different experiments. Statistics were done by One-Way ANOVA with Bonferroni post-test, ${ }^{*} \mathrm{p}<0.05$ (C) subunit B2 of the v-ATPase complex is expressed in rat brain (positive control), rat cardiomyocytes (CMC) and $\mathrm{HI}-1$ cells as shown by western blotting with an antibody from Abcam. (D) Bafilomycin disturbs cellular $\mathrm{pH}$ gradients in $\mathrm{HL}-1$ cells as shown by lysosensor DND-189 (invitrogen) life time imaging. A short life time is depicted in red and corresponds to high $\mathrm{pH}$, whereas a long life time is depicted in blue and corresponds with a low $\mathrm{pH}$.

$\mathrm{pH}$ variations in $\mathrm{HL}-1$ cells (Figure 7.4D). Future experiments should reveal if knock down of subunit B2 indeed reduces chloroquine accumulation, reduces stimulusinduced GLUT4 translocation and increases basal CD36 translocation.

The mechanisms by which v-ATPase is involved in basal and stimulated GLUT4 and CD36 translocation in cardiomyocytes is not known yet. Clearly, this topic needs further investigation since inhibition of the v-type ATPase resulted in cellular positioning of GLUT4 and CD36 (Chapter 2 and 3) that was earlier observed in cardiomyocytes from rodent models for insulin resistance, proposing that endosomal $\mathrm{pH}$ regulation is disturbed in insulin resistance. Suggestions for the mechanistic involvement of v-type ATPase in vesicular translocation can be found in $\beta$-cell, bone 
and kidney research, in which the v-type ATPase has cell specific functions (51).

Moreover, v-type ATPase activity can be altered by several mechanisms of which some relate to cell metabolism (52). For example, v-type ATPase activity itself has thoroughly been studied in yeast and then mainly the reversible dissociation of the complex into the V0 and V1 parts $(53,54)$. This regulatory mechanism occurs not only in yeast, but also in insect cells and mammalian renal cells (55). In yeasts and renal cells, v-type ATPase dissociation occurs in response to glucose depletion from the medium, although the significance of these changes is still unclear in renal cells. If this reversible dissociation is also important in other cell types and if this affects vesicular translocation remains to be elucidated (Figure 7.5). One first step could be to investigate if GLUT4 and CD36-containing vesicles in cardiomyocytes also hold the v-type ATPase complex. A second step could be to test if the association between the V0 and V1 part of the v-type ATPase affects GLUT4 and CD36 translocation.

Besides, it was observed that inhibition of v-type ATPase in $\beta$-cells resulted in increased vesicular $\mathrm{pH}$ and a rapid extrusion of insulin from its vesicles $(56,57)$. In relation to this observation, it was shown that alteration of the glucose concentration of the culture medium also affected the secretion of insulin (58). Combining these

Figure 7.5: Suggestions how v-type ATPase can be affected by metabolic changes and how vtype ATPase might be involved in intracellular vesicle trafficking. Alterations in the metabolic milieu of a cardiomyocyte can alter the activation status of AMP-activated protein kinase (AMPK) and protein kinase $A$ (PKA), which on its turn might affect v-type ATPase activity. The Vo part of the v-type ATPase might also be involved in positioning of intracellular vesicles at the sarcolemma and thus aid in docking and fusion.

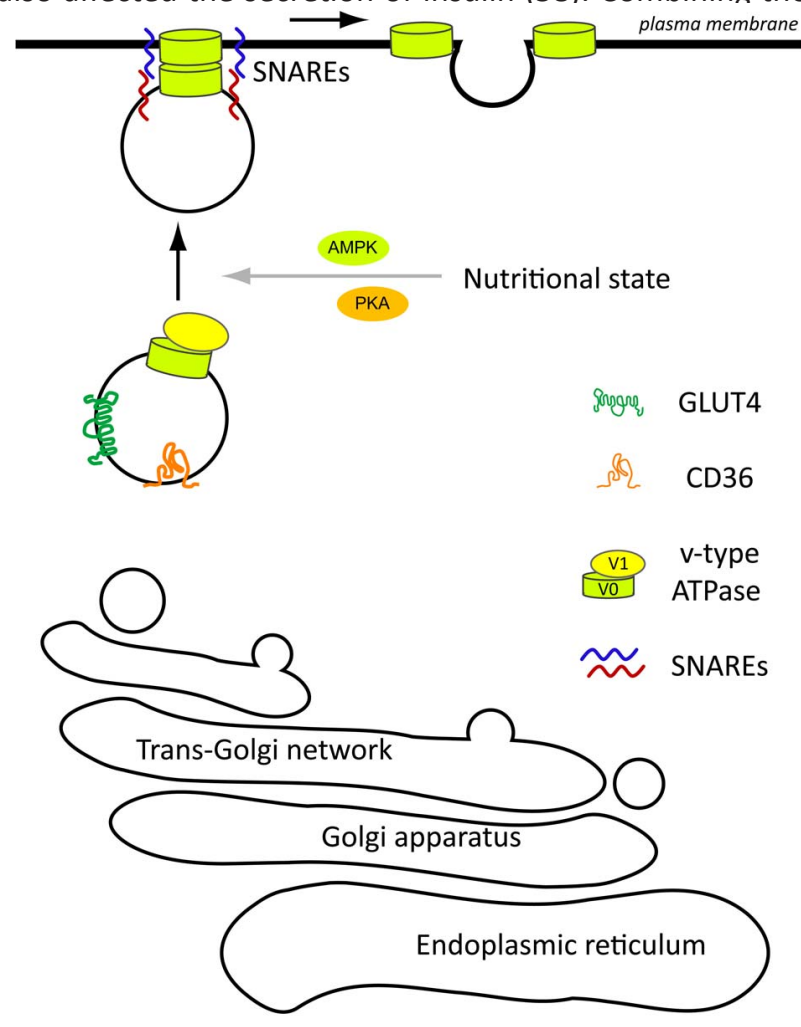


observations led to the hypothesis that increased glucose concentration augments v-type ATPase containing vesicle translocation and prime these vesicles for fusion with the plasma membrane.

How differing glucose concentrations control v-type ATPase activity and translocation might be explained by the activity of the metabolic sensors, protein kinase $A$ (PKA) and AMPK. Upon an alteration of the cellular nutritional state, cellular bicarbonate levels increase, and the soluble adenylate cyclase (sAC) is activated $(59,60)$. sAC on its turn increases cellular cAMP levels and PKA activity, resulting in increased exocytosis and/or decreased endocytosis of the v-type ATPase. How PKA exactly controls these events in not known yet, but in yeast Ras GTPase activating proteins (60), and in clear cells inhibition of RhoA and ROCKII might be involved (61). In addition to PKA also the metabolic sensor AMPK directly phosphorylates v-type ATPase on subunit A. While PKA induced phosphorylation increases v-type ATPase presence at the plasma membrane, AMPK mediated phosphorylation inhibits PKA effects. This co-regulation of v-type ATPase localization by PKA and AMPK has been observed in epididymal clear cells as well as in renal cells $(62,63)$. These results suggest that in mammalian cells, glucose depletion might affect v-type ATPase complex formation via differential subunit phosphorylation.

Moreover, the VO domain has been suggested to translocate and to participate directly in SNARE-facilitated membrane fusion. Pairing of SNARE proteins positions VO domains in adjacent membranes and then the fusion process would be catalyzed (Figure 7.5). This process is not only important in yeast (64), but also in Drosophila (65), C.elegans (66) and pancreatic $\beta$-cells (67). In our experimental model this could mean that the differential action of v-type ATPase inhibition is caused by differential presence of SNAREs in GLUT4 and CD36 vesicles. In addition, GLUT4 and CD36 could be present in different vesicles with different amounts of v-type ATPase. How exactly v-type ATPases are involved in the mechanism of GLUT4 and CD36 translocation and glucose and fatty acid uptake in cardiomyocytes needs further study.

Involvement of endosomal $\mathrm{pH}$ regulation in obesity and insulin resistance

In the insulin resistant heart, cardiomyocytes take up more fatty acids, which correlates with increased sarcolemmal presence of $\operatorname{CD} 36(8,9)$. Furthermore, insulin-stimulated glucose uptake and GLUT4 translocation are reduced in the insulin resistant heart (11). Remarkably, the subcellular distribution of GLUT4 and CD36 as observed after v-type ATPase inhibition resembles that of the insulin resistant rodent heart $(9,13)$. This allows to speculate that disturbed v-type ATPase function is one of the disturbed mechanisms that can lead to myocellular insulin resistance. How v-type ATPase function is involved in metabolic disturbed states is not known 
A

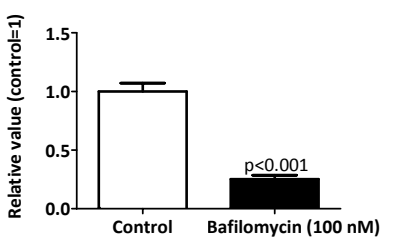

B

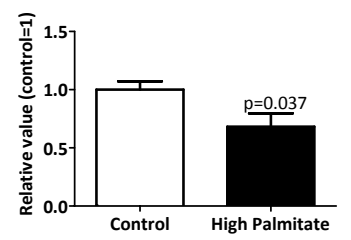

C

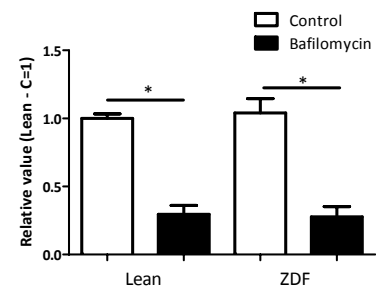

D

\section{vATPase B2}

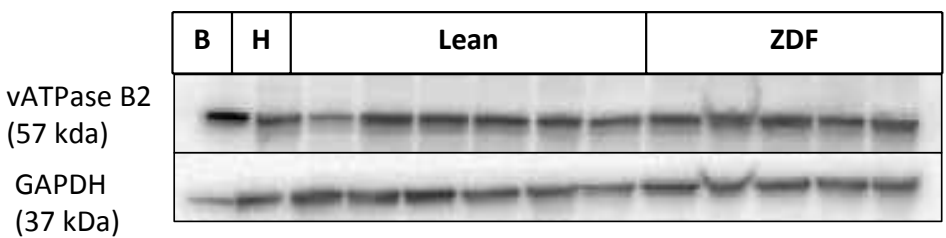

Figure 7.6: Bafilomycin reduces chloroquine accumulation in cardiomyocytes (A) cultured for two days, just as in freshly isolated cells. Culturing primary rat cardiomyocytes (B) in medium containing a high concentration of palmitate reduced chloroquine accumulation, but to a lesser extent than bafilomycin treatment. Endosomal pH regulation was not altered in cardiomyocytes from ZDF rats versus lean rats. (D) Subunit B2 expression is comparable in cardiomyocytes from lean and ZDF rats as shown by western blotting (antibody from Abcam). Bafilomycin reduces chloroquine accumulation (D) in cardiomyocytes from lean and ZDF rats, just as in freshly isolated cells. No differences were found between cardiomyocytes from lean and ZDF rats. Statistics was done by One-Way ANOVA and Student t-test. $\mathrm{P}<0.05$ was considered significant.

for cardiac dysfunction, but v-type ATP dysfunction is involved in other pathological states, which will be discussed below. Many of the subunits of the v-type ATPase exist in several isoforms which makes organ or cell specific drug targeting possible (47). In addition, our results in chapter 3 stimulated us to investigate further the involvement of endosomal $\mathrm{pH}$ regulation in experimental models for lipid-induced insulin resistance.

Some cells express v-type ATPase at the plasma membrane where they are important for: acid secretion by kidney cells into the renal tubule (68); bone resorption by osteoclasts which is important for bone density $(69,70)$; regulation of cytoplasmic pH in macrophages (71); and sperm maturation and storage (47). As a corollary, plasma membrane v-type ATPase have been found to be involved in pathologies caused by genetic defects such as renal disease (renal tubule acidosis)(72) and bone disease (elevation in bone density osteopetrosis)(73), and they have been implicated in tumor cell invasion (47). Mutations in the a3 isoform affect osteoclast functioning as shown in oc/oc mice which have a null mutation 
in the a3 locus which leads to osteopetrosis (74). Interestingly, the a3 isoform is also expressed in the lysosomes of the secretory granules of pancreatic islet cells. Indeed, oc/oc mice, that are defective in a3, show insulin secretion defects by islet cells (67), possibly linking v-type ATPase dysfunction to diabetes.

We have explored the functioning of endosomal $\mathrm{pH}$ regulation in several models for lipid-induced insulin resistance and type 2 diabetes. Our cardiomyocyte model for lipid-induced insulin resistance, as described in chapter $\mathbf{4}$ and 5, was used to measure chloroquine accumulation as a measure of disturbed $\mathrm{pH}$ regulation (Figure 7.6A-B). After two days of culturing under basal conditions, bafilomycin A similarly reduced chloroquine accumulation as in freshly isolated rat cardiomyocytes (see chapter 4). In cardiomyocytes that were cultured for two days in medium containing a high concentration of palmitate chloroquine accumulation was also reduced. We have found similar results in HL-1 cells. These results suggest that in insulin resistant cardiomyocytes v-ATPase functioning is decreased. Next, we investigated endosomal $\mathrm{pH}$ regulation in a rat model for type 2 diabetes, the Zucker Diabetic Fatty (ZDF) rat. We observed that subunit B2 protein presence was not different between lean and ZDF cardiomyocyte homogenates (Figure 7.6D). Hence, dysfunctional v-ATPase activity might be due to deregulated dissociation and association of the protein complex, rather than by protein presence alterations (54). Strikingly, $\mathrm{pH}$ regulation was not different when comparing lean and ZDF rats (Figure 7.6C). The latter results suggest that, although endosomal $\mathrm{pH}$ is disturbed in cell culture models for lipid-induced insulin resistance, ZDF rats are capable to compensate for $\mathrm{pH}$ stress in cardiomyocytes and the development of insulin resistance is due to other mechanisms. Since the genetically modified leptin-deficient ZDF rat has its drawbacks for comparison to the development of human insulin resistance, we suggest evaluation of the importance of endosomal $\mathrm{pH}$ regulation in the development of insulin resistance in animal models of high-fat diet-induced insulin resistance.

\section{Concluding remarks}

Cardiometabolic diseases, including insulin resistance-induced cardiomyopathy, remain a mayor health problem worldwide. The best remedy, life-style intervention, i.e., loosing weight and exercising more, has turned out to be difficult for people all over the world. Therefore, scientists and politicians should work hand in hand to invent new treatments for cardiometabolic disease and, stimulate the world population to change their lifestyle. In this thesis some promising new targets for the development of new cardiometabolic treatment have been evaluated and tested in in-vitro and invivo models for insulin resistance. Hopefully these new treatments can aid people in the process of life-style changes preventing and treating cardiometabolic disease. 


\section{References}

1. Shaw JE, Sicree RA, Zimmet PZ. Global estimates of the prevalence of diabetes for 2010 and 2030. Diabetes Res Clin Pract. Jan;87(1):4-14.

2. Danaei G, Finucane MM, Lu Y, Singh GM, Cowan MJ, Paciorek CJ, et al. National, regional, and global trends in fasting plasma glucose and diabetes prevalence since 1980: systematic analysis of health examination surveys and epidemiological studies with 370 country-years and 2.7 million participants. Lancet. 2011 Jul 2;378(9785):31-40.

3. The Diabetes Atlas, Second Edition. International Diabetes Federation; 2003.

4. Taegtmeyer H, McNulty P, Young ME. Adaptation and maladaptation of the heart in diabetes: Part I: general concepts. Circulation. 2002 Apr 9;105(14):1727-33.

5. Ungar I, Gilbert M, Siegel A, Blain JM, Bing RJ. Studies on myocardial metabolism. IV. Myocardial metabolism in diabetes. Am J Med. 1955 Mar;18(3):385-96.

6. Bonen A, Holloway GP, Tandon NN, Han XX, McFarlan J, Glatz JF, et al. Cardiac and skeletal muscle fatty acid transport and transporters and triacylglycerol and fatty acid oxidation in lean and Zucker diabetic fatty rats. Am J Physiol Regul Integr Comp Physiol. 2009 Oct;297(4):R1202-12.

7. Borradaile NM, Schaffer JE. Lipotoxicity in the heart. Current hypertension reports. 2005 Dec;7(6):412-7.

8. Coort SL, Luiken JJ, van der Vusse GJ, Bonen A, Glatz JF. Increased FAT (fatty acid translocase)/CD36mediated long-chain fatty acid uptake in cardiac myocytes from obese Zucker rats. Biochem Soc Trans. 2004 Feb;32(Pt 1):83-5.

9. Coort SL, Hasselbaink DM, Koonen DP, Willems J, Coumans WA, Chabowski A, et al. Enhanced sarcolemmal FAT/CD36 content and triacylglycerol storage in cardiac myocytes from obese zucker rats. Diabetes. 2004 Jul;53(7):1655-63.

10. Steinbusch LK, Schwenk RW, Ouwens DM, Diamant M, Glatz JF, Luiken JJ. Subcellular trafficking of the substrate transporters GLUT4 and CD36 in cardiomyocytes. Cell Mol Life Sci. 2011 May 6.

11. Stanley WC, Lopaschuk GD, McCormack JG. Regulation of energy substrate metabolism in the diabetic heart. Cardiovasc Res. 1997 Apr;34(1):25-33.

12. Luiken JJ, Vertommen D, Coort SL, Habets DD, El Hasnaoui M, Pelsers MM, et al. Identification of protein kinase D as a novel contraction-activated kinase linked to GLUT4-mediated glucose uptake, independent of AMPK. Cell Signal. 2008 Mar;20(3):543-56.

13. Ouwens DM, Diamant M, Fodor M, Habets DD, Pelsers MM, El Hasnaoui M, et al. Cardiac contractile dysfunction in insulin-resistant rats fed a high-fat diet is associated with elevated CD36-mediated fatty acid uptake and esterification. Diabetologia. 2007 Sep;50(9):1938-48.

14. Luiken JJ, Arumugam Y, Dyck DJ, Bell RC, Pelsers MM, Turcotte LP, et al. Increased rates of fatty acid uptake and plasmalemmal fatty acid transporters in obese Zucker rats. J Biol Chem. 2001 Nov 2;276(44):40567-73.

15. Goudriaan JR, Dahlmans VE, Teusink B, Ouwens DM, Febbraio M, Maassen JA, et al. CD36 deficiency increases insulin sensitivity in muscle, but induces insulin resistance in the liver in mice. J Lipid Res. 2003 Dec;44(12):2270-7.

16. Tanaka T, Nakata T, Oka T, Ogawa T, Okamoto F, Kusaka Y, et al. Defect in human myocardial longchain fatty acid uptake is caused by FAT/CD36 mutations. J Lipid Res. 2001 May;42(5):751-9.

17. Corpeleijn E, van der Kallen CJ, Kruijshoop M, Magagnin MG, de Bruin TW, Feskens EJ, et al. Direct association of a promoter polymorphism in the CD36/FAT fatty acid transporter gene with Type 2 diabetes mellitus and insulin resistance. Diabet Med. 2006 Aug;23(8):907-11.

18. Love-Gregory L, Sherva R, Schappe T, Qi JS, McCrea J, Klein S, et al. Common CD36 SNPs reduce protein expression and may contribute to a protective atherogenic profile. Hum Mol Genet. 2010 Jan 1;20(1):193-201.

19. Love-Gregory L, Sherva R, Sun L, Wasson J, Schappe T, Doria A, et al. Variants in the CD36 gene associate with the metabolic syndrome and high-density lipoprotein cholesterol. Hum Mol Genet. 2008 Jun 1;17(11):1695-704.

20. MaX, Bacci S, Mlynarski W, Gottardo L, Soccio T, Menzaghi C, et al. A common haplotype at the CD36 locus is associated with high free fatty acid levels and increased cardiovascular risk in Caucasians. 
Hum Mol Genet. 2004 Oct 1;13(19):2197-205.

21. Kintaka T, Tanaka T, Imai M, Adachi I, Narabayashi I, Kitaura Y. CD36 genotype and long-chain fatty acid uptake in the heart. Circ J. 2002 Sep;66(9):819-25.

22. Roberts W, Magwenzi S, Aburima A, Naseem KM. Thrombospondin-1 induces platelet activation through CD36-dependent inhibition of the CAMP/protein kinase A signaling cascade. Blood. 2010 Nov 18;116(20):4297-306.

23. Collot-Teixeira S, Martin J, McDermott-Roe C, Poston R, McGregor JL. CD36 and macrophages in atherosclerosis. Cardiovasc Res. 2007 Aug 1;75(3):468-77.

24. Kennedy DJ, Kuchibhotla S, Westfall KM, Silverstein RL, Morton RE, Febbraio M. A CD36-dependent pathway enhances macrophage and adipose tissue inflammation and impairs insulin signalling. Cardiovasc Res. 2011 Feb 15;89(3):604-13.

25. Sun B, Boyanovsky BB, Connelly MA, Shridas P, van der Westhuyzen DR, Webb NR. Distinct mechanisms for OxLDL uptake and cellular trafficking by class B scavenger receptors CD36 and SRBI. J Lipid Res. 2007 Dec;48(12):2560-70.

26. Miller TW, Isenberg JS, Shih HB, Wang Y, Roberts DD. Amyloid-beta inhibits No-cGMP signaling in a CD36- and CD47-dependent manner. PLoS One. 2010;5(12):e15686.

27. Huang MM, Bolen JB, Barnwell JW, Shattil SJ, Brugge JS. Membrane glycoprotein IV (CD36) is physically associated with the Fyn, Lyn, and Yes protein-tyrosine kinases in human platelets. Proc Natl Acad Sci U S A. 1991 Sep 1;88(17):7844-8.

28. Nergiz-Unal R, Lamers MM, van Kruchten R, Luiken JJ, Cosemans JM, Glatz JF, et al. Signaling role of CD36 in platelet activation and thrombus formation on immobilized thrombospondin or oxidized LDL. J Thromb Haemost. 2011 Jun 22.

29. Sun J, Hopkins BD, Tsujikawa K, Perruzzi C, Adini I, Swerlick R, et al. Thrombospondin-1 modulates VEGF-A-mediated Akt signaling and capillary survival in the developing retina. Am J Physiol Heart Circ Physiol. 2009 May;296(5):H1344-51.

30. Brasier AR. The nuclear factor-kappaB-interleukin-6 signalling pathway mediating vascular inflammation. Cardiovasc Res. 2010 May 1;86(2):211-8.

31. Park YM, Febbraio M, Silverstein RL. CD36 modulates migration of mouse and human macrophages in response to oxidized LDL and may contribute to macrophage trapping in the arterial intima. J Clin Invest. 2009 Jan;119(1):136-45.

32. Coraci IS, Husemann J, Berman JW, Hulette C, Dufour JH, Campanella GK, et al. CD36, a class B scavenger receptor, is expressed on microglia in Alzheimer's disease brains and can mediate production of reactive oxygen species in response to beta-amyloid fibrils. Am J Pathol. 2002 Jan;160(1):101-12.

33. Janabi M, Yamashita S, Hirano K, Sakai N, Hiraoka H, Matsumoto K, et al. Oxidized LDL-induced NF-kappa B activation and subsequent expression of proinflammatory genes are defective in monocyte-derived macrophages from CD36-deficient patients. Arterioscler Thromb Vasc Biol. 2000 Aug;20(8):1953-60.

34. Sfakianos JN, Hunter E. M-PMV capsid transport is mediated by Env/Gag interactions at the pericentriolar recycling endosome. Traffic. 2003 Oct;4(10):671-80.

35. Bieghs V, Wouters K, van Gorp PJ, Gijbels MJ, de Winther MP, Binder CJ, et al. Role of scavenger receptor $A$ and $\mathrm{CD} 36$ in diet-induced nonalcoholic steatohepatitis in hyperlipidemic mice. Gastroenterology. 2010 Jun;138(7):2477-86, 86 e1-3.

36. Park L, Wang G, Zhou P, Zhou J, Pitstick R, Previti ML, et al. Scavenger receptor CD36 is essential for the cerebrovascular oxidative stress and neurovascular dysfunction induced by amyloid-beta. Proc Natl Acad Sci U S A. 2011 Mar 22;108(12):5063-8.

37. Wouters K, van Gorp PJ, Bieghs V, Gijbels MJ, Duimel H, Lutjohann D, et al. Dietary cholesterol, rather than liver steatosis, leads to hepatic inflammation in hyperlipidemic mouse models of nonalcoholic steatohepatitis. Hepatology. 2008 Aug;48(2):474-86.

38. Browning JD, Szczepaniak LS, Dobbins R, Nuremberg P, Horton JD, Cohen JC, et al. Prevalence of hepatic steatosis in an urban population in the United States: impact of ethnicity. Hepatology. 2004 Dec;40(6):1387-95.

39. Harmon RC, Tiniakos DG, Argo CK. Inflammation in nonalcoholic steatohepatitis. Expert Rev Gastroenterol Hepatol. 2011 Apr;5(2):189-200. 
40. Lopaschuk GD, Ussher JR, Folmes CD, Jaswal JS, Stanley WC. Myocardial fatty acid metabolism in health and disease. Physiol Rev. 2010 Jan;90(1):207-58.

41. Richter EA, Garetto LP, Goodman MN, Ruderman NB. Muscle glucose metabolism following exercise in the rat: increased sensitivity to insulin. J Clin Invest. 1982 Apr;69(4):785-93.

42. Steinberg GR, Kemp BE. AMPK in Health and Disease. Physiol Rev. 2009 Jul;89(3):1025-78.

43. Liu LZ, Cheung SC, Lan LL, Ho SK, Xu HX, Chan JC, et al. Berberine modulates insulin signaling transduction in insulin-resistant cells. Mol Cell Endocrinol. 2010 Apr 12;317(1-2):148-53.

44. Hawley SA, Ross FA, Chevtzoff C, Green KA, Evans A, Fogarty S, et al. Use of cells expressing gamma subunit variants to identify diverse mechanisms of AMPK activation. Cell Metab. 2010 Jun 9;11(6):554-65.

45. van der Meer RW, Rijzewijk LJ, de Jong HW, Lamb HJ, Lubberink M, Romijn JA, et al. Pioglitazone improves cardiac function and alters myocardial substrate metabolism without affecting cardiac triglyceride accumulation and high-energy phosphate metabolism in patients with well-controlled type 2 diabetes mellitus. Circulation. 2009 Apr 21;119(15):2069-77.

46. Steinbusch LK, Wijnen W, Schwenk RW, Coumans WA, Hoebers NT, Ouwens DM, et al. Differential regulation of cardiac glucose and fatty acid uptake by endosomal $\mathrm{pH}$ and actin filaments. Am J Physiol Cell Physiol. 2010 Jun;298(6):C1549-59.

47. Hinton A, Bond S, Forgac M. V-ATPase functions in normal and disease processes. Pflugers Arch. 2009 Jan;457(3):589-98.

48. Huss $\mathrm{M}$, Wieczorek $\mathrm{H}$. Inhibitors of v-atpases: old and new players. The Journal of Experimental Biology. 2008;212:341-6.

49. Claycomb WC, Lanson NA, Jr., Stallworth BS, Egeland DB, Delcarpio JB, Bahinski A, et al. HL-1 cells: a cardiac muscle cell line that contracts and retains phenotypic characteristics of the adult cardiomyocyte. Proc Natl Acad Sci U S A. 1998 Mar 17;95(6):2979-84.

50. Schwenk RW, Dirkx E, Coumans WA, Bonen A, Klip A, Glatz JF, et al. Requirement for distinct vesicleassociated membrane proteins in insulin- and AMP-activated protein kinase (AMPK)-induced translocation of GLUT4 and CD36 in cultured cardiomyocytes. Diabetologia. 2010 Oct;53(10):220919.

51. Forgac M. Vacuolar ATPases: rotary proton pumps in physiology and pathophysiology. Nat Rev Mol Cell Biol. 2007 Nov;8(11):917-29.

52. Rojas JD, Sennoune SR, Maiti D, Bakunts K, Reuveni M, Sanka SC, et al. Vacuolar-type H+-ATPases at the plasma membrane regulate $\mathrm{pH}$ and cell migration in microvascular endothelial cells. Am J Physiol Heart Circ Physiol. 2006 Sep;291(3):H1147-57.

53. Kane PM. The where, when, and how of organelle acidification by the yeast vacuolar H+-ATPase. Microbiol Mol Biol Rev. 2006 Mar;70(1):177-91.

54. Diepholz M, Borsch M, Bottcher B. Structural organization of the V-ATPase and its implications for regulatory assembly and disassembly. Biochem Soc Trans. 2008 Oct;36(Pt 5):1027-31.

55. Sautin YY, Lu M, Gaugler A, Zhang L, Gluck SL. Phosphatidylinositol 3-kinase-mediated effects of glucose on vacuolar H+-ATPase assembly, translocation, and acidification of intracellular compartments in renal epithelial cells. Mol Cell Biol. 2005 Jan;25(2):575-89.

56. Aspinwall CA, Brooks SA, Kennedy RT, Lakey JR. Effects of intravesicular $\mathrm{H}+$ and extracellular $\mathrm{H}+$ and Zn2+ on insulin secretion in pancreatic beta cells. J Biol Chem. 1997 Dec 12;272(50):31308-14.

57. Maechler $P$, Wollheim CB. Mitochondrial glutamate acts as a messenger in glucose-induced insulin exocytosis. Nature. 1999 Dec 9;402(6762):685-9.

58. Eto K, Yamashita T, Hirose K, Tsubamoto Y, Ainscow EK, Rutter GA, et al. Glucose metabolism and glutamate analog acutely alkalinize $\mathrm{pH}$ of insulin secretory vesicles of pancreatic beta-cells. Am J Physiol Endocrinol Metab. 2003 Aug;285(2):E262-71.

59. Pastor-Soler N, Beaulieu V, Litvin TN, Da Silva N, Chen Y, Brown D, et al. Bicarbonate-regulated adenylyl cyclase $(\mathrm{sAC})$ is a sensor that regulates $\mathrm{pH}$-dependent V-ATPase recycling. J Biol Chem. 2003 Dec 5;278(49):49523-9.

60. Bond S, Forgac M. The Ras/cAMP/protein kinase A pathway regulates glucose-dependent assembly of the vacuolar (H+)-ATPase in yeast. J Biol Chem. 2008 Dec 26;283(52):36513-21.

61. Shum WW, Da Silva N, Belleannee C, McKee M, Brown D, Breton S. Regulation of V-ATPase recycling via a RhoA- and ROCKII-dependent pathway in epididymal clear cells. Am J Physiol Cell Physiol. 2011 
Jul;301(1):C31-43.

62. Gong F, Alzamora R, Smolak C, Li H, Naveed S, Neumann D, et al. VACUOLAR H+-ATPase APICAL ACCUMULATION IN KIDNEY INTERCALATED CELLS IS REGULATED BY PKA AND AMP-ACTIVATED PROTEIN KINASE. Am J Physiol Renal Physiol. 2010 Feb 10.

63. Hallows KR, Alzamora R, Li H, Gong F, Smolak C, Neumann D, et al. AMP-activated protein kinase inhibits alkaline $\mathrm{pH}$ - and PKA-induced apical vacuolar H+-ATPase accumulation in epididymal clear cells. Am J Physiol Cell Physiol. 2009 Apr;296(4):C672-81.

64. Peters C, Bayer MJ, Buhler S, Andersen JS, Mann M, Mayer A. Trans-complex formation by proteolipid channels in the terminal phase of membrane fusion. Nature. 2001 Feb 1;409(6820):581-8.

65. Hiesinger PR, Fayyazuddin A, Mehta SQ, Rosenmund T, Schulze KL, Zhai RG, et al. The v-ATPase V0 subunit a1 is required for a late step in synaptic vesicle exocytosis in Drosophila. Cell. 2005 May 20;121(4):607-20.

66. Liegeois S, Benedetto A, Garnier JM, Schwab Y, Labouesse M. The V0-ATPase mediates apical secretion of exosomes containing Hedgehog-related proteins in Caenorhabditis elegans. J Cell Biol. 2006 Jun 19;173(6):949-61.

67. Sun-Wada GH, Toyomura T, Murata Y, Yamamoto A, Futai M, Wada Y. The a3 isoform of V-ATPase regulates insulin secretion from pancreatic beta-cells. J Cell Sci. 2006 Nov 1;119(Pt 21):4531-40.

68. Wagner CA, Finberg KE, Breton S, Marshansky V, Brown D, Geibel JP. Renal vacuolar H+-ATPase. Physiol Rev. 2004 Oct;84(4):1263-314.

69. Li YP, Chen W, Liang Y, Li E, Stashenko P. Atp6i-deficient mice exhibit severe osteopetrosis due to loss of osteoclast-mediated extracellular acidification. Nat Genet. 1999 Dec;23(4):447-51.

70. Toyomura T, Murata Y, Yamamoto A, Oka T, Sun-Wada GH, Wada Y, et al. From lysosomes to the plasma membrane: localization of vacuolar-type $\mathrm{H}+$-ATPase with the a3 isoform during osteoclast differentiation. J Biol Chem. 2003 Jun 13;278(24):22023-30.

71. Nanda A, Brumell JH, Nordstrom T, Kjeldsen L, Sengelov H, Borregaard N, et al. Activation of proton pumping in human neutrophils occurs by exocytosis of vesicles bearing vacuolar-type H+-ATPases. J Biol Chem. 1996 Jul 5;271(27):15963-70.

72. Karet FE, Finberg KE, Nelson RD, Nayir A, Mocan H, Sanjad SA, et al. Mutations in the gene encoding B1 subunit of H+-ATPase cause renal tubular acidosis with sensorineural deafness. Nat Genet. 1999 Jan;21(1):84-90.

73. Frattini A, Orchard PJ, Sobacchi C, Giliani S, Abinun M, Mattsson JP, et al. Defects in TCIRG1 subunit of the vacuolar proton pump are responsible for a subset of human autosomal recessive osteopetrosis. Nat Genet. 2000 Jul;25(3):343-6.

74. Marks SC, Jr., Seifert MF, Lane PW. Osteosclerosis, a recessive skeletal mutation on chromosome 19 in the mouse. J Hered. 1985 May-Jun;76(3):171-6. 



\section{Summary / Samenvatting Curriculum Vitae Dankwoord}




\section{Summary}

The heart consists of several types of cells of which cardiomyocytes are the cells that are responsible for the contractile activity of the heart. Cardiomyocytes utilize long-chain fatty acids and glucose as main substrates for energy generation. Under normal conditions there is a finely tuned balance between the utilization of these substrates, with long-chain fatty acids providing $60-70 \%$ of needed energy. Moreover, a healthy heart is flexible regarding its substrate utilization and is able to temporarily switch to one or another substrate. During cardiac pathology a dysbalance in substrate utilization develops and cardiomyocytes are no longer able to rapidly switch between glucose and fatty acid utilization (loss of flexibility). For example, during ischemia or hypertension the heart relies almost exclusively on glucose. In contrast, substrate metabolism shifts towards fatty acid utilization in case of obesity or diabetes (Chapter $\mathbf{1}$ ).

Glucose and fatty acid uptake into cardiomyocytes is regulated by insulin, as well as increased cardiac work. Concomitantly, each of these stimuli induces translocation of glucose transporter 4 (GLUT4) and fatty acid transporter (CD36) translocation from intracellular stores to the cell membrane (sarcolemma) (Chapter 1). This suggests that similar mechanisms regulate GLUT4 and CD36 translocation. However, it is known that cardiomyocytes isolated from insulin-resistant rats initially show increased sarcolemmal presence of CD36 and take up more fatty acids, without any alteration in GLUT4 localization and in glucose uptake. When the insulin resistance progresses, GLUT4 resides more intracellularly and insulin-stimulated GLUT4 translocation and glucose uptake are reduced, ultimately leading to cardiac dysfunction. As a result, there must be mechanisms that distinguish between the recruitment of GLUT4 and CD36.

In view of the above observations, it was hypothesized that the increased sarcolemmal presence of CD36 contributes to the development of diabetes-related cardiac dysfunction. In this thesis, this hypothesis was tested in an in vitro and an in vivo study. Firstly, we set up an in vitro model in which cellular exposure to a high concentration of insulin, or palmitate, elicited the increased sarcolemmal presence of CD36 (Chapter 4). Secondly, we evaluated the involvement of CD36 in the development of cardiac dysfunction in mice on a Western type diet (Chapter 6). Furthermore, it was hypothesized that interference with the trafficking of CD36 in the diabetic heart normalizes myocardial lipid metabolism and improves insulin sensitivity, ultimately resulting in amelioration of cardiac dysfunction. To test this last hypothesis we evaluated the involvement of subcellular structures in the trafficking of GLUT4 and CD36 in insulin-sensitive and insulin-resistant cardiomyocytes (Chapters 
$\mathbf{2 , 3}$ and 7). In addition, it was tested if we could bypass defective insulin signaling via contraction mediated signaling and, by doing so; prevent the deleterious increase in basal fatty acid uptake (Chapter $\mathbf{5}$ ).

We performed a pharmacological study to assess the involvement of specific subcellular structures in GLUT4 and/or CD36 trafficking (Chapter 3). We disclosed that GLUT4 and CD36 translocation are regulated differentially on the level of actin reorganization and regulation of endosomal $\mathrm{pH}$ (Chapter 3 ). This differential regulation suggests that aberrant functioning of trafficking components may be at the basis of the altered translocation of either GLUT4 or CD36 as occurs in the heart of obese Zucker rats or of rats exposed to a high-fat diet. In addition, in studies with a cardiomyocyte cell line and primary cardiomyocytes it was found that endosomal $\mathrm{pH}$ regulation was disturbed in cardiomyocyte cultures for lipidinduced insulin resistance (Chapter 7). Hence, the protein complex involved in endosomal $\mathrm{pH}$ regulation (v-type ATPase) differently affects glucose and fatty acid uptake (Chapter 3 ) and its functioning is disturbed in lipid-induced insulin resistance (Chapter 7). Together these results suggest that normalization of v-type ATPase functioning would improve cardiomyocyte insulin sensitivity and function. Chapter 7 provides some suggestions to disclose how v-type ATPase could be involved in the mechanism of GLUT4 and CD36 translocation and glucose and fatty acid uptake in cardiomyocytes.

An in vitro model was developed to study the effect of novel treatment targets on the development of insulin resistance and contractile dysfunction (Chapters 4 and 5). For this purpose, adult rat cardiomyocytes were cultured for 48 hours in media containing a high concentration of insulin or of palmitate. It was observed that each medium induces the following maladaptive changes: enhanced sarcolemmal CD36, increase in basal palmitate uptake, excessive lipid accumulation, reduced insulin sensitivity and contractile dysfunction. Hence, our model shows the same maladaptive changes as seen in vivo, i.e. in hearts from insulin resistant rats, thus making this model particularly suited for experimental studies.

To test the hypothesis that an increased sarcolemmal presence of CD36 contributes to the development of diabetes-related cardiac dysfunction, we compared the ability of several CD36 ligands to block CD36-mediated fatty acid uptake and used this knowledge in the in vitro model described above (Chapter 4). The anti-CD36 monoclonal antibody clone 63 inhibited fatty acid uptake into rat cardiomyocytes. In addition, presence of anti-CD36 monoclonal antibody clone 63 prevented reduction of insulin-sensitivity, lipid accumulation and contractile dysfunction in cardiomyocytes exposed to a medium containing a high concentration of insulin or of palmitate. Thus, pharmacological CD36 inhibition may be considered a treatment 
strategy to prevent lipid-induced cardiomyocyte dysfunction.

Furthermore, it was tested if bypassing defective insulin signaling via contractionmediated signaling could prevent the loss of insulin-stimulated glucose uptake and increased CD36-mediated basal palmitate uptake in the in-vitro model described above (Chapter 5). Candidates in the contraction signaling pathway are AMPactivated protein kinase (AMPK) and protein kinase $D$ (PKD) because each of these kinases mediates contraction-mediated glucose uptake into cardiomyocytes. Adenoviral overexpression of each of these kinases in the above described in-vitro model prevented loss of insulin-stimulated glucose uptake. However, each acted through different mechanisms: AMPK prevented loss of insulin signaling, and PKD prevented lipid accumulation. Further research should focus on development of specific PKD activators, and should reveal by which mechanisms these kinases perform their preventive action, in order to evaluate the suitability of these kinases as treatment targets.

Most cardiac patients both have diabetes and hypertension, whereas most animal research towards cardiometabolic disease study these pathological processes separately. We aimed to study the interaction of these two cardiac stresses and wanted to obtain proof of principle for the role of CD36 in the development of cardiac dysfunction in cardiometabolic stress (Chapter 6). Metabolic stress alone, e.g. Western-type diet or ablation of CD36, did not affect cardiac function. However, the metabolic stress in combination with mechanophysical stress (by pressure overload) resulted in greater cardiac hypertrophy and dysfunction than when no metabolic stress was present. Moreover, ablation of CD36 prevented lipid accumulation upon exposure to a Western-type diet and thus prevented the development of cardiac dysfunction in these mice. These results suggest that metabolic and mechanophysical stresses interact and aggravate the development of cardiac hypertrophy and dysfunction. The preventive action of anti-CD36 monoclonal antibody clone 63 in cardiomyocyte cultured under insulin-resistance inducing conditions (Chapter 4), or ablation of CD36 in mice exposed to a Western-type diet (Chapter 6), may not only be ascribed to inhibition of CD36-mediated fatty acid uptake. CD36 has many other functions, amongst others it is involved in intracellular signaling (Chapter 7). Further research should reveal the importance of the different functions of CD36 in cardiac metabolism and function and to what extent manipulation of CD36 presence or activity is an effective tool to prevent or regress cardiometabolic diseases.

In this thesis selected promising new targets for the development of new cardiometabolic treatment have been evaluated and tested in in vitro and in vivo models for insulin resistance. Hopefully these new treatments can aid people in the process of life-style changes preventing and treating cardiometabolic disease. 


\section{Samenvatting}

Het hart bestaat uit verschillende soorten cellen maar het zijn de hartspiercellen die verantwoordelijk zijn voor het samentrekken van het hart. Hartspiercellen gebruiken vetten/vetzuren (60-70\%), maar ook suikers/glucose (30-40\%), voor de productie van energie. Daarnaast kunnen deze cellen onder normale omstandigheden makkelijk, kortdurend, overschakelen op één van deze brandstoffen. Tijdens chronische stress, zoals zuurstoftekort of hogebloeddruk, geeft het hart de voorkeur aan opname van glucose als brandstof. Andere stressfactoren, bijvoorbeeld overgewicht of type 2 diabetes, zorgen er juist voor dat hartspiercellen meer vetzuren gaan gebruiken om energie te produceren. Daarnaast zijn hartspiercellen in het gestresste hart niet meer goed in staat om tussen glucose- of vetzuurgebruik te wisselen (Hoofdstuk 1 en 2).

In gezonde hartspiercellen wordt het brandstofgebruik gereguleerd door insuline en door samentrekking van het hart. Beide stimuli verhogen de aanwezigheid van de glucose transporter 4 (GLUT4) en de vetzuurtransporter CD36 in het celmembraan en daarmee de glucose- en vetzuuropname in de hartspiercellen. Dit suggereert dat gelijkaardige mechanismen van invloed zijn op GLUT4 en CD36 verplaatsing in de hartspiercel. Onderzoek naar de onderliggende moleculaire veranderingen tijdens cardiale stress heeft echter aangetoond dat GLUT4 en CD36 translocatie, en glucose en vetzuuropname, bij insuline resistentie verschillend beïnvloed zijn. Hartspiercellen van insuline resistente ratten bleken in de eerste stadia van insuline resistentie meer CD36 in het celmembraan te huisvesten en meer vetzuren op te nemen dan hartspiercellen van controle ratten, terwijl glucose opname dan nog niet is aangetast. In een later stadium veranderde ook de subcellulaire GLUT4 lokalizatie. In tegenstelling tot CD36 verschoof GLUT4 naar meer intracellulair vanwege defecten in de insuline gemedieerde GLUT4 translocatie, uiteindelijk resulterend in verlaagde hartfunctie (Hoofdstuk 1 en 2).

Deze resultaten brachten ons tot de hypothese dat de chronische aanwezigheid van CD36 op het celmembraan bijdraagt aan de ontwikkeling van diabetes gerelateerde hartproblemen. Daarnaast suggereert dit dat de beïnvloeding van de verplaatsing van CD36 in de hartspiercel de ontwikkeling van cardiale insuline resistentie en hartdysfunctie zou kunnen voorkomen. In dit promotieproject zijn deze twee hypotheses bestudeerd in celsystemen en in diermodellen voor type 2 diabetes.

Om te kunnen intervenïeren in een verstoorde CD36 translocatie in zieke cellen hebben we eerst de CD36 verplaatsing bestudeerd in gezonde hartspiercellen. Verschillende farmacologische hulpmiddelen zijn gebruikt om te achterhalen welke 
cellulaire processen en eiwitten betrokken zijn bij de verplaatsing van GLUT4 en CD36 in hartspiercellen van de rat (Hoofdstuk 3). Het bleek dat actine filamenten en de proton pomp (v-type ATPase), welke betrokken is bij regulatie van endosomale $\mathrm{pH}$, verschillende functies hebben binnen GLUT4 en CD36 translocatie. De verschillende functies van de v-type ATPase leken erg op de veranderingen die in hartspiercellen van diabete ratten geobserveerd waren. Wij hebben de bestaande kennis omtrent subcellulaire processen betrokken bij GLUT4 en CD36 translocatie samengebracht in een review artikel (Hoofdstuk 3). Bovendien hebben wij gevonden dat endosomale $\mathrm{pH}$ regulatie verstoord was in celsystemen voor insuline resistentie (Hoofdstuk 7). De v-type ATPase is verschillend betrokken bij glucose en vetzuuropname en in insuline resistente cellen vertoont het een verstoord functioneren. Dit suggereert dat normalisering van het functioneren van de v-type ATPase tot gevolg zou kunnen hebben dat de insuline sensitiviteit en het functioneren van de cardiomyocyte verbetert. Hoofdstuk 7 geeft enkele suggesties hoe v-type ATPase precies betrokken zou kunnen zijn bij GLUT4 en CD36 translocatie en hoe dit onderzocht zou kunnen worden.

Een ander onderdeel van dit promotieproject was gericht op het opzetten van een hartspiercelsysteem om daarin vervolgens de effectiviteit van nieuwe medicinale doeleiwitten te kunnen bestuderen. Wij hebben hartspielcellen van volwassen ratten twee dagen gekweekt in media die een hoge concentratie insuline of vetzuren bevatten. Deze media zorgden voor maladaptieve veranderingen zoals permanente verplaatsing van CD36 naar het celmembraan, een verhoogde vetstapeling, verlaagde insuline gevoeligheid en verslechterde samentrekking van de hartspiercellen (Hoofdstuk 4 en 5 ). Deze veranderingen zijn gelijk aan de veranderingen die optreden in hartspiercellen wat dit model geschikt maakt voor experimentele studies.

De hypothese dat de chronische aanwezigheid van CD36 op het celmembraan bijdraagt aan de ontwikkeling van diabetes gerelateerde hartproblemen werd getest in het hierboven beschreven celsysteem (Hoofdstuk 4). Eerst werden verscheidene anti-CD36 peptiden en antilichamen getest op hun vermogen om de vetzuuropname te remmen. Vervolgens werd getoond dat het bij uitstek geschikte anti-CD36 antilichaam (kloon 63) de ontwikkeling van vetstapeling, insuline resistentie en hartspierceldysfunctie kon voorkomen in het eerder beschreven celsysteem. CD36 inhibitie lijkt zodoende een zinvol doeleiwit om lipide geïnduceerde hartspiercel dysfunctie te voorkomen.

Daarnaast is ook getest of een verstoorde insuline signalering in insuline resistente cellen voorkómen kan worden door activatie van de processen betrokken bij samentrekken van hartspiercellen (Hoofdstuk 5). Kandidaateiwitten 
in het contractieproces zijn AMP-geactiveerde proteine kinase (AMPK) en proteine kinase $D(P K D)$ omdat beide nodig zijn voor de stimulatie van glucose opname in hartspiercellen. Adenovirale overexpressie van AMPK of van PKD in het eerder beschreven celsysteem voorkwam verlies van insuline-gemedieerde glucose opname. AMPK overexpressie voorkwam verlies van insuline signalering, en PKD overexpressie voorkwam vetstapeling. Dus, AMPK en PKD beschermen tegen verlies van insulinegemedieerde glucose opname in gekweekte hartspiercellen onder insulineresistentie inducerende condities, maar zij doen dit via verschillende mechanismen. Verder onderzoek zou zich kunnen richten op de ontwikkeling van specifieke PKD activators en zou kunnen focusen op de specifieke werkingsmechanismen van deze kinases.

Vele hartpatiënten hebben naast diabetes ook een hoge bloeddruk. In de meeste moleculaire studies worden deze processen apart bestudeerd terwijl juist de interactie tussen beide pathologiën van invloed kan zijn op de uitkomst voor de patient. Ons doel was om de interactie tussen de twee onderliggende stressoren te bestuderen in een muismodel, en om de rol van CD36 in deze pathologie aan te tonen (Hoofdstuk 6). Metabole stress, bijvoorbeeld een Westerse voeding of afwezigheid van $C D 36$, had geen effect op het functioneren van het hart. De metabole stress werd zichtbaar nadat bloeddruk overbelasting werd geïnduceerd middels vernauwen van de aorta. Gezamenlijk leidden metabole stress en bloeddruk overbelasting tot een sterkere hypertrofie van het hart en tot hartdysfunctie. Bovendien voorkwam afwezigheid van CD36 vetstapeling in het hart wanneer de muizen een Westers dieet kregen. Op die manier werd hartdysfunctie voorkomen in deze muizen. De preventieve werking van anti-CD36 kloon 63 in gekweekte hartspiercellen onder insuline-resistentie inducerende condities (Hoofdstuk 4), of afwezigheid van CD36 in muizen blootgesteld aan een Westers dieet (Hoofdstuk 6), kon niet alleen maar toegeschreven worden aan vermindering van de vetzuuropname. CD36 heeft vele andere functies, waaronder ook intracellulaire signalering (Hoofdstuk 7). Verder onderzoek moet aantonen wat de rol is van deze verschillende functies van CD36 in het metabolisme en het functioneren van het hart.

In dit proefschrift zijn veelbelovende nieuwe doeleiwitten voor de ontwikkeling van nieuwe hartmetabole behandelingen bestudeerd en getest in in vitro en in vivo modellen voor insuline resistentie. Hopelijk helpen deze nieuwe inzichten mensen in het proces van leefstijlverandering die ook nodig zijn voor het voorkomen en het behandelen van hartmetabole ziektes. 


\section{Curriculum Vitae}

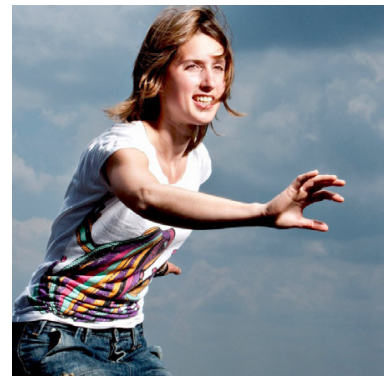

Laura Steinbusch werd geboren op 30 november 1982 in Nijmegen en groeide op in het dorpje Molenhoek. Van september 1995 tot juni 2001 volgde zij voortgezet onderwijs op het Stedelijk Gymnasium te Nijmegen. Zij genoot van alle beta-vakken met de practica eigen onderzoek (PEO) maar ook van tekenen en aardrijkskunde. Zij startte met de studie Bouwkunde aan de Technische Universiteit Eindhoven. Dit bleek toch meer computerwerk te zijn dan gedacht en de zoektocht naar een passendere studie ging voort.

In november 2002 startte zij met de bacheloropleiding Moleculaire Levenswetenschappen aan de transnationale universiteit Limburg in Maastricht en sloot deze met lof af in juli 2005 met een stage bij de afdeling farmacologie. In september 2005 startte zij met de masteropleiding Clinical Molecular Sciences aan dezelfde universiteit. De interesse voor het CD36 onderzoek werd gewekt tijdens een stage die plaatsvond bij drie vakgroepen: Biochemie, Moleculaire Genetica en Interne Geneeskunde. De masteropleiding werd afgesloten met een thesis aan de Ecole Normale Supérieure in Lyon, Frankrijk, gesponsord door een studenten reisbeurs van het Prinses Beatrix Fonds. Zij sloot haar masteropleiding cum laude af en ontving bovendien de Unilever Reasearch Prijs 2007 voor haar afstudeerscriptie.

In september 2007 startte zij haar promotieonderzoek bij de afdeling Moleculaire Genetica aan de universiteit Maastricht, verbonden aan het Cardiovascular Research Institute Maastricht (CARIM). Tijdens haar promotietraject begeleidde zij bachelor en masterstudenten uit Maastricht, maar ook uit Beijing en New York. Binnen haar promotietraject was de samenwerking met, en haar werkzaamheden bij, de groepen van Prof. Diamant (Vrije Universiteit medisch centrum, Amsterdam) en Dr. Ouwens (Leiden Universitair Medisch Centrum en Duits Diabetes Centrum) belangrijk voor het voltooien van haar project. De resultaten van dit onderzoek werden gehonoreerd met een award en presentaties, o.a. tijdens een europees congres voor onderzoek naar diabetes en een congres van de internationale vereniging voor het onderzoek naar vetzuren en lipiden. Door een reisbeurs voor jonge wetenschappers van het europees fonds voor de studie naar diabetes werd het mogelijk om onderzoek te doen in Brussel aan de Université-catholique Louvaine-la-neuf.

Vanaf november 2011 zal ze voor vijf jaar als PostDoc werkzaam zijn aan de Université de Lausanne in de groep van Prof. Thorens waar ze onderzoek zal doen naar glucose waarneming in het brein in gezondheid en ziekte. 


\section{List of Publications}

1. Laura K.M. Steinbusch, Ellen Dirkx, Nicole T.H. Hoebers, Veronique Roelants, Will A. Coumans, Benoit Viollet, Michaela Diamant, Luc Bertrand, Jan F.C. Glatz, D.Margriet Ouwens, Joost J.F.P. Luiken, Overexpression of AMP-activated protein kinase or Protein Kinase D independently prevent lipid-induced insulin resistance in cardiomyocytes, in preparation.

2. Laura K.M. Steinbusch, Robert Schwenk, Yeliz Angin, Kim Douma, Will A. Coumans, Michaela Diamant, Jan F.C. Glatz, Joost J.F.P. Luiken, D.Margriet Ouwens, Regulation of endosomal $\mathrm{pH}$ is disturbed in cardiomyocyte models for lipid-induced insulin resistance, in preparation.

3. Robert W. Schwenk, Yeliz Angin, Laura K.M. Steinbusch, Ellen Dirkx, Nicole Hoebers, Will A. Coumans, Arend Bonen, Jos L.V. Broers, Guillaume J.J.M. van Eys, Jan F.C. Glatz and Joost J.F.P. Luiken, Overexpression of VAMP3 protects against lipid-induced insulin resistance in cardiomyocytes, in preparation.

4. van Donkelaar EL, Vaessen KRD, Pawluski JL, Ferrington L, Steinbusch LKM, Steinbusch HWM. Long-term oral corticosterone treatment induces insulin resistance and depressive-like behaviour in C57BL/6J mouse, in preparation.

5. Laura K.M. Steinbusch, Yeliz Angin, Peter Simons, Kim Douma, Sabrina Gruelich, Nicole T.H. Hoebers, Will A. Coumans, Wino Wijnen, Michaela Diamant, D.Margriet Ouwens, Jan F.C. Glatz, Joost J.F.P. Luiken, CD36 inhibition prevents lipid accumulation and contractile dysfunction in rat cardiomyocyte cultures, submitted.

6. Irene O.C.M. Vroegrijk, Janna A. van Diepen, Sjoerd A.A. van den Berg, Maria Febbraio, Laura K.M. Steinbusch, Jan F.C. Glatz, Johannes A. Romijn, Louis M. Havekes, Peter J. Voshol, Patrick C.N. Rensen, Ko Willems van Dijk, CD36deficiency attenuates high fat diet-induced obesity by modulating triglyceride and fatty acid partitioning, submitted.

7. Ellen Dirkx, Guillaume J.J.M. van Eys, Robert W. Schwenk, Laura K.M. Steinbusch, Nicole Hoebers, Ben J. Janssen, Boudewijn Brans, Rhonda Bassel-Duby, Eric N. Olson, Jan F.C. Glatz and Joost J.F.P. Luiken, Protein kinase-D overexpression in the heart prevents lipid-induced insulin resistance and cardiomyopathy, submitted.

8. Laura K.M. Steinbusch et al., Ablation of CD36 prevents western-type dietrelated cardiac dysfunction following pressure overload in mice. Am J Physiol Endo Metab, 2011 June.

9. Laura K.M. Steinbusch et al., Subcellular trafficking of the substrate transporters GLUT4 and CD36 in cardiomyocytes. Cellular and Molecular Life Sciences, 2011 May.

10. Laura K.M. Steinbusch, Wino Wijnen, Robert W. Schwenk, Will A. Coumans, Nicole T.H. Hoebers, D. Margriet Ouwens, Michaela Diamant, Arend Bonen, Jan F.C. Glatz, Joost J.F.P. Luiken. Differential regulation of cardiac glucose and fatty acid uptake by endosomal pH and actin filaments. Am J Physiol Cell Physiol. 2010 Jun; 298(6):C1549-59. Evaluated in faculty of 1000 biology with an article factor of 8.

11. Martínez-Martínez P, Phernambucq M, Steinbusch L, Schaeffer L, Berrih-Aknin 
S, Duimel H, Frederik $\mathrm{P}$, Molenaar $\mathrm{P}$, De Baets $\mathrm{MH}$, Losen $\mathrm{M}$. Silencing rapsyn in vivo decreases acetylcholine receptors and augments sodium channels and secondary postsynaptic membrane folding. Neurobiol Dis. 2009 ;35: 14-23.

\section{Selection of presentations at (inter)national scientific conferences}

June 2011

$9^{\text {th }}$ meeting of the Society for Heart and Vascular Metabolism (SHVM). Poster presentation title: AMP-activated protein kinase and Protein Kinase D activation prevent cardiac lipotoxicity and insulin resistance, Laura K.M. Steinbusch, Ellen Dirkx, D.Margriet Ouwens, Veronique Roelants, Nicole T.H. Hoebers, Will A. Coumans, Benoit Viollet, Michaela Diamant, Jan F.C. Glatz, Luc Bertrand, Joost J.F.P. Luiken.

October $2010 \quad 15^{\text {th }}$ meeting of the European Council for Cardiovascular Research (ECCR). Oral presentation title: CD36 inhibition prevents insulin resistance, L.K.M. Steinbusch, Y. Angin, N. Hoebers, L. Ding, M. Diamant, D.M. Ouwens, J.F.C. Glatz, J.J.F.P. Luiken

June 20102010 meeting of the International Society for the Study of Fatty Acids and Lipids (ISSFAL). Oral presentation title: Balanced substrate supply is essential for cardiac protection of the compromised heart, L.K.M. Steinbusch, J.J.F.P. Luiken, R. Vlasblom, A. Chabowski, L. Keersmaekers, N. Hoebers, W.A. Coumans, I.O.C.M. Vroegrijk, P.J. Voshol, J.F.C. Glatz, D.M. Ouwens, M. Diamant.

January 2010 Invited lecture at Nestle Research Centre, Lausanne, Switzerland. September 2009 45 $5^{\text {th }}$ Annual meeting of the European Association for the Study of Diabetes (EASD). Oral presentation title: Ablation of fatty acid transporter CD36 protects against western-type dietrelated cardiac dysfunction following pressure overload in mice: modelling diabetic cardiomyopathy, Laura KM Steinbusch, R Vlasblom, I Vroegrijk, P Voshol, JFC Glatz, DM Ouwens, JJF Luiken, M Diamant.

November 2008 Year meeting of the Dutch Society for the study of Diabetes (Nederlandse Vereniging voor Diabetes Onderzoek). Oral Presentation title: Vesicular trafficking in the regulation of substrate uptake in cardiomyocytes, Laura KM Steinbusch, W Wijnen, DM Ouwens, M Diamant, JFC Glatz and JJFP Luiken. 


\section{Dankwoord}

Jan, Joost, Margriet en Michaela, bij deze wil ik jullie graag als allereerste allevier tegelijkertijd bedanken voor de kans op een promotie, jullie hulp bij het uitwerken van ons project, geduld en precisie bij het schrijven van papers en de tijd gestoken in allerhande discussies (al dan niet over werk). Ik zal de reis naar Banff met Jan, de MTB-tocht in Kananaskis met Jan en Margriet, het diner in het theehuis in Wenen met Michaela en Margriet, de emails met mooie bergen van Joost en Margriet en de LBP workshops met alarmbellen en ballenbakken met Joost en Jan nooit vergeten.

Daarnaast wil ik graag alle collega's van moleculaire genetica en dan met name Nicole, Robert, Yeliz, Will en Ellen bedanken voor de gestroomlijnde samenwerking in ons kleine hokje het C-lab en voor de gezellige avondjes uiteten. Zonder jullie waren sommige stressmomentjes tijdens de totstandkoming van dit proefschrift lastiger te verdragen geweest. Teşekkürler!

Dit proefschrift had aboluut niet gerealiseerd kunnen worden zonder de hulp van de afdelingen endocrinologie en metabole ziekten aan het LUMC, fysiologie van de VU in Amsterdam, het DDZ in Dusseldorf en cardiologie aan de UCL in Brussel. Irene, ontzettend bedankt voor je zorg voor mijn muizen. Ronald, een speciale dank voor jou voor al je hulp met de muizen studie, ook toen het hyperstress moment daar was. Onze in elkaar gekluste muizen OK is toch een speciale plek waard. Sabrina, vielen Dank für Ihre Hilfe mit dem Ion Optix System. Luc, Véronique, Sandrine, Magali, Louis et Christoph; Merci beaucoup pour les temps dans votre laboratoire à Brussel et pour la semaine à Canada. Et maintenant, je dois vraiment apprendre le français!

leder jaar kwamen ze weer....de studenten. Yes guys, this is about you, the students. Thanks a lot for spicing up the atmosphere in the lab when you were there. Lei, Lian, Alicia, Jurriaan, Pascal and Julie thanks for all your help and joy. If you did not see your figures yet; they are in chapter 4, 6 and 7 !

Harry, stiekem zou je in de corona willen zitten he! Ontzettend bedankt voor alle adviezen. Wetenschap brengt leuke reisjes met zich mee, dat ervoeren Karlijn en ik al van jongs af aan. Ik vond het echt leuk dat we samen naar een IPSEN symposium in Parijs zijn geweest. Gonny, ik denk dat het niet altijd leuk is om met 3 wetenschappers aan tafel te zitten, helaas gaan we nog door. Ik wil je bedanken dat je mij nee hebt leren zeggen en voor een luisterend oor van iemand die het hele promotieproces al eens van de zijlijn voorbij heeft zien komen.

Karlijn en Ilona, mijn echte zusje en degene die soms voor mijn zusje wordt aangezien. Karlijn, we kunnen "ruziën" maar ook samen reizen en fietsen. Door 
jouw studie raakte ik meer geïnteresseerd in 'duurzaamheid' en sta ik nu bekend als treehugger bij MolGen. Hopelijk kunnen we nog vele reizen samen ondernemen. Ilona, tsja als je samen promoveert, klimt, in de koffiekamer eet, carpoolt en in het regiobestuur gaat dan denken mensen al snel (?) dat je zusjes bent. Ik hoop dat je ook richting Lac Leman komt dan kunnen we tenminste nog vaak afspreken.

Tuurlijk was het niet alleen maar plezier en lol, er moest hard gewerkt worden en soms waren er ook frustraties en teleurstellingen. Gelukkig waren al die andere mensen, of 2 katten, er dan om bij uit te razen (al dan niet sportend of verzuchtend). Peggy, Guus en Vivian bedankt voor de koffie en lunchmomentjes, Nadine en Ine wel blijven fitnessen he, en Willem en Ronit bedankt voor alle adviezen. Een speciale dank aan onze carpoolclub Ilona, Maarten en Merlijn. Samen promoveren, blijven klimmen, en soms genieten van het Limburgs Landschap! Loek, Rasjel, Evert en Ineke bedankt voor de relaxte klimvakantie(tje)s en de discussies. Lara, un grand merci pour te rencontrer et j'espère que nous allons avoir des magnifiques aventures à Lausanne et dans les montagnes. Mathijs en Renske, thanks voor het samen hardlopen en cake bakken. Jan, Lide, Floris en Rozemijn: ik was inderdaad weer terug van weggeweest. Alle klimmers/kletterer bij Neoliet Heerlen wil ik bedanken voor de gezellige sfeer en het interessante taaltje wat daar ontwikkeld is "Das ist vet cool!". Amy, en al die anderen van interne geneeskunde, zeg ik merci voor onze dinsdagavond hardloopgroep en de leuke tijd op diabetescongressen. Ik vond het fijn dat ik altijd als aanhangsel met jullie meemocht.

Tsja, Merlijn, jij wilde niet persoonlijk bedankt worden maar dat doe ik lekker toch. Samen op het gym en in de JuCo, dan even apart, maar toch weer samen studeren en wonen in Maastricht, en daar ook nog eens promoveren! Ik keek altijd uit naar ons belgische biertje op vrijdagavond en ik ben zeker dat we een geweldige tijd gaan hebben in Lausanne/Genève.

Merci.....

Laura 